\title{
Functional and Morphological Diversity of Trees in Different Land Use Types along a Rainforest Margin in Sulawesi, Indonesia
}

\author{
Dissertation \\ zur Erlangung des Doktorgrades \\ der Mathematisch-Naturwissenschaftlichen Fakultäten \\ der Georg-August-Universität zu Göttingen
}

\author{
vorgelegt von \\ Kerstin Bohman \\ geboren in Århus, Dänemark
}

Göttingen 2004 
D 7

Referent: Prof. Dr. Leuschner

Korreferent: Prof. Dr. Gradstein

Tag der Mündlichen Prüfung: 25. 06. 2004 
"Scientists like simple, elegant solutions to problems, but rainforests just do not work that way."

Ian M Turner, 2001 



\section{CONTENTS}

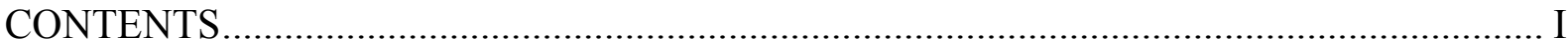

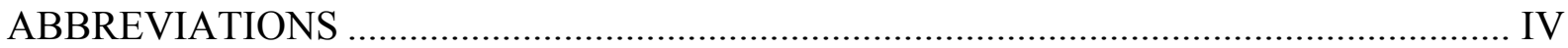

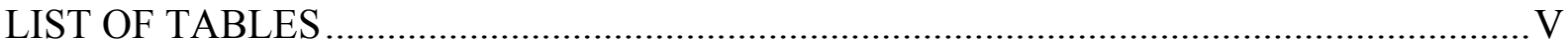

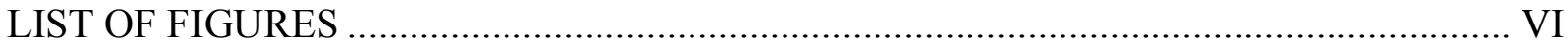

1 INTRODUCTION .......................................................................... 1

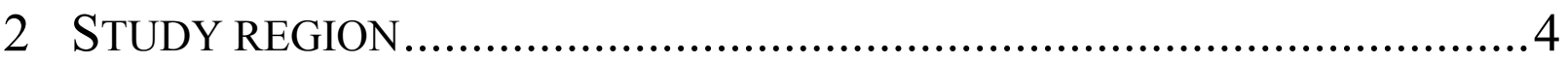

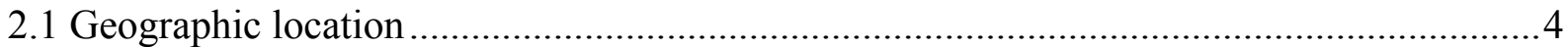

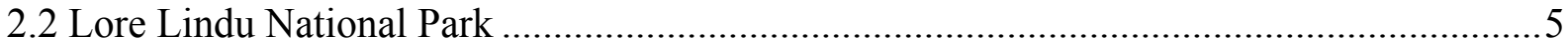

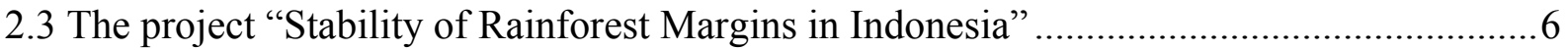

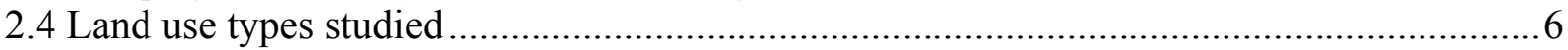

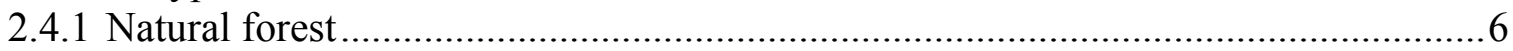

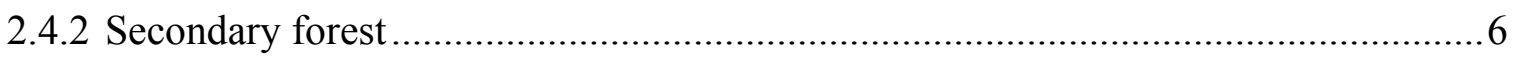

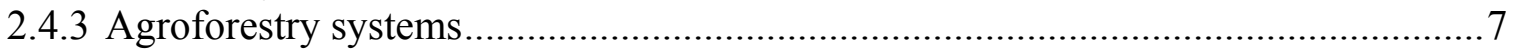

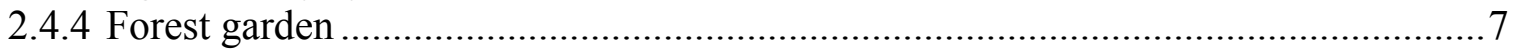

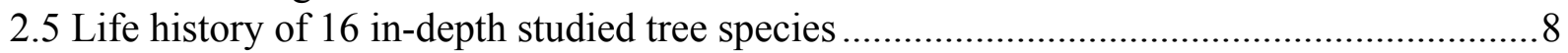

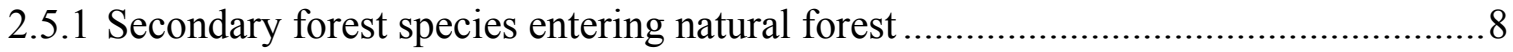

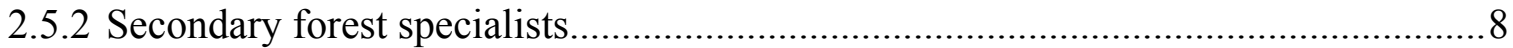

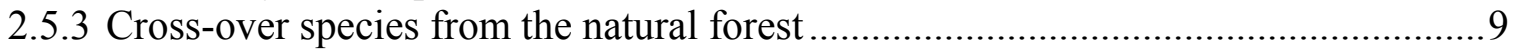

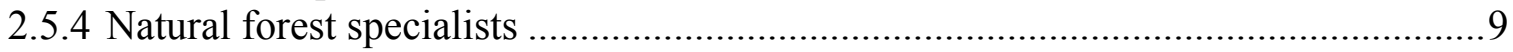

3 MATERIAL AND METHODS ....................................................... 10

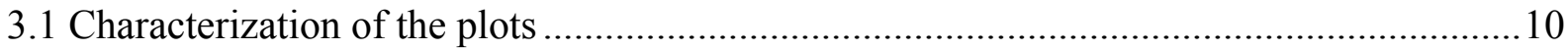

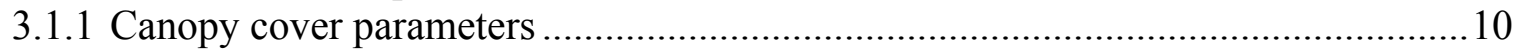

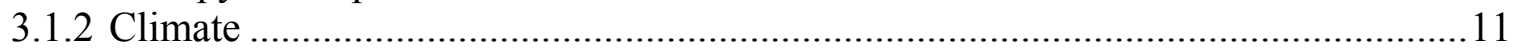

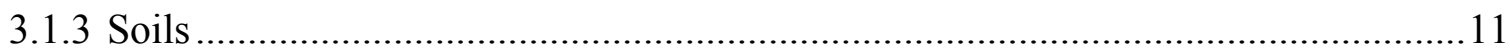

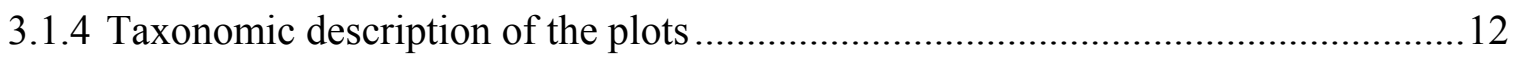

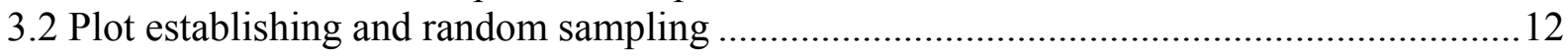

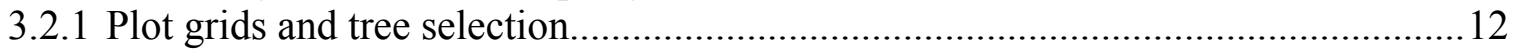

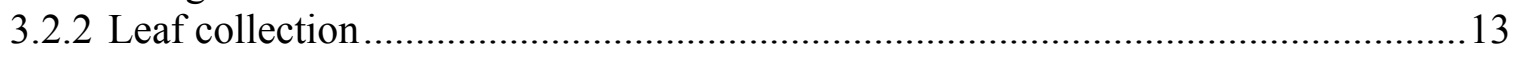

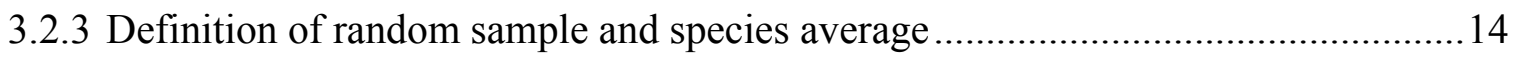

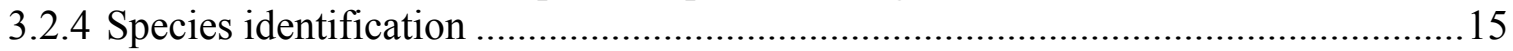

3.2.5 Additional sampling for analysis of intraspecific variation ................................. 15

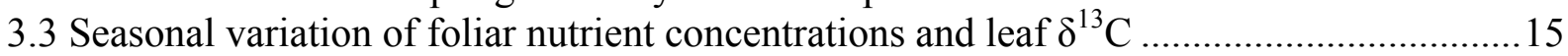

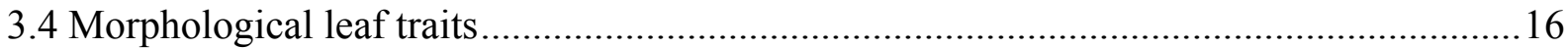

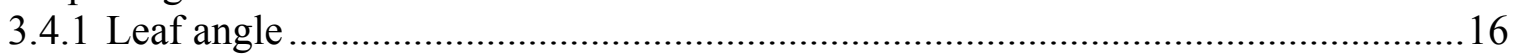

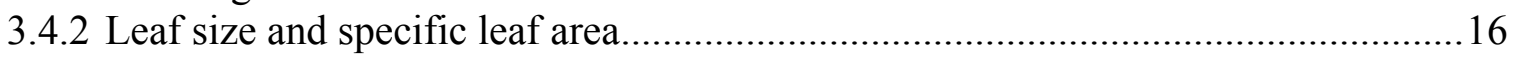

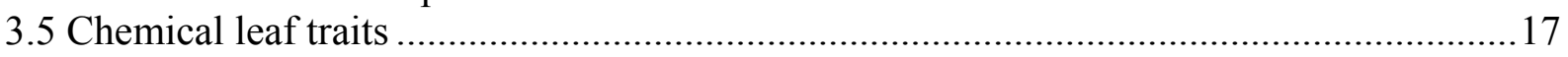



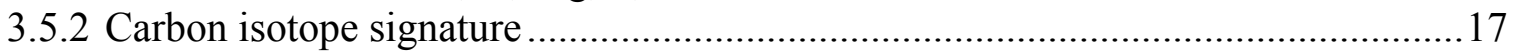

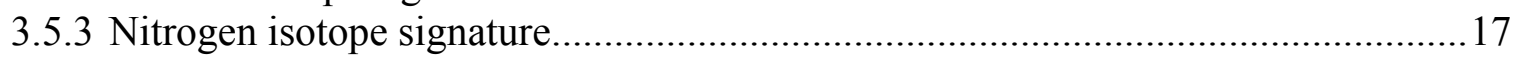

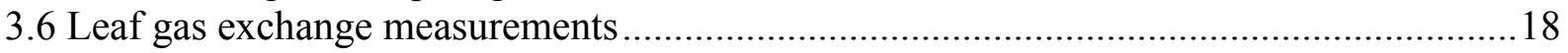

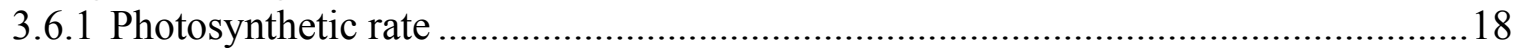

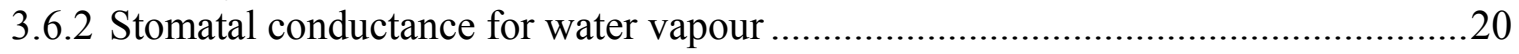

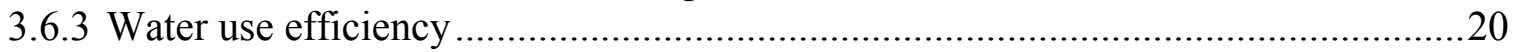

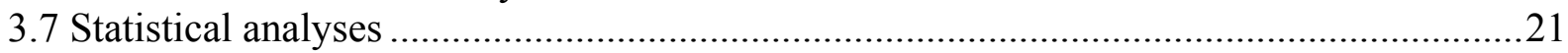

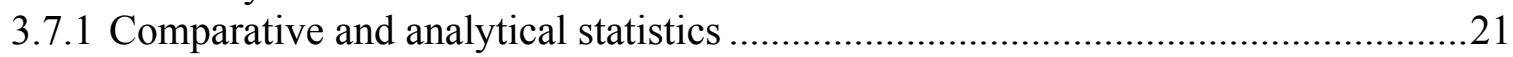

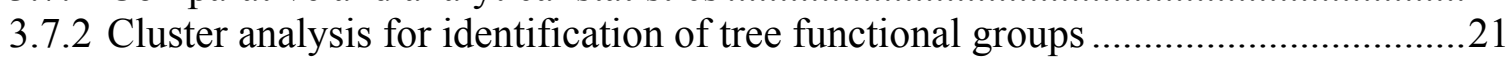

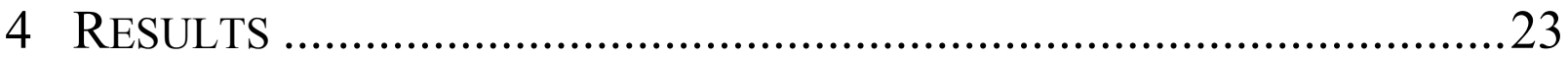




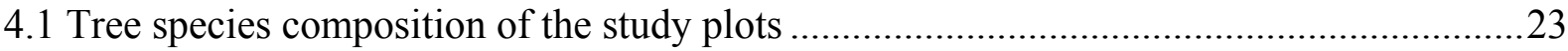

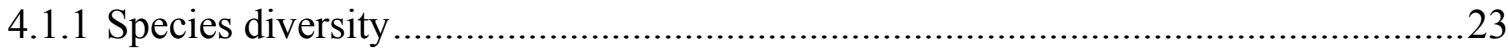

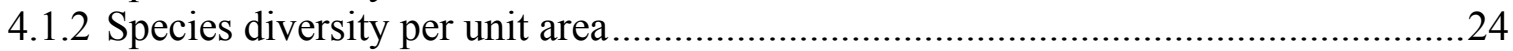

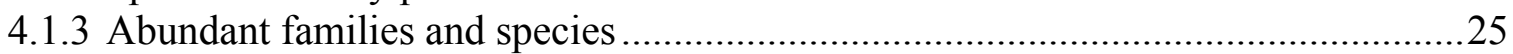

4.1.4 Overlap of families and species among land use types ......................................26

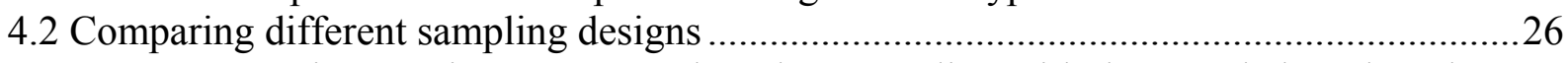

4.2.1 Comparing species average and random sampling with the sample based on the

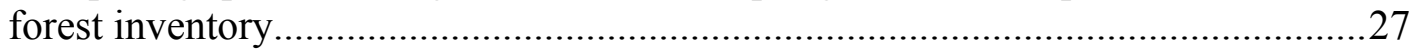

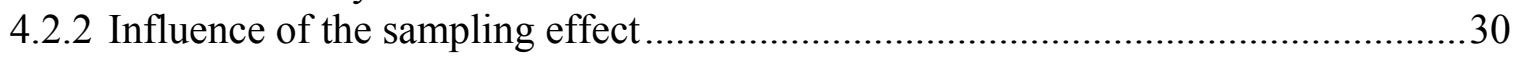

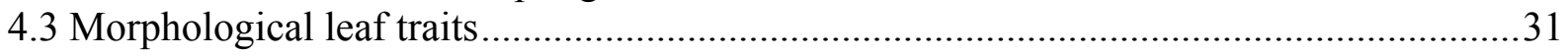

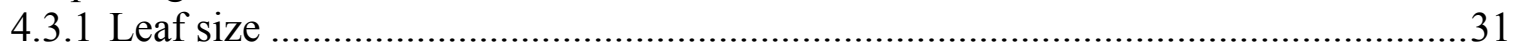

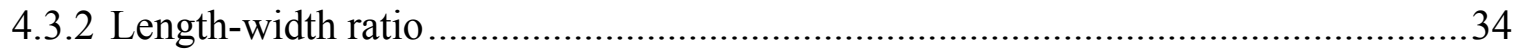

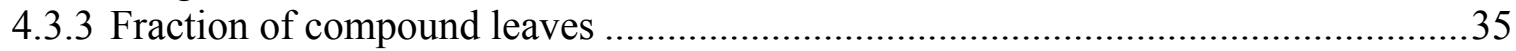

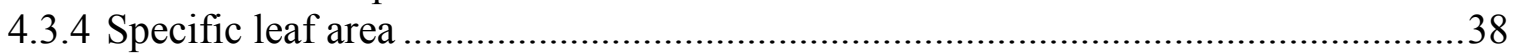

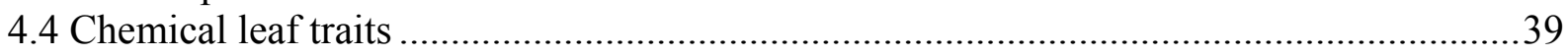

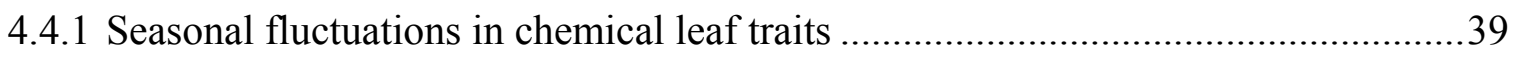

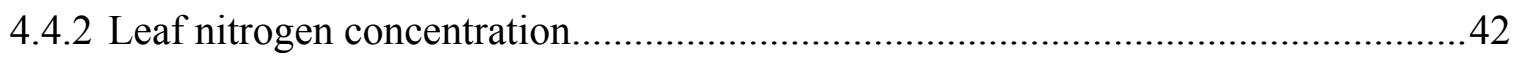

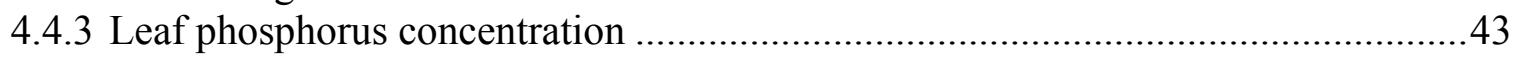

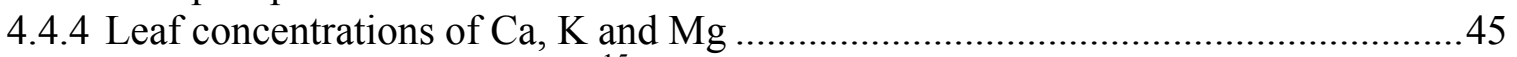

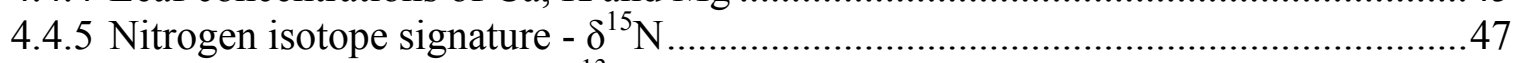

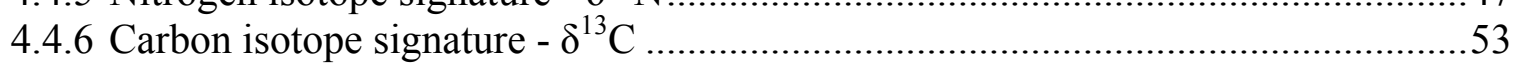

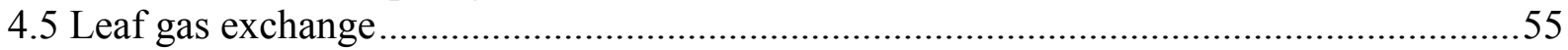

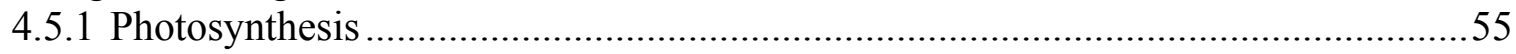

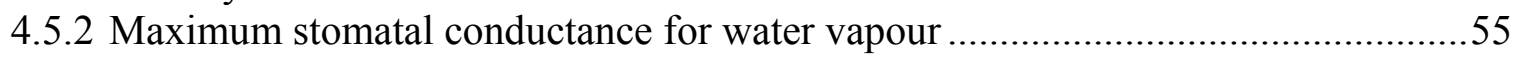

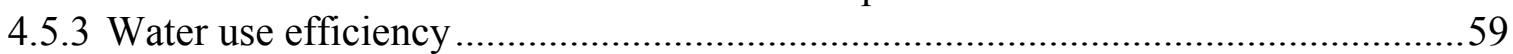

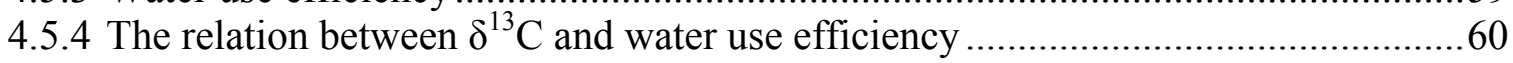

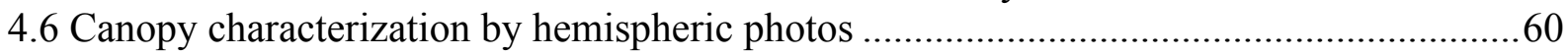

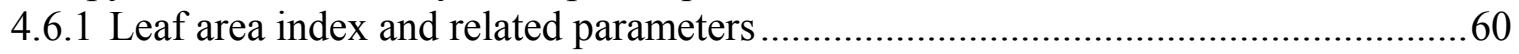

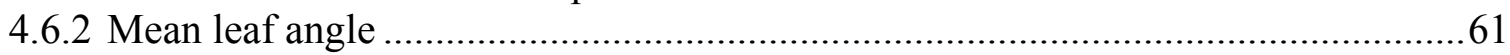

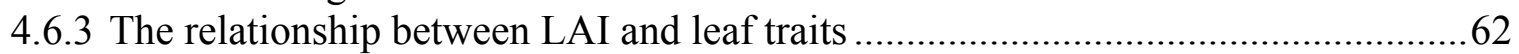

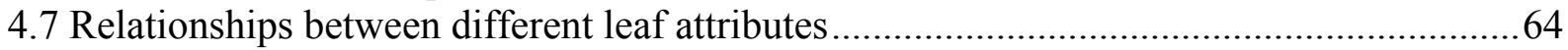

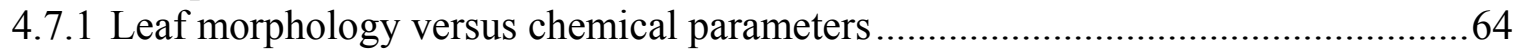

4.7.2 Relations between leaf physiology and morphological or chemical parameters .....68

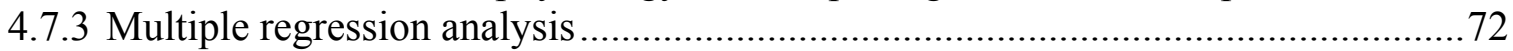

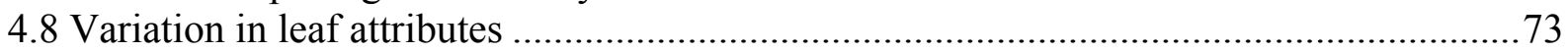

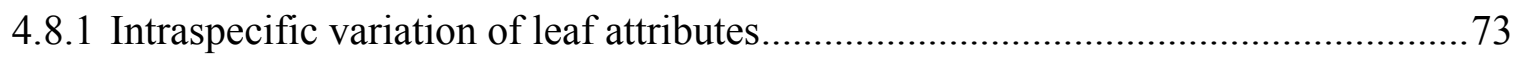

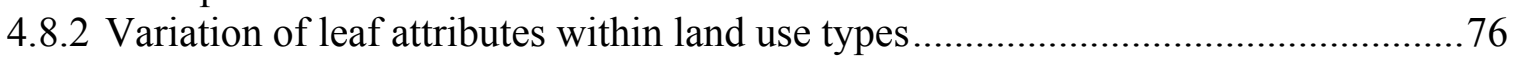

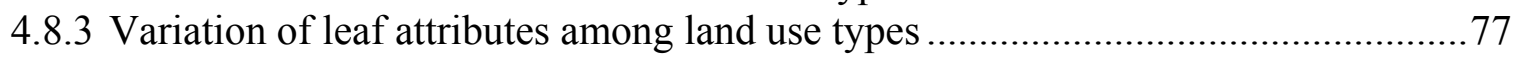

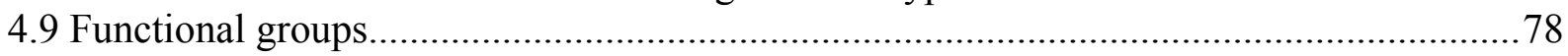

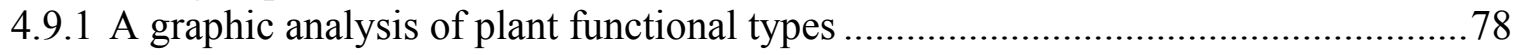

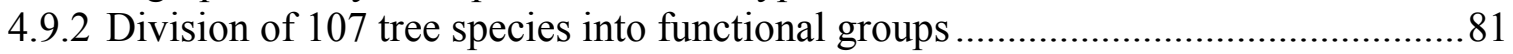

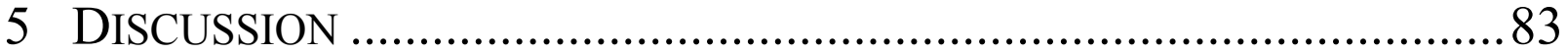

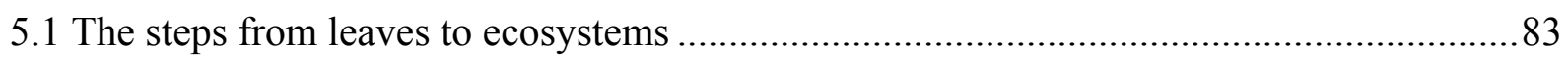

5.2 The importance of sampling design in comparative leaf morphological studies................83

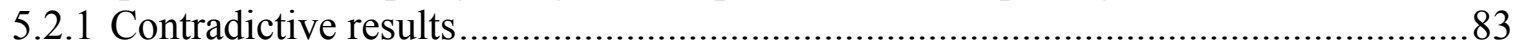

5.2.2 The influence of sampling design on the results of parameter correlation analysis. 84

5.2.3 Random sampling is the most suitable design for ecological studies of

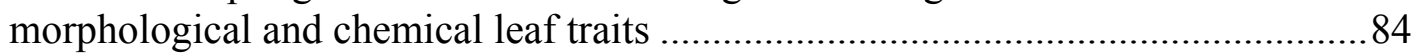

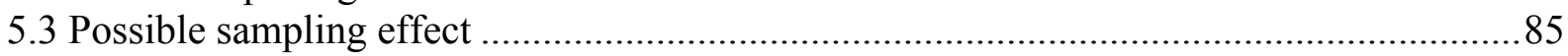

5.4 Differences between important tree-based land use types in foliar morphology, chemistry,

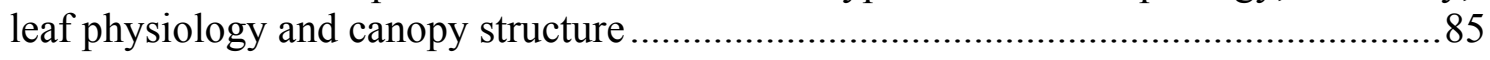




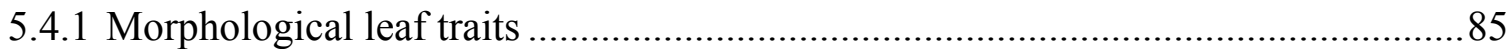

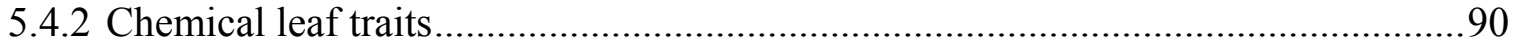

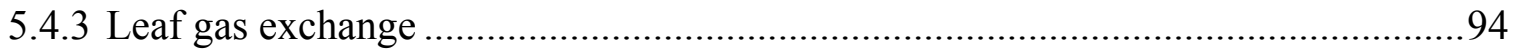

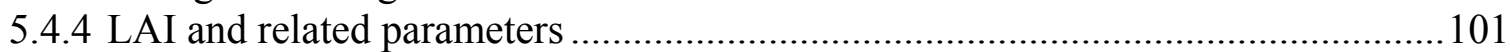

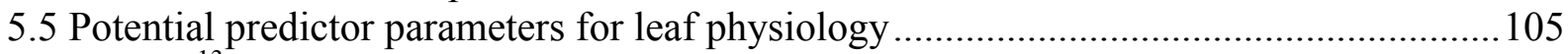

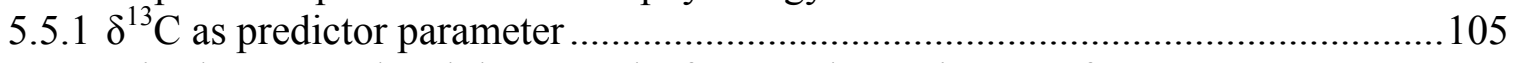

5.5.2 $\mathrm{P}$ is closer correlated than $\mathrm{N}$ to leaf gas exchange in some forest types ................. 105

5.5.3 SLA is an important predictor for leaf physiology ..............................................106

5.5.4 Different parameters suitable for predicting different forest types ........................ 107

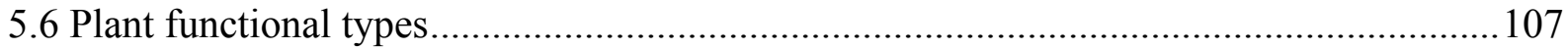

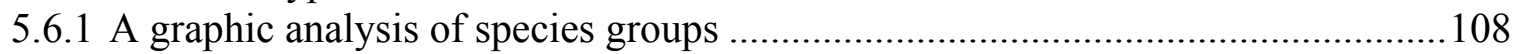

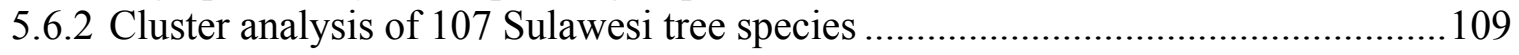

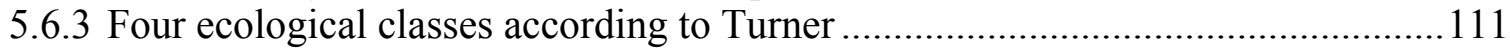

5.6.4 Conclusions concerning methods for classification of functional groups...............113

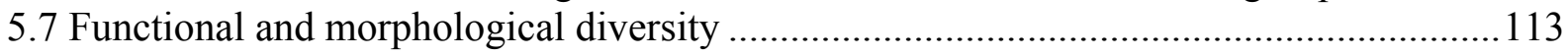

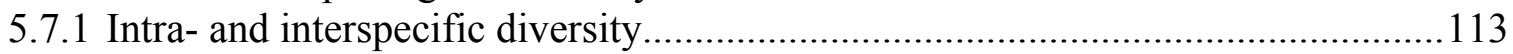

5.7.2 Different degree of variance for different parameters........................................ 114

5.7.3 General differences in diversity between land use types .................................... 114

5.7.4 The relation between adaptive flexibility and the variance in chemical and

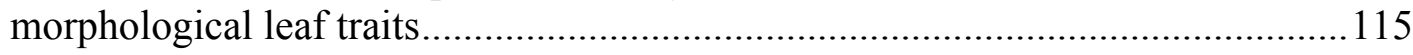

5.7.5 Ecosystem stability as a function of functional and taxonomic diversity ..............115

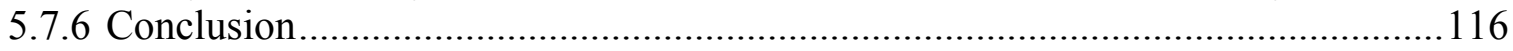

SUMMARY …

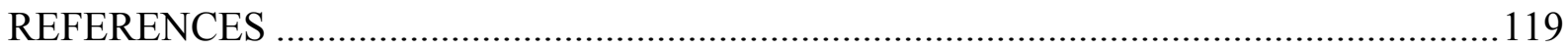

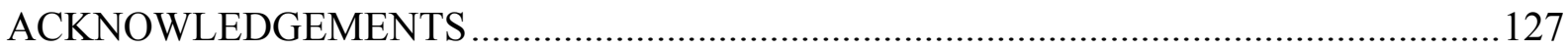

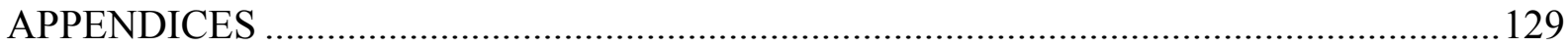




\section{AbBreviations}

AF Agroforestry system

$\mathbf{A}_{\text {max }}$-area Maximum light-saturated net photosynthesis, per leaf area $\left(\mu \mathrm{mol} \mathrm{m} \mathrm{m}^{-2}\right)$

$\mathbf{A}_{\max }$-mass Maximum light-saturated net photosynthesis, per leaf drymass ( $\mu \mathrm{mol} \mathrm{g}^{-1} \mathrm{~s}^{-1}$ )

dbh Diameter of trunk at breast height $(130 \mathrm{~cm})$

ELADP Ellipsoid Leaf Angle Parameter. Estimate of the HemiView-analysis on the distribution of leaf angles in a canopy

Fam Family

FG Forest garden

$\mathbf{g}_{\text {smax }} / \mathbf{g}_{\mathbf{s}} \quad /$ Maximum/ stomatal conductance for water vapour $\left(\mathrm{mmol} \mathrm{m} \mathrm{s}^{-2}\right)$

Ind Tree individual

LAI Leaf area index $\left(\mathrm{m}^{2} \mathrm{~m}^{-2}\right)$

LMA Leaf mass area $\left(\mathrm{g} \mathrm{cm}^{-2}\right)$, the inverse of SLA

LW Length-width ratio, the relation between maximum length and maximum width of a leaf $\left(\mathrm{cm} \mathrm{cm}^{-1}\right)$

LUT Land use type

MLA Mean leaf angle $\left(^{\circ}\right)$ calculated as canopy average by the HemiView software $\mathbf{N} \quad$ Leaf nitrogen content per unit dry mass $\left(\mathrm{g} \mathrm{kg}^{-1}\right)$

NF Natural forest

No. Number of

P Leaf phosphorus content per unit dry mass $\left(\mathrm{g} \mathrm{kg}^{-1}\right)$

RH Relative humidity (\%)

sd $\quad$ Standard deviation

SLA Specific leaf area $\left(\mathrm{cm}^{2} \mathrm{~g}^{-1}\right)$

SF Secondary forest

Sp. or Spec. Species

VPD Water vapour pressure deficit between intercellular spaces of a leaf and the atmosphere $(\mathrm{kPa})$

WUE Water use efficiency $\left(\mu \mathrm{mol} \mathrm{CO} \mathrm{CO}_{2}\left(\mathrm{~mol} \mathrm{H}_{2} \mathrm{O}\right)^{-1}\right)$ 


\section{LIST OF TABLES}

Table 3.1 List of the plots included in the study, covering four different land use types......

Table 3.2 Specification of random sample and species average parameters as referred to throughout this work. 14

Table 3.3 Leaf size classes by the Raunkiaer-Webb classification....

Table 4.1 The total number of tree individuals, species, genera and families recorded in the three land use types $\mathrm{NF}, \mathrm{SF}$ and FG....

Table 4.2 The total number of tree individuals, species, genera and families recorded on each NF, SF and FG plot.

Table 4.3 Number of families and species per $1600 \mathrm{~m}^{2}$ area units based on data from Keßler et al.

Table 4.4 Means of a set of leaf traits for secondary forest and forest garden as proportions (\%) of the corresponding natural forest mean, presented for the three different sampling designs and as a normalized species average

Table 4.5 The quota of the standard deviations $\left(\mathrm{sd} \mathrm{sd}^{-1}\right)$ yielded for a set of leaf traits in the random sample and the normalized 18 -species averages.

Table 4.6 Total nitrogen concentration, and $\delta^{15} \mathrm{~N}$ values in soil samples and sun leaves presented for four

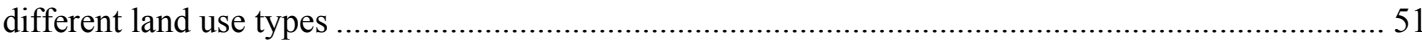

Table 4.7 Classification of the 107 species in this study according to the assumed presence of $\mathrm{N}_{2}$-fixing symbionts

(a)

Table 4.8 Means of $A_{\max }, R_{d}$ and $g_{\text {smax }}$ in mature sun leaves of 19 species occurring in three land use types ......56

Table 4.9 Correlation parameters for the dependence of $g_{s}$ on VPD in all 19 species studied............................58

Table 4.10 Land use type means of leaf area index and the parameters visible sky and ground cover as obtained from analysis of the hemispheric photos

Table 4.11 Means of the leaf angles visually observed and the MLA estimated from the HemiView-analysis ... 62

Table 4.12 Correlation parameters for correlation analysis of leaf size, SLA versus a number of morphological and chemical leaf traits in random samples of four different land use types and the complete random sample

Table 4.13 Correlation between leaf morphological and physiological parameters in a sample of all 19 species studied and the eight natural forest species and the eight secondary forest species, respectively.....

Table 4.14 Results of multiple regression analyses with stepwise parameter exclusion in the complete 19-species sample and the natural and secondary forest samples. $A_{\max }$-mass, $A_{\max }$-area and $g_{\text {smax }}$ were explained by a set of leaf chemical and morphological traits .....

Table 4.15 The coefficient of variance (sd / mean (\%)) calculated for 12 leaf traits and their intraspecific variation in the 30 most abundant species in the random samples

Table 4.16 Coefficient of variance (sd / mean (\%)) for morphological and chemical leaf traits in the normalized 18-species average samples of NF, SF and FG, and in the species average of the four AF species .... 77

Table 4.17 Ten functional groups identified through a disjoining cluster analysis.

Table 5.1 Distribution of leaf sizes among natural forests tree species on Mount Pulog, Mt. Kinabalu, San Javier, and Lore Lindu. Species means classified according to Raunkiaer (1934)

Table 5.2 Results of the investigation of putative $\mathrm{N}_{2}$-fixation by pioneer species in a rain forest in French Guiana conducted by Roggy et al. (1999) compared to the results in this study .......................................99

Table 5.3 Different parameters recommended for different forest types for predicting foliar gas exchange...... 107 


\section{LIST OF FIGURES}

Figure 2.1 The Lore Lindu National Park, Central Sulawesi, Indonesia.......................................................... 4

Figure 4.1 Means of leaf size, length-width ratio and SLA in random samples of the four land use types studied.... 31

Figure 4.2 Means of leaf size, length-width ratio and SLA in the five most frequent families............................... 32

Figure 4.3 Leaf sizes of random sample individuals and species averages of four different land use types, classified according to Raunkiaer

Figure 4.4 The relative frequency of leaf size classes of $50 \mathrm{~cm}^{2}$ within the random samples of four different land use

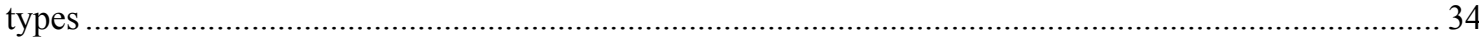

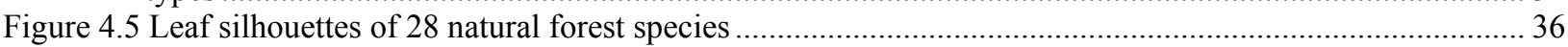

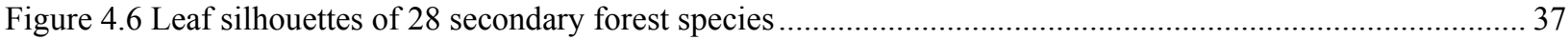

Figure 4.7 Distribution of SLA and leaf size means among all species found in the natural and secondary forest stands.

Figure 4.8 Leaf nutrient concentrations during ten months. Species means for five natural and five secondary forest species. Rainfall data for the period September 2001 to June 2002 .

Figure 4.9 Species means of ${ }^{15} \mathrm{~N}$ and ${ }^{13} \mathrm{C}$ signatures, leaf $\mathrm{N}$ concentration and $\mathrm{C} / \mathrm{N}$ over ten months for five natural and five secondary forest species. Rainfall data for the period September 2001 to June 2002 .......

Figure 4.10 Means of foliar N, P and total C, as well as the ratios C/N, N/P and C/P for the five most frequent families in the random sample

Figure 4.11 Means of foliar $\mathrm{N}$ and $\mathrm{P}$ concentrations and the ratios $\mathrm{C} / \mathrm{N}, \mathrm{N} / \mathrm{P}$ and $\mathrm{C} / \mathrm{P}$ in the random samples of the four land use types studied.

Figure 4.12 Means for leaf $\mathrm{K}, \mathrm{Mg}$ and $\mathrm{Ca}$ concentrations and the ratios of $\mathrm{K} / \mathrm{Mg}$ and $\mathrm{Ca} / \mathrm{Mg}$ in the five most frequent families in the random sample.....

Figure 4.13 Means for leaf $\mathrm{K}, \mathrm{Mg}$ and $\mathrm{Ca}$ concentration and the ratios of $\mathrm{K} / \mathrm{Mg}$ and $\mathrm{Ca} / \mathrm{Mg}$ in the random samples of

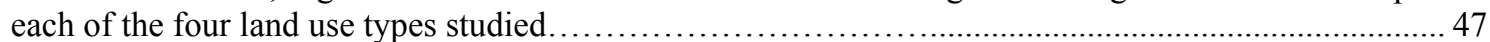

Figure 4.14 Means of $\delta^{15} \mathrm{~N}$ and total $\mathrm{N}$ concentration in soil samples from the four land use types studied ............. 48

Figure 4.15 Frequency distribution of $\delta^{15} \mathrm{~N}$ and total $\mathrm{N}$, respectively, in leaves of all individuals $(\mathrm{n}=354)$ and species $(n=107)$ in the random sample

Figure 4.16 Frequency distribution of $\delta^{15} \mathrm{~N}$ among the individuals of the random samples of each land use type..... 49

Figure 4.17 Species means of foliar $\delta^{15} \mathrm{~N}$ versus total nitrogen concentration for the trees of four different land use

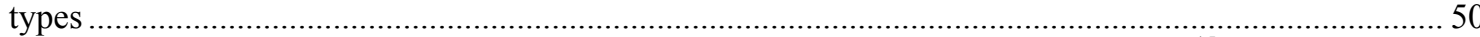

Figure 4.18 A. Total leaf nitrogen concentration versus total nitrogen concentration of soil. B. $\delta^{15} \mathrm{~N}$ in leaves versus $\delta^{15} \mathrm{~N}$ values in soil. C. Exponential relation between the soil $\delta^{15} \mathrm{~N}$ and the total leaf $\mathrm{N}$ concentration. ..... 51

Figure $4.19 \delta^{15} \mathrm{~N}$ versus total leaf nitrogen concentration for species occurring in four different land use types. The mean values and standard deviations of Roggy's samples for each of three groups defined by their results are inserted in the graphs (putative $\mathrm{N}_{2}$-fixers, non- $\mathrm{N}_{2}$-fixers and uncertain other species)

Figure 4.20 Means of the foliar $\delta^{13} \mathrm{C}$ values for the five most frequent families in the random sample (for definition of random sample, see Table 3.2). Different letters mark significantly different means..........................5 54

Figure 4.21 Means of the foliar $\delta^{13} \mathrm{C}$ values for the random samples in the four land use types studied....................55

Figure 4.22 A. Means of $\mathrm{A}_{\max }$-area in 19 species, covering three land use types. B. $\mathrm{g}_{\text {smax }}$ of 19 species..................5 57

Figure $4.23 \mathrm{~g}_{\text {smax }}$ versus the $\mathrm{b}$-value from $\mathrm{g}_{\mathrm{s}}$ versus VPD regressions for 13 species of $\mathrm{NF}$, $\mathrm{SF}$ and AF................. 58

Figure 4.24 Photosynthetic water use efficiency at light saturation for each of the 19 species included in the physiological study

Figure $4.25 \delta^{13} \mathrm{C}$ plotted as a function of water use efficiency

Figure 4.26 Relationships between LAI and SLA (A) and foliar N concentration (B) in random samples of eight plots, covering three different land use types.

Figure 4.27 A-F. LAI versus SLA and leaf N concentration in random samples at plot level, presented for each land use type separately

Figure 4.28 A. $\delta^{13} \mathrm{C}$ versus $\mathrm{C} / \mathrm{N}$ ratio in the complete random sample, comprising trees from four different land use types. B \& C. $\delta^{13} \mathrm{C}$ versus leaf length-width ratio in a sample of individuals from two large-leaved families.

Figure 4.29 Leaf nitrogen and phosphorus concentrations versus SLA of trees in random samples from four different land use types....

Figure 4.30 Leaf size versus leaf length-width ratio in the random samples of four different land use types ........... 67

Figure 4.31 A-D A. Leaf angle versus $\mathrm{g}_{\text {smax }}$ and $\mathrm{A}_{\max }$-area in a sample of secondary forest species. B. $\mathrm{A}_{\max }-\operatorname{area}$ versus leaf size in a sample of secondary forest species. C. $g_{\text {smax }}$ versus $\delta^{13} \mathrm{C}$ in a sample of 19 species from three different land use types. D. $\mathrm{A}_{\max }$-area versus $\delta^{13} \mathrm{C}$ in a sample of 19 species from three different land use types. 
Figure 4.32 A. Relation between $\mathrm{A}_{\max }$-mass and SLA within the secondary forest and natural forest. B.Relation between $\mathrm{A}_{\max }$-mass and leaf $\mathrm{P}$ and $\mathrm{N}$ concentrations, respectively, in the 19 species sample.

Figure 4.33 Physiological versus morphological characteristics in the sample of means for the 19 species studied. Left: $\mathrm{g}_{\text {smax }}$ versus SLA. Right: $\mathrm{A}_{\max }$ versus SLA.

Figure 4.34 Mean, lower and upper quartile, maximum and minimum values of 10 leaf traits in 19 species occurring in three different land use types

Figure 4.35 Intraspecific coefficient of variance (sd / mean (\%)) in 11 morphological and chemical leaf traits for eight natural forest species, eight secondary forest species and three agroforestry system species

Figure 4.36 A graphic overview of the relative values of some important leaf traits in the five most frequent families of the random sample. 78

Figure 4.37 A graphic overview of the relative values of some important leaf traits in the four land use types studied and in 12 abundant species..... 80

Figure 5.1 Two-way classification of tree species from the tropical rainforest based on size at maturity and the pioneer-climax axis, constructed by Turner (2001) based on several other authors 



\section{INTRODUCTION}

Tropical rainforests are considered to be the most complex, diverse and species rich terrestrial ecosystems on earth. Undisturbed tropical rainforests can host 200 to 300 different tree species on 1 ha (Whitmore 1993; Turner 2001), to be compared with a maximum of 10 species per ha in the central European temperate forests (Ellenberg 1996) and a total of 10 tree species occurring in the boreal forests (FAO 2001). The high species diversity is associated with a high diversity in plant form and function. It has been proved that the functional diversity is at least as important as the species diversity alone, when aiming to protect natural ecosystems (Hooper \& Vitousek 1997). Out of the over 30 thousand tropical rainforest tree species that occur, current knowledge on their ecology comprises information on perhaps a few hundred. In contrast to the very thoroughly studied tree species of the temperate zone, where a high degree of species-specific physiological and morphological diversity has already been recognized (Cornelissen et al. 2003; Hagemeier 2002), detailed information about single tropical tree species is very limited (Turner 2001). We do not know in detail which species, or combinations of species, are crucial for important ecosystem functions, and if some species could be lost without altering ecosystem functions (Lawton \& Brown 1994).

Worldwide, rainforests are standing under high exploiting pressure and are subject to an alarming rate of encroachment and deforestation. The global annual deforestation rate in the humid tropics between the years 1990 and 1997 has been estimated to 0.52\% (Achard et al. 2002). The rate in Southeast Asia was assessed to $0.91 \%$, which was twice as high as in the African and Latin American tropics. 1.06 million ha forest was converted to agricultural land per year in Southeast Asia in this seven-year period (Achard et al. 2002). The trend has not attenuated since 1997. A major driving force is the immense population increase in this part of the world (Jerkins 2003). Areas of particularly explosive socio-economic change following population increase often coincide spatially with biodiversity hot spots in tropical regions, inevitably leading to conflicts between economic growth and nature conservation (Barthlott 2003).

The loss of biodiversity may have negative consequences for all humans and for world economy, since we are all depending on the services provided by nature, such as maintenance of the atmospheric gas composition, control of regional climate and water flows, generation and maintenance of soils, waste disposal, nutrient cycling and pest control (Lawton \& Brown 1994). Furthermore, we are facing climate changes that are difficult to 
predict, but surely influence and interact with the ecosystems. Biodiversity may play a key role in the ecosystems' ability to cope with climate changes.

In order to enable fairly qualified estimations of the consequences of the environmental change on tropical forests it is necessary to investigate forest ecosystem functioning in more depth. In particular, more data on the physiology and the response to environmental factors and potential climatic change of the trees dominating these systems, and constituting the major part of their biomass, is highly requested (Reiners et al. 1994; Borchert 1998; Trichon 1998).

Indonesia constitutes an important part of the world's tropical rainforest belt, hosting ten percent of all remaining tropical rainforests in the world and half of the Southeast Asian rainforest (FAO 2001). In the Indonesian province Central Sulawesi, as in many other tropical areas, young secondary forests and agroforestry systems with cocoa and coffee are the main tree-based land use types that follow rainforest clearings (Siebert 2002). A fourth tree-based land use type occurring in the area is the forest garden, where fruits and crops are cultivated in the shade of remaining old natural forest trees. The tree communities of secondary forests and agroforestry systems must be investigated thoroughly, since these are gaining land with the same high rate as the natural rainforest is disappearing. Young secondary forest patches may show a high variety in tree morphology and potential physiological response that should not be disregarded. For example, there is some dispute on the role of young secondary forests as a sink for atmospheric carbon. Schulze et al. (2000) discuss the effect of preservation of natural forests on the global carbon cycle as opposed to the favouring of regrowth proposed in the Kyoto Protocol. For assessing to which extent alternative ecosystems could replace the ecological services once carried by the natural rainforest, it is fundamental to analyse the main differences in structure, morphology, photosynthesis, water use, etc. between tree-based land use types prevailing in the forest margin.

Another important field where ecological data on tropical tree species is needed in a closer perspective is reforestation. Information on several ecological qualities is necessary for selection of suitable species for plantation on degraded land. Among them are shade tolerance, potential growth rate, water use efficiency, nutrient demand, occurrence of $\mathrm{N}_{2}$ fixing symbionts, etc..

Since assessing physiological capacities of trees is technically and financially demanding, more easily accessible data that could serve as indicators would be very useful 
for the mentioned purposes. For this, the relations between morphological, chemical and functional attributes of tropical trees need to be investigated.

For assessing large-scale responses to species composition shifts or climatic change, or for planning reforestation measures at the ecosystem level, grouping tree species according to their functional traits and ecological strategies may be of advantage, since it enables scaling up the functioning of species to that of ecosystems (Cornelissen et al. 2003; Garnier et al. 2001). A more refined grouping than the prevailing division into early- and latesuccessional (or primary and secondary) species is necessary in many contexts.

This work was conducted in Central Sulawesi, as a part of the first phase of the German-Indonesian research project "Stability of Rainforest Margins in Indonesia" (SFB 552), studying tree communities in natural and secondary forests, forest gardens and agroforestry systems. It is one of few studies comprising a large number of co-existing tree species in an extensive random sampling of mature trees. Morphological and physiological leaf traits were investigated in 354 individuals of 107 species by randomised sampling, as well as through in-depth studies on 19 important species. Main questions to be answered were the following:

1. How do the tree-based land use types prevailing in Central Sulawesi forest margins differ in structure, morphology and physiology?

2. What are typical values of maximum photosynthetic net rate, stomatal conductance and morphological and chemical leaf traits in the tree species of these four land use types?

3. Which leaf traits could be suitable for predicting important physiological traits of tropical trees?

4. Which functional groups can be identified among the studied species, based on a large number of tree attributes?

5. What is the most suitable sampling design for this kind of study? 


\section{STUDY REGION}

\subsection{Geographic location}

The field work was conducted inside and along the borders of Lore Lindu National Park, in the districts of Donggala and Poso in the Central Sulawesi province of Indonesia.

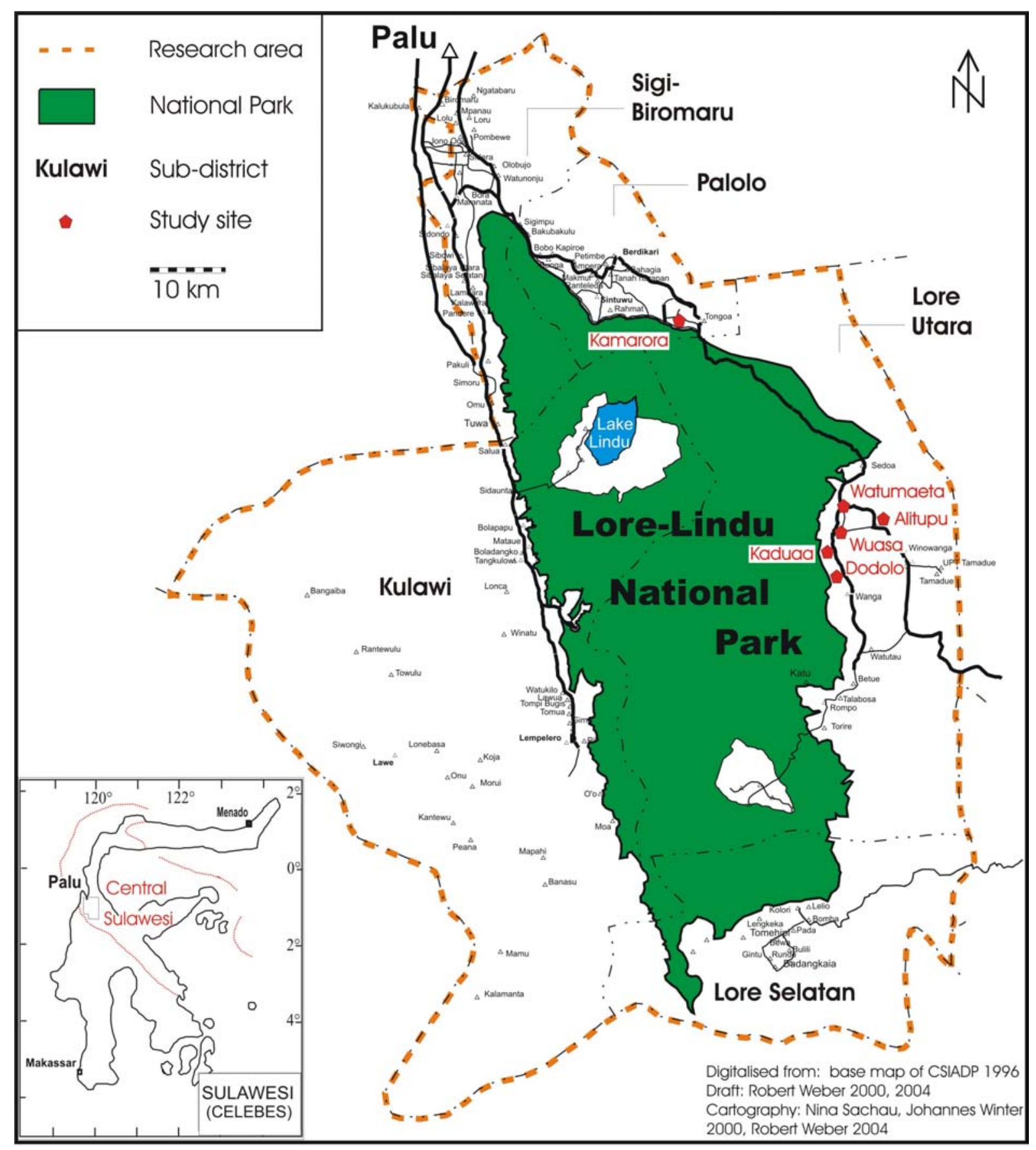

Figure 2.1 The Lore Lindu National Park is situated south of the Central Sulawesi province capital Palu. The park comprises 217000 ha and has been declared a Man and Biosphere Reserve by UNESCO. The dashed line indicates the complete research area of the STORMA project. 
The study sites were situated in the Napu valley $(1100 \mathrm{~m}$ asl $)$ in the area of the villages Wuasa, Kaduaa, Dodolo, Alitupu and Watumaeta (Lore Utara Sub-district, Poso Regency, $01^{\circ} 25^{\prime} \mathrm{S}, 120^{\circ} 20^{\prime} \mathrm{E}$ (Wuasa village)) and in the vicinity of Kamarora (900 m asl, Palolo Subdistrict, Donggala Regency, $01^{\circ} 11^{\prime} \mathrm{S}, 120^{\circ} 03^{\prime} \mathrm{E}$ ) (Figure 2.1). The Lore Utara sub-district has a total land area of $2010 \mathrm{~km}^{2}$, of which $45 \%$ belongs to the National Park. Only $10 \%$ is used as agricultural area and the population density is low $\left(16.9\right.$ persons $\left.\mathrm{km}^{-2}\right)$. The southern district is dominated by large, uninhabited grasslands. In the Palolo sub-district the relative vicinity to the province capital, among other reasons, has caused a three times higher population density ( 53.6 persons $\mathrm{km}^{-2}$ ). This area is intensively used for cocoa plantation and paddy rice cultivation, resulting in $33 \%$ of the area being used for agriculture. Only $10 \%$ of the sub-district area is inside the national park. However, the population growth during the last two decades (1980-2002) has been higher in the Lore Utara area than in Palolo, mainly due to governmental transmigration projects, where people from other, densely populated islands are resettled, and to refugees coming from a neighbouring area of civil conflicts (Maertens et al. 2004).

\subsection{Lore Lindu National Park}

Lore Lindu National Park, which was established in 1993, consists of complex mountain chains with steep valleys. The northernmost edge of the park is situated about 30 $\mathrm{km}$ from the province capital Palu (Figure 2.1). It has been declared a Man and Biosphere Reserve by UNESCO and was founded on two prior, smaller natural reserves. The about 217000 ha comprise approximately 10\% lowland forest, 70\% submontane forest and 20\% montane forest. The highest mountain peaks are Nokilalaki $(2355 \mathrm{~m})$ and Rore Katimbu (2610 m). It covers the main part of the catchment area of the two rivers in the region, Gumbasa and Lariang (Pangau 2003).

Human impact on the forest in the area has been exaggerating continuously during the last five years (van Rheenen et al. 2004), because of population growth and unclear tenure circumstances. What was claimed as traditional property by the local people ended up inside the national park borders and is still used for crop plantations inside the forest (Ebersberger 2002). A larger threat to the forest than old coffee plantations or small scale rattan collection are the immense loggings that started in June 2001. Settlements were established in the cleared area and the cuttings, which are politically difficult to handle, have continued since. 


\subsection{The project "Stability of Rainforest Margins in Indonesia"}

This work was a part of the first phase of the research project STORMA, Stability of Rainforest Margins in Indonesia (SFB 552), which is a cooperation between the Universities of Göttingen and Kassel in Germany and the Tadulako University, Palu, and the Bogor Institute of Agriculture (IPB) in Indonesia, funded by the DFG (Deutsche Forschungsgemeinschaft).

The Lore Lindu National Park and its surrounding valleys were chosen as research area because of its large, partly still undisturbed forest areas that however, have been subject to escalating encroachment during the last few years. The aims of the project are to analyse the key factors and processes that lead to destabilisation and forest degradation, to identify social, economic, political and ecological conditions that are decisive for stability in the forest margin and to investigate the consequences of land use change. The research is conducted interdisciplinary, bringing together the aspects of sociology, economy, cultural geography, as well as ecology, agronomy, soil science and hydrology.

\subsection{Land use types studied}

Trees in four kinds of tree-based land use types were studied: natural forest, young secondary forest, forest garden and cocoa agroforestry system.

\subsubsection{Natural forest}

The study plots in the submontane natural forest were situated at least $1 \mathrm{~km}$ inside the border of the Lore Lindu National Park to minimize human influence. The upper canopy reached about $35 \mathrm{~m}$. Single emergent trees occurred, belonging to the species Ficus benjaminii, Polyalthia canangoides and others. The degree of disturbance on the plots was generally low, but rattan collection and logging of single trees occurred locally in the Napu area. It is a matter of discussion how these forest stands shall be termed. Old-growth forest might be argued as the most suitable term, since there is some human impact. Nevertheless, the term "Natural forest" has been adopted commonly within the project and will be used throughout this work. It indicates the near natural state of these forests.

\subsubsection{Secondary forest}

The secondary forest sites had developed on former slash-and-burn fields after a shorter period of annual culture, generally maize. The young fallow trees had an age of 3 - 5 years and were 4 - $7 \mathrm{~m}$ high, forming a dense canopy. The understorey was typically dominated by 
grass, Urticaceae shrubs, Zingiberaceae etc.. The secondary forest areas consisted mainly of patches of 4 - 10 ha, located in between annual culture fields and cash crop plantations in close vicinity of the natural forest margin. The studied plots were all very similar in structure, grew on the same soil type and were situated not more than $200 \mathrm{~m}$ from the natural forest border.

\subsubsection{Agroforestry systems}

Most agroforestry systems in the area were composed of cocoa trees of $1.5-2 \mathrm{~m}$ height, sheltered by leguminous shade trees. This kind of system was studied. The $5-8 \mathrm{~m}$ high, frequently pruned shade trees were mainly Gliricidia sepium, but also Erythrina sp.. Integrated in the cocoa plantations were occasionally coffee bushes (Coffea arabica (canephora)) and climbing vegetable plants like Chayote (Sechium edule) and pumpkin species (Cucurbita spp.). The plantations were about 5 - 10 years old, continuously replanted and extended. Herbicide treatment was applied approximately twice a year. The plantations were however not chemically fertilized. The studied agroforestry plantations were situated at a distance of $500 \mathrm{~m}$ from the natural forest border and were typically surrounded by grassland, often dominated by Alang-alang (Imperata cylindrica), village settlements or annual cultures, such as maize or peanuts.

\subsubsection{Forest garden}

The studied forest garden plots were situated inside the natural forest within a $1000 \mathrm{~m}$ broad margin zone. The forest garden consisted of planted crops between remnant natural forest trees. The stem density of forest trees was approximately $10-20 \%$ of that in the former natural forest. It is unclear whether the natural forest trees in the forest garden were deliberately selected on hand of their characteristics, e.g. nitrogen-rich leaf litter, shade spending etc., or if the original natural forest was just thinned out arbitrarily. Cocoa was dominating among the planted trees, but there were also single trees of coffee and crops like durian, papaya, avocado and banana. This land use type was undergoing changes in the whole research area, step by step being converted into plain cash crop plantations, strictly ruled by the world marked demands. At the time of this study, cocoa commanded a higher price and was thus rapidly replacing coffee in many plantations. 


\subsection{Life history of 16 in-depth studied tree species}

Knowledge on life history of tree species is deciding for accurate speculations about their ecological behaviour and for analysing the underlying reasons for interspecific differences in function. The following is a description of some main life history traits of the 16 in-depth-studied forest tree species (the agroforestry species are not covered), based on own observations. A brief overview of life history and morphology of these species can also be found in Appendix 6. The information will be referred to when discussing functional groups.

\subsubsection{Secondary forest species entering natural forest}

Two classic pioneer species with low $\mathrm{A}_{\max }$ and large leaves, Macaranga hispida and, less abundant, Macaranga tanarius can also be found within the natural forest. Likewise, two of the species with highest $\mathrm{A}_{\max }$, Trema orientalis and Pipturus argentus, occur in the natural forest. The small-leaved Trema orientalis, as well as Grewia glabra, can grow tall (up to $30 \mathrm{~m}$ ) under optimal site conditions, also within the natural forest, and are thus not only occurring in gaps, whereas the large-leaved, short-lived small trees $P$. argentus and the Macarangas generally only manage on riverbanks or in gaps. However, P. argentus has also been observed in the understorey, which is an interesting contrast to its high $\mathrm{A}_{\max }$ measured.

\subsubsection{Secondary forest specialists}

Among the pioneer species studied, Homalanthus populneus, together with Acalypha caturus, is one of the few species that was never observed inside the natural forest. The occurrence of this species was found to be limited to young secondary forests and road sides. It forms shrubs as young, and can reach about $8-10 \mathrm{~m}$ as a grown up tree. Homalanthus populneus was observed to bear either flowers or fruits more or less constantly, from a certain age or size. This Euphorbiaceae has a sticky milk like sap and has seldom any leaf losses through herbivory. Acalypha caturus is similar, also forming shrubs when young, but was never observed larger than about $6 \mathrm{~m}$. It has soft hairs on leaves, buds and twigs, as opposite to Homalanthus populneus glabrous leaves.

Another small stature Euphorbiaceae, Mallotus mollissimus, was also exclusively seen in young secondary forest stands. This relatively large leaved species has black sap. It has strikingly long, soft petioles, which lead to a closely vertical leaf angle. The nicely smelling flowers of this species form long $(20 \mathrm{~cm})$ axes. The soft leaves and petioles are covered by a light brown fuzz layer and are often subject to herbivory. 


\subsubsection{Cross-over species from the natural forest}

Bischofia javanica can grow big (up to $35 \mathrm{~m}$ ) and can be found outside the natural forest as single tree on an annual culture field or above the pioneers in a secondary forest stand. It has been observed to have extraordinary re-growth forces. From a stub or a fallen tree lots of water-shoots appear within short time and a new canopy can develop from a stub.

Cananga odorata is the other "cross over", or generalist species in this study. This medium sized tree is primarily found in the natural forest, but has been observed in large numbers colonizing forest gaps, as well as integrated in secondary forest stands.

Cananga odorata and Bischofia javanica showed the highest $\mathrm{A}_{\max }$ among the natural forest species studied. This is coherent with their observed life history characters. In contrast, the extremely low rate measured in Meliosma sumatrana is somewhat contradictive to the fact that this species is often found in larger gaps within the natural forest, side by side with Cananga odorata and Bischofia javanica.

\subsubsection{Natural forest specialists}

Out of the studied natural forest species, Semecarpus forstenii, Siphonodon celastrineus, Litsea sp. and Pimelodendron amboinicum are those who would never be observed outside dense natural forest. Semecarpus forstenii has, like several other Anacardiaceae, a highly skin irritating sap that gets dark brown by air exposure. This species has, through the sap and its very hard leaf structure, a very effective defence against herbivory. Pimelodendron amboinicum is a slow growing tree with eatable yellow cherry sized fruits that often, as Siphonodon celastrineus, has moss or lichen epiphytes on the older ones of its very small leaves.

Aglaia argentea is one of the most common compound leaved species in the natural forest that can get $35 \mathrm{~m}$, and thus belongs to the highest natural forest trees. Yet, the crown often remains rather thin and poorly branched. Aglaia argentea has in some seldom cases been observed as an old, not very well doing, remaining natural forest tree above young, emerging secondary forest stands but was never seen as seedling or young tree in these habitats. 


\section{MATERIAL AND METHODS}

\subsection{Characterization of the plots}

\subsubsection{Canopy cover parameters}

Leaf area index, LAI, is widely used to describe the photosynthetically and transpirationally active surface area of a canopy. It is defined as the one-sided leaf surface area per ground area $\left(\mathrm{m}^{2} \mathrm{~m}^{-2}\right)$.

Hemispherical photos were made with a $180^{\circ}$ wide angle Fish-eye lens with orthographic projection, mounted on a digital camera. The camera and the lens were fixed on a tripod $130 \mathrm{~cm}$ above the ground, equalized horizontally and oriented to the north-south axis, looking upwards to the sky.

The canopies on six plots of three different land use types were screened with this method: two natural forest plots, two secondary forest plots and two agroforestry plots. 15 photos were taken on each plot. The 15 photo sites were randomly spread over each plot, using the same kind of grids as for the random collection of leaves.

The photos were taken in the morning or late afternoon, in order to avoid direct sunbeams, which could give reflections on leaves and overexposed areas around the sun that might be incorrectly interpreted as gaps in the HemiView-analysis. In total 135 hemisphere pictures were taken. The pictures were analysed by the software HemiView 2.1 (Delta-T Devices Ltd., Cambridge, UK). The analysis based on the gap fraction in the subsections of each hemispheric photo. The amount and areas of the gaps were measured and used for calculations of further parameters as follows.

\subsubsection{Leaf area index}

The leaf area index value, LAI $\left(\mathrm{m}^{2} \mathrm{~m}^{-2}\right)$ calculated by the HemiView software refers to the total one-sided leaf area per unit ground area.

\subsubsection{Ellipsoidal leaf angle distribution}

The ellipsoidal leaf angle distribution parameter, ELADP, refers to the frequency distribution of LAI among leaves of different angular orientation and can take values from 0.01 (all leaf angles closely vertical) to 100 (all angles closely horizontal). The estimate is based on the zenith angles of the incoming beams. ELADP is described by an equation assuming that the canopy elements are distributed in the same proportions and orientations 
as the surface of an ellipsoid revolution. If the vertical radius in the ellipse is $a$ and the horizontal radius is $b$, then the ELADP can be described as:

$$
\operatorname{ELADP}=\mathrm{b} / \mathrm{a}
$$

Thus, an ELADP $=1$ represents a canopy where the elements angles are in average $45^{\circ}$ from the vertical. An ELADP-value above 1 indicates canopy elements closer to the horizontal and a value below 1 indicates a higher rate of canopy elements closer to the vertical.

\subsubsection{Mean leaf angle}

Mean leaf angle (MLA) is the average angle of the leaf surfaces to the horizontal. This parameter is derived from the ELADP.

\subsubsection{Visible sky and ground cover}

The Visible Sky parameter indicates how many percent of the sky is visible on a hemisphere picture. This parameter has also been referred to as canopy openness by Trichon et al (1998). Connected to this parameter is the Ground Cover value, which specifies the amount of ground area that is covered by the canopy, presented in percent as well.

\subsubsection{Climate}

Central Sulawesi covers both sides of the equator on $120^{\circ}$ eastern longitude, with the study site located on the southern hemisphere, about $150 \mathrm{~km}$ from the equator. It is influenced by the Australian-Asian monsoon system throughout the year. Mean temperature in Wuasa, Napu valley, was $21^{\circ} \mathrm{C}$ and the mean relative humidity $82.6 \%$. Yearly rainfall was $1596 \mathrm{~mm}$ (Data for Dec. 2001 to Dec. 2002, provided by sub-project B1 of the STORMA project). Air pressure was generally around $880 \mathrm{hPa}$ (according to own recordings). The studied forests are humid, submontane tropical rainforests according to Whitmore's definition (1993).

\subsubsection{Soil}

The ground preparation after clear cut in the study region was always burning of stumps, left wood and understorey vegetation. Thus, all secondary forest stands, as well as the cocoa plantations studied, were growing on soils enriched by the ash from the previous forest. None of the plots were chemically fertilized, according to the land owners. The only fertilization measures taken by the farmers was letting cut branches from the shadow trees in the agroforestry sites remain on the ground to decompose. Data on soil nitrogen 
concentrations recorded by the STORMA sub-project D4 was available for ten of the studied plots, with all four land use types being covered.

Ground water level is typically about $70 \mathrm{~cm}$ below surface in the Napu valley.

\subsubsection{Taxonomic description of the plots}

The tree sampling was conducted in close cooperation with the taxonomist Paul Keßler from the National Herbarium of the Netherlands and the Department of Systematic Botany, Göttingen University, and his local team, who made a complete systematic forest inventory of trees on the same plots (except for four $400 \mathrm{~m}^{2} \mathrm{SF}$ plots that were additionally established for the random sampling) (Pitopang et al. 2004; Kessler et al. 2004). For this forest inventory all trees with a dbh (diameter of trunk at breast height $(130 \mathrm{~cm}))$ above $10 \mathrm{~cm}$ were recorded together with their height and dbh. The results of the forest inventory were further analysed within this work to obtain plot and land use specific diversity data. Number of families, genera and species were calculated per plot and land use type. The results were used for comparison with the taxonomic structure of the random sample of sun canopy trees from the same plots and allowed evaluation of different sampling designs applied. Out of the 1171 trees from the complete forest inventory used in these analyses, 1159 were at least identified at family level and for 1152 trees the genera could also be detected. Morphospecies were always recognized.

\subsection{Plot establishing and random sampling}

\subsubsection{Plot grids and tree selection}

In order to obtain a representative sample of the tree individuals occurring on each plot a random sampling method was designed. Based on the estimated trunk density in the different land use types, different plot sizes were defined for reaching a similar sample size on all plots. Thus, the plot size in the natural forest, the forest garden and agroforestry system was $2500 \mathrm{~m}^{2}$, compared to $400 \mathrm{~m}^{2}$ in the secondary forest, which has a much higher stem density.

Plot grids with an $\mathrm{x}$-axis in north-south direction and an east-west oriented $\mathrm{y}$-axis were established using compass, ropes and wooden sticks, marking every $5 \mathrm{~m}$. This resulted in a grid with 121 nodes on $2500 \mathrm{~m}^{2}$. In each plot grid 20 spots were randomly selected. The closest mature or pre-mature tree with fully sunlit leaves to each spot was recorded and sampled (see below). The trunk circumference was measured and height was estimated. The 
phenological status of the individual (presence of fruits and flowers) and the name, or other identification, were recorded. Subsequently, the tree was marked with an individual number on a plastic label for future needs. Herbarium specimens of unknown species were collected in parallel.

Table 3.1 List of the plots included in the study, covering four different land use types on altitudes between 700 and $1100 \mathrm{~m}$ asl. The study sites were situated in the Palolo and Lore Utara sub-districts in the Indonesian province of Central Sulawesi. (Abbr. - Abbreviation, NF - Natural forest, FG - Forest garden, SF - Secondary forest, AF - Agroforestry system)

\begin{tabular}{lllcccl}
\hline Study area & Abbr. & Land use type & Sub-plot & $\begin{array}{r}\text { Plot size } \\
{[\mathrm{ha}]}\end{array}$ & $\begin{array}{r}\text { Altitude } \\
{[\mathrm{m} \text { a s 1 }]}\end{array}$ & Sub district \\
\hline Napu 1 & NF1 & NF & & 0.25 & 1100 & $\begin{array}{l}\text { Lore Utara } \\
\text { Lapu 2 }\end{array}$ \\
NF2 & NF & 1 & 0.25 & 1100 & Pore Utara \\
Gunung Potong & NF3 & NF & 2 & 0.25 & 900 & \\
& & & 3 & 0.25 & & \\
& & & 4 & 0.25 & & \\
Kamarora 1 & FG1 & FG & & 0.25 & 700 & Palolo \\
Kamarora 2 & FG2 & FG & & 0.25 & 700 & Palolo \\
Alitupu 1 & A1 & SF & 1 & 0.04 & 1100 & Lore Utara \\
& & & 2 & 0.04 & & \\
Alitupu 2 & A2 & SF & 1 & 0.04 & 1100 & Lore Utara \\
& & & 2 & 0.04 & & \\
Kaduaa & $\mathrm{K}$ & SF & 1 & 0.04 & 1100 & Lore Utara \\
& & & 2 & 0.04 & & \\
Watumaeta & W & SF & 1 & 0.04 & 1100 & Lore Utara \\
& & & 2 & 0.04 & & \\
Dodolo 1 & AFD1 & AF & & 0.25 & 1100 & Lore Utara \\
Dodolo 2 & AFD2 & AF & & 0.25 & 1100 & Lore Utara \\
Kaduaa & AFK & AF & & 0.25 & 1100 & Lore Utara \\
Watumaeta & AFW & AF & & 0.25 & 1100 & Lore Utara \\
\hline
\end{tabular}

In this manner three natural forest plots (Gunung potong, Napu I and II), four secondary forest plots (Watumaeta, Kaduaa, Alitupu I and II), two forest garden plots (Kamarora I and II) and four agroforestry plots (Dodolo I and II, Kaduaa and Watumaeta) were established and sampled. The plots are listed in Table 3.1. They belonged to the jointly selected focal study sites within the STORMA project and were studied by several of the project's natural science researchers.

\subsubsection{Leaf collection}

For obtaining data on several leaf traits, e.g. nutrient concentration, carbon isotope ratio $\left(\delta^{13} \mathrm{C}\right)$, nitrogen isotope ratio $\left(\delta^{15} \mathrm{~N}\right)$, leaf size, specific leaf area (SLA) and other morphological characteristics, exclusively fully sunlit mature, vigorous leaves were collected from each of the randomly selected trees. In the secondary forest and the 
agroforestry systems leaves could be accessed with a branch cutter on an extendable stick at heights of $3-6 \mathrm{~m}$. For sampling the natural forest trees at $15-25 \mathrm{~m}$, local tree climbers and the staff of the Herbarium Celebense in Palu were employed, using climbing equipment with ropes and iron hooks or manual climbing techniques. Due to extreme tree heights and trunks with too many lianas and other epiphytes, which made it impossible to reach the sunlit parts of the crown, a few randomly selected trees could not be sampled. These trees were as far as possible replaced by other randomly sampled individuals, in some cases on neighbouring sub-plots, resulting in slightly different numbers of sampled individuals per sub-plot. In total, sun leaves of 354 trees were randomly sampled. Depending on leaf size, 4 - 30 leaves per tree were collected with their petiole and put in paper bags.

Random sampling of the natural forest and forest garden plots was conducted between February and October 2001. Sampling of secondary forest and agroforestry plots was carried out between March and July the same year.

\subsubsection{Definition of random sample and species average}

Most comparative studies on tree ecology are focused on certain tree species or families that are common, or have been selected more or less arbitrarily. This allows detection of differences between the taxa, but often cannot give information on the "average tree" in a stand. This study is an attempt to apply a random sampling strategy in very species rich forests. This was achieved by sampling the stems randomly, as described above, in order to get a representative sample of the trees in the stand, irrespective of frequency and species identity. By this means, forest stands as assemblies of trees may be compared with respect to functional traits, instead of comparing species means. To assure comparability of the leaf traits studied, only upper canopy branches were sampled.

Table 3.2 Specification of random sample and species average parameters as referred to throughout this work. (NF - Natural forest, SF - Secondary forest, AF - Agroforestry system, FG - Forest garden)

\begin{tabular}{|c|c|c|c|c|c|c|c|c|c|}
\hline & \multicolumn{3}{|c|}{ Random sample } & \multirow[b]{2}{*}{ FG } & \multirow[b]{2}{*}{ Total } & \multicolumn{4}{|c|}{ Species average } \\
\hline & NF & SF & $\mathbf{A F}$ & & & NF & SF & $\mathbf{A F}$ & FG \\
\hline $\begin{array}{l}\text { No. individuals } \\
\text { sampled } \\
\text { No. species }\end{array}$ & 119 & 160 & 49 & 26 & 354 & & & & \\
\hline sampled & 69 & 35 & 4 & 18 & 107 & 69 & 35 & 4 & 18 \\
\hline $\begin{array}{l}\text { Canopy strata } \\
\text { sampled }\end{array}$ & $\begin{array}{l}\text { Upper } \\
\text { canopy }\end{array}$ & $\begin{array}{l}\text { Upper } \\
\text { canopy }\end{array}$ & $\begin{array}{l}\text { Upper } \\
\text { canopy }\end{array}$ & $\begin{array}{l}\text { Upper } \\
\text { canopy }\end{array}$ & $\begin{array}{l}\text { Upper } \\
\text { canopy }\end{array}$ & $\begin{array}{l}\text { Upper } \\
\text { canopy }\end{array}$ & $\begin{array}{l}\text { Upper } \\
\text { canopy }\end{array}$ & $\begin{array}{l}\text { Upper } \\
\text { canopy }\end{array}$ & $\begin{array}{l}\text { Upper } \\
\text { canopy }\end{array}$ \\
\hline No. of plots & 3 & 4 & 4 & 2 & 13 & 3 & 4 & 4 & 2 \\
\hline $\begin{array}{l}\text { Total plot size } \\
{\left[\mathrm{m}^{2}\right]}\end{array}$ & 15000 & 3200 & 10000 & 5000 & 33200 & 15000 & 3200 & 10000 & 5000 \\
\hline
\end{tabular}


Based on the species composition of the random sample, a species average was additionally calculated for some leaf traits. This is the mean of the 4 to 69 species present in each land use type, with each species being represented by a mean of 1 to 10 individuals. The sampling parameters for the two sample designs as referred to throughout this work are defined in Table 3.2. Means at the land use level always include all plots studied, and if nothing else is mentioned, always base on the random sample. The only exception to this definition occurs in the sampling design chapter, where only two of the three natural forest plots were included (see chapter 4.2).

\subsubsection{Species identification}

The collected samples were either immediately identified, or brought to the National Herbarium of the Netherlands for identification. Herbarium Celebense in Palu also contributed with valuable identification work and the preparation of herbaria specimen.

The scientific plant names throughout this work consequently follow the Checklist of woody plants of Sulawesi, Indonesia (Keßler et al. 2002).

\subsubsection{Additional sampling for analysis of intraspecific variation}

Only a minority of the tree species occurred with a sufficient number of individuals in the random sample to study intraspecific variation in leaf traits. Leaves from additional tree individuals of eight abundant natural forest species, eight secondary forest species and three agroforestry species were sampled to attain a replication number of 10 tree individuals per species for assessment of intraspecific variations of morphological and chemical leaf traits.

\subsection{Seasonal variation of foliar nutrient concentrations and leaf $\delta^{13} \mathrm{C}$}

To analyse possible seasonal trends in foliar nutrient concentrations and leaf $\delta^{13} \mathrm{C}$ and $\delta^{15} \mathrm{~N}$ throughout the year, leaves from 10 species were sampled repeatedly during one year. This was done for five abundant late-successional species (Aglaia argentea, Pimelodendron amboinicum, Litsea sp., Semecarpus forstenii, Siphonodon celastrineus) and five abundant secondary forest species (Acalypha caturus, Trema orientalis, Pipturus argentus, Grewia glabra, Homalanthus populneus) with each species represented by five individuals. A leaf sample of about 10 mature sun leaves was collected from every tree four times at threemonth intervals, resulting in the following collection dates in the natural forest: August and November 2001, February and May 2002. Samples from the secondary forest species were collected in July and October 2001 and January and April 2002. These samples were 
analysed for the concentrations of calcium, potassium, magnesium, phosphorus, total carbon, nitrogen and their $\delta^{15} \mathrm{~N}$ and $\delta^{13} \mathrm{C}$ values.

\subsection{Morphological leaf traits}

\subsubsection{Leaf angle}

The natural leaf angles of 30 sun leaves from each of the 19 species used for physiological studies were assessed through in situ observation. Mature sun leaves in the upper canopy were classified according to the angle of their midrib in relation to a fictive vertical axis. They were divided into six classes: $0-30^{\circ}, 30-60^{\circ}, 60-90^{\circ}, 90-120^{\circ}$ or 120 $180^{\circ}$, where $0^{\circ}$ is vertically upwards.

\subsubsection{Leaf size and specific leaf area}

Four to ten sun leaves per tree were scanned directly after sampling with a flat bed graphics scanner (CanoScan N340P, Canon, Japan), and thereafter dried at $70^{\circ} \mathrm{C}$ for $48 \mathrm{~h}$. The dried leaves were weighed for calculating SLA. Leaf area, length and width of the leaves were determined from the digital images with the program WinFolia (Régent Instruments Inc., Quebec, Canada). In the case of compound leaves, only one leaflet was analysed for leaf size. For this, the middle leaflet at the long side of a leaf was used. These data were treated as equivalent to those from simple leaves throughout the study. This seems to be justified because leaflets of compound leaves have been found to be independent of each other in regards of gas exchange and are in many species abscised individually (Raunkiaer 1934; Bout \& Okitsu 1999). Leaf areas were classified according to Webb's modified version of Raunkiaer's leaf size class system (Webb 1959). The class sizes are presented in Table 3.3. Leaf length was measured as the linear distance between petiol base and apex. Leaf width was measured as the longest possible vertical to the base-apex line.

Table 3.3 Leaf size classes by the Raunkiaer-Webb classification (Buot \& Okitsu 1999)

\begin{tabular}{ll}
\hline Leaf size class & Size range $\left[\mathbf{c m}^{2}\right]$ \\
\hline Leptophyll & $<0.25$ \\
Nanophyll & $0.25-2.25$ \\
Microphyll & $2.25-20.25$ \\
Notophyll & $20.25-45.00$ \\
Mesophyll & $45.00-182.25$ \\
Macrophyll & $182.25-1640.25$ \\
Megaphyll & $>1640.25$ \\
\hline
\end{tabular}




\subsection{Chemical leaf traits}

For chemical analysis the petioles were cut off and the leaves were dried in paper bags at $70^{\circ} \mathrm{C}$ for $48 \mathrm{~h}$, thereafter ground to fine powder. One sample per tree, consisting of $4-30$ fully sunlit leaves, was used for the following analyses.

\subsubsection{Concentrations of $\mathrm{Ca}, \mathrm{K}, \mathrm{Mg}, \mathrm{P}, \mathrm{N}$ and $\mathrm{C}$}

The total concentrations of $\mathrm{Ca}, \mathrm{K}, \mathrm{Mg}$ and phosphorus in the leaf samples were detected through $\mathrm{HNO}_{3}$-pressure digestion and subsequent atomic emission spectrometry (Optima 2000 DV, Perkin Elmer). The total carbon and nitrogen concentrations were determined using gas chromatography in an elemental analyser (Vario EL, Elementar).

\subsubsection{Carbon isotope signature}

Ground leaf material was analysed for its $\delta^{13} \mathrm{C}$ signature with a gas isotope mass spectrometer (Finnigan, MAT 251).

The $\delta^{13} \mathrm{C}$-value shows the difference between ${ }^{13} \mathrm{C}:{ }^{12} \mathrm{C}$ isotope ratios of the sample (sa) and of a standard $(\mathrm{PDB}=$ PeeDee Belemite $)$. It is calculated as

$$
\delta^{13} \mathrm{C}=\left[\left({ }^{13} \mathrm{C}_{\mathrm{sa}} /{ }^{12} \mathrm{C}_{\mathrm{sa}}\right) /\left({ }^{13} \mathrm{C}_{\mathrm{PDB}} /{ }^{12} \mathrm{C}_{\mathrm{PDB}}\right)\right] * 1000[\% \mathrm{\%}] \quad(\text { Garten et al 1991) }
$$

The $\delta^{13} \mathrm{C}$-value of the $\mathrm{CO}_{2}$ in the air is approximately $-7 \%$.

\subsubsection{Nitrogen isotope signature}

The $\delta^{15} \mathrm{~N}$ value is calculated as the relation between the two isotopes ${ }^{14} \mathrm{~N}$ and ${ }^{15} \mathrm{~N}$ in a sample, compared to the international standard quota of ${ }^{14} \mathrm{~N}$ and ${ }^{15} \mathrm{~N}$ for air.

Ground leaf samples were analysed for $\delta^{15} \mathrm{~N}$ with a gas isotope mass spectrometer (Finnigan, MAT 251).

Soil samples were ground and analysed the same way as the plant samples.

\subsubsection{Classification of species according to their $N_{2}$-fixing ability}

Roggy et al. (1999) investigated tropical tree species likeliness to be depending on $\mathrm{N}_{2}$ fixation for their $\mathrm{N}$ supply in an extensive survey using a known non- $\mathrm{N}_{2}$-fixing species as reference. They thereby pointed at the importance of considering the total nitrogen concentration of leaves together with the $\delta^{15} \mathrm{~N}$ values for a proper estimation of possible $\mathrm{N}_{2}$ fixation. Roggy et al. achieved a mean leaf $\mathrm{N}$ concentration of $2 \%$ and a mean $\delta^{15} \mathrm{~N}$ of 
$4.93 \%$ for the non-N-fixing reference species Dicorynia guianensis (Caesalpiniaceae) and divided their sampled tree species into three separate clusters, according to total $\mathrm{N}$ and $\delta^{15} \mathrm{~N}$, compared to the reference species. They called the groups "supposed $\mathrm{N}_{2}$-fixers", "supposed non- $\mathrm{N}_{2}$-fixers" and "uncertain other species".

The 107 species investigated in this study were classified using thresholds based on the means of each group in Roggy's samples in the following manner. Thresholds for the “supposed $\mathrm{N}_{2}$-fixers" group was set to the mean $\delta^{15} \mathrm{~N}$ value of that group in Roggy's sample, added the standard deviation (thus, $\leq 3.60 \%$ ) and mean total $\mathrm{N}$ minus standard deviation (thus, $\geq 2.06 \%$ ). The "supposed non- $\mathrm{N}_{2}$-fixers" were defined as those species having $\delta^{15} \mathrm{~N}$ values above the threshold $3.60 \%$, regardless of total $\mathrm{N}$ values. The third group, "uncertain other species", was defined by the same $\delta^{15} \mathrm{~N}$ limit as the $\mathrm{N}_{2}$-fixing group, but combined with the lower range of total $\mathrm{N}$ values $(\leq 2.06 \%)$. The thresholds are depicted in Table 4.7 .

\subsection{Leaf gas exchange measurements}

In a more detailed analysis, eight species in each of the two forest types and the tree species present in the agroforestry plantations were selected (19 species in total). The species were chosen because of their abundance and also with the aim of covering a broad morphological spectrum concerning leaf size and structure. Five of the pioneer species and two of the species of the natural forest belonged to the family Euphorbiaceae. The other families represented were Anacardiaceae, Annonaceae, Celastraceae, Lauraceae, Fabaceae, Meliaceae, Sabiaceae, Sterculiaceae, Tiliaceae, Ulmaceae and Urticaceae.

Wooden towers were built for access to the sun leaves of the trees in the natural and secondary forests. The towers were $10-15 \mathrm{~m}$ high in the natural forest, and $4-5 \mathrm{~m}$ high in the secondary forest. All trees in the agroforestry systems could be reached from the ground.

\subsubsection{Photosynthetic rate}

\subsubsection{The Li-6400 system}

Net rates of photosynthesis were measured with a portable gas exchange measurement system (Li-6400, LiCor Inc., Lincoln, NE, USA). This equipment allows in situ gas exchange measurements in the field at intact leaves in natural position at the tree. The system measures concentration differences in $\mathrm{CO}_{2}$ and $\mathrm{H}_{2} \mathrm{O}$ between the air stream flowing through the leaf chamber and a reference air stream. $\mathrm{CO}_{2}$ - and $\mathrm{H}_{2} \mathrm{O}$-concentrations are measured by infrared gas analysis. The Li-6400 system consists of a console and a sensor 
head. The console contains a computer, a display, and a small keyboard for managing the system. The leaf chamber and the gas analysers are located in the sensor head. The temperature in the chamber can be controlled by Peltier devices, enabling adjustment of defined vapour pressure deficits (VPD). A red and blue light source enables controlled irradiation of the leaf.

Several times during the working period the analysers were additionally calibrated with a gas of a defined $\mathrm{CO}_{2}$-concentration and air of defined humidity generated by a dew-point generator (Li-610, Li-Cor Inc., Lincoln, NE, USA).

A zero-calibration of the sample and reference gas analysers (IRGA) of the Li-6400 was carried out every morning before starting the measurements.

It was regularly checked that the two IRGAs, matched each other internally. This check was done before logging of each data point.

\subsubsection{Measurement protocol}

Net rates of photosynthesis were measured at 10 - 15 fully sunlit, mature leaves of each species, on at least two different mature or premature trees (typically the fifth leaf, counted from the terminal bud of a twig). During the measurements leaf temperature was maintained at $28^{\circ} \mathrm{C}$ and VPD around $1.4 \mathrm{kPa}$. Ambient $\mathrm{CO}_{2}$-levels were used. Mean $\mathrm{CO}_{2}$-level was 369 $\pm 6 \mathrm{ppm}$.

The central part of a leaf, close to the mid rib, was clamped into the $6 \mathrm{~cm}^{2}$ leaf chamber. The photosynthetic light response at seven irradiation levels (photon flux densities, PPFD, 2000, 1500, 1000, 500, 200, 50 and $0 \mu \mathrm{mol} \mathrm{s}^{-1} \mathrm{~m}^{-2}$ ) was determined, starting at the highest irradiance. Values were logged after a time period of at least 12 minutes of irradiation, when steady state was reached, which could be controlled on the display of the Li-6400 system. Maximum photosynthetic net rate at saturating light intensity and ambient $\mathrm{CO}_{2}$ concentration, $A_{\max }$, is assumed to be equivalent to the level of the plateau reached in the light response curve. From the $\mathrm{A}_{\max }$-area value (in $\mu \mathrm{mol} \mathrm{CO} \mathrm{Cm}^{-2} \mathrm{~s}^{-1}$ ) given by the Li-6400 system and specific leaf area data of the species (in $\mathrm{cm}^{2} \mathrm{~g}^{-1}$ ), $\mathrm{A}_{\max }$ per mass unit (in $\mu \mathrm{mol}$ $\mathrm{CO}_{2} \mathrm{~g}^{-1} \mathrm{~s}^{-1}$ ) was calculated.

All measurements were conducted during the hours when leaves shoved maximum photosynthetic capacity (between 9 am and 3 pm). After rainfall the measurements were discontinued until the next day. The investigations were carried out between October 2001 and June 2002. 


\subsubsection{Stomatal conductance for water vapour}

Stomatal conductance for water vapour at natural light intensity and humidity conditions were measured. This was done with a portable steady state porometer (Li-1600, LiCor Inc., Lincoln, NE, USA). Ten to twenty fully expanded, mature, vigorous sun leaves per species (typically the fifth leaf, counted from the terminal bud of a twig) from at least two different mature or premature tree individuals were measured in their natural position. Each leaf was repeatedly measured on 7 to 9 occasions during a day, in 45 minutes intervals, creating 10 - 20 daily courses of stomatal conductance per species. All measurements took place between 9 am and 2:30 pm.

Leaf and cuvette temperature, VPD and flux density of photosynthetically active radiation (PAR) were recorded simultaneously with all measurements. Transpiration of a leaf placed in the Li-1600 leaf chamber is determined by measuring the flow rate of dry air needed to maintain a constant relative humidity inside the cuvette against the transpiration of the leaf. This target humidity was set to the surrounding humidity at the site of measurement just before starting measuring each leaf. Stomatal conductance $\left(g_{s}\right)$ is calculated directly from the measured values of relative humidity, leaf and air temperature, and flow rate by the Li-1600 in mmol m$~ m^{-2} \mathrm{~s}^{-1}$. The VPD ( $\left.\mathrm{kPa}\right)$ was calculated from the relative humidity (RH \%) and leaf temperature $\left(\mathrm{T} \mathrm{C}^{\circ}\right)$ as follows:

$$
\mathrm{VPD}=6.1078^{((17.08 * \mathrm{~T}) /(234.18+\mathrm{T}))}-\mathrm{RH} / 100 * 6.1078^{((17.08 * \mathrm{~T}) /(234.18+\mathrm{T}))}
$$

To determine maximum stomatal conductance $\left(\mathrm{g}_{\mathrm{smax}}\right)$ of a leaf, only peak $\mathrm{g}_{\mathrm{s}}$ values recorded at humidity readings $<80 \%$ were considered. Readings at $\mathrm{RH}>80 \%$ (mainly in early morning hours and immediately before afternoon rainfall) were often thought to be less reliable.

Conductance values reported are all stomatal conductance of the lower leaf side.

\subsubsection{Water use efficiency}

For calculating water use efficiency (WUE) as

$$
\text { WUE }=\mathrm{A}_{\max }-\mathrm{area} / \mathrm{g}_{\mathrm{s}} \quad\left[\mu \mathrm{mol} \mathrm{CO} \mathrm{CO}_{2}\left(\mathrm{~mol} \mathrm{H}_{2} \mathrm{O}\right)^{-1}\right]
$$

the $g_{s}$ values measured by the Li-6400-system, corresponding to each $A_{\max }$ value were used. Thus, the two values used for calculating WUE were obtained simultaneously, in a given leaf, at the same $\mathrm{RH}$, light intensity $\left(2000 \mu \mathrm{mol} \mathrm{s}^{-1} \mathrm{~m}^{-2}\right)$, leaf temperature $\left(28^{\circ} \mathrm{C}\right)$, VPD $(1.4$ 
$\mathrm{kPa})$ and ambient $\mathrm{CO}_{2}$-concentrations $(369 \pm 6 \mathrm{ppm})$. The measurements were conducted in $10-15$ leaves from at least two different tree individuals.

\subsection{Statistical analyses}

\subsubsection{Comparative and analytical statistics}

Mean and standard deviation were calculated for all investigated parameters from the measured values of individual trees in the random sample and/or as species average. For further statistical analysis, the computer program SAS (Statistical Analysis System, SASInstitute Inc., Cary, NC, USA) was used.

First, all data were tested for normal distribution using Shapiro \& Wilk's test ( $\mathrm{p}<$ 0.05). For not normally distributed data, non-parametric tests were used for further analyses.

The non-parametric, univariate Wilcoxon test was used to detect significant differences between two samples of non-normal distribution. For analysis of variance between normally distributed samples ANOVA (in balanced samples) or GLM (unbalanced samples) were used. Significantly different means were marked with different letters (according to Scheffé) throughout tables and figures.

Correlation analyses were conducted with Pearson's test. Correlations are presented with the squared correlation coefficient $\left(r^{2}\right)$ and probability $(p)$.

Multiple regression analyses were done with the stepwise exclusion method, where given variables were stepwise introduced one by one, and eventually excluded again, until the set of parameters yielding the maximum degree of explanation $\left(\mathrm{R}^{2} \mathrm{Model}\right)$ for the variance in the dependent variable was found. The results of the multiple regression analyses are presented as the degree of explanation $\left(\mathrm{R}^{2}\right.$ Model, in \%) achieved by the whole model, as well as by each of the included parameters $\left(\mathrm{R}^{2}\right)$.

Significances are always given at the $\mathrm{p}<0.05$ degree.

\subsubsection{Cluster analysis for identification of tree functional groups}

The 107 species investigated in this study were divided into functional groups by means of cluster analysis, according to the method described below.

Initially a hierarchic cluster analysis of the 107 species based on the five selected leaf traits SLA, leaf size, N, P and $\delta^{13} \mathrm{C}$ was conducted to determine the optimal number of functional groups (clusters) to be defined. The analysis showed that in a model with 10 clusters, $97 \%$ of the total variation would be explained by inter-cluster variance, indicating a 
high homogeny within the clusters. Further, in a 7-cluster model 95\% would be inter-cluster variance, in a 5-cluster model $92 \%$ and in a 2-cluster 60\%. Köhler et al. (2000) suggested the definition of 10 to 20 functional groups in samples of tropical tree species. However, in this study the number of functional groups defined was intended to be set relatively low, to avoid the risk of constructing artificial classes by setting the number too high, as experienced during the first trials.

Thereafter, a disjoining cluster analysis determined for 10 clusters was carried out, based on the five leaf traits mentioned above, resulting in 10 non-overlapping clusters. 


\section{Results}

\subsection{Tree species composition of the study plots}

\subsubsection{Species diversity}

A complete forest inventory of trees on the natural forest (NF), secondary forest (SF) and forest garden (FG) plots comprising 1013 trees with $\mathrm{dbh}>10 \mathrm{~cm}$ of all canopy strata was conducted by Paul Keßler and his team of field assistants and plant systematics specialists (National Herbarium of the Netherlands and Dept. of Systematic Botany, University of Göttingen. Pitopang et al. 2004; Kessler et al. 2004). The random sample of the upper canopy on the same plots included $30 \%$ of that number of tree individuals, i.e. 305 trees in total, disregarding dbh (Table 4.1. For definitions of random sample, see Table 3.2).

Table 4.1 The total number of tree individuals (Ind), species, genera and families recorded in the three land use types natural forest (NF), secondary forest (SF) and forest garden (FG). The values are presented for the complete taxonomic inventory, done by Paul Keßler and his team ( $\mathrm{dbh}>10 \mathrm{~cm}$, all canopy strata), in the first columns, followed by the corresponding values from the random sample to the right (no dbh limit, upper canopy only). In some cases the number of families or genera could not be specified, due to unidentified morphospecies. In these cases the lowest value indicates the case that all unidentified species belong to one genus and the highest that they all represent different genera.

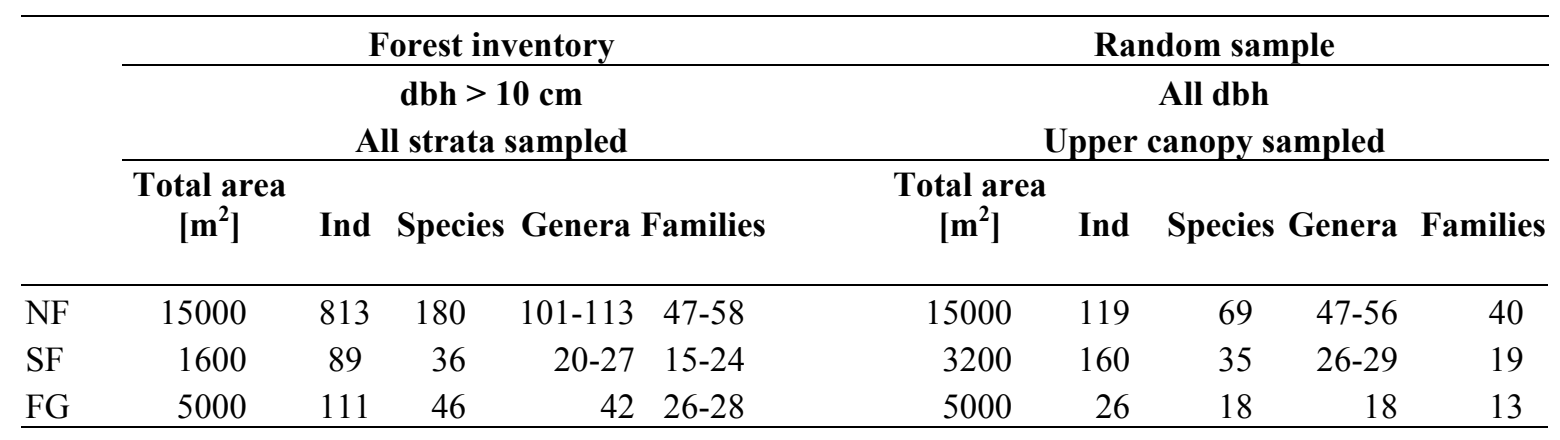

The number of trees recorded per NF sub-plot varied between 121 and 152 individuals per $2500 \mathrm{~m}^{2}$ in the inventory, and between 18 and 24 in the random sample. The number of families recorded per $2500 \mathrm{~m}^{2}$ in the natural forest was $23-32$ in the inventory and $8-14$ in the random samples. The number of tree individuals on each of the $400 \mathrm{~m}^{2}$-SF plots ranged between 14 and 29 in the inventory and was 20 in the random sample. Here the count of different families was between 3 and 9 compared with $4-8$ in the random samples. The corresponding numbers for the forest garden plots were 39 and 72 individuals per $2500 \mathrm{~m}^{2}$ - 
plot in the inventory, and 10 and 16 in the random sample, with a family number of 14 to 22 in the inventory, and 8 in both FG random samples. These plot level data are presented in Table 4.2.

Table 4.2 The total number of tree individuals (Ind), species, genera and families recorded on each natural forest (NF), secondary forest (SF) and forest garden (FG) plot. Values are presented for the forest inventory conducted by Keßler et al. (Pitopang et al. 2004; Kessler et al. 2004), and for the random sample. It was attempted to sample 20 sun canopy trees per plot by random, which could not be achieved on all sub-plots. Therefore, the number of sampled trees was increased on other sub-plots as replacement. The results of the 1 ha plot NF3 (Gunung Potong) are presented for each of its four sub-plots, in order to achieve higher comparability with the other $2500 \mathrm{~m}^{2}$-plots. In some cases the number of families or genera could not be specified, due to unidentified morphospecies. In these cases the lowest value indicates the case that all unidentified species belong to one genus and the highest that they all represent different genera.

\begin{tabular}{|c|c|c|c|c|c|c|c|c|c|c|c|}
\hline \multirow[b]{3}{*}{ LUT } & \multirow[b]{3}{*}{ Plot } & \multirow[b]{3}{*}{$\begin{array}{c}\text { Sub- } \\
\text { plot }\end{array}$} & \multirow[b]{3}{*}{$\begin{array}{c}\text { Plot size } \\
{\left[\mathbf{m}^{2}\right]}\end{array}$} & \multirow{2}{*}{\multicolumn{4}{|c|}{$\begin{array}{c}\text { Forest inventory } \\
\mathrm{dbh}>10 \mathrm{~cm} \\
\text { All strata sampled }\end{array}$}} & \multirow{2}{*}{\multicolumn{4}{|c|}{$\begin{array}{c}\text { Random sample } \\
\text { All dbh } \\
\text { Upper canopy sampled }\end{array}$}} \\
\hline & & & & & & & & & & & \\
\hline & & & & Ind & Species & Genera & Families & Ind & ecies & Genera & Families \\
\hline $\mathrm{NF}$ & NF1 & & 2500 & 124 & 58 & $34-42$ & $28-33$ & 19 & 15 & 12 & 8 \\
\hline $\mathrm{NF}$ & NF2 & & 2500 & 121 & 51 & $33-40$ & 23 & 24 & 18 & $16-18$ & 13 \\
\hline $\mathrm{NF}$ & NF3 & 1 & 2500 & 138 & 54 & 40 & 23 & 20 & 17 & $13-16$ & 14 \\
\hline NF & NF3 & 2 & 2500 & 152 & 66 & $49-50$ & $31-32$ & 21 & 17 & $10-14$ & 12 \\
\hline NF & NF3 & 3 & 2500 & 142 & 50 & $38-39$ & 24 & 17 & 13 & 13 & 10 \\
\hline $\mathrm{NF}$ & NF3 & 4 & 2500 & 136 & 58 & $40-42$ & $25-26$ & 18 & 15 & $14-15$ & 11 \\
\hline SF & $\mathrm{A} 1$ & 1 & 400 & 26 & 7 & 6 & 3 & 20 & 7 & 7 & 4 \\
\hline $\mathrm{SF}$ & A1 & 2 & 400 & & & & & 20 & 9 & 9 & 5 \\
\hline SF & A2 & 1 & 400 & 20 & 9 & $4-8$ & $3-7$ & 20 & 6 & 6 & 4 \\
\hline SF & $\mathrm{A} 2$ & 2 & 400 & & & & & 20 & 7 & 7 & 5 \\
\hline SF & K & 1 & 400 & 29 & 12 & $10-12$ & $7-9$ & 20 & 13 & $10-12$ & 7 \\
\hline SF & $\mathrm{K}$ & 2 & 400 & & & & & 20 & 13 & $10-12$ & 7 \\
\hline $\mathrm{SF}$ & $\mathrm{W}$ & 1 & 400 & 14 & 7 & $3-5$ & $3-5$ & 20 & 11 & 10 & 8 \\
\hline SF & $\mathrm{W}$ & 2 & 400 & & & & & 20 & 8 & 8 & 7 \\
\hline FG & FG1 & & 2500 & 39 & 19 & 19 & 14 & 10 & 10 & 10 & 8 \\
\hline FG & $\mathrm{FG} 2$ & & 2500 & 72 & 34 & 29 & $20-22$ & 16 & 10 & $9-10$ & 8 \\
\hline
\end{tabular}

\subsubsection{Species diversity per unit area}

The number of individuals, species and families in SF and NF counted on small plots of the same size can be compared in Table 4.3. The number of families in SF (15 - 24) was slightly lower than in NF (19 - 27) on a $1600 \mathrm{~m}^{2}$-plot, and the species number in SF was lower than in NF, reaching $72-90 \%$ of the NF number. The forest garden, as well as the agroforestry system, had lower taxonomic diversity, which is associated with their lower 
total number of tree individuals and because they are managed land use types. The natural forest plots had 2.3 times more individuals than the forest garden on a $1600 \mathrm{~m}^{2}$-plot, and twice as many species.

Table 4.3 Number of families and species per $1600 \mathrm{~m}^{2}$ area units based on data from Keßler et al. on trees with dbh > $10 \mathrm{~cm}$ (Kessler et al. 2004; Pitopang et al. 2004). In order to enable comparisons of species diversity per area unit data for $1600 \mathrm{~m}^{2}$ was taken out of the larger NF and FG plots $\left(^{*}\right)$. In case of more than one unidentified family in the sample, only one has been counted in this table (**). (Ind - Number of individuals sampled)

\begin{tabular}{lcccccc}
\hline Plot & Sub-plot & $\begin{array}{c}\text { Plot size } \\
{\left[\mathbf{m}^{\mathbf{2}}\right]}\end{array}$ & Ind & Species & Genera & Families \\
\hline SF & & 1600 & 89 & 35 & $20^{* *}$ & $15^{* *}$ \\
NF1* & & 1600 & 89 & 42 & $29 * *$ & $27 * *$ \\
NF2* & & 1600 & 74 & 44 & $30^{* *}$ & 21 \\
NF3* & 1 & 1600 & 96 & 38 & 32 & 20 \\
NF3* & 2 & 1600 & 85 & 40 & 30 & 22 \\
NF3* & 3 & 1600 & 90 & 41 & $30^{* *}$ & $19^{* *}$ \\
NF3* & 4 & 1600 & 100 & 50 & $39 * *$ & $21^{* *}$ \\
FG1* & & 1600 & 27 & 16 & 16 & 13 \\
FG2* & & 1600 & 54 & $24 * *$ & $23 * *$ & $18^{* *}$ \\
\hline
\end{tabular}

\subsubsection{Abundant families and species}

According to the inventory data, the most abundant tree family in terms of stems in the natural forest was Lauraceae, to which $13.5 \%$ of all recorded trees belonged. This family was represented by 10 genera and 25 species. Consequently, the most frequent single Lauraceae species (Cryptocarya crassinerviopsis) represented only $2.7 \%$ of the total number of natural forest trees. The second most abundant family was Meliaceae (12.7\%) followed by Urticaceae (10.1\%) and Euphorbiaceae (8.8\%). The most abundant single species was the Urticaceae Pouzolzia sp. which represented $6.9 \%$ of the trees. The second and third most common species, Aglaia argentea (4.3\%) and Chisocheton sp. (4.0\%), both belonged to the Meliaceae.

Contrary to the natural forest, where the single most abundant family (Lauraceae) contributed only $13.5 \%$ of the trees, the Euphorbiaceae dominated the secondary forests, with $45 \%$ of all trees belonging to this family. The second most important family in terms of stems in the secondary forest was Ulmaceae (9.3\%), followed by Annonaceae (5.4\%). The three most abundant species were all Euphorbiaceae members: Homalantus populneus (18.6\%), Acalypha caturus (12.4\%) and Glochidium rubrum (6.2\%). 
The forest garden, being a system with selected natural forest trees shading planted crops, had a tree composition consisting to $21.6 \%$ of Rubiaceae. There were two species present of this family, of which Coffea arabica was the most frequent, comprising $20.7 \%$ of the trees in the forest garden. The second most frequent family in terms of stems was Urticaceae (9.9\%) with Boehmeria sp. as the most common species (7.2\%).

\subsubsection{Overlap of families and species among land use types}

More than half (29) of the in total 56 families recorded were represented in more than one land use type. Eleven families $(20 \%)$ were found in three or four land use types. Rubiaceae was the only family found in all four land use types. In total, 10 genera and 12 species of this family occurred on the study plots. Out of 217 species $38(18 \%)$ were present in more than one land use type, mainly NF and FG, but there were also coincidences between SF and NF, e. g. among Euphorbiaceae and Lauraceae. Only 7 species (3\%) were found in more than two different land use types.

\subsection{Comparing different sampling designs}

To investigate the consequences of applying different sampling strategies, mean values of important leaf trait parameters were calculated for the three land use types natural forest, secondary forest and forest garden according to the following three sampling designs:

1. The random sample comprises tree individuals present in the sun canopy, irrespective of species identity or dbh.

(NF*: 43 trees, SF: 160 trees and FG: 26 trees)

2. The species average is the mean of the 18 to 35 species present within each land use type in the random samples applied in this comparison, with each species being represented by a mean of 1 to 10 individuals. Since the species average bases on the random sample it likewise only concerns the sun canopy and disregards dbh. (NF*: 28 species, $\mathrm{SF}: 35$ species and FG: 18 species)

3. The third set of means was based on the results of the complete forest inventory of the plots, which comprised trees with dbh above $10 \mathrm{~cm}$ in all strata of the forest. Each individual tree recorded in the complete inventory was combined with leaf trait data 
obtained for its species. These data were then used for calculating means at land use type level.

(NF*: 198 trees, SF: 78 trees and FG: 86 trees)

(*) Because morphological and chemical data was not available for all species found in the complete forest inventory (3), the natural forest data in this comparative study includes the plots NF1 and NF2 only. Thus, the number of individuals and species in this sampling design comparison differs from the general sample specification listed in Table 3.2. Of the 247 trees with $\mathrm{dbh}>10 \mathrm{~cm}$ recorded on these two plots species-specific leaf trait data was available for 198, which were used for calculating averages. The corresponding numbers for the SF was 78 out of 89 trees, and in the forest garden 86 out of 111 trees.

Agroforestry systems were excluded in this study, because of its low number of species.

Means with standard deviation yielded by the three methods are presented in Appendix 10.

The general aim of this study was to analyse differences in the tree ecology among land use types. Thus, the secondary forest and forest garden means are presented relative to natural forest values in Table 4.4, elucidating the relative difference between the land use types yielded by each of the three sampling designs

\subsubsection{Comparing species average and random sampling with the sample based on the forest inventory}

According to the Lore Lindu data set, the sampling design has a considerable influence on the conclusions that can be drawn from comparative leaf morphological studies. Random sample, species average and the forest inventory sample yielded different results for most of the leaf traits studied. Differences between the land use types with respect to leaf traits were generally more pronounced in the random sample than in the other two samples. Counting the number of incidents of largest divergence between the land use types among the three sampling designs for each of the 15 parameters listed in Table 4.4 showed, that in 19 cases of 30 ( 15 parameter and two land use types), the difference between the land use types was largest in the random sample, but only in 4 cases in the species average. In 7 of totally 30 cases the difference was largest in the inventory sample. Noteworthy is that the differences between SF or FG and natural forest was most pronounced in the inventory sample in the case of two important leaf traits, SLA and leaf N concentration. 
The extent of influence of the sampling design varies depending on which parameter is considered. For example, the relation between secondary forest or forest garden and natural forest values of total $\mathrm{C}$ concentration and $\delta^{13} \mathrm{C}$, were nearly constant, regardless of sampling design. In contrast, very large influence was shown in the case of compound leaves, leaf size and leaf phosphorus concentration. The random sample suggested that the secondary forest only reached $22 \%$ of the rate of compound leaved trees in the natural forest, whereas the species average suggested $140 \%$. Similarly, the forest inventory sample showed contradictive results compared to the other samples in the case of leaf size, indicating smaller leaves in the secondary forest ( $68 \%$ of NF) and forest garden ( $89 \%$ of NF) than in the natural forest, whereas the random sample suggested the mean leaf size in SF to be $139 \%$ of NF and FG to be $128 \%$ of NF. The same kind of contradictions among the samples was further found for leaf $\mathrm{N}$ concentration in the forest garden and for $\mathrm{Mg}$ in both land use types. Moreover, the species average sample suggested a lower SLA in the forest garden compared to natural forest, whereas the random sample and inventory sample both suggested the opposite.

The largest difference between the three sampling methods was found for the compound leaf parameter, which differed with $118 \%$-units between species average and random sample in the secondary forest and 20\%-units in the forest garden, followed by leaf size, which differed with $71 \%$-units between the random sample and the inventory sample for secondary forest and 39\%-units in the forest garden. A considerable difference was also found for leaf $\mathrm{P}$ concentration in SF between random sample and species average, diverging by $52 \%$-units, but only $11 \%$-units in FG. The sampling design showed least influence on total carbon and $\delta^{13} \mathrm{C}$ throughout the land use types. The difference between the sampling designs within these two parameters was only between 2 and 5\%-units.

Conclusively, the relative differences between SF or FG and NF were in most cases largest in the random sample among the three sampling designs evaluated. The choice of sampling design has different influence on different parameters. The most sensitive parameters were fraction of compound leaved species or trees, leaf size and leaf $\mathrm{P}$ concentration. The least sensitive parameters were total $\mathrm{C}$ and $\delta^{13} \mathrm{C}$. 
Table 4.4 Means of a set of leaf traits for secondary forest and forest garden as proportions (\%) of the corresponding natural forest mean, presented for the three different sampling designs and as a normalized species average in which the species number is normalized by random selection to 18 for every land use type. * = The NF values are based on the results from the plots NF1 and NF2. (Inv - Forest inventory sample, Rand - Random sample, Sp av - Species average, Norm sp av - Normalized species average)

\begin{tabular}{|c|c|c|c|c|c|c|c|c|c|c|c|c|}
\hline \multirow[b]{2}{*}{ Sampling method } & \multicolumn{4}{|c|}{ Secondary forest } & \multicolumn{4}{|c|}{ Forest garden } & \multicolumn{4}{|c|}{ Natural forest } \\
\hline & Inv & Rand & Sp av & $\begin{array}{l}\text { Norm } \\
\text { Sp av }\end{array}$ & Inv & Rand & Sp av & $\begin{array}{l}\text { Norm } \\
\text { Sp av }\end{array}$ & Inv & Rand & Sp av & $\begin{array}{l}\text { Norm } \\
\text { Sp av }\end{array}$ \\
\hline No. individuals sampled & 78 & 160 & & & 86 & 26 & & & 198 & 43 & & \\
\hline No. species sampled & 23 & 35 & 35 & 18 & 33 & 18 & 18 & 18 & 53 & 28 & 28 & 18 \\
\hline No. plots included & 4 & 4 & 4 & 4 & 2 & 2 & 2 & 2 & 2 & 2 & 2 & 2 \\
\hline Total plot area $\left[\mathrm{m}^{2}\right]$ & 1600 & 1600 & 1600 & 1600 & 5000 & 5000 & 5000 & 5000 & 5000 & 15000 & 15000 & 15000 \\
\hline Strata sampled & All & $\begin{array}{l}\text { Upper } \\
\text { canopy }\end{array}$ & $\begin{array}{l}\text { Upper } \\
\text { canopy }\end{array}$ & $\begin{array}{l}\text { Upper } \\
\text { canopy }\end{array}$ & All & $\begin{array}{l}\text { Upper } \\
\text { canopy }\end{array}$ & $\begin{array}{l}\text { Upper } \\
\text { canopy }\end{array}$ & $\begin{array}{l}\text { Upper } \\
\text { canopy }\end{array}$ & All & $\begin{array}{l}\text { Upper } \\
\text { canopy }\end{array}$ & $\begin{array}{l}\text { Upper } \\
\text { canopy }\end{array}$ & $\begin{array}{l}\text { Upper } \\
\text { canopy }\end{array}$ \\
\hline Leaf size $\left[\mathrm{cm}^{2}\right]$ & 68 & 139 & 121 & 113 & 89 & 128 & 121 & 132 & 100 & 100 & 100 & 100 \\
\hline Length-width ratio & 80 & 65 & 84 & 59 & 101 & 93 & 93 & 72 & 100 & 100 & 100 & 100 \\
\hline SLA $\left[\mathrm{cm}^{2} \mathrm{~g}^{-1}\right]$ & 141 & 118 & 99 & 121 & 112 & 102 & 94 & 110 & 100 & 100 & 100 & 100 \\
\hline $\mathrm{Ca}\left[\mathrm{g} \mathrm{kg}^{-1}\right]$ & 95 & 107 & 103 & 99 & 98 & 80 & 88 & 87 & 100 & 100 & 100 & 100 \\
\hline $\mathrm{K}\left[\mathrm{g} \mathrm{kg}^{-1}\right]$ & 90 & 118 & 118 & 93 & 114 & 133 & 128 & 114 & 100 & 100 & 100 & 100 \\
\hline $\mathrm{Mg}\left[\mathrm{g} \mathrm{kg}^{-1}\right]$ & 77 & 93 & 110 & 62 & 106 & 117 & 118 & 83 & 100 & 100 & 100 & 100 \\
\hline $\mathrm{P}\left[\mathrm{g} \mathrm{kg}^{-1}\right]$ & 152 & 193 & 141 & 183 & 102 & 113 & 104 & 132 & 100 & 100 & 100 & 100 \\
\hline $\mathrm{N}\left[\mathrm{g} \mathrm{kg}^{-1}\right]$ & 120 & 119 & 103 & 119 & 115 & 94 & 94 & 107 & 100 & 100 & 100 & 100 \\
\hline $\mathrm{C}\left[\mathrm{g} \mathrm{kg}^{-1}\right]$ & 104 & 105 & 103 & 104 & 106 & 111 & 107 & 107 & 100 & 100 & 100 & 100 \\
\hline $\mathrm{C} / \mathrm{N}$ & 89 & 88 & 102 & 91 & 93 & 119 & 118 & 105 & 100 & 100 & 100 & 100 \\
\hline $\mathrm{N} / \mathrm{P}$ & 76 & 60 & 70 & 61 & 103 & 81 & 82 & 78 & 100 & 100 & 100 & 100 \\
\hline $\mathrm{C} / \mathrm{P}$ & 68 & 50 & 68 & 56 & 91 & 96 & 96 & 86 & 100 & 100 & 100 & 100 \\
\hline$\delta^{13} \mathrm{C}[\%]$, & 97 & 93 & 97 & 94 & 100 & 100 & 101 & 99 & 100 & 100 & 100 & 100 \\
\hline$\delta^{15} \mathrm{~N}[\% 0]$ & 106 & 137 & 98 & 81 & 147 & 150 & 127 & 104 & 100 & 100 & 100 & 100 \\
\hline $\begin{array}{l}\text { Fraction of } \\
\text { compound leaves [\%] }\end{array}$ & 30 & 22 & 140 & 283 & 32 & 17 & 37 & 100 & 100 & 100 & 100 & 100 \\
\hline
\end{tabular}




\subsubsection{Influence of the sampling effect}

To investigate the influence of the sampling effect on the ecological comparison of the four land use types, normalized sub-samples with equal species numbers were created from the random samples by selection of each 18 species at random in the two forest types NF and $\mathrm{SF}$, thus equalising the species number in FG. Mean values for leaf traits were calculated in these normalized samples, and the results presented as values relative to those of NF in Table 4.4. The absolute values are given in Appendix 10. Standard deviations of the species averages based on random samples ( $n=69$ and 35 species, respectively) as proportion of the standard deviations of the normalized species averages $(n=18$ tree species) are listed in Table 4.5. Comparing these proportions showed that the two approaches gave very similar results concerning variability within land use types for most leaf parameters, i.e. the proportions were close to 1 for most parameters. However, some noteworthy exceptions occurred. The differences in variability between the two samples

Table 4.5 The quota of the standard deviations $\left(\mathrm{sd} \mathrm{sd}^{-1}\right)$ yielded in the random sample (rand.) of the 69 natural forest species, or 35 secondary forest species, respectively, and the normalized 18-species averages (sp. av.) of the leaf trait means. Values $>1$ indicate a higher variation among the species in the random sample than in the normalized species average.

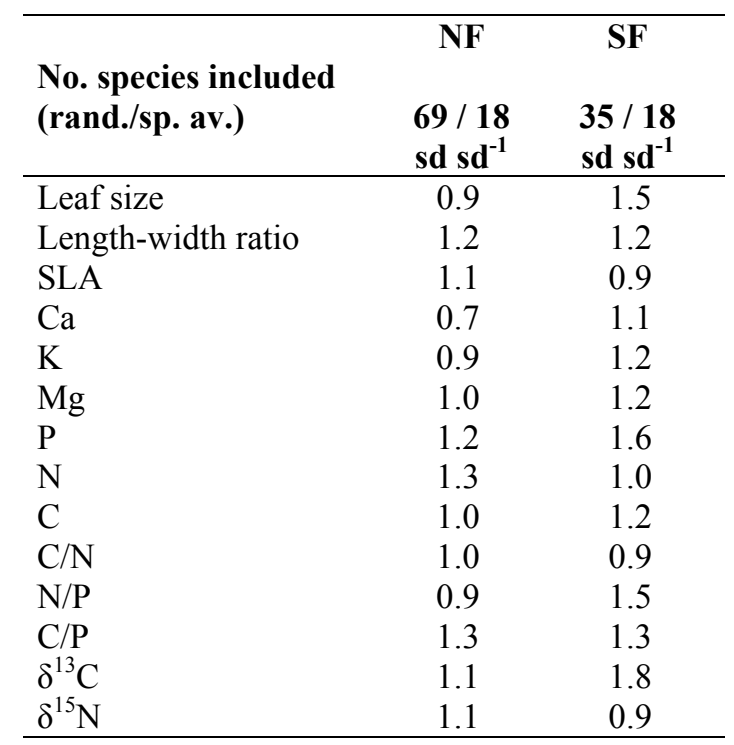

were larger within the secondary forest than in the natural forest, although the difference in species number included was smaller. The largest differences occurred in the $\mathrm{SF}$ for $\delta^{13} \mathrm{C}$ $\left(1.8 \mathrm{sd} \mathrm{sd}^{-1}\right)$, leaf $\mathrm{P}$ concentration $\left(1.6 \mathrm{sd} \mathrm{sd}^{-1}\right)$ and leaf size $\left(1.5 \mathrm{sd} \mathrm{sd}^{-1}\right)$. In the natural forest the variability among the 69 species in the random sample did not exceed the variability in the normalized 18 -species sample with more than $30 \%$. It is important to notice that the 
normalized species average revealed higher variability than the random sample based species averages for some parameters and lower for others. Conclusively, a sampling effect seems to be of minor importance in among the samples in this study.

\subsection{Morphological leaf traits}

\subsubsection{Leaf size}

The 107 studied species showed a wide range of leaf sizes. Typically, the secondary forest trees had the biggest leaf sizes (extreme species means: Macaranga tanarius: $1250 \mathrm{~cm}^{2}$; Dendrocnide sp.: $591 \mathrm{~cm}^{2}$ ), whereas the smallest leaves were found in the natural forest (Ficus sp.:12.8 $\mathrm{cm}^{2}$; Pimelodendron amboinicum: $29.4 \mathrm{~cm}^{2}$ ) and in the agroforestry shade tree Gliricidia sepium $\left(8.9 \mathrm{~cm}^{2}\right)$. If the entire compound leaf was taken into account, the Sugar Palm (Arenga pinnata) had the biggest leaf area $\left(274\right.$ leaflets $* 589 \mathrm{~cm}^{2}=16 \mathrm{~m}^{2}$ ). The between-species variation in leaf size was larger in the natural forest (46-fold) than in the secondary forest stands (31-fold). The variation within the forest garden and agroforestry system species was lower (FG: 14-fold; AF: 22-fold), mainly because the species numbers were smaller.

An analysis of variance applied to the leaf size data showed that all four land use types differed significantly from each other $(\mathrm{p}<0.05)$, with means of $140 \mathrm{~cm}^{2}(\mathrm{NF}), 222 \mathrm{~cm}^{2}$ (SF), $205 \mathrm{~cm}^{2}$ (FG) and $79 \mathrm{~cm}^{2}$ (AF) (Figure 4.1, Appendix 11).
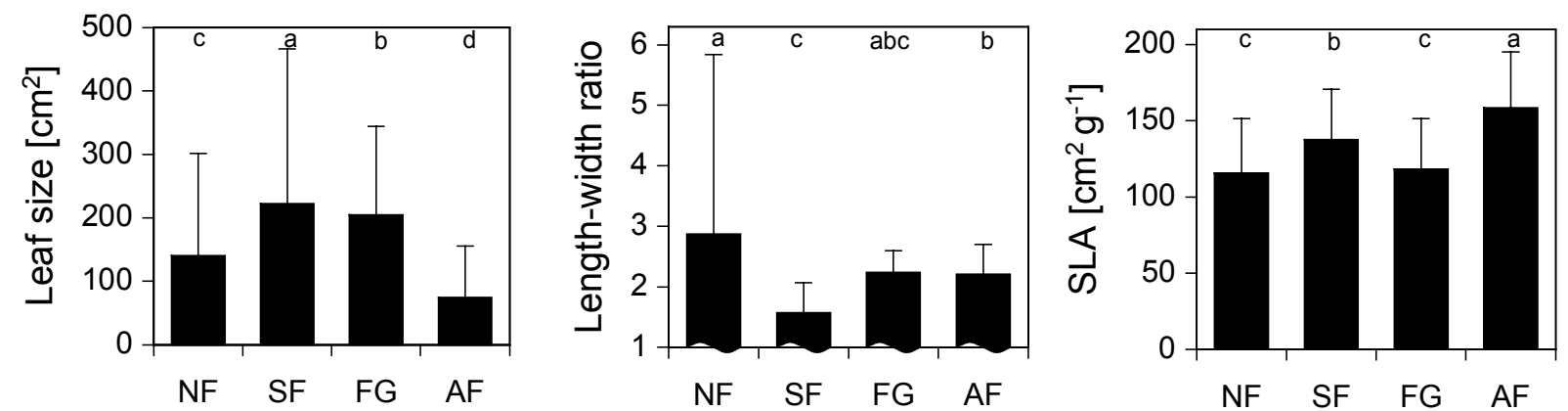

Figure 4.1 Means and standard deviation of leaf size, length-width ratio and specific leaf area (SLA) in random samples of the four land use types studied (For number of tree individuals, species and plots covered see Table 3.2). Significantly different means are marked with different letters ( $\mathrm{p}<$ 0.05). Number of individuals: NF: 119, SF: 160, FG: 25, AF: 49 (NF - Natural forest, SF Secondary forest, FG - Forest garden, AF - Agroforestry system) 
A closer inspection of the five families with largest numbers of trees in the random sample showed a very large variation in leaf size in the two families Euphorbiaceae and Urticaceae, which were present in several land use types in this study. The leaf size of the smallest and the largest Euphorbiaceae differed 42-fold, and that of the Urticaceae 15-fold.
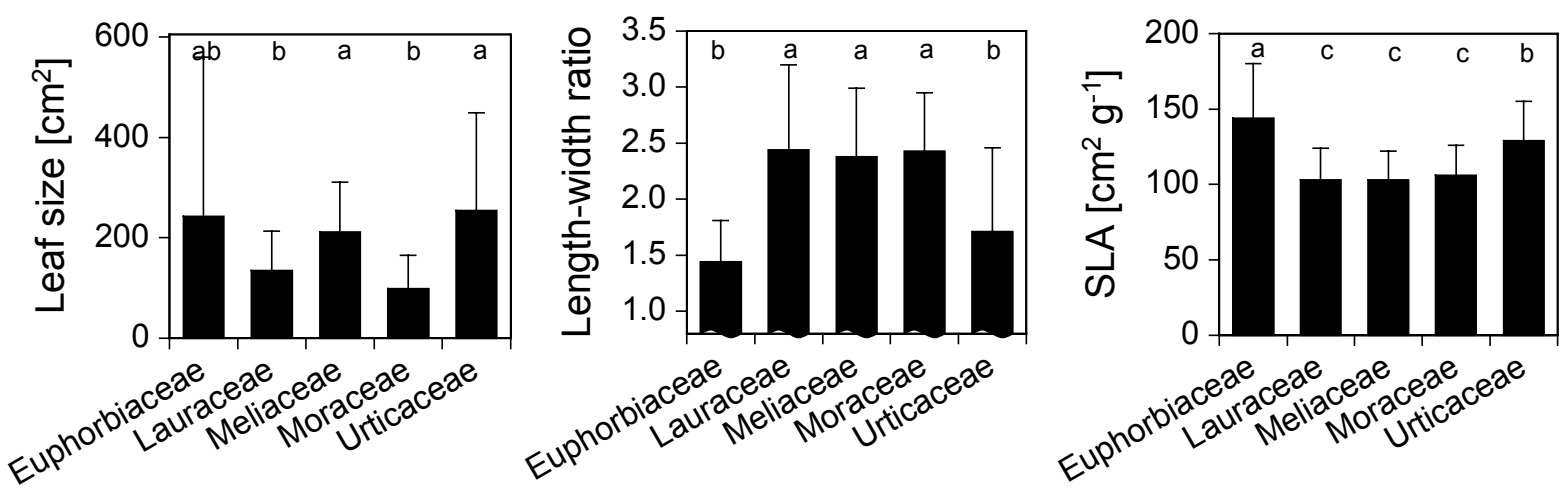

Figure 4.2 Means (and standard deviation) of leaf size, length-width ratio and specific leaf area (SLA) in the five most frequent families in the random samples (For specification of plots covered, see Table 3.2). Total number of species / individuals representing each family: Euph.: 10/85, Laura.: 9/23, Melia.: 7/20, Mora.: 10/13, Urti.: 10/57. Different letters mark significantly different means (p $<0.05)$.

Meliaceae, with Aglaia argentea as most common species, and Lauraceae both primarily include late-successional trees with moderate leaf sizes and a smaller range of leaf sizes (4fold and 5-fold differences among the species), whereas the Moraceae showed the smallest mean leaf size among the abundant families (Figure 4.2, Appendix 12).

For a complete list of means of leaf size, length-width ratio and specific leaf area of all 107 recorded species and 51 families see Appendix 4 (species) and Appendix 5 (families).

\subsubsection{Raunkiaer's leaf size classes}

Figure 4.3 shows the tree individuals and the species of the four land use types grouped according to Raunkiaer's leaf size classes. Here the refined system by Webb (1959) was used. It can be seen that the microphyll size only occurred in the natural forest ( $1 \%$ of the trees) and in the agroforestry system (58\% of the trees, which all belonged to Gliricidia sepium). Natural forest canopies consisted of leaves from four Raunkiaer classes, whereas

the other land use types only covered three different classes. Secondary forest trees in the random sample were nearly equally divided between the mesophyllous (51\%) and macrophyllous (48\%) groups, while half of the tree individuals were macrophyllous, only $34 \%$ of the species belonged to this class. A single tree individual in the study, a secondary 


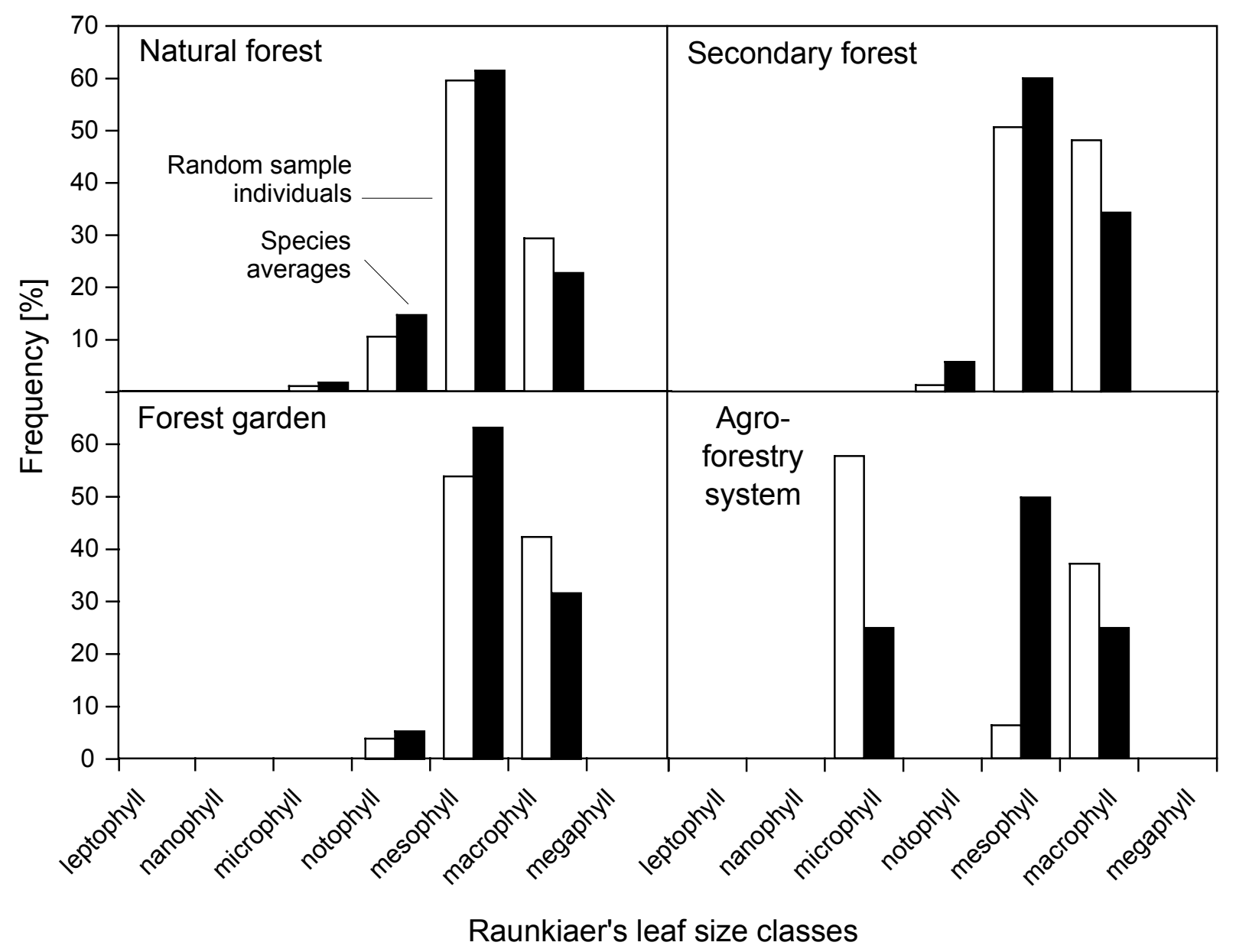

Figure 4.3 Leaf sizes of random sample individuals and species averages of four different land use types, classified according to Raunkiaer. For number of individuals and plots covered, see Table 3.2. The number of trees, or species, in each class is presented as percentage of total sample. Microphyll: 2.25 - $20.25 \mathrm{~cm}^{2}$, notophyll: $20.25-45 \mathrm{~cm}^{2}$, mesophyll: $45-182.25 \mathrm{~cm}^{2}$, macrophyll: 182.25 $1640.25 \mathrm{~cm}^{2}$ (Raunkiaer 1934; Webb 1959).

forest Macaranga tanarius tree, reached the megaphyll class, having a leaf size of $2208 \mathrm{~cm}^{2}$. In the agroforestry system, two of the four species (Coffea arabica and Erythrina sp.) belonged to the mesophyllous group; however, they only represent $6 \%$ of the individuals.

As comparison to the Raunkiaer classes a division of leaf sizes into $50 \mathrm{~cm}^{2}$-classes is illustrated in Figure 4.4. The right skewed distribution of leaf size within all land use types is obvious in this graph. Secondary forest covered the largest number of classes, and agroforestry system the lowest number. Forest garden showed the most equal distribution over the classes covered, whereas natural forest and agroforestry systems leaf sizes were highly concentrated to the smaller classes. 


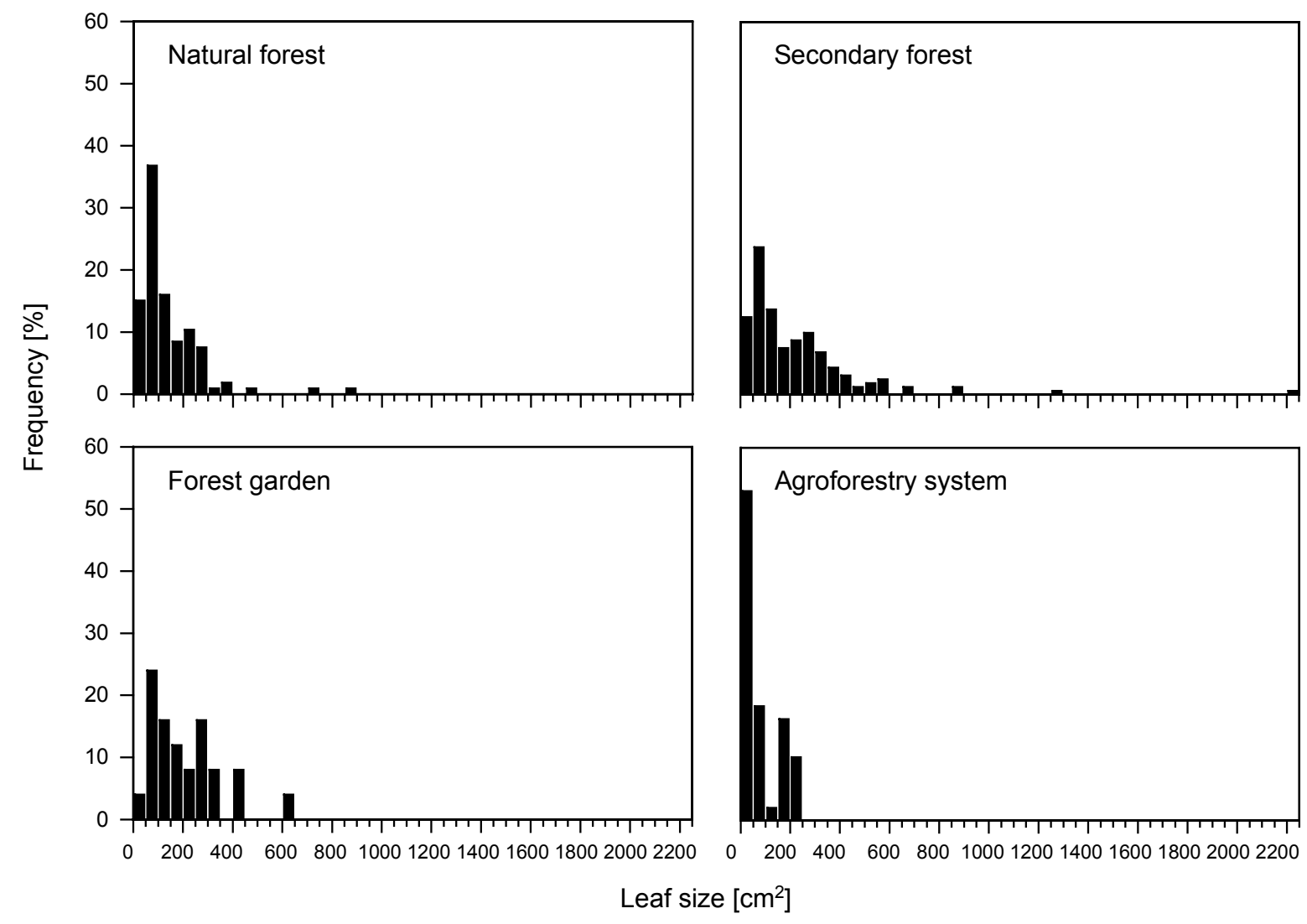

Figure 4.4 The relative frequency of leaf size classes of $50 \mathrm{~cm}^{2}$ within the random samples of four different land use types. For number of individuals and plots covered, see Table 3.2.

\subsubsection{Length-width ratio}

The mean leaf length-width ratios were significantly different between natural forest, secondary forest and agroforestry system, whereas the forest garden differed from none of the other land use types (Figure 4.1, Appendix 11). The highest mean value (2.87) indicates a lanceolate leaf form and was found for the natural forest. This land use type also showed the highest variability in length-width ratio among its species (sd: 2.97). The lowest lengthwidth ratio mean (1.6) was found for the secondary forest. The lowest obtained mean for a species was 1.1, recorded for Dendrocnide sp.3 and Macaranga tanarius, both pioneer species (Appendix 4). The agroforestry species all had an intermediate leaf form: the mean for this land use type is 2.2. Looking at the five most frequent families in the study, two significantly different groups were found: Urticaceae and Euphorbiaceae, with more round leaves (length-width ratios of 1.7 and 1.4), in contrast to Meliaceae, Moraceae and Lauraceae which had more lanceolate leaves and means close to 2.4 (Figure 4.2, Appendix 5). This division reflects the general pattern of pioneer species having small and late- 
successional species having large length-width ratios, which is clearly illustrated in Figure 4.5 and Figure 4.6 where the leaf silhouettes of 28 randomly selected species from the natural and secondary forests are presented.

\subsubsection{Fraction of compound leaves}

The fraction of individuals with compound leaves in the random sample was $23 \%$ in the natural forest, but only $5 \%$ in secondary forest and $4 \%$ in the forest garden. In contrast, if species are considered, a higher rate of compound-leaved species (20\%) was found in the secondary forest than the natural forest $(14 \%)$ and forest garden $(5 \%)$. The agroforestry systems were composed of 50\% compound-leaved species (Erythrina sp. and Gliricidia sepium), which represents $59 \%$ of the trees. Important compound leaf species in the samples were Aglaia argentea, Meliosma sumatrana, Bischofia javanica among the late-successional species, the Burseraceae species collected in the secondary forest, and Gliricidia sepium, and Erythrina sp. in the agroforestry systems.

Since this work mainly focuses on the relation between leaf morphology and physiology, it will not be indicated whether a given leaf is a part of a larger compound leaf or stands alone as a single leaf. It is assumed that this difference is of only minor relevance for leaf function. 


\section{Natural forest species}

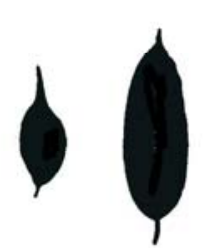

Moraceae

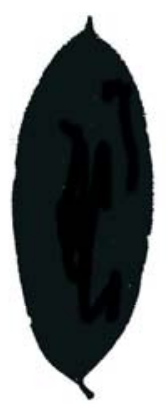

\section{Lauraceae}

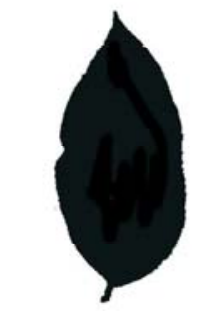

Fagaceae
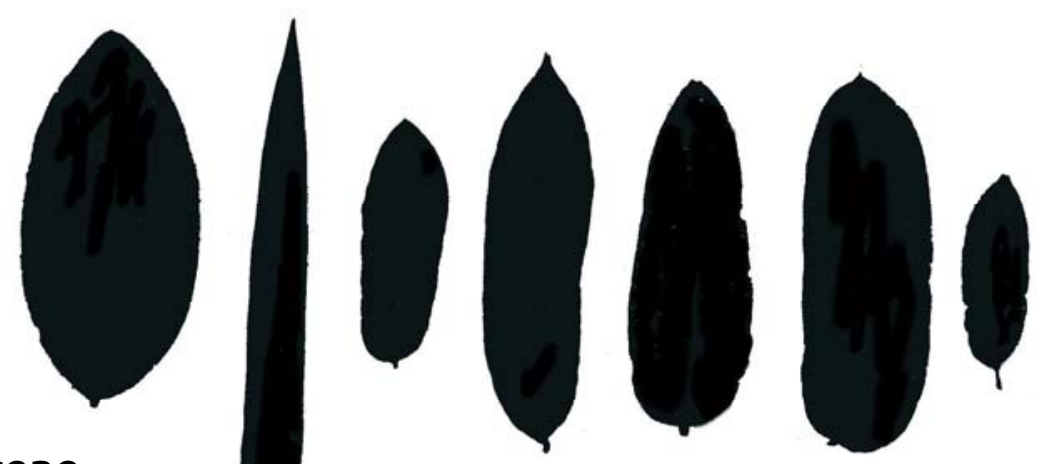

Meliaceae
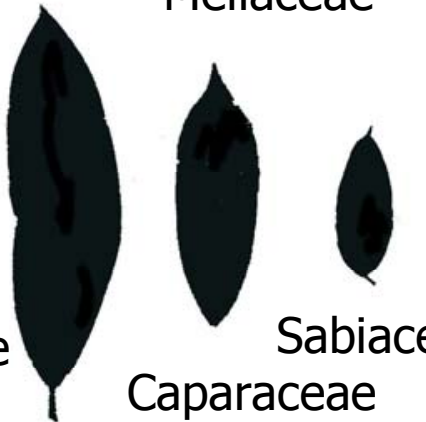

Sabiaceae) Caparaceae
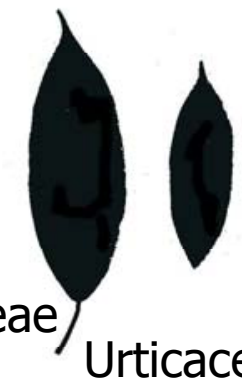

Urticaceae

Anacardiaceae

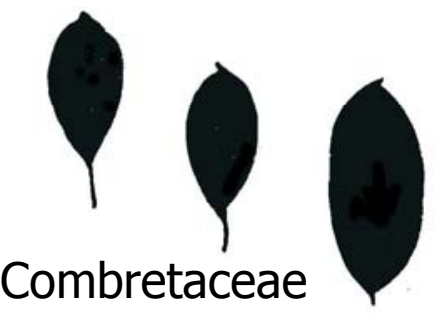

Celastraceae

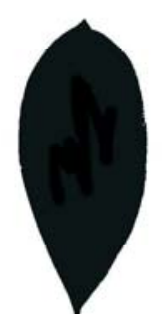

Rubiaceae Apocynaceae

\section{Elaeocarpaceae}

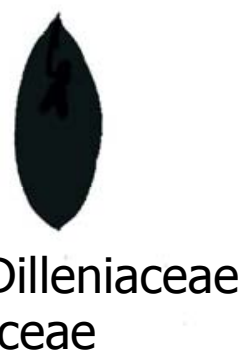

$10 \mathrm{~cm}$

Figure 4.5 Leaf silhouettes of 28 natural forest species. The prevailing elongated leaf form among natural forest species can be seen. The principal difference concerning leaf forms and sizes between natural and secondary forest tree species can be studied by comparison with Figure 4.6. 


\section{Secondary forest species}

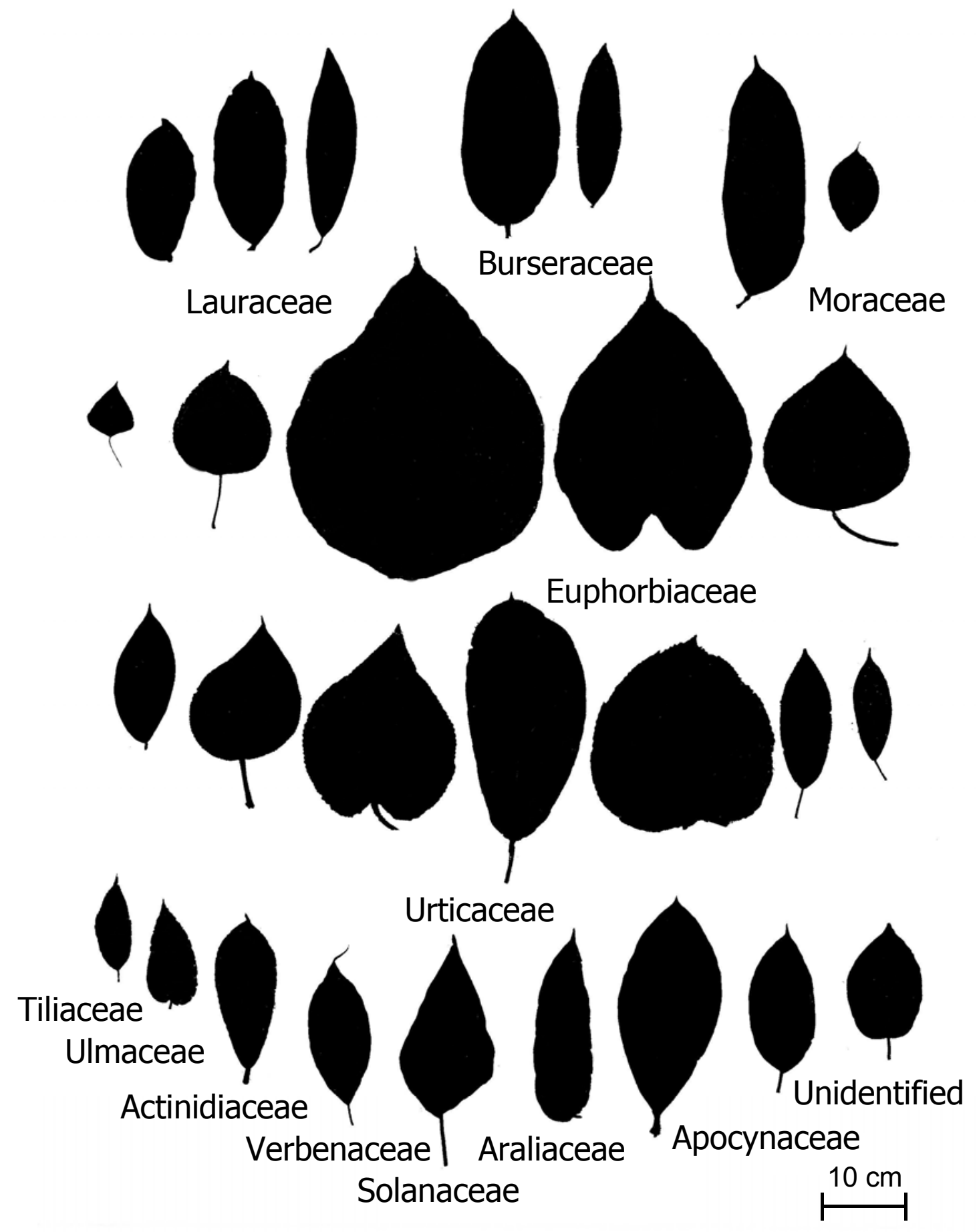

Figure 4.6 Leaf silhouettes of 28 secondary forest species. The prevailing rounded leaf form among secondary forest species is obvious. 


\subsubsection{Specific leaf area}

Specific leaf area (SLA) ranged from $40.5 \mathrm{~cm}^{2} \mathrm{~g}^{-1}$ (Dracaena sp., Liliaceae) to $236 \mathrm{~cm}^{2}$ $\mathrm{g}^{-1}$ (Urticaceae sp.2). Three of the four land use types differed significantly from each other
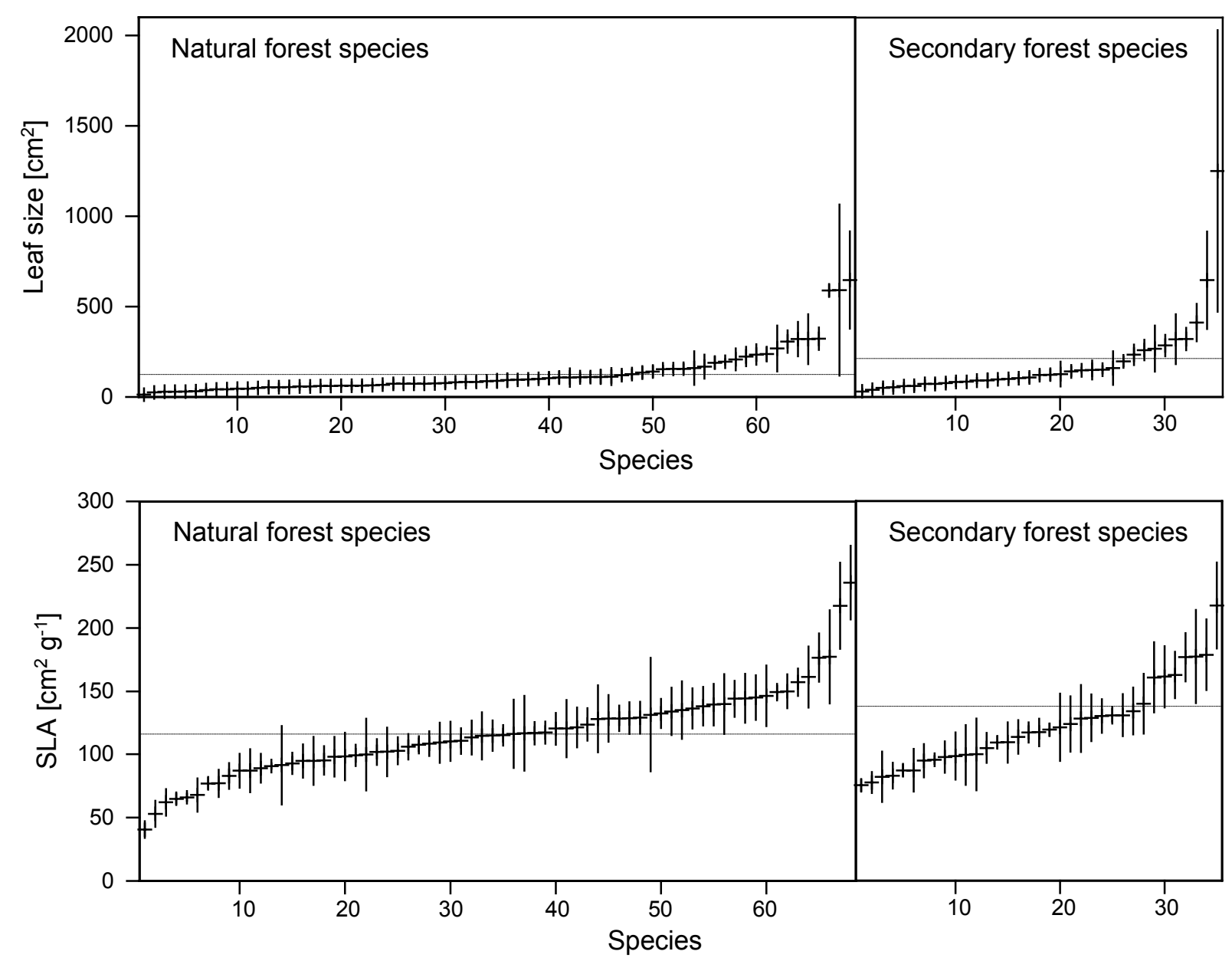

Figure 4.7 Distribution of specific leaf area (SLA) and leaf size means among all species found in the natural and secondary forest stands. Each data point represents one species. The vertical lines illustrate standard deviations. The dashed lines indicate the land use type means.

in terms of SLA ( $\mathrm{p}<0.05$, means: $116 \mathrm{~cm}^{2} \mathrm{~g}^{-1}$ (NF), $138 \mathrm{~cm}^{2} \mathrm{~g}^{-1}$ (SF), $160 \mathrm{~cm}^{2} \mathrm{~g}^{-1}$ (AF), Figure 4.1, Appendix 11), with the natural forest's typical late-successional species having the lowest values and the agroforestry species, especially the Fabaceae, showing particularly high SLA means. The mean value for the forest garden $\left(118 \mathrm{~cm}^{2} \mathrm{~g}^{-1}\right)$ was very similar to the value for the natural forest. The natural forest not only exhibited the lowest mean SLA, but also the greatest variation between the sampled species. A 6-fold variation was found within the 69 natural forest species, whereas the species in the secondary forest (35) and forest garden (18) only differed by a factor 3 . The four species in the AF showed just a 2-fold 
variation. Among the five most frequent families three significantly different groups were recognized: Euphorbiaceae with a mean SLA of $144 \mathrm{~cm}^{2} \mathrm{~g}^{-1}$, Urticaceae with $129 \mathrm{~cm}^{2} \mathrm{~g}^{-1}$, and the group comprising Meliaceae, Lauraceae and Moraceae with SLA-values between 103 and $106 \mathrm{~cm}^{2} \mathrm{~g}^{-1}$. The variability among the species within these families was relatively small, with standard deviations of about 20\% (Appendix 12, Figure 4.2).

\subsection{Chemical leaf traits}

\subsubsection{Seasonal fluctuations in chemical leaf traits}

\subsubsection{Seasonal fluctuations in leaf nutrient concentrations and $\delta^{15} N$ and $\delta^{13} C$ signatures}

Two main conclusions could be drawn concerning the spatial and temporal variability of nutrient concentrations and $\delta^{15} \mathrm{~N}$ and $\delta^{13} \mathrm{C}$ signatures within and among the ten species over the four sampling dates. First, that the intraspecific variation at a given sampling date often was larger than the interspecific variation, especially in the secondary forest (for example $\mathrm{Ca}$, Figure 4.8). Second, that the fluctuations within the species between the four sampling dates were only poorly synchronised among the species, indicating that fluctuations in leaf nutrient concentrations and $\delta^{15} \mathrm{~N}$ and $\delta^{13} \mathrm{C}$ signatures among the ten studied tree species were not depending on seasonal differences in environmental conditions.

In a more detailed analysis however, it was observed that the intraspecific changes in nutrient concentrations over the four sampling dates were more parallel among the natural forest species than among the secondary species, for example in the case of $\mathrm{C} / \mathrm{N}$ ratio and Mg (Figure 4.9 and Figure 4.8). This indicates that changes within species in the natural forest might have been due to environmental factors to a larger extent than in the secondary forest. Since the secondary forest trees were in a very dynamic growth phase there can be many reasons for large individual variations in leaf traits.

\subsubsection{Relation between seasonal rainfall changes and foliar nutrient concentrations}

The rainfall in the area is quite equally spread over the year without pronounced dry periods (See 3.1.2 Climate). However, during the measuring period, which lasted from September 2001 till June 2002, a certain decrease in rainfall could be observed during December, January and February. In these months daily rainfall mean sank below $5 \mathrm{~mm}$, instead of the usual 10-15 $\mathrm{mm}$ per day. 

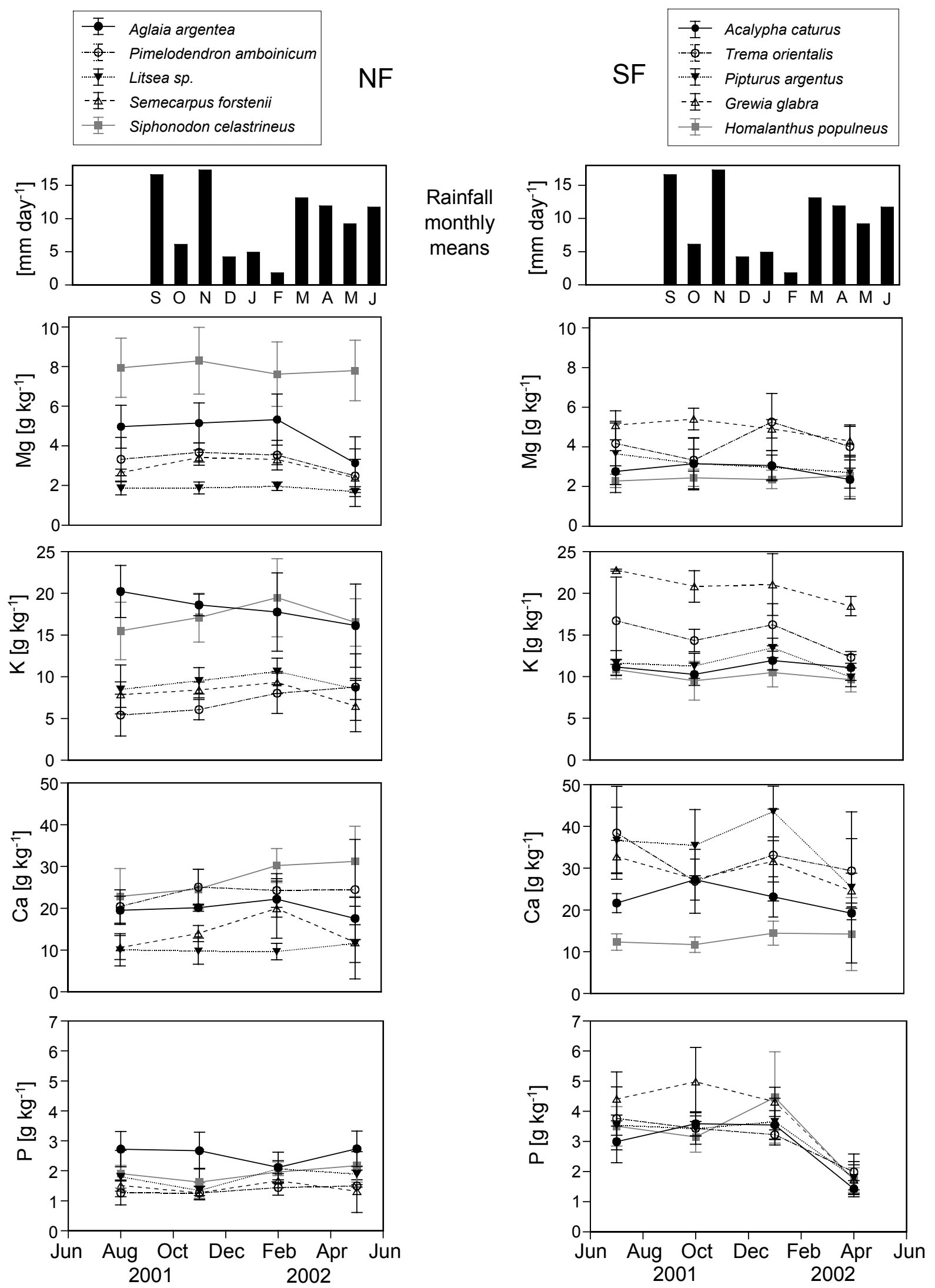

Figure 4.8 Leaf nutrient concentrations during ten months. Species means with standard deviation for five natural and five secondary forest species ( $n=5$ trees per data point). Rainfall data for the period September 2001 to June 2002 are based on Kleinhans, unpubl.. 

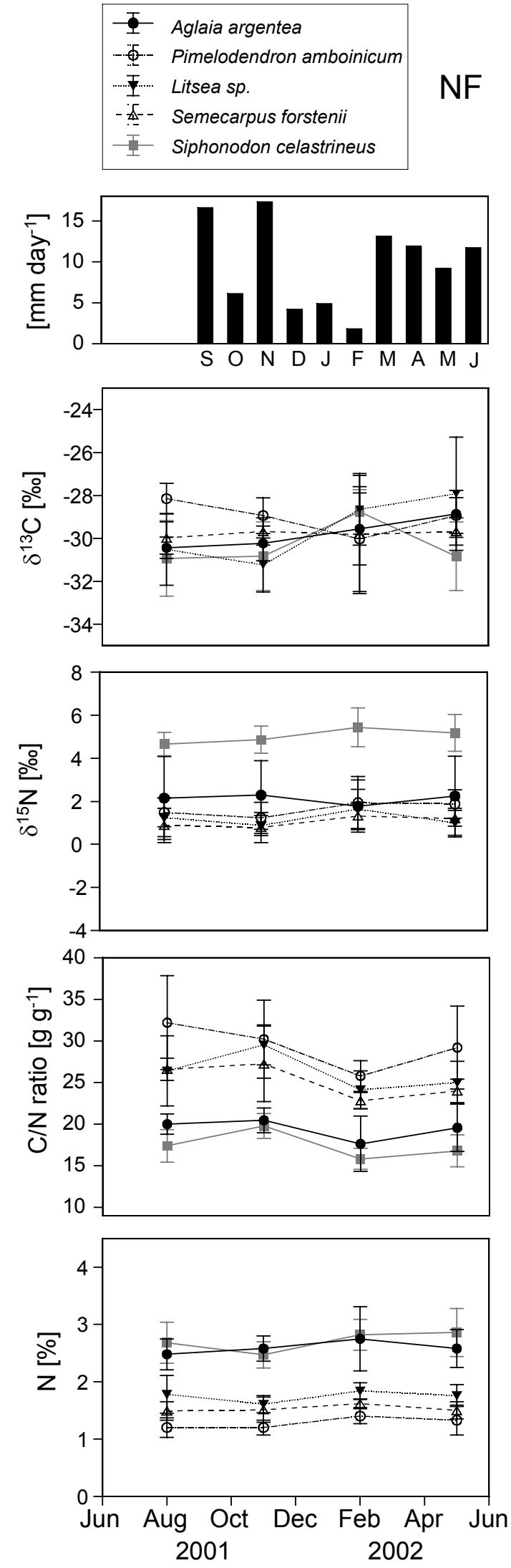

$\mathrm{NF}$
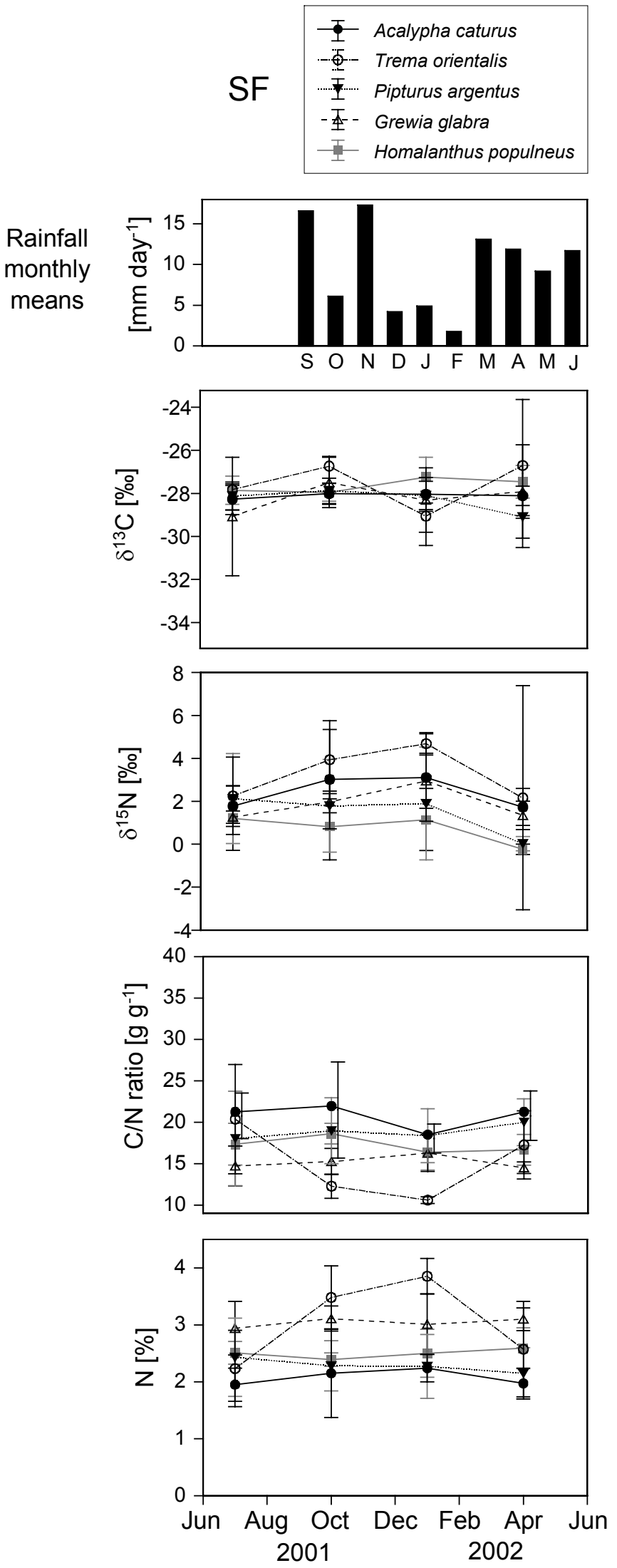

Figure 4.9 Species means with standard deviation of ${ }^{15} \mathrm{~N}$ and ${ }^{13} \mathrm{C}$ signatures, leaf $\mathrm{N}$ concentration and $\mathrm{C} / \mathrm{N}$ over ten months for five natural and five secondary forest species ( $n=5$ trees per data point). Rainfall data for the period September 2001 to June 2002 are based on Kleinhans, unpubl.. 
The only obvious changes in leaf nutrient concentrations in association with this period were a lower $\mathrm{C} / \mathrm{N}$ ratio in all the natural forest species and some of the secondary forest species (Figure 4.9), and a lower leaf $\mathrm{P}$ concentration of all secondary forest species (Figure 4.8) at the first sampling date after the dry period. The possible relation of these observations to rainfall decrease is however unclear. Further, some of the ten studied species showed differences in their $\delta^{13} \mathrm{C}$ value obtained in the dry period, compared to the other sampling dates. However, since some species showed higher, and others lower $\delta^{13} \mathrm{C}$ values in the dry period, these fluctuations were most likely not caused by the rainfall decrease.

\subsubsection{Leaf nitrogen concentration}

\subsubsection{Species level}

There was a four-fold range in leaf $\mathrm{N}$ concentrations among the 107 species studied. The highest nitrogen concentrations per unit leaf dry mass (N-mass, \%) were obtained in the Urticaceae Dendrocnide sp.3 (4.5\%) and the leguminous Erythrina sp. (4.3\%). The lowest value was found in the natural forest species Baccaurea sp. (0.92\%, Euphorbiaceae), followed by Chionanthus sp. (1.1\%, Oleaceae). $\mathrm{C} / \mathrm{N}$ ratios were coherently lowest in Dendrocnide sp.3 (9.6) and Erythrina sp. (10.6), followed by other Urticaceae and the leguminous Gliricidia sepium, and highest in Chionanthus sp. (41.8) and Baccaurea sp. (41.4).

Means for chemical leaf traits in all 107 species studied are presented in Appendix 7.

\subsubsection{Family level}

Figure 4.10 shows leaf nitrogen concentration and the ratio of nitrogen to total carbon concentration or to phosphorus among the five most frequent families in the study. The mainly pioneer family Urticaceae showed the significantly highest mean leaf $\mathrm{N}$ concentration (2.6\%). The predominantly late-successional family Moraceae had the lowest mean value (1.7\%) among the five.

\subsubsection{Land use type level}

Figure 4.11 presents the mean nitrogen content per unit leaf mass and the average relative concentrations of the elements nitrogen, phosphorus and carbon in each land use type. The agroforestry system showed the significantly highest mean leaf $\mathrm{N}$ concentration (35 $\left.\mathrm{g} \mathrm{kg}^{-1}\right)$ among the four land use types. Secondary forest had in turn a significantly higher mean $\left(25 \mathrm{~g} \mathrm{~kg}^{-1}\right)$ than natural forest $\left(21 \mathrm{~g} \mathrm{~kg}^{-1}\right)$ and forest garden $\left(20 \mathrm{~g} \mathrm{~kg}^{-1}\right)$. The same 

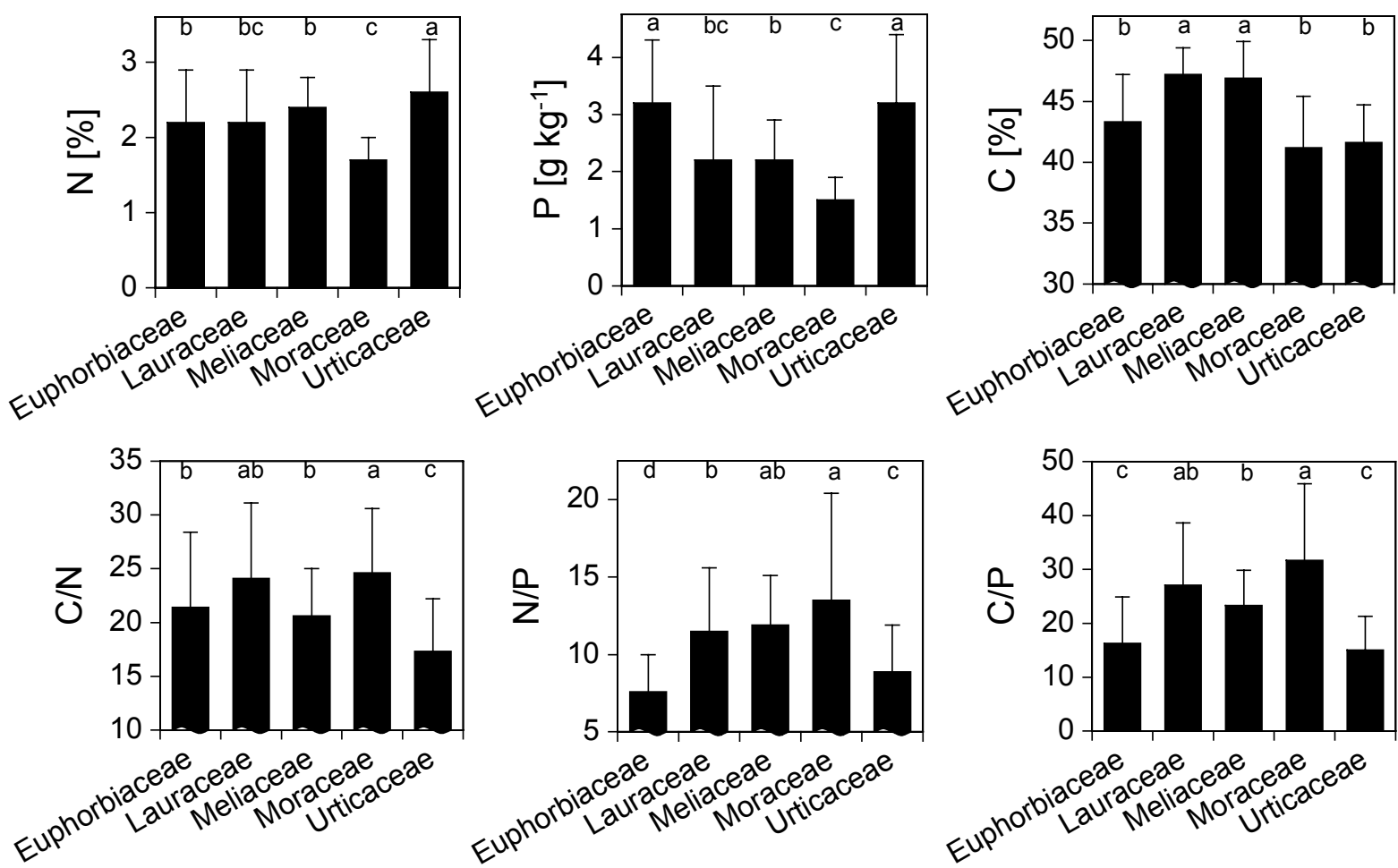

Figure 4.10 Means and standard deviation of foliar nitrogen concentration (N), phosphorus (P) and total carbon concentration (C), as well as the ratios $\mathrm{C} / \mathrm{N}, \mathrm{N} / \mathrm{P}$ and $\mathrm{C} / \mathrm{P}$ for the five most frequent families in the random sample (for definition of random sample, see Table 3.2). Significantly different means are marked by different letters $(p<0.05)$. Total number of species / individuals representing each family were: Euphorbiaceae: 10/85, Lauraceae: 9/23, Meliaceae: 7/20, Moraceae: 10/13, Urticaceae: 10/57.

relation was recognized for the $\mathrm{C} / \mathrm{N}$ ratio: the agroforestry system had the lowest mean $\mathrm{C} / \mathrm{N}$ ratio $\left(14 \mathrm{~g} \mathrm{~g}^{-1}\right)$ and forest garden the highest $\left(26 \mathrm{~g} \mathrm{~g}^{-1}\right)$.

\subsubsection{Leaf phosphorus concentration}

\subsubsection{Species level}

Two species occurring in the secondary forest showed much higher leaf phosphorus concentrations, and lower $\mathrm{C} / \mathrm{P}$ ratios, than the other species. These were Lauraceae sp.1 (P: $6.7 \mathrm{~g} \mathrm{~kg}^{-1}$; C/P: $65 \mathrm{~g} \mathrm{~g}^{-1}$ ) and Dendrocnide sp.3 (P: $6.5 \mathrm{~g} \mathrm{~kg}^{-1} ; \mathrm{C} / \mathrm{P}: 70 \mathrm{~g} \mathrm{~g}^{-1}$ ). The third highest $\mathrm{P}$ concentration $\left(4.3 \mathrm{~g} \mathrm{~kg}^{-1}\right)$ was obtained in the likewise secondary forest species Solanum sp.. The lowest concentration was found in a species of the late-successional genus Ficus (Ficus sp.10, Moraceae, $0.56 \mathrm{~g} \mathrm{~kg}^{-1}$ ), which also reached the highest C/P ratio (748 g $\left.\mathrm{g}^{-1}\right)$. The range of leaf phosphorus concentrations, as well as $\mathrm{C} / \mathrm{P}$, was about a factor 12 among the 107 species in this study. This is three times as much as the range found for leaf 

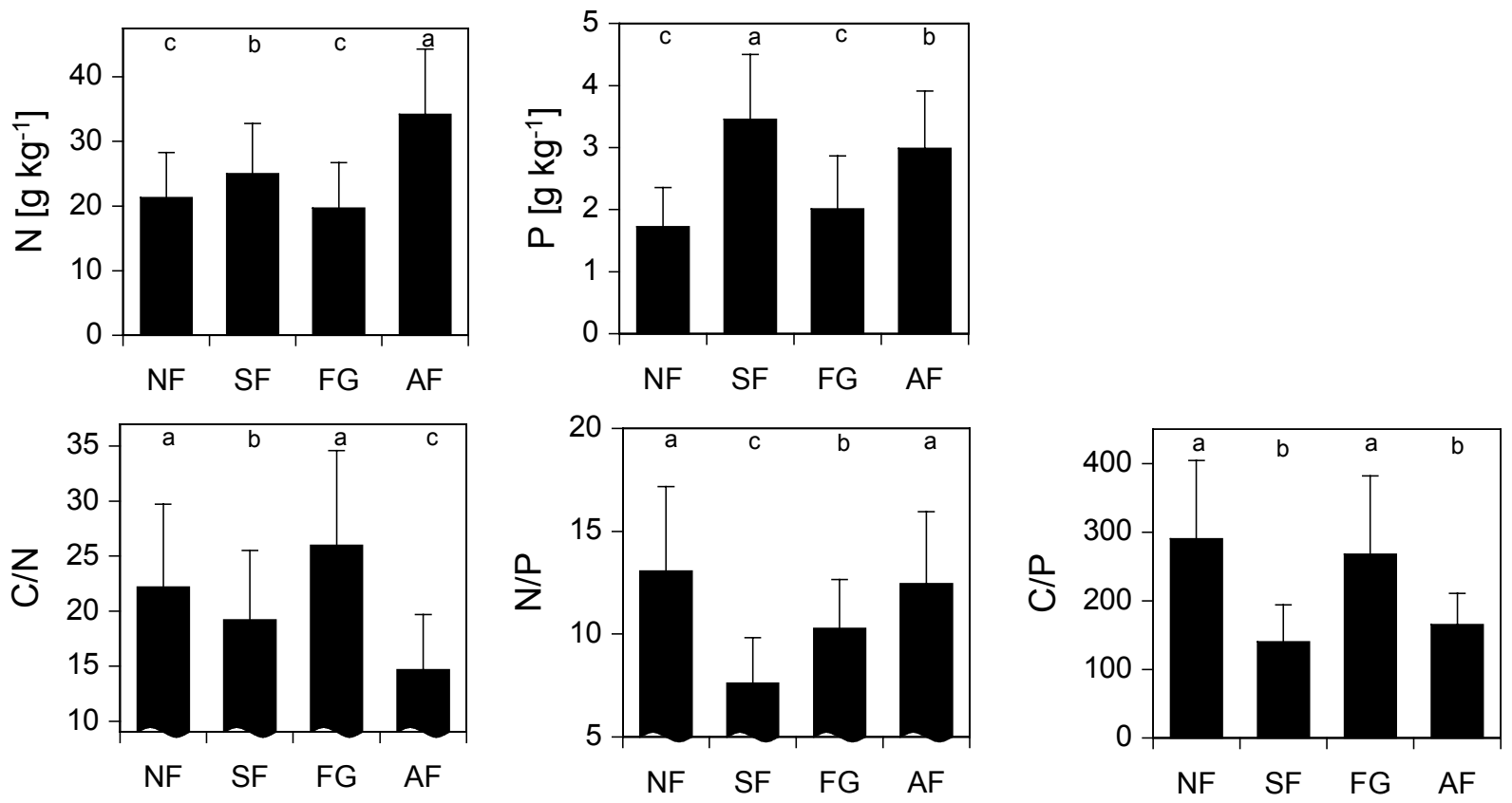

Figure 4.11 Means of foliar nitrogen $(\mathrm{N})$ and phosphorus $(\mathrm{P})$ concentrations and the ratios $\mathrm{C} / \mathrm{N}, \mathrm{N} / \mathrm{P}$ and $\mathrm{C} / \mathrm{P}$ in the random samples of the four land use types studied (for definition of the random samples, see Table 3.2). Significantly different means are marked by different letters $(\mathrm{p}<0.05)$. Number of individuals: NF: 119, SF: 160, FG: 25, AF: 49.

(NF - Natural forest, $\mathrm{SF}$ - Secondary forest, FG - Forest garden, AF - Agroforestry system)

nitrogen concentration.

The quota between leaf nitrogen and phosphorus (N/P) reached highest values in Ficus sp.10 (34 $\left.\mathrm{g} \mathrm{g}^{-1}\right)$ and Capparis sp. $\left(29 \mathrm{~g} \mathrm{~g}^{-1}\right)$, while the lowest value found was $3.5 \mathrm{~g} \mathrm{~g}^{-1}$ (Urticaceae sp.1).

Means of chemical leaf traits for all studied species are presented in Appendix 7.

\subsubsection{Family level}

Among the most frequent families in the study, the phosphorus concentration varied from $1.5 \mathrm{~g} \mathrm{~kg}^{-1}$ in Moraceae to $3.2 \mathrm{~g} \mathrm{~kg}^{-1}$ in Euphorbiaceae and Urticaceae. Consequently, the highest C/P ratio was found in Moraceae (31.7) and the lowest in Urticaceae (15.1). The $\mathrm{N} / \mathrm{P}$ ratio in Euphorbiaceae (7.6) was the lowest obtained and that of Moraceae (13.5) the highest (Figure 4.10).

\subsubsection{Land use type level}

Secondary forest stands had the highest mean leaf phosphorus concentration $\left(3.4 \mathrm{~g} \mathrm{~kg}^{-1}\right)$ among the four land use types studied. This was significantly more than the $2.8 \mathrm{~g} \mathrm{~kg}^{-1}$ found in the agroforestry systems. Natural forest $\left(1.7 \mathrm{~g} \mathrm{~kg}^{-1}\right)$ and forest garden $\left(2.0 \mathrm{~g} \mathrm{~kg}^{-1}\right)$ means 
were the lowest (Figure 4.11, Appendix 11). The carbon phosphorus ratio showed two significantly different groups: secondary forest and agroforestry system (140 and $\left.171 \mathrm{~g} \mathrm{~g}^{-1}\right)$ and natural forest and forest garden (268 and $290 \mathrm{~g} \mathrm{~g}^{-1}$ ). Looking at the N/P ratio interestingly revealed three significantly different groups: natural forest together with the agroforestry system having the highest mean N/P ratios (13.0 and $\left.12.4 \mathrm{~g} \mathrm{~g}^{-1}\right)$, followed by forest garden $\left(10.2 \mathrm{~g} \mathrm{~g}^{-1}\right)$ and the lowest rate that was obtained in the secondary forest $(7.6 \mathrm{~g}$ $\left.\mathrm{g}^{-1}\right)$ (Figure 4.11).

\subsubsection{Leaf concentrations of $\mathrm{Ca}, \mathrm{K}$ and $\mathrm{Mg}$}

The variation in leaf concentrations of the nutrients calcium, potassium and magnesium per unit dry mass was astonishingly high. In particular, there was a very high variation among species within one land use type. It is at the first sight hard to generalize about typical concentrations in species from a certain land use type, or a certain family. The mean values and the standard deviations of $\mathrm{Ca}, \mathrm{K}$ and $\mathrm{Mg}$ concentrations in four land use types is illustrated in Figure 4.12 and for five frequent families in Figure 4.13.

\subsubsection{Species level}

The highest leaf Ca concentration was found in Ficus sp.8 (71.9 $\left.\mathrm{g} \mathrm{kg}^{-1}\right)$ and the lowest in Eleaocarpus sp. (4.6 $\left.\mathrm{g} \mathrm{kg}^{-1}\right)$. Noteworthy was the large number of Urticaceae species with high $\mathrm{Ca}$ concentrations. The range of $\mathrm{Ca}$ concentrations among the 107 species studied was 16-fold.

The potassium concentrations varied with a factor 9 among the species studied, from 5.0 $\mathrm{g} \mathrm{kg}^{-1}$ in Lithocarpus sp. to $43.7 \mathrm{~g} \mathrm{~kg}^{-1}$ in Nothaphoebe sp..

An unidentified species in the secondary forest showed the lowest magnesium concentration among all species: $0.9 \mathrm{~g} \mathrm{~kg}^{-1}$. The highest value found was $16.3 \mathrm{~g} \mathrm{~kg}^{-1}$ in the Sugar Palm, Arenga pinnata. Thus, there was an 18-fold variation in species means of $\mathrm{Mg}$ concentration.

A complete list of species means of leaf nutrient concentrations is presented in Appendix 7.

\subsubsection{Family level}

The five most frequent families could be separated into two groups according to their mean Ca concentration: Moraceae and Urticaceae had Ca means of 33.7 and $35.4 \mathrm{~g} \mathrm{~kg}^{-1}$, whereas the other three families had much lower means (between 15.2 and $17.5 \mathrm{~g} \mathrm{~kg}^{-1}$ ). 
With regard to potassium concentrations, only one family was significantly different from the others: Euphorbiaceae with the very low mean of $9.8 \mathrm{~g} \mathrm{~kg}^{-1}$. Meliaceae showed the highest mean potassium concentration among the five families $\left(16.4 \mathrm{~g} \mathrm{~kg}^{-1}\right)$.

The distribution of mean magnesium concentrations was similar to that of potassium, with Euphorbiaceae having the lowest mean $\left(3.0 \mathrm{~g} \mathrm{~kg}^{-1}\right)$, significantly separated from the other four families, and Meliaceae showing the highest mean $\mathrm{Mg}$ concentration $\left(6.5 \mathrm{~g} \mathrm{~kg}^{-1}\right)$ (Figure 4.12, Appendix 12).
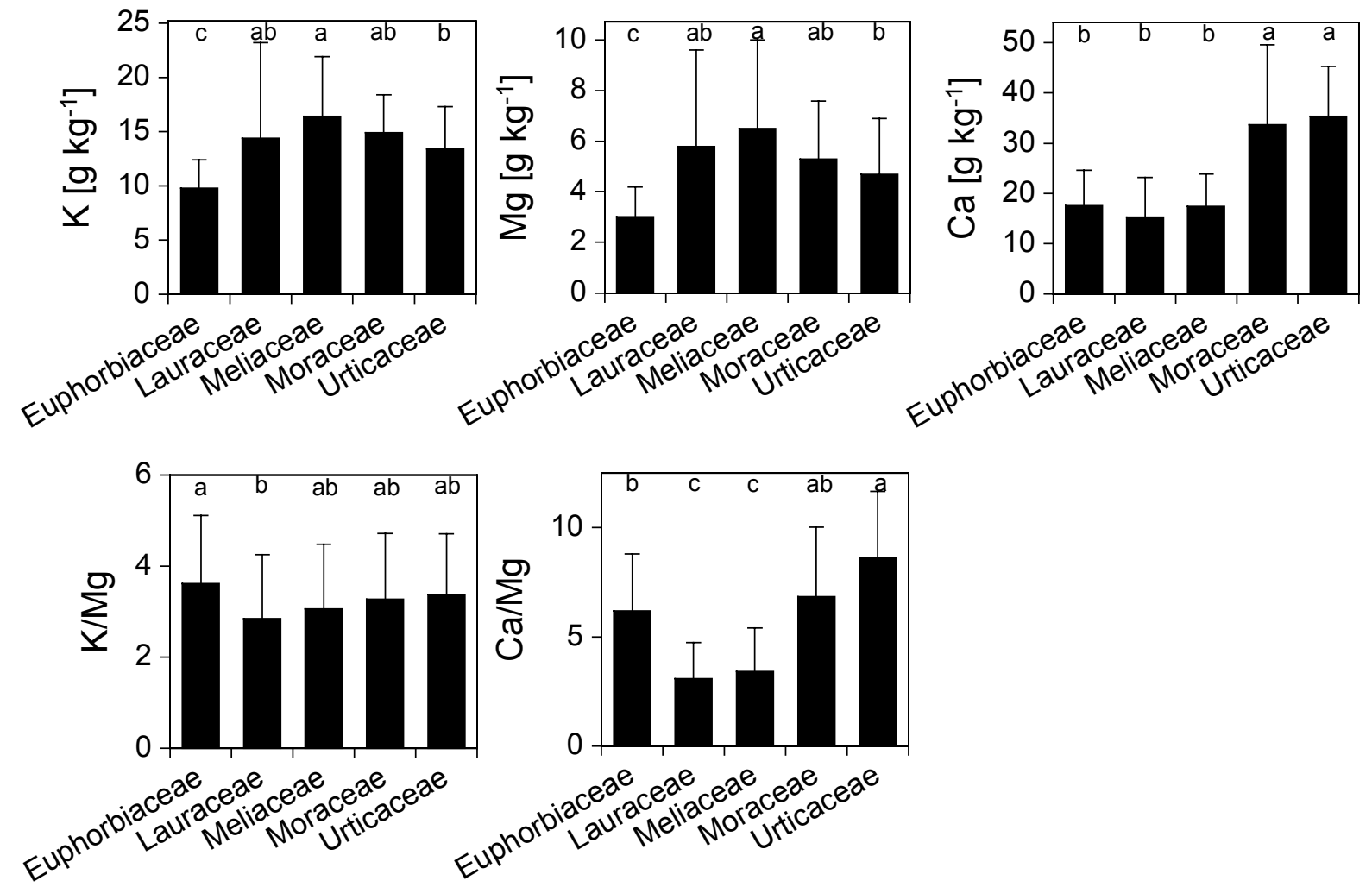

Figure 4.12 Means with standard deviation for leaf potassium $(\mathrm{K})$, magnesium $(\mathrm{Mg})$ and calcium (Ca) concentrations and the ratios of $\mathrm{K} / \mathrm{Mg}$ and $\mathrm{Ca} / \mathrm{Mg}$ in the five most frequent families in the random sample (for definition of random sample, see Table 3.2). Total number of species / individuals representing each family were: Euph.: 10/85, Laura.: 9/23, Melia.: 7/20, Mora.: 10/13, Urti.: 10/57.

\subsubsection{Land use type level}

The agroforestry systems had the lowest mean calcium concentration $\left(14.6 \mathrm{~g} \mathrm{~kg}^{-1}\right)$, which was significantly different from the natural forest $\left(20.8 \mathrm{~g} \mathrm{~kg}^{-1}\right)$ and the secondary forest $\left(24.1 \mathrm{~g} \mathrm{~kg}^{-1}\right)$. The mean value for forest garden $\left(18.1 \mathrm{~g} \mathrm{~kg}^{-1}\right)$ could not be separated from any of the other three land use types (Figure 4.13). 
The secondary forest showed the lowest mean potassium concentration $\left(12.8 \mathrm{~g} \mathrm{~kg}^{-1}\right)$, and the agroforestry system the highest $\left(15.5 \mathrm{~g} \mathrm{~kg}^{-1}\right)$. The difference between these two was statistically significant.

Mean leaf magnesium concentration was lowest in the secondary forest $\left(3.4 \mathrm{~g} \mathrm{~kg}^{-1}\right)$ and the agroforestry system $\left(3.7 \mathrm{~g} \mathrm{~kg}^{-1}\right)$ and highest in the natural forest $\left(5.5 \mathrm{~g} \mathrm{~kg}^{-1}\right)$.
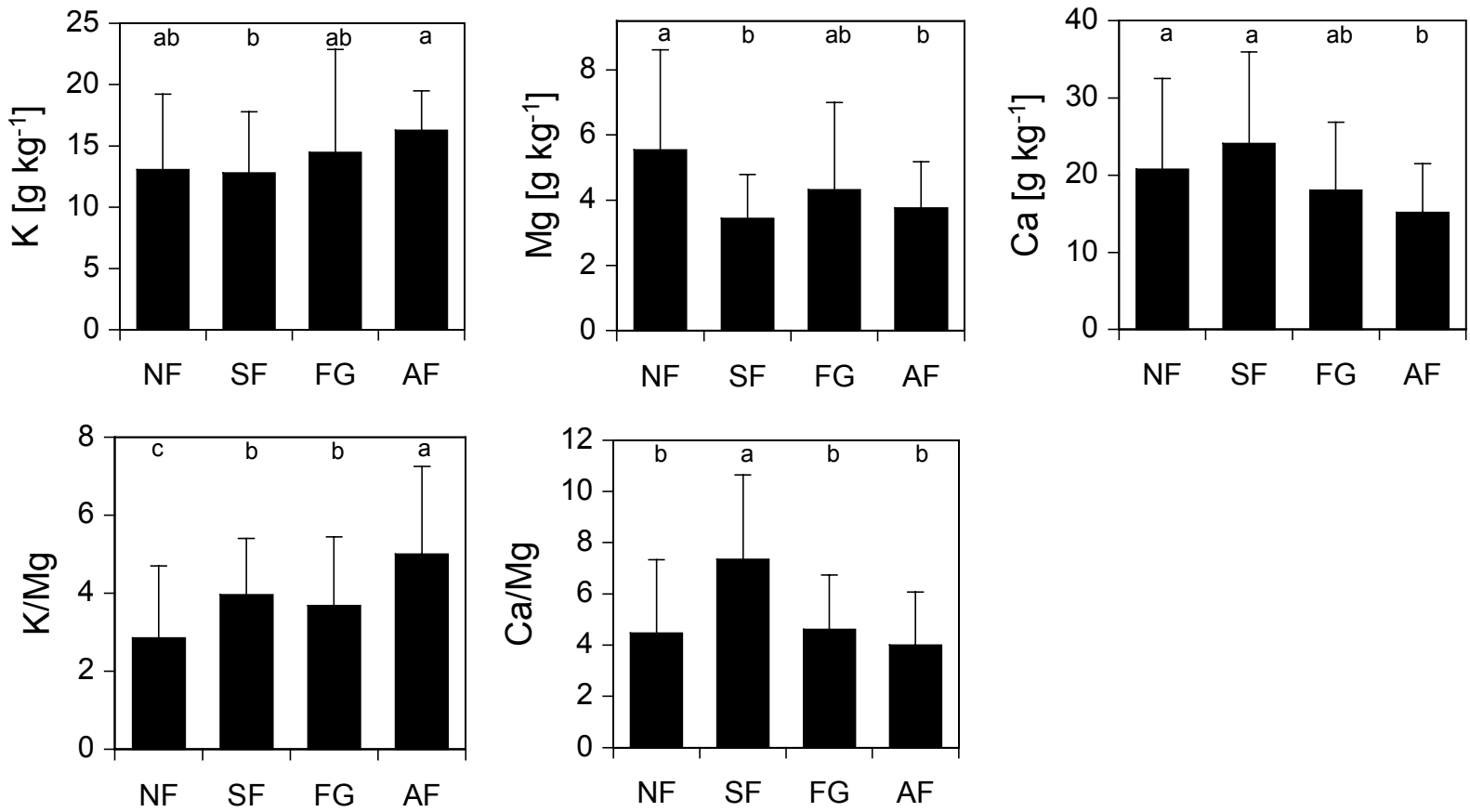

Figure 4.13 Means with standard deviation for leaf potassium $(\mathrm{K})$, magnesium $(\mathrm{Mg})$ and calcium (Ca) concentration and the ratios of $\mathrm{K} / \mathrm{Mg}$ and $\mathrm{Ca} / \mathrm{Mg}$ in the random samples of each of the four land use types studied (for definition of random sample, see Table 3.2).

(NF - Natural forest, SF - Secondary forest, FG - Forest garden, AF - Agroforestry system)

\subsubsection{Nitrogen isotope signature $-\delta^{15} \mathrm{~N}$}

\subsubsection{Soil nitrogen}

As can be seen in Table 4.6 and Figure 4.14 the $\delta^{15} \mathrm{~N}$ value in soil samples taken at $0-$ $10 \mathrm{~cm}$ depth differed significantly between the four land use types. The highest soil $\delta^{15} \mathrm{~N}$ value was obtained in the agroforestry system (6.62\%o), decreasing over secondary forest and natural forest to the lowest mean $\delta^{15} \mathrm{~N}$ that was found in the forest garden $(3.25 \%$ ).

The total soil nitrogen concentration was highest in the natural and secondary forests $(0.44 \%$ and $0.37 \%)$, which showed about twice as high values as the forest garden $(0.20 \%)$. 
The nitrogen concentration in the agroforestry soils was intermediate $(0.32 \%)$ and was not statistically different from the other three land use types (Figure 4.14, Table 4.6).

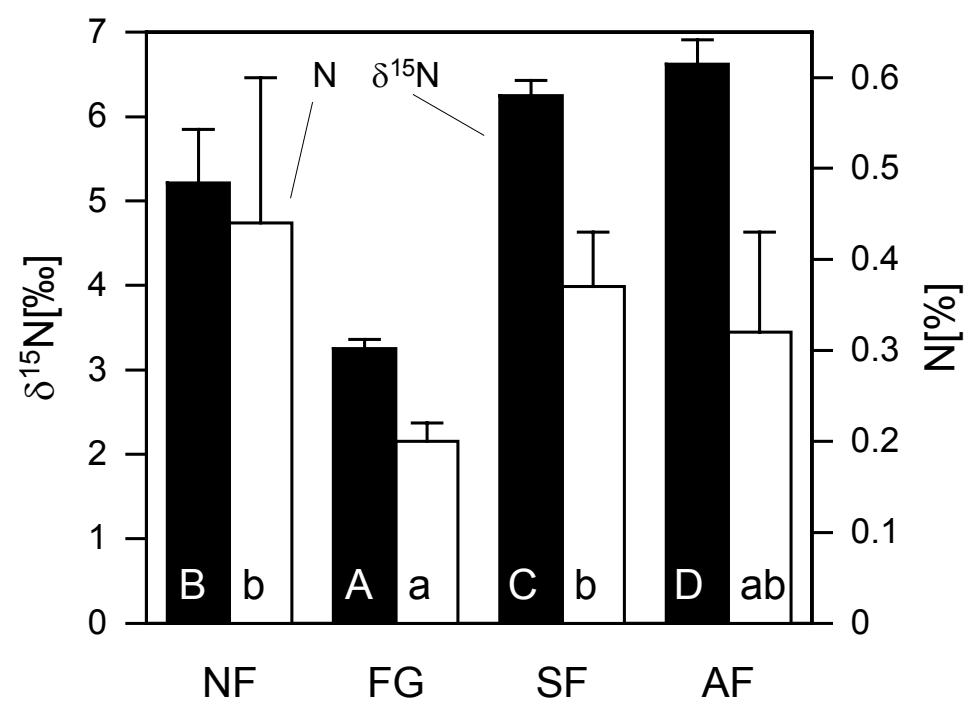

Figure 4.14 Means with standard deviation of $\delta^{15} \mathrm{~N}$ (black) and total $\mathrm{N}$ concentration (white) in soil samples from 0-10 cm taken in the four land use types studied. (Number of samples per land use type: $\mathrm{n}_{\mathrm{NF}}=9, \mathrm{n}_{\mathrm{FG}}=3, \mathrm{n}_{\mathrm{SF}}=5, \mathrm{n}_{\mathrm{AF}}=6$ )

\subsubsection{Foliar $\delta^{15} N$ values at the species level}

The species means of foliar $\delta^{15} \mathrm{~N}$ values obtained in this study ranged from $-0.71 \%$, found in Burseraceae sp.2, to 8.75\% measured in Notaphoebe umbellata. Thus, the variation in $\delta^{15} \mathrm{~N}$ among the 107 species was 17 -fold, which is much more than the variation of foliar nitrogen concentration (4.8-fold) among the 107 species studied in four land use types.

Foliar $\delta^{15} \mathrm{~N}$ was normally distributed, while the total nitrogen concentration was skewed right. This is found true for the complete random sample (354 individuals), as well as for the species means (107 species) (Figure 4.15). Figure 4.16 shows the frequency distribution of $\delta^{15} \mathrm{~N}$ for the individuals sampled in each land use type. The distribution in the secondary forest was limited to a few classes, in contrast to the other three land use types. Most secondary forest individuals concentrated around $2.5 \%$. The difference in typical $\delta^{15} \mathrm{~N}$ values among the four agroforestry system species can be observed, with two first peaks representing Gliricidia sepium and Erythrina sp. (lowest $\delta^{15} \mathrm{~N}$ values) followed by Coffea arabica and Theobroma cacao, with higher $\delta^{15} \mathrm{~N}$ values. Because of the occurrence of two potentially $\mathrm{N}_{2}$-fixing leguminous species and two non- $\mathrm{N}_{2}$-fixing species, the agroforestry system covered a wide range of $\delta^{15} \mathrm{~N}$ values. It was also noteworthy, that the forest garden had a rather wide range as well, given the small sample (26 individuals). 

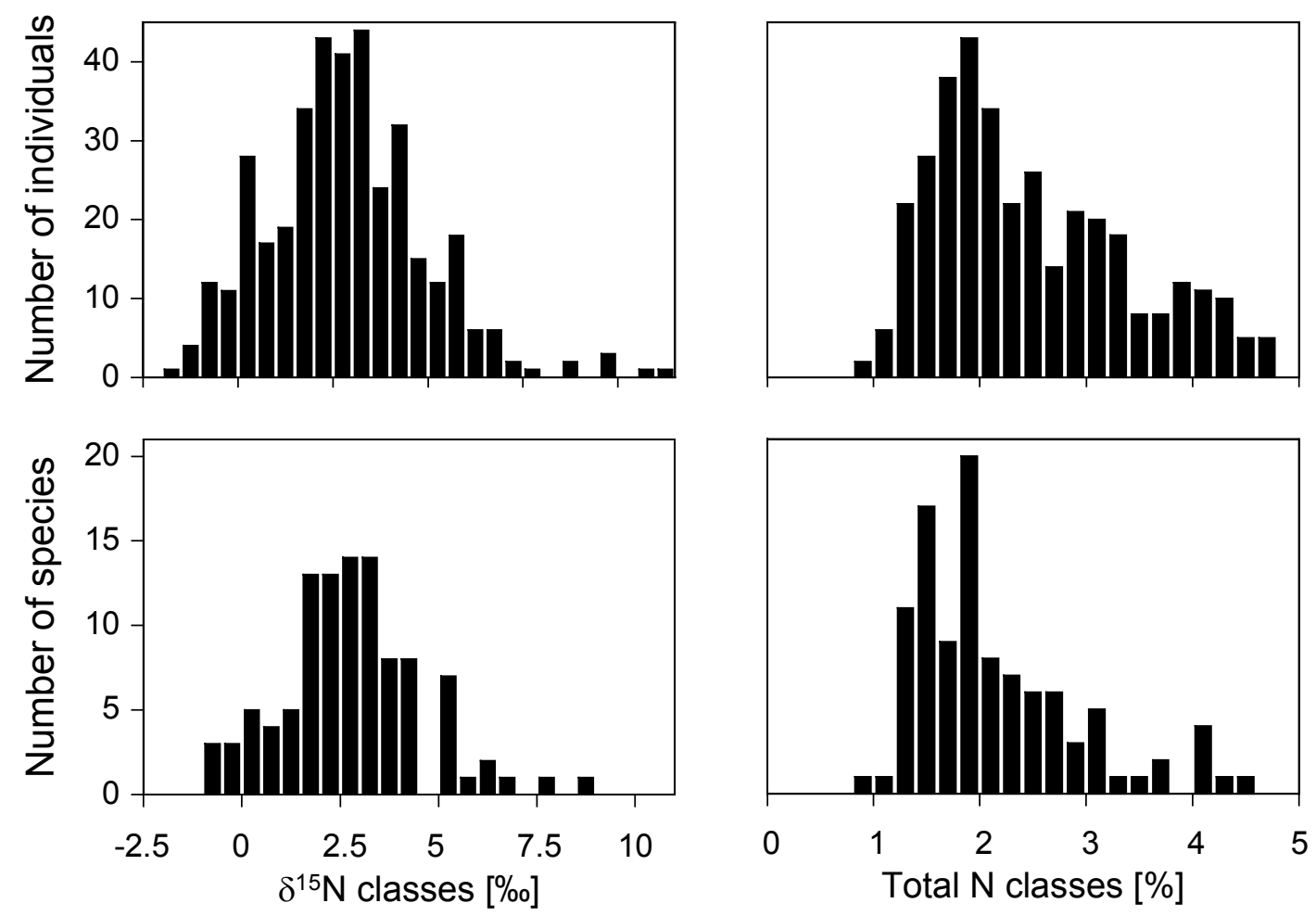

Figure 4.15 Frequency distribution of $\delta^{15} \mathrm{~N}$ and total $\mathrm{N}$, respectively, in leaves of all individuals $(\mathrm{n}=$ 354 , above) and species $(\mathrm{n}=107$, below) in the random sample, covering all four studied land use types (for definition of random sample and species covered, see Table 3.2). Class width was 0.5\%o for $\delta^{15} \mathrm{~N}$ and $0.2 \%$ for $\mathrm{N}$.

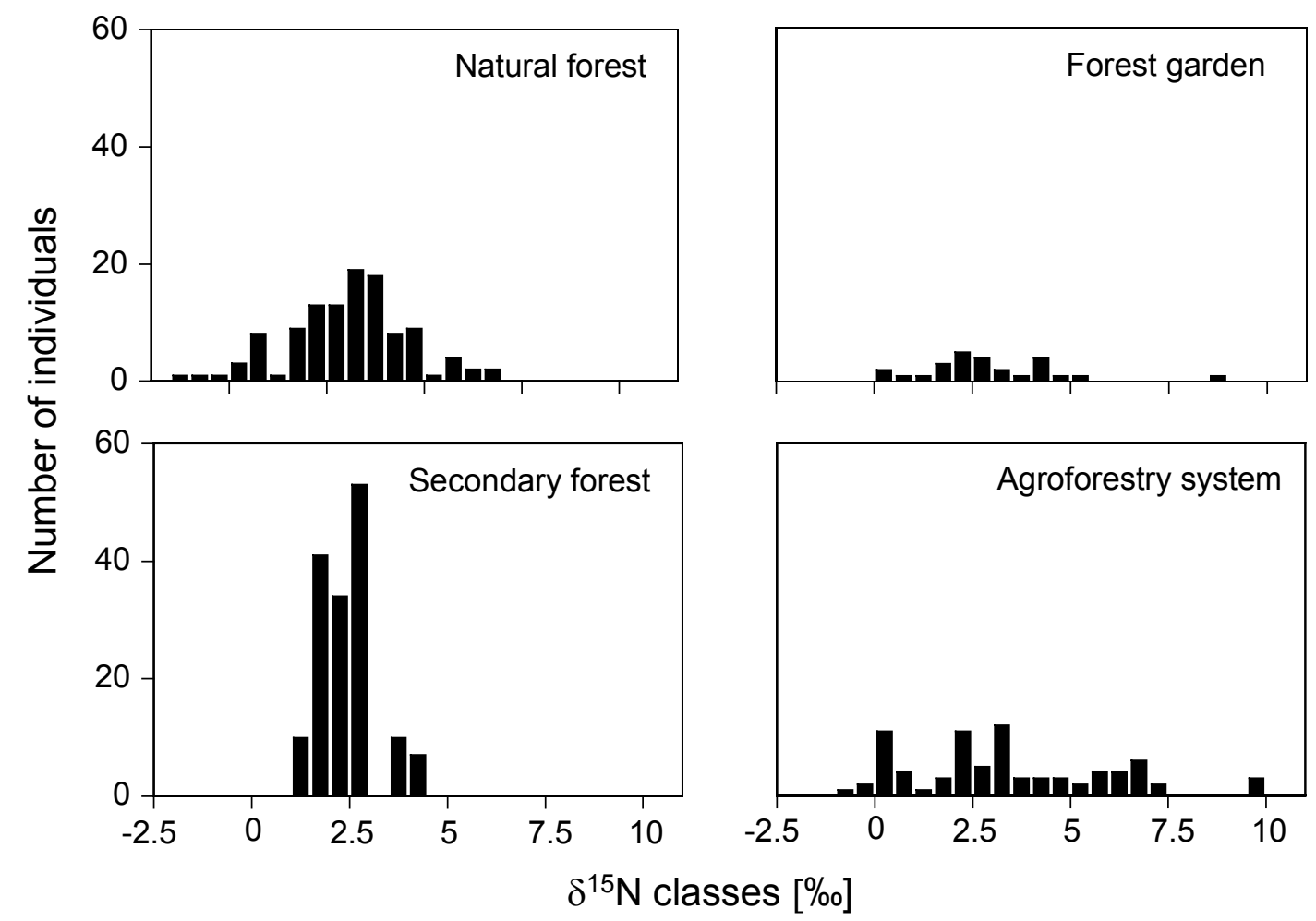

Figure 4.16 Frequency distribution of $\delta^{15} \mathrm{~N}$ among the individuals of the random samples of each land use type. Class width: 0.5\%o-units. For definition of random sample, see Table 3.2. 
Significant, positive correlations were found between foliar $\delta^{15} \mathrm{~N}$ and total nitrogen concentration among species in three of the four studied land use types (NF: $\mathrm{r}^{2}=0.08, \mathrm{p}=$ $0.02, \mathrm{SF}: \mathrm{r}^{2}=0.20, \mathrm{p}<0.01, \mathrm{FG}: \mathrm{r}^{2}=0.29, \mathrm{p}=0.02$, Figure 4.17).

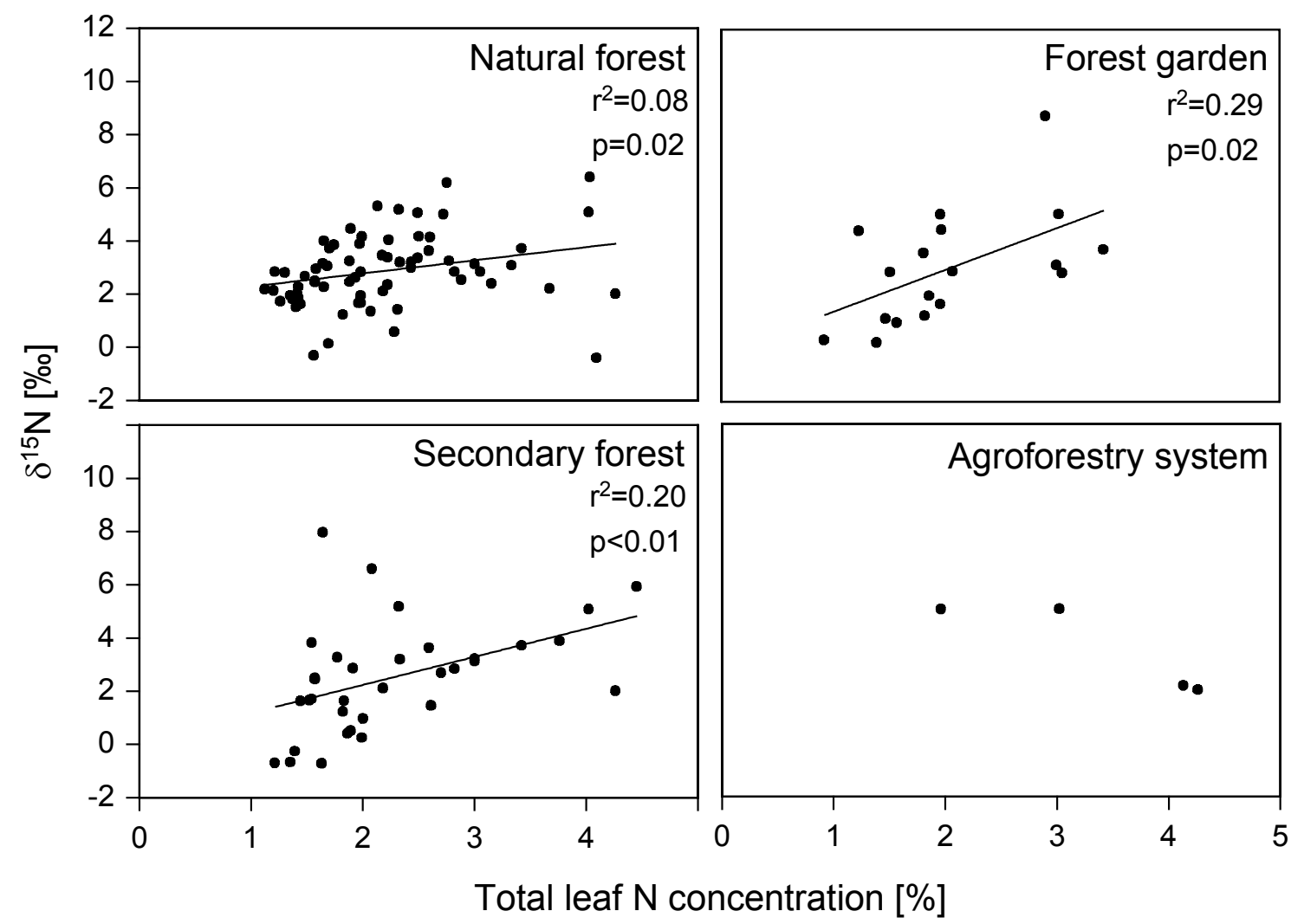

Figure 4.17 Species means of foliar $\delta^{15} \mathrm{~N}$ versus total nitrogen concentration for the trees of four different land use types. Significant, positive correlations between foliar $\delta^{15} \mathrm{~N}$ and total nitrogen concentrations were found in three of the four studied land use types.

\subsubsection{The relation between nitrogen in foliage and soil}

Nitrogen concentrations of soil and foliage were compared at the plot level, comprising all four land use types (For definition of plots, see Table 4.1). Neither a correlation between the $\mathrm{N}$ concentrations of soil and that of leaves (Figure $4.18 \mathrm{~A}$ ), nor between the means of $\delta^{15} \mathrm{~N}$ in soil and leaf material could be detected (Figure $4.18 \mathrm{~B}$ ). $\delta^{15} \mathrm{~N}$ of soil and total leaf nitrogen concentration showed an exponential relation (Figure $4.18 \mathrm{C}$ ). The lowest quotas between foliar $\delta^{15} \mathrm{~N}$ and $\delta^{15} \mathrm{~N}$ in soil were found in the natural forest $(0.46)$ and the agroforestry system $(0.45)$, whereas the $\delta^{15} \mathrm{~N}$ in foliage and soil was equal in the forest garden, giving a quota of 1.0 in that land use type. The secondary forest value was intermediate (0.61). 

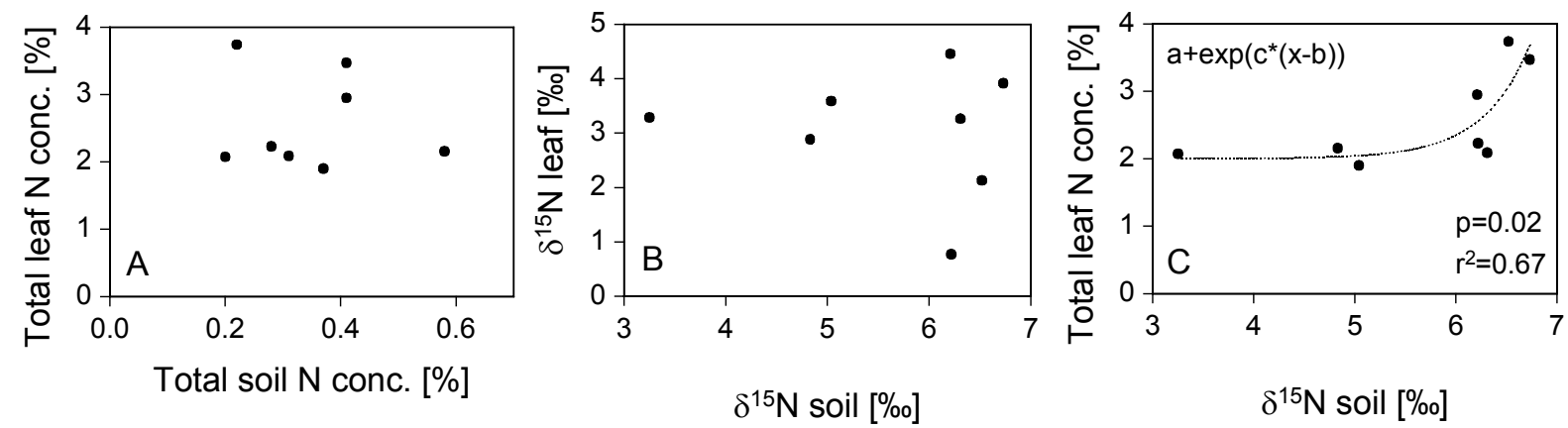

Figure 4.18 Relationships between means of $\delta^{15} \mathrm{~N}$ and total nitrogen concentration in soil samples and random samples of leaves from eight plots, covering four land use types. (For specification of number of species and individuals included, see Table 4.1.) A. Total leaf nitrogen concentration versus total nitrogen concentration of soil. B. $\delta^{15} \mathrm{~N}$ in leaves versus $\delta^{15} \mathrm{~N}$ values in soil. C.

Exponential relation between the soil $\delta^{15} \mathrm{~N}$ and the total leaf nitrogen concentration $(\mathrm{a}=2.0, \mathrm{~b}=6.5$, $\mathrm{c}=2.2)$.

Table 4.6 Total nitrogen concentration, and $\delta^{15} \mathrm{~N}$ values in soil samples $(0-10 \mathrm{~cm})$ and sun leaves presented as means and standard deviation for four different land use types (AF-agroforestry system, FG-forest garden, NFnatural forest, SF-secondary forest). Means with the different superscript are statistically different $(p \leq 0.05)$. Quotas between mean leaf and soil for $\delta^{15} \mathrm{~N}$ and total nitrogen concentration are listed in the right part of the table.

\begin{tabular}{|c|c|c|c|c|c|c|c|c|c|}
\hline & $\begin{array}{l}\delta^{15} \mathbf{N} \\
\text { leaf } \\
{[\% o]}\end{array}$ & \multicolumn{2}{|c|}{$\begin{array}{l}N_{\text {tot }} \\
\text { leaf } \\
{[\%]}\end{array}$} & \multicolumn{2}{|c|}{$\begin{array}{c}\delta^{15} \mathbf{N} \\
\text { soil } \\
{[\% o]}\end{array}$} & \multicolumn{2}{|c|}{$\begin{array}{l}\mathbf{N}_{\text {tot }} \\
\text { soil } \\
{[\%]}\end{array}$} & \multirow[t]{2}{*}{$\begin{array}{c}\delta^{15} \mathrm{~N} \text { leaf } / \\
\delta^{15} \mathrm{~N} \text { soil }\end{array}$} & \multirow[t]{2}{*}{$\begin{array}{c}\mathbf{N} \text { leaf } / \\
\mathbf{N} \text { soil }\end{array}$} \\
\hline & mean sd & mean & sd & mean & sd & mean & sd & & \\
\hline NF & $2.56^{\mathrm{a}} 1.53$ & $2.13^{\mathrm{A}}$ & 0.70 & $5.21^{b}$ & 0.64 & $0.44^{\mathrm{B}}$ & 0.16 & 0.46 & 47 \\
\hline FG & $2.97^{\mathrm{a}} 1.79$ & $1.97^{\mathrm{A}}$ & 0.70 & $3.25^{\mathrm{a}}$ & 0.11 & $0.20^{\mathrm{A}}$ & 0.02 & 1.01 & 101 \\
\hline SF & $2.72^{\mathrm{a}} 2.22$ & $2.50^{\mathrm{B}}$ & 0.78 & $6.25^{\mathrm{c}}$ & 0.18 & $0.37^{\mathrm{B}}$ & 0.06 & 0.61 & 67 \\
\hline $\mathbf{A F}$ & $3.23^{\mathrm{a}} 2.35$ & $3.48^{\mathrm{C}}$ & 1.06 & $6.62^{\mathrm{d}}$ & 0.29 & $0.32^{\mathrm{AB}}$ & 0.11 & 0.45 & 113 \\
\hline
\end{tabular}

\subsubsection{Possible $\mathrm{N}_{2}$-fixing species}

Mean values with standard deviation of the three groups of species detected by Roggy et al. (1999) are projected graphically on the total-N-versus $\delta^{15} \mathrm{~N}$-plots for the species in this study in Figure 4.19. The two species with known $\mathrm{N}_{2}$-fixing symbionts in this study are the Fabaceae Gliricidia sepium, Erythrina sp., whereas Coffea arabica and Theobroma cacao are known non- $\mathrm{N}_{2}$-fixers. These four species fitted in to the respective frames based on Roggy et al., confirming that this classification method may be applicable to the data in this study (Figure 4.19 below, right).

According to this assessment, the natural forest studied had a larger proportion of putative $\mathrm{N}_{2}$-fixing species (30\%) than the secondary forest and the forest garden (23 and 
$16 \%$, respectively). The proportion of uncertain species was somewhat lower in the natural forest. The highest proportion of non- $\mathrm{N}_{2}$ - fixing species, besides the $50 \%$ in the agroforestry system, was found in the forest garden (32\%), whereas the secondary and natural forests were both suggested to consist to $26 \%$ of non- $\mathrm{N}_{2}$-fixing species.

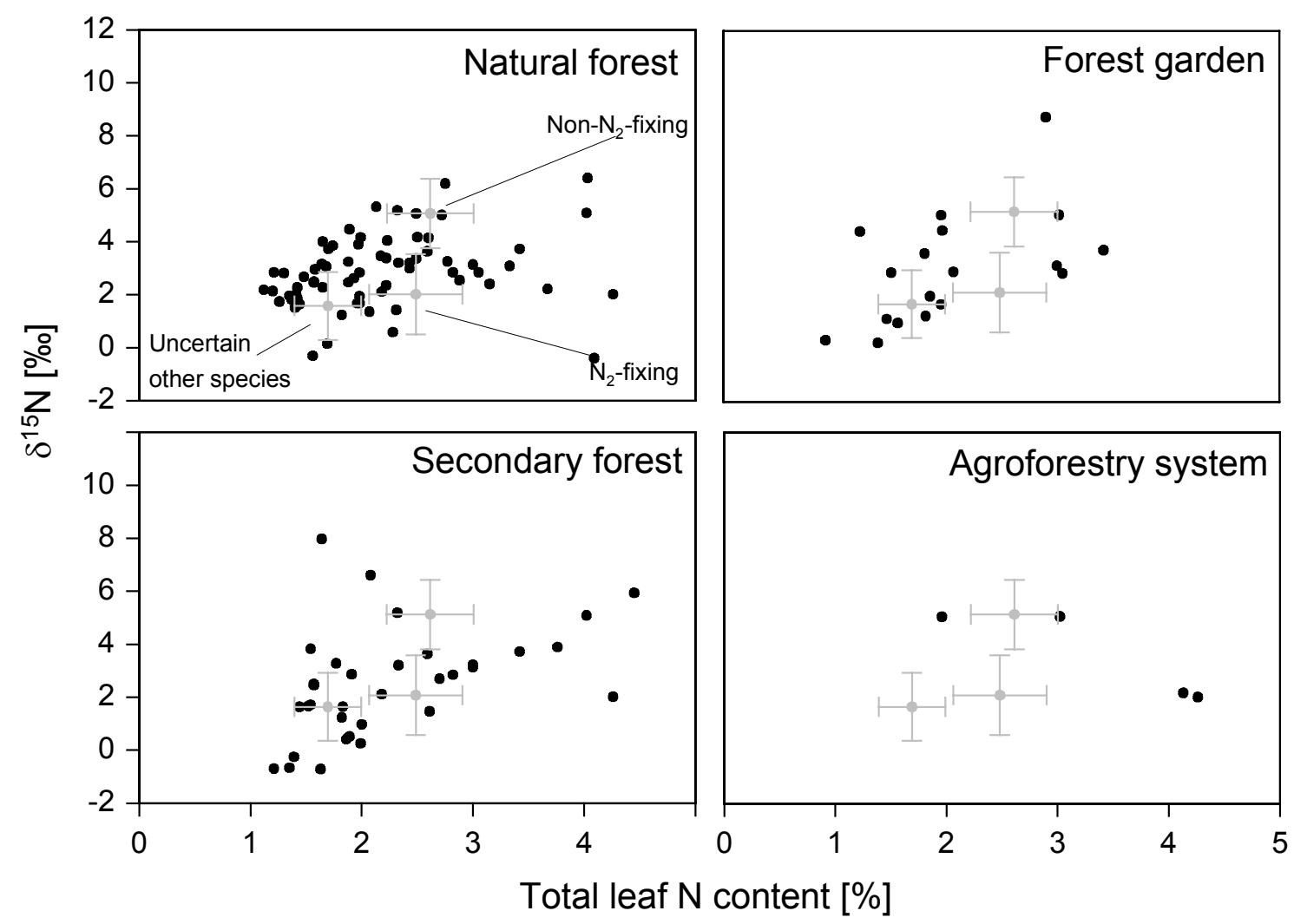

Figure $4.19 \delta^{15} \mathrm{~N}$ versus total leaf nitrogen concentration for species occurring in four different land use types. The mean values and standard deviations of Roggy's samples for each of three groups defined by their results are inserted in the graphs (putative $\mathrm{N}_{2}$-fixers, non- $\mathrm{N}_{2}$-fixers and uncertain other species (Roggy et al. 1999)). The data of Roggy et al. was used for classifying the species investigated in this study.

To the large fraction of supposed $\mathrm{N}_{2}$-fixers found in the natural forest belonged, for example, Rauvolfia sumatrana, Ficus sp.11, Pouzolzia sp., Elaeocarpus sp. and Aralia sp.. Important putative $\mathrm{N}_{2}$-fixers in the secondary forest stands were Trema orientalis, Pipterus argentus, Macaranga tanarius and Homalantus populneus. The following three supposed $\mathrm{N}_{2}$-fixers were found in the forest garden: Sarcosperma paniculata, Trema orientalis and Litsea sp.3. 
Putative non- $\mathrm{N}_{2}$-fixing natural forest species with high $\delta^{15} \mathrm{~N}$ and low total $\mathrm{N}$ values were Pandanus sp., Dracaena sp., Terminalia sp. and Horsfieldia costulata. Typical species of this group found in the secondary forest were Glochidion rubrum and Geunsia sp.. All non-

Table 4.7 Classification of the 107 species in this study according to the assumed presence of $\mathrm{N}_{2}$-fixing symbionts. Three groups were defined, based on the results of Roggy et al. (1999). Thresholds and proportions of species belonging to each group are presented for each of the four land use types.

\begin{tabular}{|c|c|c|c|c|c|c|}
\hline & \multicolumn{2}{|c|}{ Thresholds } & \multicolumn{4}{|c|}{$\begin{array}{c}\text { Proportion of species } \\
{[\%]}\end{array}$} \\
\hline & $\begin{array}{c}\text { Total N } \\
{[\%]}\end{array}$ & $\begin{array}{l}\delta^{15} \mathbf{N} \\
{[\% o]}\end{array}$ & $\begin{array}{c}\text { Natural } \\
\text { forest }\end{array}$ & $\begin{array}{l}\text { Forest } \\
\text { garden }\end{array}$ & $\begin{array}{c}\text { Secondary } \\
\text { forest }\end{array}$ & $\begin{array}{c}\text { Agroforestry } \\
\text { system }\end{array}$ \\
\hline $\mathrm{N}_{2}$-fixing & $\geq 2.06$ & $\leq 3.60$ & 30 & 16 & 23 & 50 \\
\hline Non- $\mathrm{N}_{2}$-fixing & All N values & $>3.60$ & 26 & 32 & 26 & 50 \\
\hline Uncertain other species & $<2.06$ & $\leq 3.60$ & 41 & 47 & 51 & 0 \\
\hline $\begin{array}{l}\text { No. species with } \\
\text { incomplete data }\end{array}$ & & & $2(3 \%)$ & $1(5 \%)$ & 0 & 0 \\
\hline
\end{tabular}

$\mathrm{N}_{2}$-fixing species in the forest garden had high $\delta^{15} \mathrm{~N}$ values and rather low total $\mathrm{N}$ concentrations. These were Dracontomeleon dao, Grewia glabra, Ficus sp.7 and Nothaphoebe umbellata, as well as the crops Theobroma cacao and Coffea arabica.

It can be seen in Figure 4.19 that the secondary forest comprised a number of species which according to their high $\delta^{15} \mathrm{~N}$, probably did not possess any $\mathrm{N}_{2}$-fixing symbionts, but still reached remarkably high leaf nitrogen concentrations. The most noteworthy of these species were Tabernamontana macrocarpa, Dendrocnide sp.3, Solanum sp. and Mallotus mollissimus. Natural forest species in the same category were Dysoxylum sp.4, Aglaia sp. and Beilschmiedia sp.. These natural forest species however, all had lower total nitrogen concentrations than the typical secondary forest species of pioneer character in this group.

\subsubsection{Carbon isotope signature $-\delta^{13} \mathrm{C}$}

\subsubsection{Species level}

The measured mean foliar $\delta^{13} \mathrm{C}$ values among the 107 species studied varied from 26.0\% in Ficus sp.8 to $-33.8 \%$ in an unidentified natural forest tree, followed by Ficus sp.9 $\left(-33.1 \%\right.$ ) and Litsea sp.1 (-32.6\%o). $\delta^{13} \mathrm{C}$ values for all species studied are listed in Appendix 7. 


\subsubsection{Family level}

Two significantly different groups were found among the five most frequent families concerning leaf $\delta^{13} \mathrm{C}$. Urticaceae and Euphorbiaceae had a less negative value (-28.1\%o) than the other three families (Figure 4.20, Appendix 12). Lauraceae showed the most negative mean $(-30.8 \%$ ). Thus, families with mainly pioneer tree species (with some single exceptions in Euphorbiaceae) seem to have elevated $\delta^{13} \mathrm{C}$ values, and thus a higher water use efficiency than the others, given that all other factors were similar.

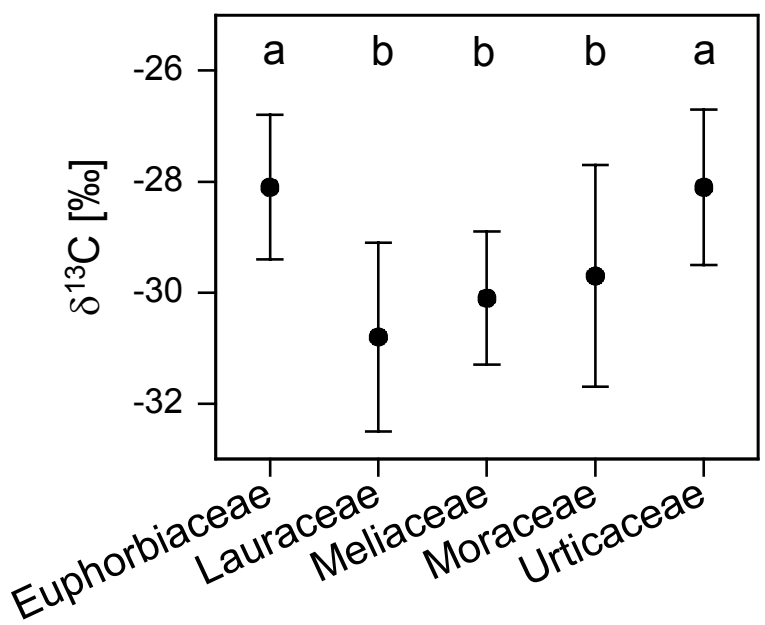

Figure 4.20 Means with standard deviation of the foliar $\delta^{13} \mathrm{C}$ values for the five most frequent families in the random sample (for definition of random sample, see Table 3.2). Different letters mark significantly different means.

\subsubsection{Land use type level}

The four land use types were divided into two groups in terms of their foliar $\delta^{13} \mathrm{C}$ signatures. Natural forest and forest garden showed significantly more negative values than the other two land use types. The two groups differed by about $2 \%$ : $-30.2 \%$ was found in the natural forest and $-29.8 \%$ in the forest garden, to be compared to $-27.8 \%$ of the secondary forest and the agroforestry system (Figure 4.21, Appendix 11). 


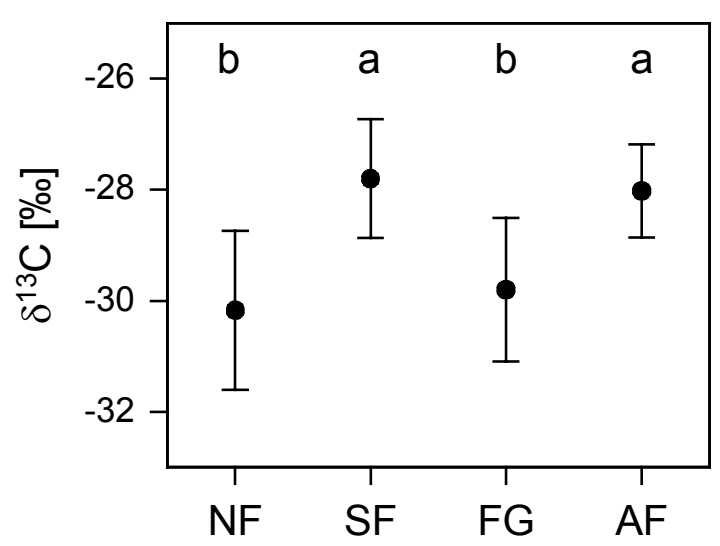

Figure 4.21 Means with standard deviation of the foliar $\delta^{13} \mathrm{C}$ values for the random samples in the four land use types studied (for number of individuals, species and plots covered, see Table 3.2). (NF- Natural forest, SF - Secondary forest, FG - Forest garden, AF - Agroforestry system)

\subsection{Leaf gas exchange}

\subsubsection{Photosynthesis}

The light saturated net photosynthesis rate per unit leaf area $\left(\mathrm{A}_{\max }\right.$-area $)$ varied fivefold among the 19 species studied, ranging from $3.6 \mu \mathrm{mol} \mathrm{m}^{-2} \mathrm{~s}^{-1}$ in Meliosma sumatrana in the natural forest, to $21.3 \mu \mathrm{mol} \mathrm{m} \mathrm{m}^{-2}$ in the secondary forest species Trema orientalis (Table 4.8, Figure 4.22 A). The three studied land use types differed significantly from each other. The natural forest mean reached only $62 \%$ of the mean rate of the agroforestry system $(7.6$ compared to $12.2 \mu \mathrm{mol} \mathrm{m} \mathrm{m}^{-2} \mathrm{~s}^{-1}$ ), which in turn showed a lower rate than the highly productive secondary forest (mean: $17.5 \mu \mathrm{mol} \mathrm{m} \mathrm{s}^{-1}$ ). The dark respiration rates measured at daytime at constant temperature $\left(28^{\circ} \mathrm{C}\right)$ varied between -2.35 and $-0.54 \mu \mathrm{mol} \mathrm{m}^{-2} \mathrm{~s}^{-1}$ (Table 4.8). The secondary forest mean was 52\% higher than the natural forest mean. Particularly high $\mathrm{R}_{\mathrm{d}}$ rates were found in Erythrina sp. in the agroforestry system $(-2.35 \mu \mathrm{mol}$ $\left.\mathrm{m}^{-2} \mathrm{~s}^{-1}\right)$.

\subsubsection{Maximum stomatal conductance for water vapour}

Maximum of stomatal conductance for water vapour $\left(\mathrm{g}_{\text {smax }}\right)$ as recorded in daily courses of $10-20$ leaves showed a wide range of species means, from the lowest mean observed in Meliosma sumatrana to the more than ten times higher rate in Mallotus mollissimus (68 and $734 \mathrm{mmol} \mathrm{s}^{-1} \mathrm{~m}^{-2}$, Table 4.8, Figure 4.22 B). The three studied land use types differed significantly concerning their mean $g_{s m a x}$ of their respective species $(p<0.05$, means: 367 (NF), 609 (SF), 520 (AF) $\mathrm{mmol} \mathrm{s}^{-1} \mathrm{~m}^{-2}$ ). Several groups of significantly different species 
Table 4.8 Means and standard deviation of light saturated net photosynthesis $\left(\mathrm{A}_{\max }\right)$, daytime dark respiration rate $\left(R_{d}\right)$ and maximum stomatal conductance for water vapour $\left(g_{\text {smax }}\right)$ in mature sun leaves of 19 species occurring in three land use types. Significantly different species means within each land use type are indicated by different letters $(\mathrm{p}<0.05)$. Capital letters are used for means on land use type level.

\begin{tabular}{|c|c|c|c|c|c|c|}
\hline \multirow{2}{*}{$\begin{array}{l}\text { Land use type } \\
\text { Species }\end{array}$} & \multicolumn{2}{|c|}{$\frac{A_{\max }}{\left(\mu \mathrm{mol} \mathrm{m}^{-2} \mathrm{~s}^{-1}\right)}$} & \multicolumn{2}{|c|}{ 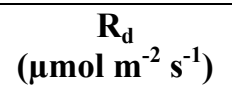 } & \multicolumn{2}{|c|}{$\begin{array}{c}\mathrm{g}_{\text {smax }} \\
\left(\mathrm{mmol} \mathrm{m}^{-2} \mathrm{~s}^{-1}\right)\end{array}$} \\
\hline & mean & sd & mean & sd & mean & sd \\
\hline \multicolumn{7}{|l|}{ Natural forest } \\
\hline Aglaia argentea & $8.5^{\mathrm{bc}}$ & 1.2 & $-0.86^{\mathrm{ab}}$ & 0.54 & $305^{\mathrm{b}}$ & 130 \\
\hline Pimelodendron amboinicum & $5.1^{\mathrm{cd}}$ & 1.0 & $-1.15^{\mathrm{ab}}$ & 0.47 & $248^{\mathrm{b}}$ & 36 \\
\hline Bishofia javanica & $9.6^{\mathrm{b}}$ & 3.7 & $-1.71^{\mathrm{b}}$ & 0.84 & $583^{\mathrm{a}}$ & 135 \\
\hline Cananga odorata & $13.2^{\mathrm{a}}$ & 2.4 & $-1.01^{\mathrm{ab}}$ & 0.37 & $547^{\mathrm{a}}$ & 206 \\
\hline Litsea sp.1 & $5.4^{\mathrm{cd}}$ & 2.0 & $-0.57^{\mathrm{a}}$ & 0.49 & $148^{\mathrm{b}}$ & 71 \\
\hline Meliosma sumatrana & $3.6^{\mathrm{d}}$ & 0.8 & $-0.54^{\mathrm{a}}$ & 0.20 & $68^{\mathrm{b}}$ & 49 \\
\hline Semecarpus forstenii & $9.1^{\mathrm{b}}$ & 1.9 & $-1.11^{\mathrm{ab}}$ & 0.41 & $198^{\mathrm{b}}$ & 63 \\
\hline Siphonodon celastrineus & $5.3^{\mathrm{cd}}$ & 2.5 & $-0.56^{\mathrm{a}}$ & 0.42 & $147^{\mathrm{b}}$ & 78 \\
\hline Mean & $7.5^{\mathrm{C}}$ & 3.7 & $-0.94^{\mathrm{A}}$ & 0.61 & $368^{\mathrm{C}}$ & 232 \\
\hline \multicolumn{7}{|l|}{ Secondary forest } \\
\hline Acalypha caturus & $16.7^{\mathrm{abc}}$ & 1.8 & $-1.46^{\mathrm{ab}}$ & 0.58 & $684^{\mathrm{ab}}$ & 134 \\
\hline Grewia glabra & $20.3^{\mathrm{a}}$ & 2.3 & $-1.87^{\mathrm{b}}$ & 0.49 & $625^{\mathrm{abc}}$ & 203 \\
\hline Hommalanthus populneus & $18.3^{\mathrm{ab}}$ & 1.8 & $-1.41^{\mathrm{ab}}$ & 0.44 & $532^{\mathrm{abc}}$ & 191 \\
\hline Macaranga hispida & $14.3^{\mathrm{abc}}$ & 2.6 & $-0.99^{\mathrm{ab}}$ & 0.34 & $457^{\mathrm{c}}$ & 131 \\
\hline Macaranga tanarius & $14.2^{\mathrm{abc}}$ & 2.8 & $-1.31^{\mathrm{a}}$ & 0.21 & $484^{\mathrm{bc}}$ & 190 \\
\hline Mallotus mollissimus & $15.9^{\mathrm{c}}$ & 2.6 & $-1.30^{\mathrm{ab}}$ & 0.35 & $734^{\mathrm{a}}$ & 115 \\
\hline Pipturus argentus & $20.2^{\mathrm{a}}$ & 2.2 & $-1.51^{\mathrm{ab}}$ & 0.26 & $676^{\mathrm{abc}}$ & 166 \\
\hline Trema orientalis & $20.3^{\mathrm{a}}$ & 1.9 & $-1.60^{\mathrm{ab}}$ & 0.56 & $682^{\mathrm{ab}}$ & 192 \\
\hline Mean & $17.5^{\mathrm{A}}$ & 3.3 & $-1.43^{\mathrm{B}}$ & 0.47 & $609^{\mathrm{A}}$ & 205 \\
\hline \multicolumn{7}{|l|}{ Agroforestry system } \\
\hline Erythrina sp. & $13.0^{\mathrm{b}}$ & 3.4 & $-2.35^{\mathrm{b}}$ & 1.31 & $646^{\mathrm{a}}$ & 149 \\
\hline Gliricidia sepium & $19.9^{\mathrm{a}}$ & 2.1 & $-1.82^{\mathrm{ab}}$ & 0.36 & $711^{\mathrm{a}}$ & 185 \\
\hline Theobroma cacao & $7.4^{\mathrm{c}}$ & 2.3 & $-0.90^{\mathrm{a}}$ & 0.55 & $205^{\mathrm{b}}$ & 71 \\
\hline Mean & $13.2^{\mathrm{B}}$ & 5.9 & $-1.69^{\mathrm{B}}$ & 1.02 & $521^{\mathrm{B}}$ & 267 \\
\hline
\end{tabular}

means were also found within these land use types. For example, Cananga odorata and Bischofia javanica had significantly higher $g_{\text {smax }}$ than the other six species studied in the natural forest. The two Euphorbiaceae species Macaranga hispida and Mallotus mollissimus represented the lowest and highest extremes, respectively, within the secondary forest, differing significantly from the other six secondary forest species. In the agroforestry 
system, the leguminous shadow tree species showed a threefold higher maximum stomatal conductance than Theobroma cacao.
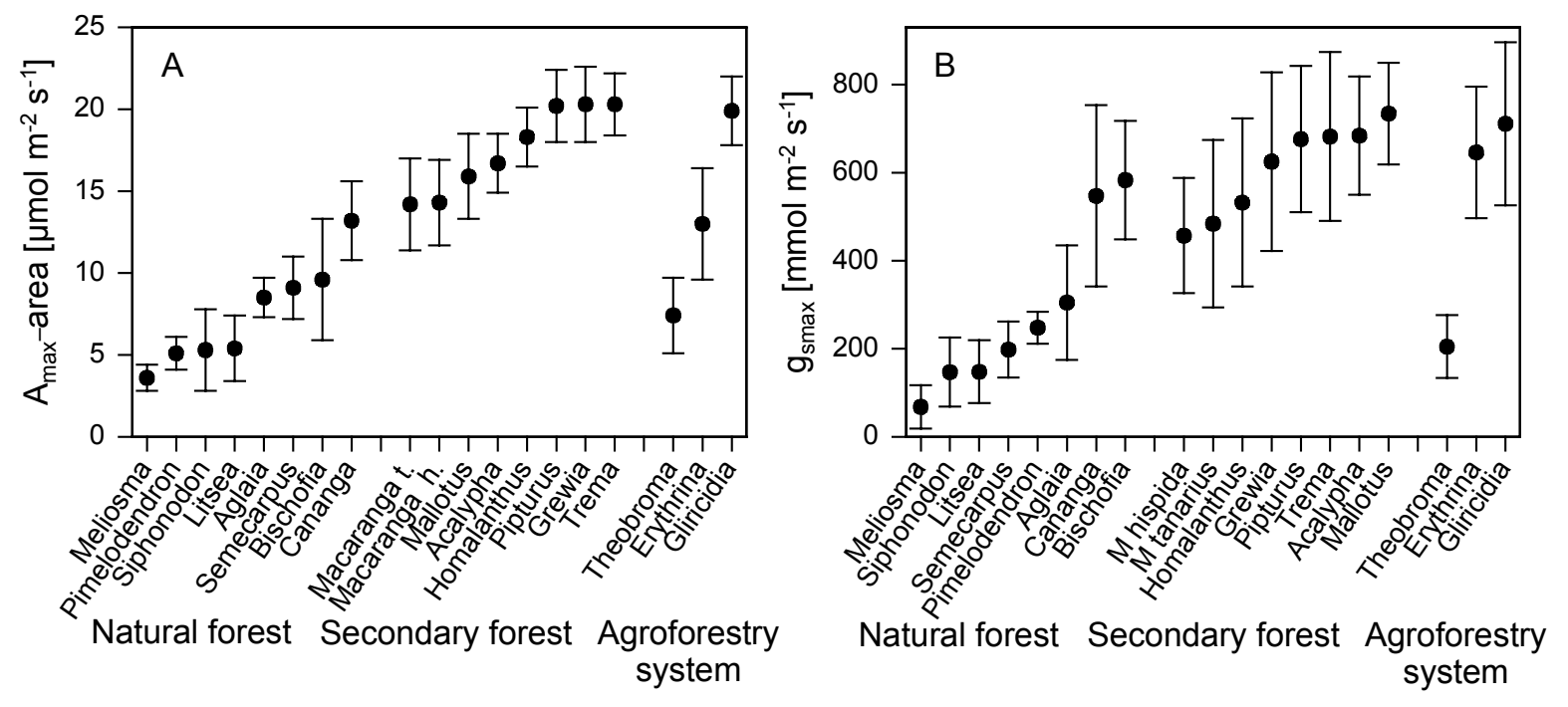

Figure 4.22 A. Means and standard deviation of light saturated net photosynthesis per leaf area $\left(\mathrm{A}_{\max }\right.$-area) in 19 species, covering three land use types, based on measurements on 10 mature sunlit leaves in at least two mature trees per species. B. Maximum stomatal conductance for water vapour ( $\mathrm{g}_{\text {smax }}$ ) of 19 species. Daily courses on between 10 and 20 mature sunlit leaves from 2 - 4 mature trees of each of the 19 species were measured and the peak $\mathrm{g}_{\mathrm{s}}$ values selected. Only values recorded at relative humidity levels $<80 \%$ were selected for calculation of the means and standard deviations of $g_{\text {smax }}$ presented.

\subsubsection{1 $g_{\text {smax }}$ as related to VPD}

Stomatal conductance $\left(g_{s}\right)$ showed a significant negative correlation with water vapour pressure deficit (VPD) in all secondary forest species studied, but only in two of the eight natural forest species. All three species in the agroforestry system showed a significant negative correlation (Table 4.9). The mean slope (b) of the relation $g_{s}=V P D * b+A$ was significantly larger in the eight secondary forest species $\left(-30.0 \pm 11.0\left(\mu \mathrm{mol} \mathrm{m} \mathrm{m}^{-2}\right) / \mathrm{Pa}\right)$ than the eight natural forest species $\left(-10.8 \pm 8.5\left(\mu \mathrm{mol} \mathrm{m}^{-2} \mathrm{~s}^{-1}\right) / \mathrm{Pa}\right)$, indicating a higher sensibility of stomatal response to VPD in the secondary forest species. Among the 13 species with significant humidity dependence of $\mathrm{g}_{\mathrm{s}}$, b showed a significant negative correlation with $g_{\text {smax }}\left(\mathrm{p}<0.01, \mathrm{r}^{2}=0.56, \mathrm{n}=13\right.$. Figure 4.23). 


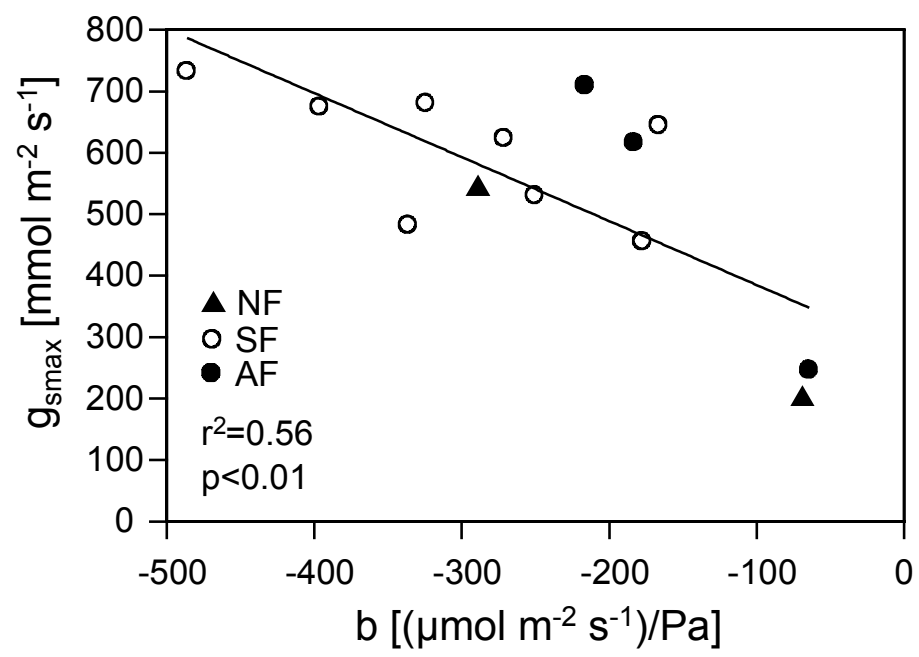

Figure 4.23 Maximal stomatal conductance $\left(g_{\text {smax }}\right)$ versus the slope (b-value) from $g_{s}$ versus VPD regressions for 13 species of NF, SF and AF. (Only b-values from significant $g_{s}-$ VPD regressions were considered. $\left.\mathrm{g}_{\mathrm{s}}=\mathrm{VPD} * \mathrm{~b}+\mathrm{A}\right)$.

Table 4.9 Correlation parameters for the dependence of stomatal conductance on water vapour pressure deficit $(V P D)$ in all 19 species studied $\left(g_{s}=V P D * b+A\right)$. Means of $b$ for each land use type presented, with different letters indicating significant differences. ( $\mathrm{n}$ - sample size, A - intercept, $\mathrm{b}$ - slope, $\mathrm{r}^{2}$ - degree of explanation, $\mathrm{p}-$ probability)

\begin{tabular}{|c|c|c|c|c|c|}
\hline Species & $\mathbf{n}$ & $\mathbf{A}$ & $\mathbf{b}$ & $\mathbf{r}^{2}(-)$ & $\mathbf{p}$ \\
\hline \multicolumn{6}{|l|}{ Natural forest } \\
\hline Aglaia argentea & 8 & 316 & -3.8 & 0.02 & 0.76 \\
\hline Bischofia javanica & 43 & 594 & -5.6 & 0.02 & 0.40 \\
\hline Cananga odorata & 30 & 984 & -28.9 & 0.59 & $<0.01$ \\
\hline Litsea sp.1 & 7 & 326 & -18.1 & 0.53 & 0.06 \\
\hline Meliosma sumatrana & 5 & 165 & -9.5 & 0.43 & 0.23 \\
\hline Pimelodendron aboinicum & 22 & 315 & -6.5 & 0.53 & $<0.01$ \\
\hline Semecarpus forstenii & 13 & 269 & -8.0 & 0.11 & 0.26 \\
\hline Siphonodon celastrineus & 11 & 233 & -6.0 & 0.14 & 0.24 \\
\hline & \multicolumn{5}{|c|}{$-10.8 \pm 8.5^{\mathrm{B}}$} \\
\hline \multicolumn{6}{|l|}{ Secondary forest } \\
\hline Acalypha caturus & 47 & 660 & -15.6 & 0.11 & 0.02 \\
\hline Grewia glabra & 66 & 907 & -27.2 & 0.31 & $<0.01$ \\
\hline Homalanthus populneus & 53 & 904 & -25.1 & 0.18 & $<0.01$ \\
\hline Mallotus mollissimus & 73 & 1150 & -48.7 & 0.53 & $<0.01$ \\
\hline Macaranga hispida & 66 & 638 & -17.8 & 0.40 & $<0.01$ \\
\hline Macaranga tanarius & 48 & 804 & -33.7 & 0.52 & $<0.01$ \\
\hline Pipturus argentus & 42 & 985 & -39.7 & 0.58 & $<0.01$ \\
\hline Trema orientalis & 55 & 1036 & -32.5 & 0.44 & $<0.01$ \\
\hline & \multicolumn{5}{|c|}{$-30.0 \pm 11.0^{\mathrm{A}}$} \\
\hline \multicolumn{6}{|l|}{ Agroforestry system } \\
\hline Erythrina sp. & 114 & 839 & -16.7 & 0.13 & $<0.01$ \\
\hline Gliricidia sepium & 105 & 966 & -21.7 & 0.62 & $<0.01$ \\
\hline \multirow[t]{2}{*}{ Theobroma cacao } & 101 & 293 & -6.9 & 0.19 & $<0.01$ \\
\hline & \multicolumn{5}{|c|}{$-15.1 \pm 7.5^{\mathrm{AB}}$} \\
\hline
\end{tabular}




\subsubsection{Water use efficiency}

Photosynthetic water use efficiency (WUE) as measured under light saturation, ambient $\mathrm{CO}_{2}$-concentration, $28^{\circ} \mathrm{C}$ leaf temperature and $1.4 \mathrm{kPa}$ VPD in the 19 in-depth studied species is presented in Figure 4.24.

The natural forest species showed the largest span of water use efficiency values, ranging from $34 \mu \mathrm{mol} \mathrm{mol}^{-1}$ achieved in Bischofia javanica to $84 \mu \mathrm{mol} \mathrm{mol}{ }^{-1}$ in Meliosma sumatrana. The eight secondary forest species showed a slightly shorter, somewhat lower range, from $28 \mu \mathrm{mol} \mathrm{mol}^{-1}$ (Grewia glabra) to $64 \mu \mathrm{mol} \mathrm{mol}^{-1}$ (Acalypha caturus). Water use efficiency rates of the agroforestry species were high, ranging from 53 (Gliricidia sepium) to $61 \mu \mathrm{mol} \mathrm{mol}{ }^{-1}$ (Theobroma cacao).

Natural forest mean was $52 \pm 17 \mu \mathrm{mol} \mathrm{mol}^{-1}$, secondary forest mean $45 \pm 12 \mu \mathrm{mol} \mathrm{mol}^{-1}$ and mean within the agroforestry system was $56 \pm 4 \mu \mathrm{mol} \mathrm{mol}^{-1}$. There was no significant difference between the means of the three land use types.

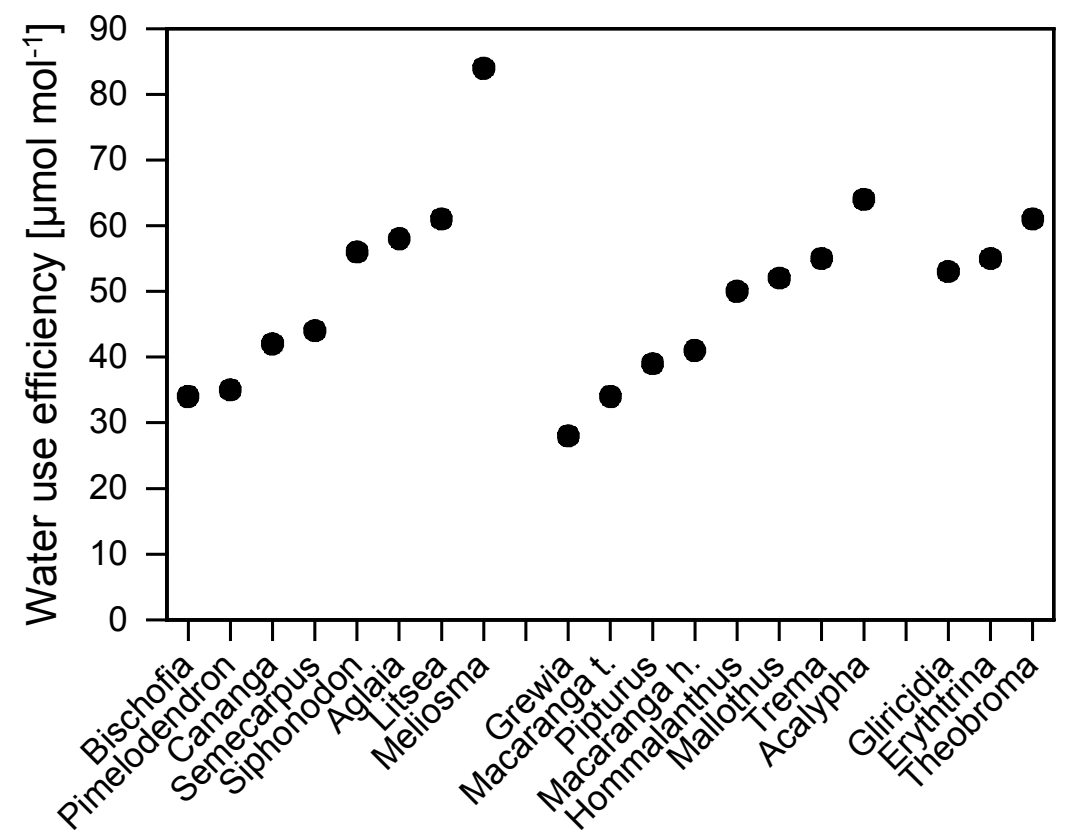

\section{Natural forest Secondary forest Agroforestry system}

Figure 4.24 Photosynthetic water use efficiency at light saturation $\left(2000 \mu \mathrm{mol} \mathrm{m}^{-2} \mathrm{~s}^{-1}\right.$, leaf temperature: $28^{\circ} \mathrm{C}$, VPD: $1.4 \mathrm{kPa}$, ambient $\mathrm{CO}_{2}$-concentration: $369 \pm 6 \mathrm{ppm}$ ) for each of the 19 species included in the physiological study, covering three different land use types. The values were measured with the Li-6400 system on 10-15 leaves from two trees per species. 


\subsubsection{The relation between $\delta^{13} \mathrm{C}$ and water use efficiency}

No significant correlation was found between $\delta^{13} \mathrm{C}$ and water use efficiency in the sample of 19 species covering three land use types $\left(p=0.18, r^{2}=0.10(-), n=19\right.$, Figure 4.25). The agroforestry system showed a significant negative relation between these parameters $\left(\mathrm{p}<0.01, \mathrm{r}^{2}=1(-), \mathrm{n}=3\right)$, whereas no correlation was found in the secondary ( $\mathrm{p}$ $\left.=0.21, \mathrm{r}^{2}=0.24(-), \mathrm{n}=8\right)$ or the natural forest samples $\left(\mathrm{p}=0.57, \mathrm{r}^{2}=0.06(-), \mathrm{n}=8\right)$.

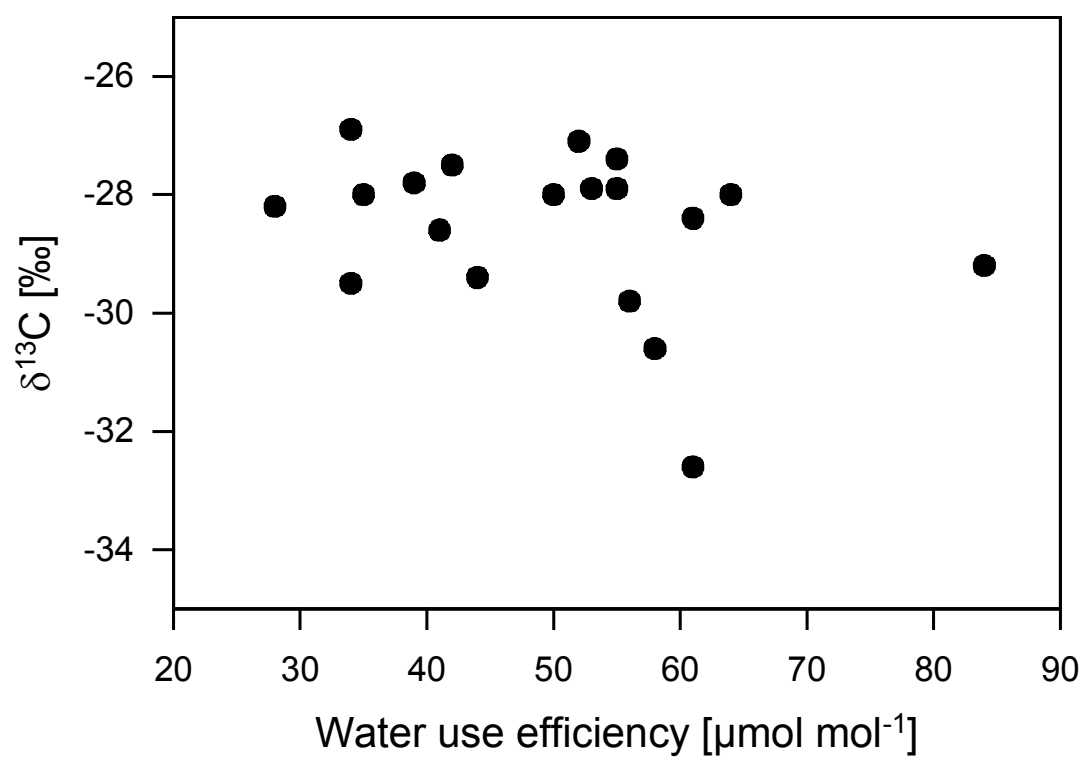

Figure $4.25 \delta^{13} \mathrm{C}$ plotted as a function of water use efficiency. No significant correlation was found in the sample of 19 species $\left(r^{2}=0.13(-), p=0.13, a=-26.9, b=-0.06\right)$.

\subsection{Canopy characterization by hemispheric photos}

\subsubsection{Leaf area index and related parameters}

The results of the HemiView-analysis are shown in Table 4.10. The leaf area index (LAI) differed significantly between the three land use types investigated. Natural forest had the highest mean $\left(3.6 \mathrm{~m}^{2} \mathrm{~m}^{-2}\right)$, as well as the broadest range (min. $2.5, \max .6 .8 \mathrm{~m}^{2} \mathrm{~m}^{-2}$ ), followed by secondary forest (mean: $2.5 \mathrm{~m}^{2} \mathrm{~m}^{-2}$, min.: 0.7 , max.: $3.9 \mathrm{~m}^{2} \mathrm{~m}^{-2}$ ). The lowest mean LAI $\left(1.3 \mathrm{~m}^{2} \mathrm{~m}^{-2}\right)$ and the most narrow range (min.: 0.8 , max.: $2.3 \mathrm{~m}^{2} \mathrm{~m}^{-2}$ ) was found in the agroforestry system.

The ground in the secondary forest plots was covered by a canopy to $73 \%$, which is close to the value of $77 \%$ in the natural forest. Only half (47\%) of the ground area was covered by canopy in the agroforestry system. Related to the ground cover parameter is the 
Table 4.10 Land use type means (with standard deviation) of leaf area index and the parameters visible sky and ground cover as obtained from analysis of the hemispheric photos. Each mean value was based on 30 photos (n) taken at randomly selected spots on $2-4$ plots per land use type. (NF-Natural forest, SF-Secondary forest and AF-Agroforestry system). The letters a-c indicate significantly different means $(\mathrm{p}<0.01)$.

\begin{tabular}{lrrrrrrr}
\hline & & $\begin{array}{c}\text { Leaf Area Index } \\
{\left[\mathbf{m}^{2} \mathbf{~ m}^{-2}\right]}\end{array}$ & \multicolumn{2}{c}{$\begin{array}{c}\text { Visible Sky } \\
{[\%]}\end{array}$} & \multicolumn{2}{c}{$\begin{array}{c}\text { Ground cover } \\
{[\%]}\end{array}$} \\
& N & mean & sd & mean & sd & mean & sd \\
\hline $\mathrm{NF}$ & 30 & $3.6^{\mathrm{a}}$ & 0.9 & $5.8^{\mathrm{c}}$ & 1.2 & $77^{\mathrm{a}}$ & 18 \\
$\mathrm{SF}$ & 30 & $2.5^{\mathrm{b}}$ & 0.6 & $11.0^{\mathrm{b}}$ & 8.3 & $73^{\mathrm{a}}$ & 27 \\
$\mathrm{AF}$ & 30 & $1.3^{\mathrm{c}}$ & 0.5 & $27.4^{\mathrm{a}}$ & 10.6 & $47^{\mathrm{b}}$ & 26 \\
\hline
\end{tabular}

visible sky-parameter, which refers to the relative proportion of gaps on the hemisphere and has also been referred to as canopy openness. This parameter also differed significantly between the three land use types, indicating 5.8\% gap area in the natural forest (min.: $3.0 \%$, max.: $7.9 \%$ ), $11 \%$ in the secondary forest (min.: $3.3 \%$, max.: $42.4 \%$ ), and nearly one third $(27 \%)$ of the hemispheric view was open sky in the agroforestry system (min.: $4.0 \%$, max.: $40.0 \%)$.

\subsubsection{Mean leaf angle}

Table 4.11 shows mean leaf angles for three land use types. The first set of means are averages of the visually observed leaf angles of eight NF-species, eight SF-species and three AF-species, respectively, and the second set are the mean leaf angle values calculated in the HemiView-analysis (MLA). Since the tip-petiole direction was considered only for the visually observed leaves, generating a leaf angle scale from $0^{\circ}-180^{\circ}$, where $0^{\circ}$ was vertically upwards, these values had to be transformed before comparison with the MLA values, which were defined on a $0^{\circ}-90^{\circ}$ scale, disregarding the tip-petiole direction.

As can be seen in Table 4.11, the two generated means for SF are quite coherent, both being around $45^{\circ}$. The means of the visually observed species in the natural forest $\left(30^{\circ}\right)$ and the agroforestry system $\left(15^{\circ}\right)$ indicate more horizontally orientated leaves than the overall estimates of $54^{\circ}$ and $50^{\circ}$ suggested by the MLA for these land use types. Because all other investigated parameters in this study refer to mature sun leaves, and because the petiole direction can be interesting in this context, the visually observed angles on the scale from $0^{\circ}$ to $180^{\circ}$ will primarily be taken into account in further analyses.

Leaf angles of 19 species are listed in Appendix 6. 
Table 4.11 Means of the leaf angles visually observed and the mean leaf angles (MLA) estimated from the HemiView-analysis. The corresponding midrib angles are the transformed value of the observed leaf angles that can be compared with MLA. (h) - horizontal, (v) - vertical, * (number of observations underlying the mean $=30)$

\begin{tabular}{|c|c|c|c|c|c|c|}
\hline & \multirow{3}{*}{$\begin{array}{l}\text { No. leaves } \\
\text { observed }\end{array}$} & \multicolumn{3}{|c|}{ Visually observed leaves } & \multicolumn{2}{|c|}{ HemiView } \\
\hline & & \multicolumn{2}{|c|}{$\begin{array}{c}\text { Observed } \\
\text { leaf angle } \\
\left(0^{\circ}(v)-180^{\circ}(v)\right) \\
{\left[{ }^{\circ}\right]}\end{array}$} & \multirow[t]{2}{*}{$\begin{array}{l}\text { Corresponding } \\
\text { midrib angle } \\
\left(0^{\circ}(\mathrm{h})-\mathbf{9 0}^{\circ}(\mathrm{v})\right) \\
{\left[{ }^{\circ}\right]}\end{array}$} & \multicolumn{2}{|c|}{$\begin{array}{c}\text { MLA } \\
\left(0^{\circ}(\mathrm{h})-90^{\circ}(\mathrm{v})\right) \\
{\left[{ }^{\circ}\right]}\end{array}$} \\
\hline & & mean & sd & & mean & sd \\
\hline NF & 240 & 116 & 27 & 30 & $54 *$ & 17 \\
\hline SF & 240 & 138 & 25 & 48 & $41 *$ & 20 \\
\hline $\mathrm{AF}$ & 90 & 95 & 17 & 15 & $50 *$ & 21 \\
\hline
\end{tabular}

\subsubsection{The relationship between LAI and leaf traits}

As illustrated in Figure 4.26, random sample averages at plot level for SLA and leaf N concentration showed significant negative correlations with LAI in a sample comprising eight plots of three different land use types. Including nine plots only yielded tendencies because of extreme standard deviation for the LAI-value achieved on one of the agroforestry plots (see Figure 4.27 E, F). For the number of species and individuals included in each plot sample, see Table 3.1.

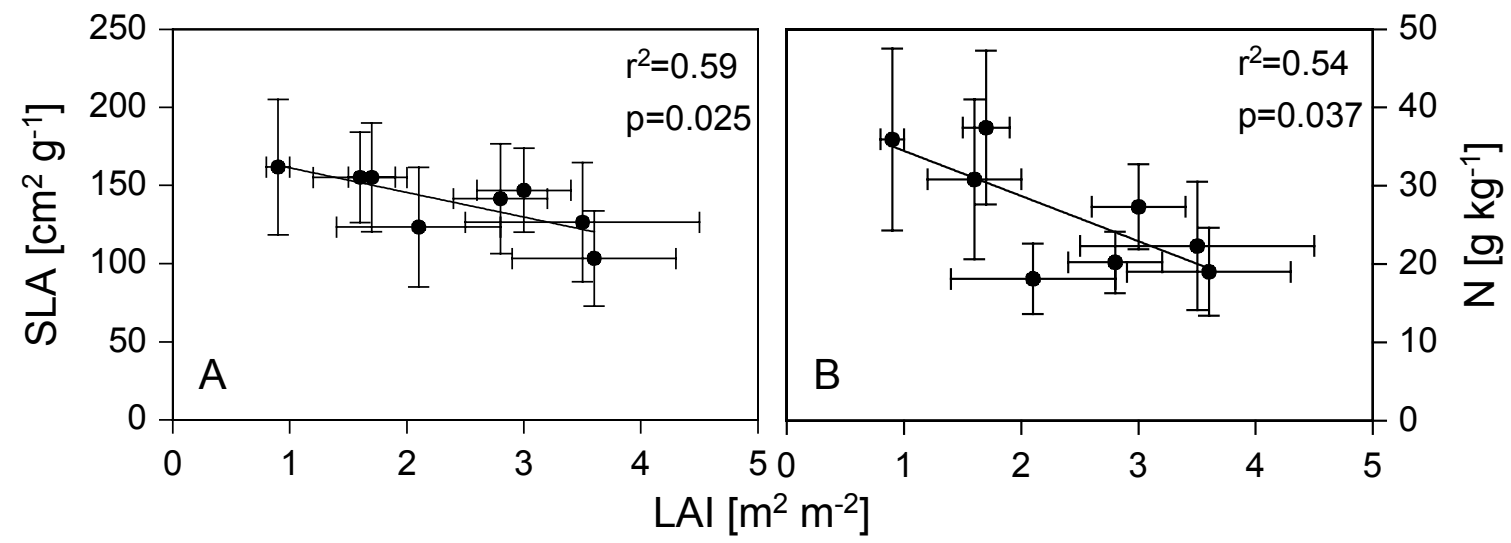

Figure 4.26 Relationships between LAI and SLA (A) and foliar N concentration (B) in random samples of eight plots, covering three different land use types. For the number of species and individuals included in each plot sample, see Table 3.1.

However, considering plots of secondary forest only, a positive correlation between SLA and LAI was found (Figure 4.27 C; $p<0.01, \mathrm{r}^{2}=1$ ). The mean $\mathrm{N}$ concentration of the secondary forest plots did not show any correlation with LAI (Figure 4.27 D; $p=0.39, r^{2}=$ 
0.65). The two studied natural forest sites were very similar, concerning LAI, as well as SLA and N. No correlation analysis could be conducted in this sample (Figure 4.27 A, B). The agroforestry plot means varied greatly for LAI, but were very homogenous in terms of $\mathrm{N}$ concentration and SLA (Figure 4.27 E, F). This land use type did not show any correlation between LAI and any of the two leaf traits either.

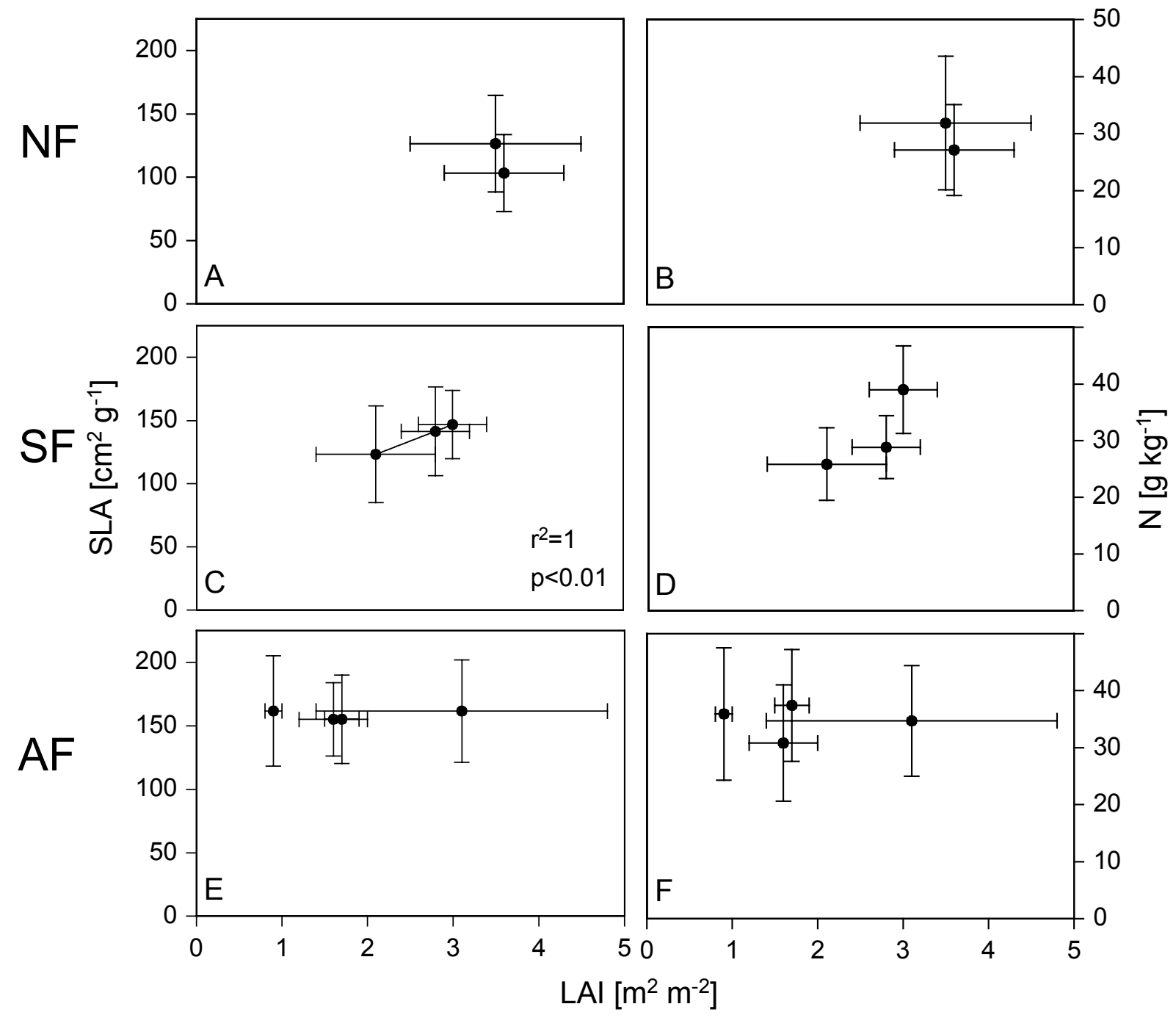

Figure 4.27 A-F. Leaf area index (LAI) versus specific leaf area (SLA) and leaf N concentration in random samples at plot level, presented for each land use type separately (NF - Natural forest, SF Secondary forest, AF - Agroforestry system.) A \& B. No correlation analysis was possible in the natural forest, since LAI was measured on two NF plots only. C. SLA versus LAI in a sample of three secondary forest plots. D. Leaf N concentration versus SLA showed a non significant, positive trend in the secondary forest $\left(r^{2}=0.64, p=0.39\right)$. E \& F. LAI versus SLA (E) and leaf $N$ concentration $(\mathrm{F})$ in the sample of four agroforestry system plots. 


\subsection{Relationships between different leaf attributes}

\subsubsection{Leaf morphology versus chemical parameters}

\subsubsection{1 $\delta^{13}$ C versus other leaf attributes}

$\delta^{13} \mathrm{C}$ showed weak but significant correlations with leaf size (positive) and length-width ratio (negative) in the complete random sample, comprising four land use types, as well as within the secondary forest sample. Looking at some families and species, $\delta^{13} \mathrm{C}$ showed a strong, negative correlation to the leaf length-width ratio in the Euphorbiaceae and Urticaceae families (Figure 4.28 B, C).
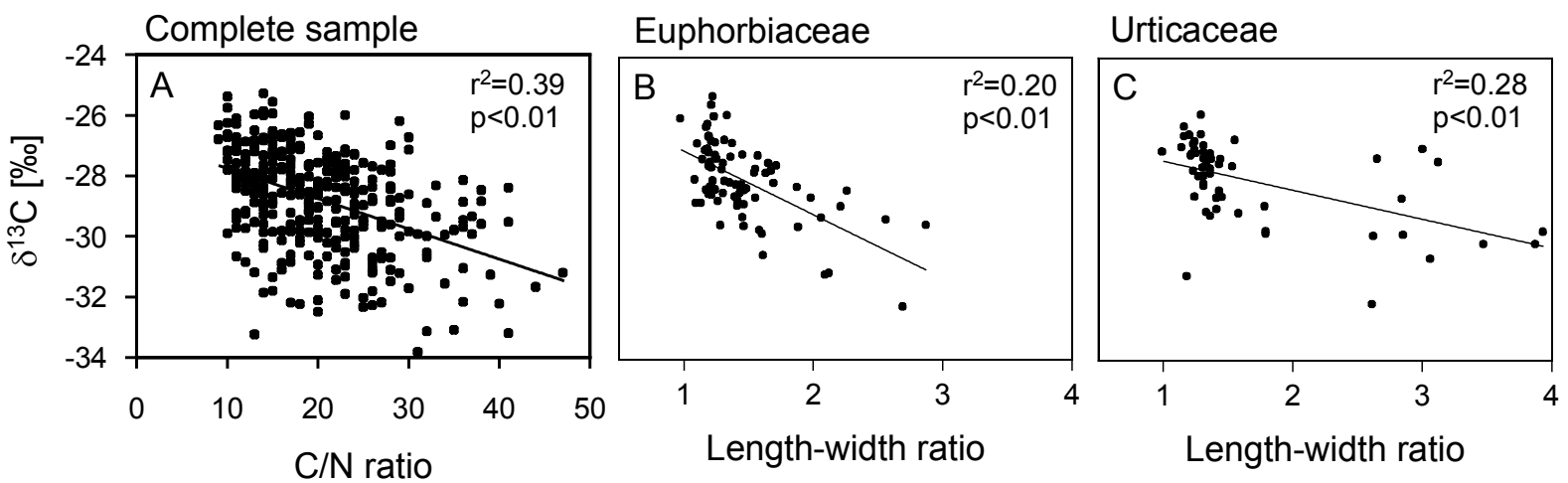

Figure 4.28 A. $\delta^{13} \mathrm{C}$ versus $\mathrm{C} / \mathrm{N}$ ratio in the complete random sample, comprising trees from four different land use types (for specification of random sample, see Table 3.2). B \& C. $\delta^{13} \mathrm{C}$ versus leaf length-width ratio in a sample of individuals from two large-leaved families. The Euphorbiaceae sample is based on 85 individuals of 10 species (B) and the Urticaceae on 57 individuals of 10 species $(\mathrm{C})$.

A positive correlation of $\delta^{13} \mathrm{C}$ to SLA was detected in the complete random sample of four land use types and in the agroforestry system, whereas the family Urticaceae showed a negative correlation between $\delta^{13} \mathrm{C}$ and SLA. A negative correlation with total carbon concentration was found in the complete random sample and in the natural forest.

$\delta^{13} \mathrm{C}$ also correlated positively with $\mathrm{N}$ and $\mathrm{P}$ in certain samples. Correlations to $\mathrm{N}$ were found in the complete random sample, the natural and secondary forests, the agroforestry system and within the families Euphorbiaceae and Fabaceae. Correlations to P were detected in the complete random sample of four land use types, within the secondary forest, in the Euphorbiaceae and Urticaceae families and in the species Litsea sp.1. Figure 4.28 A shows the relation between $\delta^{13} \mathrm{C}$ and $\mathrm{C} / \mathrm{N}$ ratio in the complete random sample, which yielded a higher $\mathrm{r}^{2}$-value than correlations with $\mathrm{C}$ or $\mathrm{N}$ in that sample. A strong correlation between 
total carbon and $\delta^{13} \mathrm{C}$ was observed in the late-successional species Litsea sp.1 (Lauraceae), which was the species with the most negative $\delta^{13} \mathrm{C}$ among all species investigated.

All correlation parameters for the relation between $\delta^{13} \mathrm{C}$ and other leaf traits in different samples are given in Table 4.12 and Appendix 3.

\subsubsection{SLA versus other leaf attributes}

SLA showed a negative correlation with leaf length-width ratio in the complete random sample, the natural forest and agroforestry system, as well as within the families Fabaceae and Euphorbiaceae. In contrast, the predominantly late-successional family Lauraceae and the widespread, but mainly pioneer-species family, Urticaceae showed positive correlations between SLA and length-width ratio.

A significant negative relation of SLA to leaf size was found in the complete random sample, the agroforestry system, and the families Lauraceae and Urticaceae.

Further, there was a clear positive correlation between SLA and leaf phosphorus and, more pronounced, nitrogen concentrations in the complete random sample, within each of

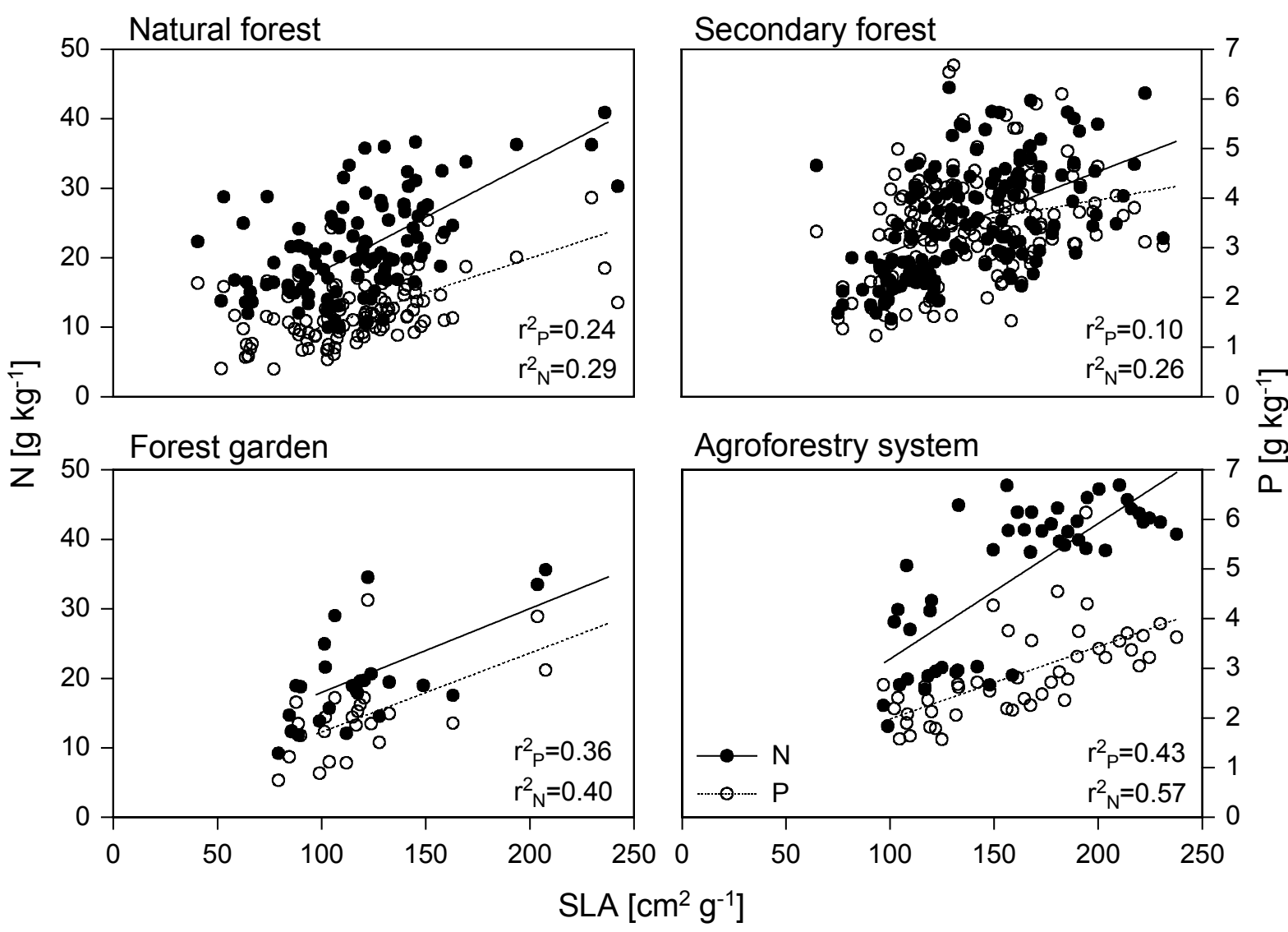

Figure 4.29 Leaf nitrogen and phosphorus concentrations versus specific leaf area (SLA) of trees in random samples from four different land use types. For specification of the random samples, see Table 3.2. ( $\mathrm{p}<0.01$ in all eight correlations) 
Table 4.12 Correlation parameters $\mathrm{r}^{2}$ (italic, above) and $\mathrm{p}$ (below) for Pearson's correlation analysis of leaf size, specific leaf area (SLA) versus a number of morphological and chemical leaf traits in random samples of four different land use types and the complete random sample, comprising all four land use types studied. Negative correlations are marked with (-) behind the $\mathrm{r}^{2}$ value. $\mathrm{p}$-values $<0.05$ are marked bold. (No. ind. - Number of individuals, Compl. - Complete random sample, NF - Natural forest, SF - Secondary forest, FG - Forest garden, AF - Agroforestry system, LW - length-width ratio, SLA - specific leaf area)

\begin{tabular}{|c|c|c|c|c|c|c|c|c|c|c|c|c|c|c|c|}
\hline \multirow[t]{2}{*}{ No. ind. } & $\begin{array}{c}\text { Compl. } \\
354 \\
\end{array}$ & $\begin{array}{l}\text { NF } \\
119 \\
\end{array}$ & $\begin{array}{c}\text { SF } \\
160 \\
\end{array}$ & $\begin{array}{c}\text { FG } \\
25 \\
\end{array}$ & $\begin{array}{c}\text { AF } \\
49 \\
\end{array}$ & $\begin{array}{c}\text { Compl. } \\
354 \\
\end{array}$ & $\begin{array}{l}\text { NF } \\
119 \\
\end{array}$ & $\begin{array}{l}\text { SF } \\
160 \\
\end{array}$ & $\begin{array}{c}\text { FG } \\
25 \\
\end{array}$ & $\begin{array}{c}\text { AF } \\
49 \\
\end{array}$ & $\begin{array}{c}\text { Compl. } \\
354 \\
\end{array}$ & $\begin{array}{l}\text { NF } \\
119 \\
\end{array}$ & $\begin{array}{c}\text { SF } \\
160 \\
\end{array}$ & $\begin{array}{c}\text { FG } \\
25 \\
\end{array}$ & $\begin{array}{c}\text { AF } \\
49 \\
\end{array}$ \\
\hline & \multicolumn{5}{|c|}{ Leaf size } & \multicolumn{5}{|c|}{ SLA } & \multicolumn{5}{|c|}{$\delta^{13} \mathrm{C}$} \\
\hline Leaf size & & & & & & $\begin{array}{r}0.01(-) \\
\mathbf{0 . 0 4}\end{array}$ & $\begin{array}{r}0.03(-) \\
0.11\end{array}$ & $\begin{array}{r}0.005(-) \\
0.35\end{array}$ & $\begin{array}{r}0.002(-) \\
0.86\end{array}$ & $\begin{array}{r}0.25(-) \\
<\mathbf{0 . 0 1}\end{array}$ & $\begin{array}{l}0.02 \\
\mathbf{0 . 0 1}\end{array}$ & $\begin{array}{r}0.002 \\
0.72\end{array}$ & $\begin{array}{r}0.05 \\
<\mathbf{0 . 0 1}\end{array}$ & $\begin{array}{r}0.002 \\
0.84\end{array}$ & $\begin{array}{r}0.05(-) \\
0.14\end{array}$ \\
\hline \multirow[t]{2}{*}{ LW } & $<0.001$ (-) & 0.05 & $0.11(-)$ & 0.004 & $0.11(-)$ & $0.05(-)$ & $0.05(-)$ & $0.02(-)$ & $0.12(-)$ & $0.11(-)$ & $0.04(-)$ & 0.001 & $0.08(-)$ & 0.02 & $0.02(-)$ \\
\hline & 0.66 & 0.02 & $<0.01$ & 0.78 & 0.04 & $<0.01$ & 0.03 & 0.06 & 0.08 & 0.02 & $<0.01$ & 0.74 & $<0.01$ & 0.53 & 0.29 \\
\hline \multirow[t]{2}{*}{ SLA } & $0.01(-)$ & $0.03(-)$ & 0.005 (-) & $0.002(-)$ & $0.25(-)$ & & & & & & 0.08 & 0.005 & 0.002 & $0.02(-)$ & 0.13 \\
\hline & 0.04 & 0.11 & 0.33 & 0.86 & $<0.01$ & & & & & & $<0.01$ & 0.45 & 0.62 & 0.51 & 0.01 \\
\hline \multirow[t]{2}{*}{$\mathrm{Ca}$} & 0.005 & 0.04 & $0.002(-)$ & $0.10(-)$ & $0.04(-)$ & 0.002 (-) & 0.03 & $0.03(-)$ & 0.07 & $0.06(-)$ & 0.02 & 0.01 & 0.07 & 0.10 & $0.10(-)$ \\
\hline & 0.17 & 0.05 & 0.63 & 0.08 & 0.19 & 0.35 & 0.08 & 0.03 & 0.22 & 0.09 & $<0.01$ & 0.24 & $<0.01$ & 0.13 & 0.02 \\
\hline \multirow[t]{2}{*}{$\mathbf{K}$} & $<0.001$ (-) & 0.03 & $<0.001(-)$ & $0.06(-)$ & $0.21(-)$ & 0.04 & 0.06 & $<0.001$ (-) & 0.13 & 0.22 & 0.01 & $<0.001$ & 0.01 & 0.21 & 0.27 \\
\hline & 0.68 & 0.09 & 0.93 & 0.27 & $<0.01$ & $<0.01$ & $<0.01$ & 0.96 & 0.08 & $<0.01$ & 0.05 & 0.8 & 0.2 & 0.02 & $<0.01$ \\
\hline \multirow[t]{2}{*}{ Mg } & 0.001 & 0.05 & 0.002 & $0.08(-)$ & 0.10 & $0.02(-)$ & 0.01 & $0.02(-)$ & $<0.001$ & $0.18(-)$ & $0.03(-)$ & 0.02 & 0.01 & 0.38 & $0.22(-)$ \\
\hline & 0.54 & 0.02 & 0.66 & 0.17 & 0.02 & $<0.01$ & 0.23 & 0.11 & 0.97 & $<0.01$ & $<0.01$ & 0.1 & 0.16 & $<0.01$ & $<0.01$ \\
\hline \multirow[t]{2}{*}{$\mathbf{P}$} & 0.008 & 0.01 & $<0.001$ & $0.06(-)$ & $0.17(-)$ & 0.24 & 0.24 & 0.10 & 0.36 & 0.43 & 0.27 & 0.006 & 0.01 & $0.001(-)$ & 0.25 \\
\hline & 0.09 & 0.22 & 0.88 & 0.26 & $<0.01$ & $<0.01$ & $<0.01$ & $<0.01$ & $<0.01$ & $<0.01$ & $<0.01$ & 0.37 & 0.13 & 0.89 & $<0.01$ \\
\hline \multirow[t]{2}{*}{$\mathbf{N}$} & $0.006(-)$ & $<0.001$ (-) & 0.008 & $0.07(-)$ & $0.72(-)$ & 0.42 & 0.29 & 0.26 & 0.40 & 0.57 & 0.16 & 0.04 & 0.11 & 0.006 & 0.22 \\
\hline & 0.13 & 0.84 & 0.27 & 0.21 & $<0.01$ & $<0.01$ & $<0.01$ & $<0.01$ & $<0.01$ & $<0.01$ & $<0.01$ & 0.03 & $<0.01$ & 0.71 & $<0.01$ \\
\hline \multirow[t]{2}{*}{ C } & 0.03 (-) & $0.005(-)$ & $0.04(-)$ & $0.02(-)$ & $0.27(-)$ & 0.01 & $0.004(-)$ & 0.03 & $0.17(-)$ & 0.14 & $0.02(-)$ & $0.05(-)$ & $0.01(-)$ & $0.01(-)$ & 0.01 \\
\hline & $<0.01$ & 0.45 & 0.02 & 0.5 & $<0.01$ & 0.07 & 0.56 & 0.03 & 0.04 & $<0.01$ & 0.01 & 0.01 & 0.11 & 0.63 & 0.5 \\
\hline \multirow[t]{2}{*}{$\mathbf{C} / \mathbf{N}$} & $0.001(-)$ & 0.005 (-) & $0.02(-)$ & 0.004 & 0.68 & $0.34(-)$ & $0.21(-)$ & $0.26(-)$ & $0.39(-)$ & $0.49(-)$ & $0.20(-)$ & $0.08(-)$ & $0.18(-)$ & $0.03(-)$ & $0.12(-)$ \\
\hline & 0.63 & 0.49 & 0.05 & 0.76 & $<0.01$ & $<0.01$ & $<0.01$ & $<0.01$ & $<0.01$ & $<0.01$ & $<0.01$ & $<0.01$ & $<0.01$ & 0.39 & 0.01 \\
\hline \multirow[t]{2}{*}{$\delta^{13} \mathrm{C}$} & 0.02 & 0.001 & 0.05 & 0.002 & $0.05(-)$ & 0.08 & 0.005 & 0.002 & $0.02(-)$ & 0.10 & & & & & \\
\hline & 0.01 & 0.72 & $<0.01$ & 0.84 & 0.14 & $<0.01$ & 0.46 & 0.63 & 0.51 & 0.01 & & & & & \\
\hline \multirow[t]{2}{*}{$\mathbf{N} / \mathbf{P}$} & $0.04(-)$ & $0.03(-)$ & 0.002 & $0.001(-)$ & $0.37(-)$ & $0.006(-)$ & $0.008(-)$ & 0.02 & $0.02(-)$ & 0.01 & $0.06(-)$ & 0.02 & 0.04 & 0.008 & $0.002(-)$ \\
\hline & $<0.01$ & 0.11 & 0.63 & 0.88 & $<0.01$ & 0.14 & 0.32 & 0.06 & 0.55 & 0.49 & $<0.01$ & 0.09 & 0.01 & 0.66 & 0.77 \\
\hline \multirow[t]{2}{*}{$\mathbf{C} / \mathbf{P}$} & $0.02(-)$ & $0.03(-)$ & $0.01(-)$ & 0.002 & 0.08 & $0.26(-)$ & $0.23(-)$ & $0.10(-)$ & $0.29(-)$ & $0.42(-)$ & $0.26(-)$ & $0.008(-)$ & $0.04(-)$ & $0.01(-)$ & $0.29(-)$ \\
\hline & $<0.01$ & 0.09 & 0.2 & 0.83 & 0.05 & $<0.01$ & $<0.01$ & $<0.01$ & $<0.01$ & $<0.01$ & $<0.01$ & 0.32 & $<0.01$ & 0.59 & $<\mathbf{0 . 0 1}$ \\
\hline \multirow[t]{2}{*}{$\delta^{15} \mathbf{N}$} & $<0.001$ & $0.006(-)$ & 0.003 & 0.05 (-) & 0.25 & $<0.001$ (-) & $<0.001$ & 0.005 & 0.05 & $0.24(-)$ & 0.006 & $0.02(-)$ & 0.05 & 0.14 & $0.06(-)$ \\
\hline & 0.7 & 0.41 & 0.55 & 0.26 & $<0.01$ & 0.97 & 0.84 & 0.36 & 0.27 & $<0.01$ & 0.14 & 0.15 & $<0.01$ & 0.05 & 0.1 \\
\hline
\end{tabular}


the four land use types (Figure 4.29). This relation was also visible in the families Euphorbiaceae and Lauraceae. Leaf phosphorus and nitrogen concentrations showed a strong interrelationship in all samples $\left(\mathrm{r}^{2}=0.51(\mathrm{NF}), \mathrm{r}^{2}=0.53(\mathrm{SF}), 0.28\right.$ (complete sample), $\mathrm{p}<0.01)$.

Parameters for all correlations between SLA and other leaf traits in different samples are given in Table 4.12 and Appendix 2.

\subsubsection{Leaf size versus other leaf attributes}

Leaf size was found negatively correlated to specific leaf area in the complete random sample, the agroforestry system and in the Urticaceae and Lauraceae families, but not within natural or secondary forest (Table 4.12, Appendix 1). Generally, leaf size was found closer related to length-width ratio than to specific leaf area in the various samples studied. Leaf size was negatively correlated to length-width ratio in SF and AF (Figure 4.30) and within four of the five most frequent families, indicating that round leaves were generally larger

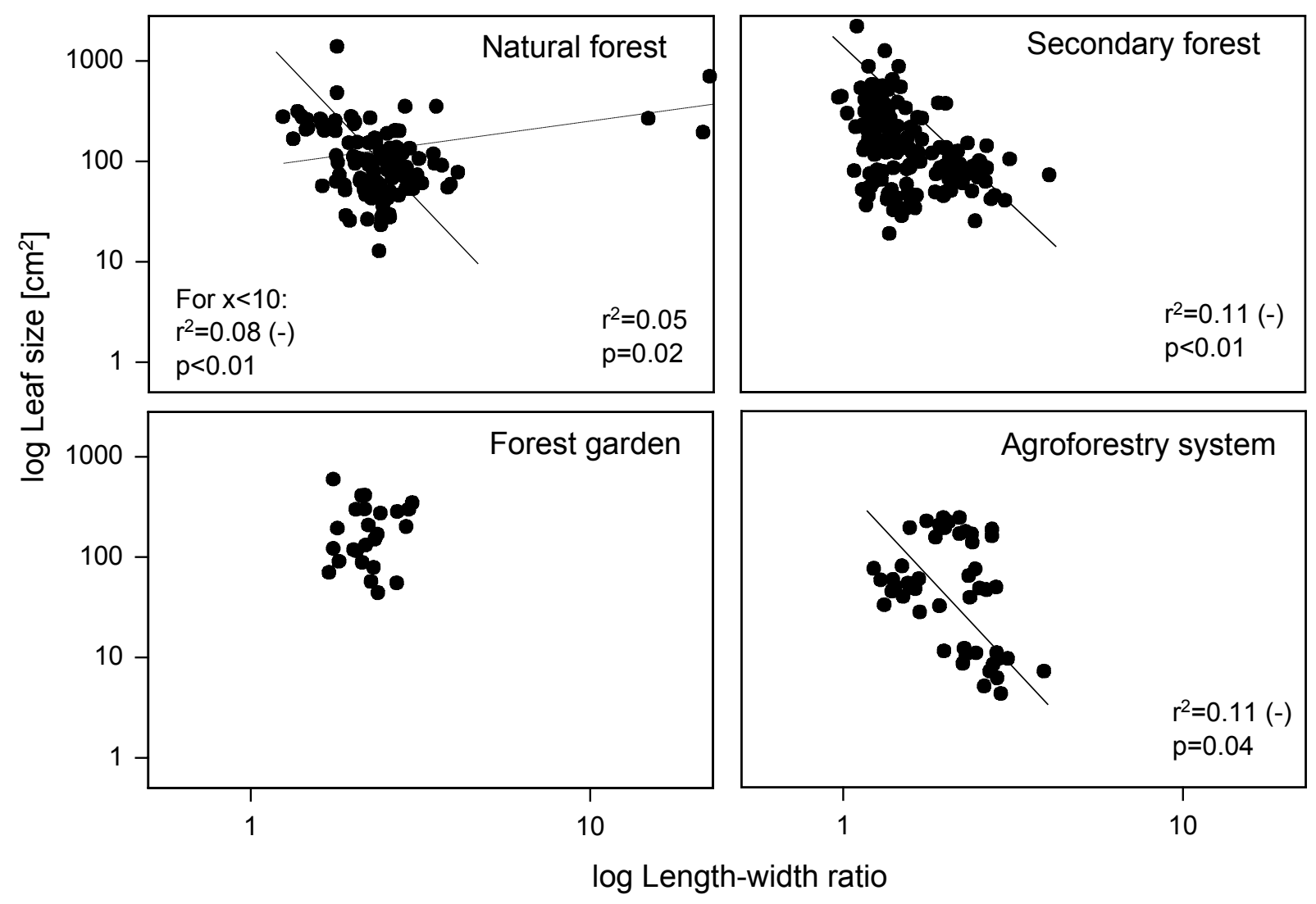

Figure 4.30 Leaf size versus leaf length-width ratio in the random samples of four different land use types. Including three species with very large length-width ratios in the natural forest gave a positive correlation within that land use type, whereas excluding them gave a negative. For numbers of individuals and species included, see Table 3.2. 
than lanceolate leaves. In the natural forest leaf size and leaf length-width ratio showed a negative correlation only if three species with very high length-width ratios were excluded, whereas including them gave a positive relation (Figure 4.30, Table 4.12, Appendix 1).

Leaf size further showed a negative relation to total carbon concentration in the complete random sample, SF and AF. Significant correlations between nitrogen concentration and leaf size were only found in the agroforestry system and within the family Lauraceae. These correlations were strong and negative. The $\mathrm{N} / \mathrm{P}$ ratio though, was shown to decrease with increasing leaf sizes in the complete random sample.

Leaf size showed a negative correlation with calcium in the two agroforestry species Theobroma cacao and Gliricidia sepium.

Parameters for all correlations between leaf size and other leaf traits in different samples are presented in Table 4.12 and Appendix 1.

\subsubsection{Relations between leaf physiology and morphological or chemical parameters}

Light saturated net photosynthetic rate, $A_{\max }$, can be expressed per unit leaf area $\left(A_{\max }{ }^{-}\right.$ area) or per unit leaf mass ( $\mathrm{A}_{\max }$-mass). These two measures yielded partly different results when used for regression analysis and correlations with morphological and chemical parameters. The results of these correlation analyses, as well as for maximum stomatal conductance ( $\left.g_{\text {smax }}\right)$, versus morphological and chemical leaf traits are listed in Table 4.13. The analyses were not conducted for the agroforestry system data because of its low species number.

\subsubsection{Correlation between $A_{\max }$ and morphological or chemical leaf traits}

One of the most important differences between the correlations found for $\mathrm{A}_{\max }$-mass and those for $\mathrm{A}_{\max }$-area was the remarkable dependence of $\mathrm{A}_{\max }$-area on leaf size among the secondary forest species. The larger the leaves, the lower their photosynthetic net rate per area unit $\left(r^{2}=0.56, p=0.03\right.$, Figure $\left.4.31 \mathrm{~B}\right)$. There was also a clear trend indicating a positive relation between length-width ratio and $\mathrm{A}_{\max }$-area among the same species $(\mathrm{p}=$ $\left.0.05, \mathrm{r}^{2}=0.49\right)$. $\mathrm{A}_{\max }$-mass and $\mathrm{A}_{\max }$-area were both positively related to SLA in the 19species sample $\left(\mathrm{r}^{2}=0.76, \mathrm{p}<0.01\right.$ and $\mathrm{r}^{2}=0.42, \mathrm{p}<0.01$, Figure $\left.4.32 \mathrm{~A}\right)$. For $\mathrm{A}_{\max }$-mass this was also true in each of the two land use types analysed.

An important result of this study was that $\mathrm{A}_{\max }$ showed a closer correlation to leaf $\mathrm{P}$ concentration ( $\mathrm{A}_{\max }$-mass versus P-mass: $\left.\mathrm{r}^{2}=0.74, \mathrm{p}<0.01\right)$, than to $\mathrm{N}$ concentration per unit mass $\left(\mathrm{N}\right.$-mass: $\left.\mathrm{r}^{2}=0.66, \mathrm{p}<0.01\right)$ if all 19 species were taken into account (Table 4.13, Figure $4.32 \mathrm{~B}$ ). At the land use level though, $\mathrm{A}_{\max }$-mass was found correlating with $\mathrm{N}$-mass 
Table 4.13 Correlation between leaf morphological and physiological parameters in a sample of all 19 species studied and the eight natural forest species and the eight secondary forest species, respectively. p-values $<0.05$ are marked in bold. $(\mathrm{n}=$ number of species, $(-)=$ negative relationship)

\begin{tabular}{|c|c|c|c|c|c|c|}
\hline \multirow[t]{2}{*}{ Correlation parameters } & \multicolumn{2}{|c|}{$\begin{array}{l}\text { All species } \\
(n=19)\end{array}$} & \multicolumn{2}{|c|}{$\begin{array}{c}\text { Natural forest } \\
\text { species } \\
(n=8)\end{array}$} & \multicolumn{2}{|c|}{$\begin{array}{c}\text { Secondary forest } \\
\text { species } \\
(\mathbf{n}=\mathbf{8})\end{array}$} \\
\hline & $\mathbf{r}^{2}$ & p & $\mathbf{r}^{2}$ & $\mathbf{p}$ & $\mathbf{r}^{2}$ & p \\
\hline $\begin{array}{l}A_{\max }-\text { area } \\
\text { - versus: } \\
\text { - Leaf size } \\
\text { - Length-width ratio } \\
\text { - SLA } \\
\text { - Leaf angle } \\
\text { - Ca } \\
\text { - K } \\
\text { - Mg } \\
\text { - P-mass } \\
\text { - P-area } \\
\text { - N-mass } \\
\text { - N-area } \\
\text { - } \delta^{13} \mathrm{C}\end{array}$ & $\begin{array}{l}0.01 \\
0.17(-) \\
0.42 \\
0.002(-) \\
0.28 \\
0.04 \\
0.05(-) \\
0.72 \\
0.26 \\
0.45 \\
0.01 \\
0.36\end{array}$ & $\begin{array}{r}0.67 \\
0.08 \\
<\mathbf{0 . 0 1} \\
0.87 \\
\mathbf{0 . 0 2} \\
0.44 \\
0.33 \\
<\mathbf{0 . 0 1} \\
\mathbf{0 . 0 3} \\
<\mathbf{0 . 0 1} \\
0.73 \\
<\mathbf{0 . 0 1}\end{array}$ & $\begin{array}{l}0.18 \\
0.03(-) \\
0.33 \\
0.002 \\
0.0001(-) \\
0.08(-) \\
0.04(-) \\
0.08 \\
0.006(-) \\
0.1 \\
0.02(-) \\
0.14\end{array}$ & $\begin{array}{l}0.30 \\
0.70 \\
0.14 \\
0.91 \\
0.98 \\
0.49 \\
0.65 \\
0.48 \\
0.85 \\
0.45 \\
0.73 \\
0.37\end{array}$ & $\begin{array}{l}0.56(-) \\
0.49 \\
0.05 \\
0.75(-) \\
0.67 \\
0.59 \\
0.44 \\
0.46 \\
0.06 \\
0.48 \\
0.44 \\
0.08(-)\end{array}$ & $\begin{array}{r}\mathbf{0 . 0 3} \\
0.05 \\
0.58 \\
<\mathbf{0 . 0 1} \\
\mathbf{0 . 0 1} \\
\mathbf{0 . 0 3} \\
0.08 \\
0.06 \\
0.55 \\
0.06 \\
0.07 \\
0.49\end{array}$ \\
\hline $\begin{aligned} A_{\max }-\text { mass } & \text { versus : } \\
& \text { - Leaf size } \\
& \text { - Length-width ratio } \\
& \text { - SLA } \\
& \text { - Leaf angle } \\
& - \text { Ca } \\
& -\mathrm{K} \\
& -\mathrm{Mg} \\
& -\mathrm{P}-\text { mass } \\
& -\mathrm{P} \text {-area } \\
& -\mathrm{N}-\text { mass } \\
& -\mathrm{N}-\text { area } \\
& -\delta^{13} \mathrm{C}\end{aligned}$ & $\begin{array}{l}0.004 \\
0.16(-) \\
0.76 \\
0.003(-) \\
0.16 \\
0.07 \\
0.05(-) \\
0.74 \\
0.08 \\
0.66 \\
0.001(-) \\
0.45\end{array}$ & $\begin{array}{r}0.80 \\
0.09 \\
<\mathbf{0 . 0 1} \\
0.81 \\
0.09 \\
0.29 \\
0.37 \\
<\mathbf{0 . 0 1} \\
0.22 \\
<\mathbf{0 . 0 1} \\
0.96 \\
<\mathbf{0 . 0 1}\end{array}$ & $\begin{array}{l}0.04 \\
0.07(-) \\
0.76 \\
0.004 \\
0.02 \\
0.08(-) \\
0.02(-) \\
0.10 \\
0.09(-) \\
0.11 \\
0.17(-) \\
0.31\end{array}$ & $\begin{array}{r}0.65 \\
0.53 \\
<\mathbf{0 . 0 1} \\
0.87 \\
0.72 \\
0.49 \\
0.77 \\
0.46 \\
0.47 \\
0.43 \\
0.31 \\
0.14\end{array}$ & $\begin{array}{l}0.23(-) \\
0.37 \\
0.69 \\
0.08(-) \\
0.17 \\
0.42 \\
0.21 \\
0.40 \\
0.14(-) \\
0.74 \\
0.03 \\
0.003\end{array}$ & $\begin{array}{r}0.22 \\
0.10 \\
\mathbf{0 . 0 1} \\
0.48 \\
0.32 \\
0.08 \\
0.25 \\
0.10 \\
0.37 \\
<\mathbf{0 . 0 1} \\
0.69 \\
0.91\end{array}$ \\
\hline $\begin{array}{l}g_{\text {smax }} \text { versus: } \\
\text { - Leaf size } \\
\text { - Length-width ratio } \\
\text { - SLA } \\
\text { - Leaf angle } \\
\text { - Ca } \\
\text { - K } \\
\text { - Mg } \\
\text { - P-mass } \\
\text { - P-area } \\
\text { - N-mass } \\
\text { - N-area } \\
\text { - } \delta^{13} \mathrm{C}\end{array}$ & $\begin{array}{l}0.003 \\
0.28(-) \\
0.48 \\
0.01(-) \\
0.20 \\
0.03 \\
0.04(-) \\
0.64 \\
0.18 \\
0.42 \\
0.001(-) \\
0.41 \\
\end{array}$ & $\begin{array}{r}0.85 \\
\mathbf{0 . 0 2} \\
<\mathbf{0 . 0 1} \\
0.64 \\
0.05 \\
0.51 \\
0.42 \\
<\mathbf{0 . 0 1} \\
0.07 \\
<\mathbf{0 . 0 1} \\
0.91 \\
<\mathbf{0 . 0 1} \\
\end{array}$ & $\begin{array}{l}0.006 \\
0.25(-) \\
0.36 \\
0.007(-) \\
0.001 \\
0.03(-) \\
0.001(-) \\
0.08 \\
0.03(-) \\
0.04 \\
0.12(-) \\
0.16 \\
\end{array}$ & $\begin{array}{l}0.84 \\
0.20 \\
0.12 \\
0.84 \\
0.94 \\
0.70 \\
0.94 \\
0.51 \\
0.71 \\
0.65 \\
0.41 \\
0.32\end{array}$ & $\begin{array}{l}0.37(-) \\
0.04 \\
0.001(-) \\
0.57(-) \\
0.67 \\
0.17 \\
0.24 \\
0.64 \\
0.36 \\
0.08 \\
0.17 \\
0.04\end{array}$ & $\begin{array}{l}0.11 \\
0.63 \\
0.95 \\
\mathbf{0 . 0 3} \\
\mathbf{0 . 0 1} \\
0.31 \\
0.22 \\
\mathbf{0 . 0 2} \\
0.12 \\
0.50 \\
0.31 \\
0.62 \\
\end{array}$ \\
\hline
\end{tabular}



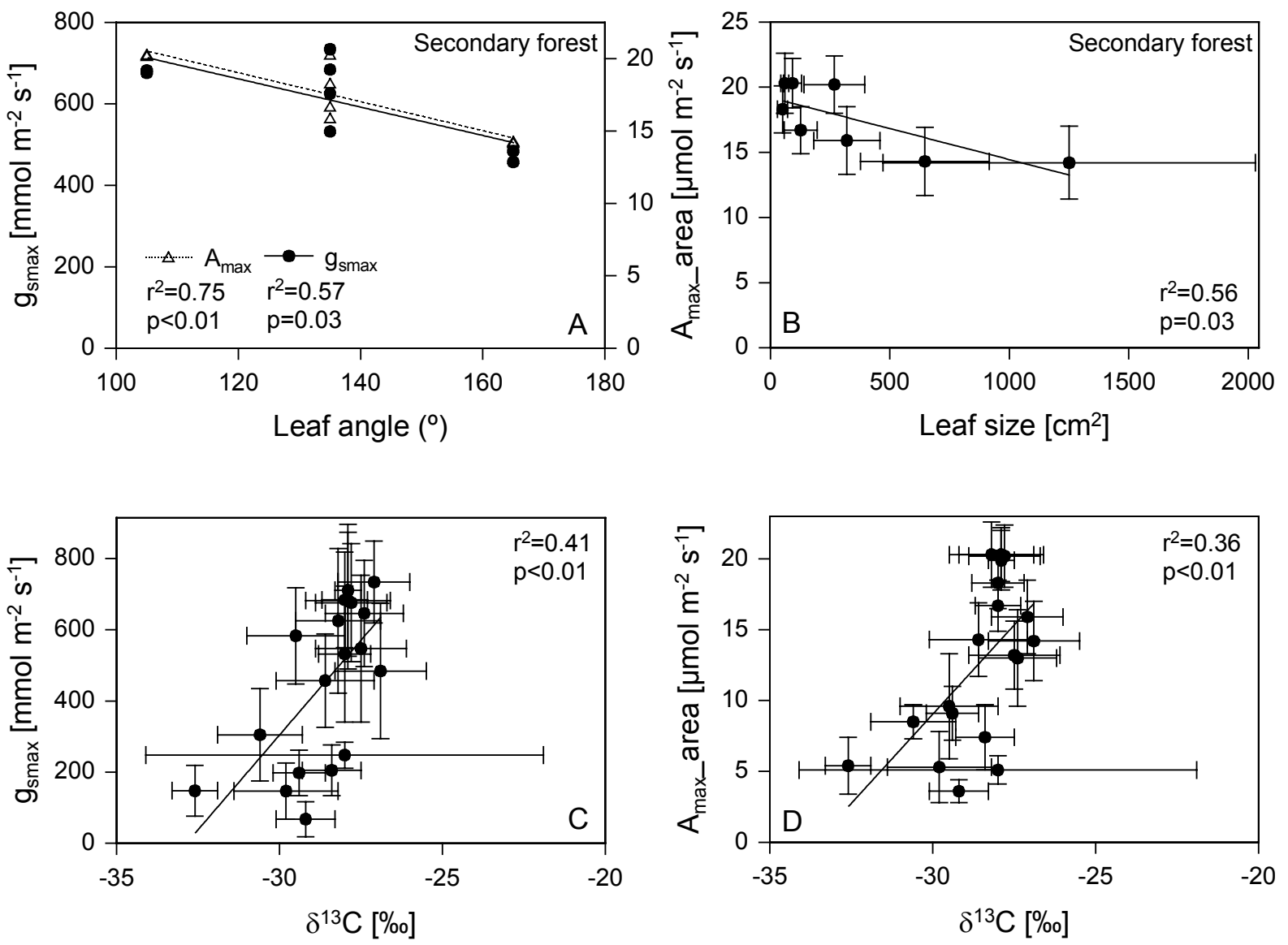

Figure 4.31 A-D A. Leaf angle ( $0^{\circ}$ equals vertically upwards) versus maximum stomatal conductance $\left(\mathrm{g}_{\text {smax }}\right)$ and light-saturated net photosynthesis rate per unit leaf area $\left(\mathrm{A}_{\max }-\mathrm{area}\right)$ in a sample of eight secondary forest species. B. $A_{\max }$-area versus leaf size in a sample of eight secondary forest species. C. $\mathrm{g}_{\text {smax }}$ versus $\delta^{13} \mathrm{C}$ in a sample of 19 species from three different land use types. D. $\mathrm{A}_{\max }$-area versus $\delta^{13} \mathrm{C}$ in a sample of 19 species from three different land use types.

$\mathrm{N}-\mathrm{mass}\left[\mathrm{g} \mathrm{kg}^{-1}\right]$

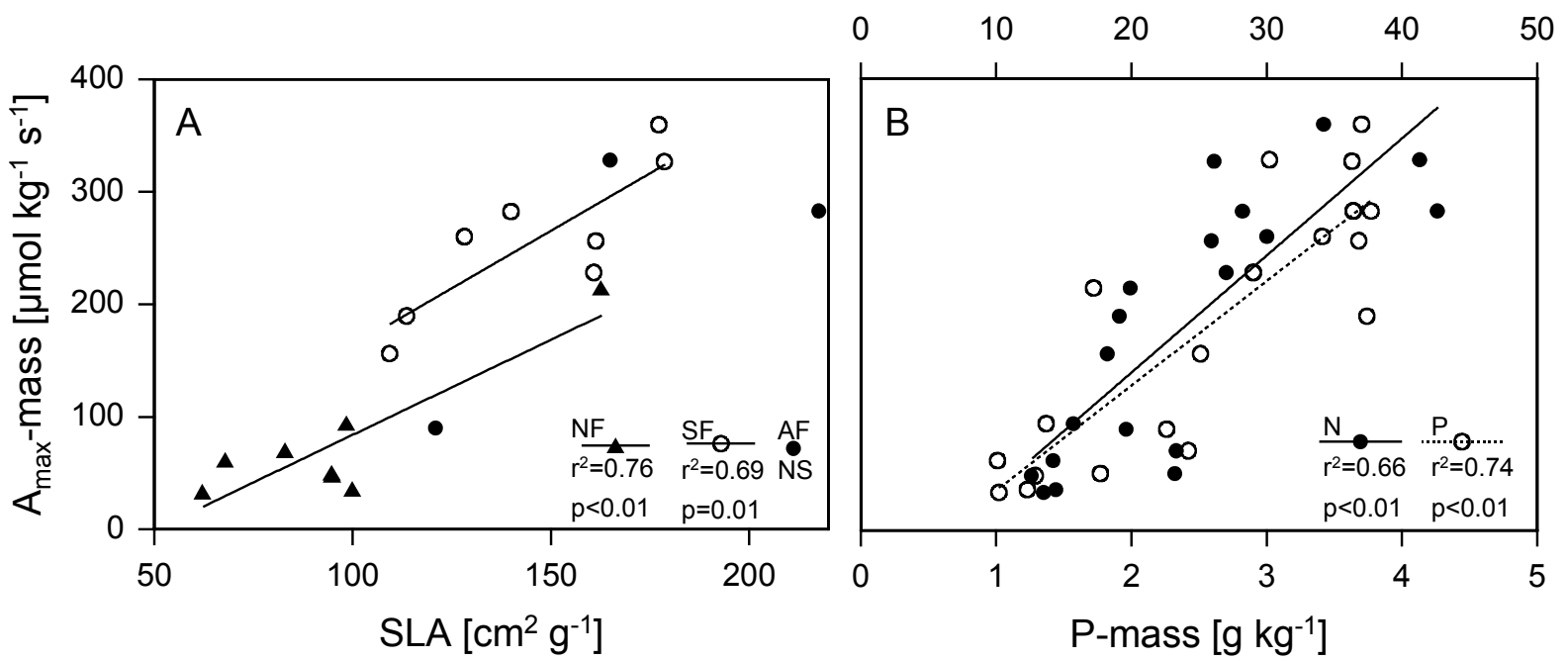

Figure 4.32 A. Relation between $\mathrm{A}_{\max }$-mass and specific leaf area (SLA) within the secondary forest and natural forest. $\mathrm{B}$. Relation between $\mathrm{A}_{\max }$-mass and leaf $\mathrm{P}$ and $\mathrm{N}$ concentrations, respectively, in the 19 species sample. 
in the secondary forest, but not among the natural forest species. No correlation was found between $\mathrm{A}_{\max }$-mass and leaf phosphorus concentration at the land use type level.

Further there was a clear correlation between $\mathrm{A}_{\max }$ and $\delta^{13} \mathrm{C}$ in the 19 -species sample $\left(\mathrm{r}^{2}\right.$ $=0.36, \mathrm{p}<0.01$, Table 4.13, Figure 4.31 D).

Correlations with leaf angle, $\mathrm{Ca}$ and $\mathrm{K}$ were found for $\mathrm{A}_{\max }$-area only in the secondary forest, and $\mathrm{Ca}$ also in the 19-species sample.

\subsubsection{Correlations between $g_{\text {smax }}$ and morphological or chemical leaf traits}

Comparing $g_{\text {smax }}$ with the chemical and morphological leaf traits showed that stomatal conductance was significantly related to SLA, length-width ratio and $\delta^{13} \mathrm{C}$ in the 19 -species sample (Table 4.13, Figure 4.31 C, Figure 4.34). Contrary to $\mathrm{A}_{\max }$-area, $\mathrm{g}_{\text {smax }}$ showed no correlation with leaf size in secondary forest, or any other sample. Another interesting result was the observed negative correlation between $g_{\text {smax }}$ and leaf angle among the secondary forest species $\left(\mathrm{r}^{2}=0.57(-), \mathrm{p}=0.03\right)$.

Maximum stomatal conductance was, like $\mathrm{A}_{\max }$, stronger linked to P-mass $\left(\mathrm{r}^{2}=0.64, \mathrm{p}<\right.$ $0.01)$ than to $\mathrm{N}$-mass $\left(\mathrm{r}^{2}=0.42, \mathrm{p}<0.01\right)$ in the 19 -species sample. A significant correlation between $\mathrm{P}$ and $\mathrm{g}_{\text {smax }}$ was also found in the secondary forest sample, whilst no correlation between $\mathrm{N}$ and $\mathrm{g}_{\text {smax }}$ could be seen in that sample $\left(\mathrm{r}^{2}=0.08, \mathrm{p}=0.50\right)$. Stomatal conductance in the natural forest showed neither a correlation to N, nor to P. Noteworthy is a strong correlation between $\mathrm{g}_{\mathrm{smax}}$ and leaf $\mathrm{Ca}$ concentration found among the secondary forest species $\left(r^{2}=0.67, p=0.01\right)$.
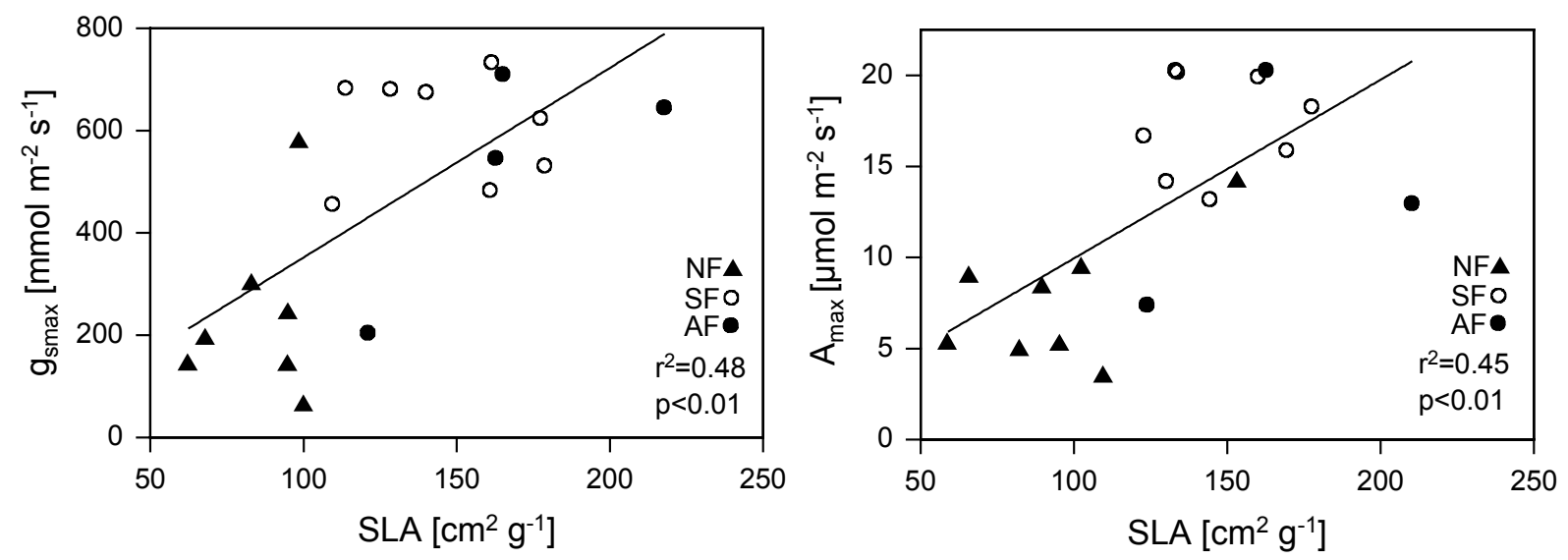

Figure 4.33 Physiological versus morphological characteristics in the sample of means for the 19 species studied. Left: Maximal stomatal conductance for water vapour $\left(\mathrm{g}_{\text {smax }}\right)$ versus specific leaf area (SLA). Right: Light saturated net photosynthesis $\left(\mathrm{A}_{\max }\right)$ versus specific leaf area (SLA). 


\subsubsection{Multiple regression analysis}

Multiple regression analyses were conducted to identify models explaining the relative influence of several morphological and chemical leaf traits on $\mathrm{A}_{\max }$ and $\mathrm{g}_{\text {smax }}$ in the samples of natural forest species, secondary forest species and in the complete 19-species sample, which covers three land use types. The results presented in Table 4.14 were the best fitted models among those examined in the analyses.

The highest explanation power of the models $\left(\mathrm{R}^{2}\right.$ Model values) were always achieved on the secondary forest sample, where $A_{\max }$-mass could be explained to $97 \%, A_{\max }$-area to $92 \%$

Table 4.14 Results of multiple regression analyses with stepwise parameter exclusion in the complete 19species sample and the natural and secondary forest samples ( 8 species each). Light-saturated net photosynthesis based on leaf mass ( $\mathrm{A}_{\max }$-mass) and on leaf area ( $\mathrm{A}_{\max }$-area), as well as maximum stomatal conductance $\left(\mathrm{g}_{\mathrm{smax}}\right)$ were explained by a set of leaf chemical and morphological traits. Partial degree of explanation $\left(\mathrm{R}^{2}\right)$ for the single parameters and total degree of explanation for the suggested model $\left(\mathrm{R}^{2}\right.$ Model $)$ are expressed as percent of total variance.

\begin{tabular}{|c|c|c|c|}
\hline & $\begin{array}{c}\text { Complete } \\
\text { sample } \\
\mathbf{n}=19\end{array}$ & $\begin{array}{c}\text { Natural } \\
\text { forest } \\
n=8\end{array}$ & $\begin{array}{c}\text { Secondary } \\
\text { forest } \\
n=8\end{array}$ \\
\hline \multirow[t]{2}{*}{ Parameters } & $\mathbf{R}^{2}$ & $\mathbf{R}^{2}$ & $\mathbf{R}^{2}$ \\
\hline & \multicolumn{3}{|c|}{$A_{\max }-$ mass } \\
\hline SLA & $76 \%$ & $76 \%$ & $11 \%$ \\
\hline P-mass & $10 \%$ & & \\
\hline Leaf size & & $16 \%$ & $12 \%$ \\
\hline $\mathrm{Mg}$ & $3 \%$ & & \\
\hline $\mathrm{Ca}$ & $2 \%$ & & \\
\hline N-mass & $1 \%$ & & $73 \%$ \\
\hline \multirow[t]{2}{*}{$\mathbf{R}^{2}$ Model } & $92 \%$ & $92 \%$ & $97 \%$ \\
\hline & \multicolumn{3}{|c|}{$A_{\max }-$ area } \\
\hline P-mass & $72 \%$ & & \\
\hline $\mathrm{Mg}$ & $4 \%$ & & \\
\hline $\mathrm{Ca}$ & $4 \%$ & & $67 \%$ \\
\hline $\mathrm{C} / \mathrm{N}$ & $4 \%$ & & \\
\hline Length-width ratio & & & $12 \%$ \\
\hline Leaf angle & & & $13 \%$ \\
\hline SLA & & $32 \%$ & \\
\hline Leaf size & & $32 \%$ & \\
\hline \multirow[t]{2}{*}{$\mathbf{R}^{2}$ Model } & $84 \%$ & $64 \%$ & $92 \%$ \\
\hline & & $\mathbf{g}_{\text {smax }}$ & \\
\hline SLA & $48 \%$ & $36 \%$ & \\
\hline P-area & $17 \%$ & & \\
\hline $\mathrm{Ca}$ & & & $67 \%$ \\
\hline $\mathrm{N}$-area & & & $14 \%$ \\
\hline $\mathbf{R}^{2}$ Model & $65 \%$ & $36 \%$ & $81 \%$ \\
\hline
\end{tabular}


and $\mathrm{g}_{\text {smax }}$ to $81 \%$ by sets of influential variables. The corresponding $\mathrm{R}^{2}$ Model values for the natural forest sample were $92 \%$ and $64 \%$ for $A_{\max }$-mass and $A_{\max }$-area, and $36 \%$ for $g_{\text {smax }}$.

The model that was most successful in explaining $g_{\text {smax }}$ and $A_{\max }$-area among secondary forest species interestingly ascribes as much as $67 \%$ of the variability to the parameter $\mathrm{Ca}$ concentration. In the natural forest SLA was estimated as the most important parameter for estimating $\mathrm{g}_{\mathrm{smax}}$, as well as $\mathrm{A}_{\max }$. This was also true in the 19-species sample. The second most influential parameter for these samples was generally $\mathrm{P}$ concentration.

Generally, the results of the multiple regression analysis agreed with the results obtained from single-parameter correlation analyses, but there were some divergences. The suggested multiple regression models estimated the influence of $\mathrm{N}$ on $\mathrm{A}_{\max }$ lower in some cases than did the correlation analyses. Further, the two analyses disagreed concerning the explanation of $\mathrm{g}_{\mathrm{smax}}$ in the secondary forest sample. According to the multiple regression analysis, $\mathrm{g}_{\text {smax }}$ was not depending on $\mathrm{P}$ at all, but to $14 \%$ on $\mathrm{N}$-area in this sample, whereas the correlation analysis suggested that $\mathrm{g}_{\text {smax }}$ could be explained to $64 \%$ by $\mathrm{P}(\mathrm{p}=0.02)$ and showed no correlation with $\mathrm{N}$.

\subsection{Variation in leaf attributes}

\subsubsection{Intraspecific variation of leaf attributes}

Figure 4.34 visualizes the intraspecific variation of ten important leaf morphological and chemical parameters. The graphs show the maximum and minimum value, the upper and lower quartile and mean calculated from 10-individual samples for each of 19 species. Following this first overview, the degree of variation was further analysed and quantified by the coefficient of variance.

Table 4.15 presents the coefficient of variance of chemical and morphological leaf traits within the 30 most frequent species in the random samples. For 19 of the species, the coefficient of variance was additionally listed for light-saturated net photosynthesis and maximum stomatal conductance.

It is obvious that some parameters show high intraspecific variance throughout the species, whereas others are constantly less variable in most species. Calcium concentration was the most variable parameter within many species. Leaf size was likewise very variable in most species, whereas SLA showed a universally low variance. $\mathrm{P}, \mathrm{N} / \mathrm{P}$ ratio and $\delta^{15} \mathrm{~N}$ varied a lot within the species, while $\mathrm{N}$ or $\mathrm{C} / \mathrm{N}$ ratio showed less variance (Figure 4.35).

Looking at the two gas exchange parameters included revealed that $g_{\text {smax }}$ varied more 
within species than $A_{\max }$, and that both were usually more variable among the individuals of natural forest species, than within the secondary forest, or the agroforestry system.
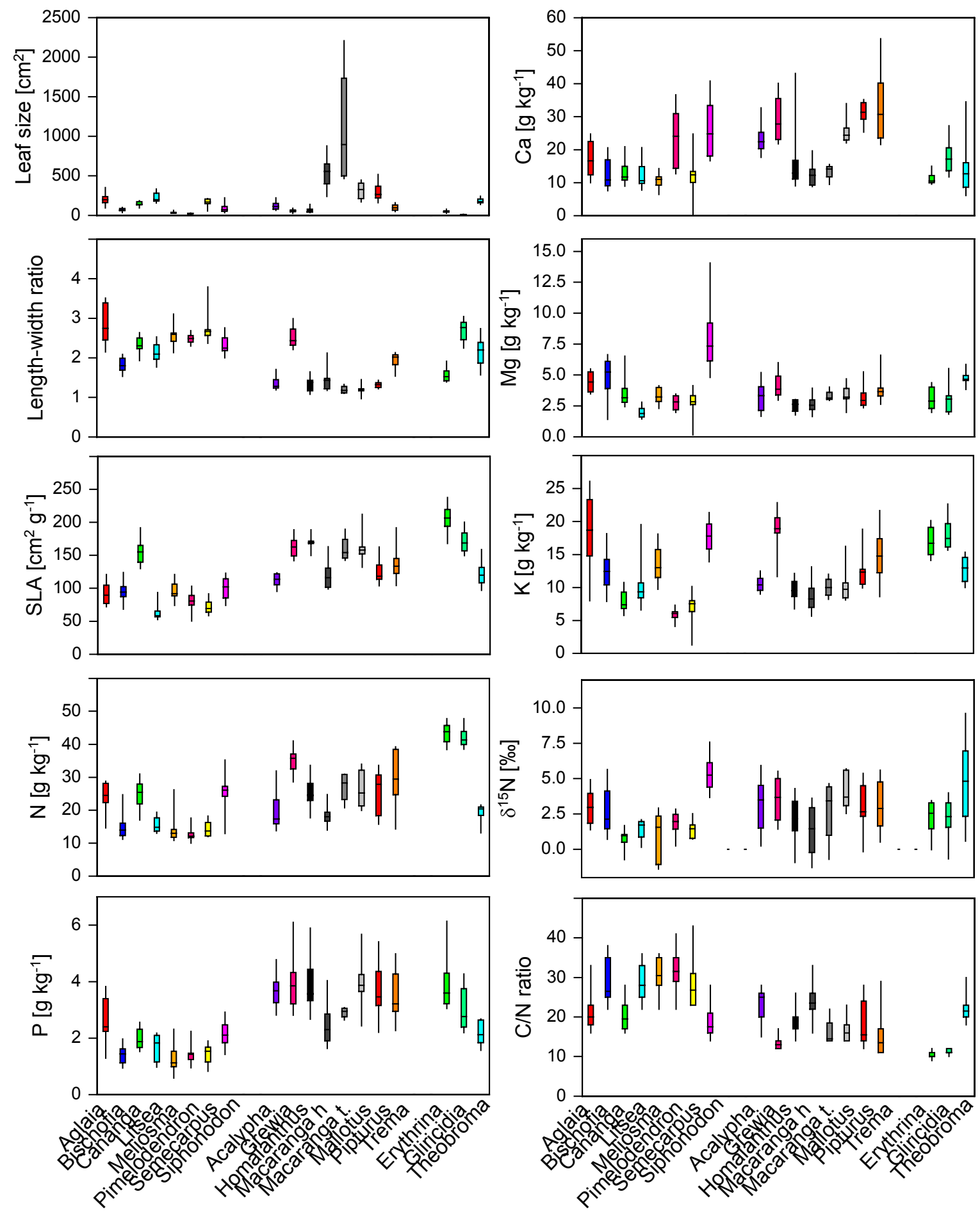

Natural forest Secondary forest Agroforestry system

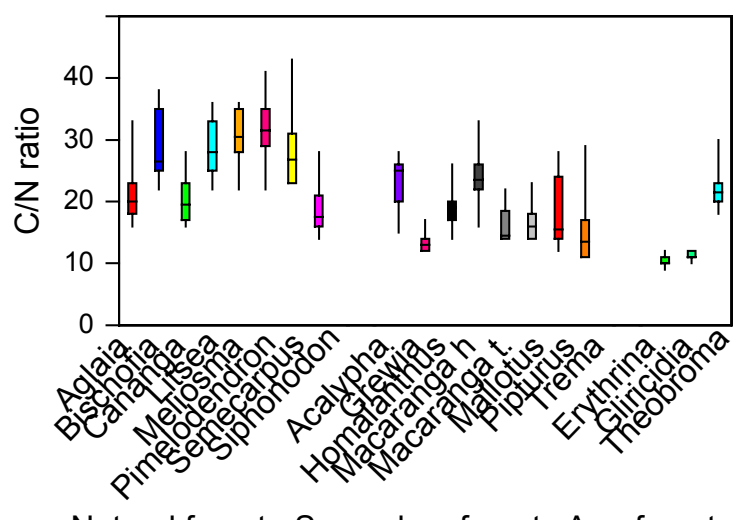

Natural forest Secondary forest Agroforestry system

Figure 4.34 Mean, lower and upper quartile, maximum and minimum values of 10 leaf traits in 19 species occurring in three different land use types. The calculations were based on 10 individuals per species, except for the Macaranga tanarius means, which were based on 4 individuals. 
Table 4.15 The coefficient of variance (sd / mean (\%)) calculated for 12 leaf traits and their intraspecific variation in the 30 most abundant species in the random samples (number of individuals underlying each species mean was 3 -10). Parameters presented are leaf size (LS), length-width ratio (LW), specific leaf area (SLA), weight related concentration of calcium $(\mathrm{Ca})$, phosphorus $(\mathrm{P})$, nitrogen $(\mathrm{N})$ and element ratios $(\mathrm{C} / \mathrm{N}$, $\mathrm{N} / \mathrm{P}$ ), as well as $\delta^{13} \mathrm{C}$ and $\delta^{15} \mathrm{~N}$. Additionally, the coefficient of variance for $\mathrm{A}_{\max }$ and $\mathrm{g}_{\text {smax }}$ is presented for 19 of the species. The species are listed under the land use type where they were most frequent. (Ind - number of individuals underlying the coefficient of variance)

\begin{tabular}{|c|c|c|c|c|c|c|c|c|c|c|c|c|c|}
\hline & Ind & LS & LW & SLA & $\mathrm{Ca}$ & $\mathrm{P}$ & $\mathrm{N}$ & $\mathrm{C} / \mathrm{N}$ & $\mathrm{N} / \mathrm{P}$ & $\delta^{13} \mathrm{C}$ & $\delta^{15} \mathrm{~N}$ & $\mathrm{~A}_{\max }$ & $\mathrm{g}_{\text {smax }}$ \\
\hline \multicolumn{14}{|l|}{ Natural forest } \\
\hline Aglaia argentea & 10 & 41 & 17 & 17 & 33 & 30 & 18 & 25 & 26 & 5 & 43 & 14 & 43 \\
\hline Actinodaphne sp. & 5 & 42 & 15 & 9 & 22 & 31 & 7 & 6 & 30 & 3 & 101 & & \\
\hline Bischofia javanica & 10 & 28 & 11 & 17 & 38 & 24 & 26 & 20 & 25 & 5 & 59 & 39 & 23 \\
\hline Cananga odorata & 10 & 19 & 9 & 12 & 30 & 18 & 17 & 19 & 13 & 3 & 94 & 18 & 38 \\
\hline Chionanthus sp. & 4 & 22 & 18 & 25 & 42 & 9 & 13 & 11 & 8 & 4 & 21 & & \\
\hline Cryptocaria crassinervia & 5 & 24 & 12 & 19 & 33 & 41 & 3 & 2 & 29 & 6 & 44 & & \\
\hline Dysoxylum sp. 2 & 5 & 17 & 36 & 10 & 20 & 16 & 10 & 10 & 23 & 2 & 10 & & \\
\hline Litsea sp. 1 & 10 & 26 & 11 & 19 & 35 & 28 & 15 & 17 & 26 & 9 & 45 & 37 & 48 \\
\hline Litsea sp. 3 & 5 & 25 & 27 & 10 & 51 & 45 & 27 & 39 & 39 & 3 & 26 & & \\
\hline Meliosma sumatrana & 10 & 36 & 11 & 15 & 24 & 47 & 32 & 15 & 54 & 2 & 200 & 22 & 73 \\
\hline Pimelodendron amboinicum & 10 & 13 & 5 & 19 & 36 & 25 & 16 & 17 & 18 & 3 & 46 & 20 & 15 \\
\hline Pouzolzia sp. & 7 & 33 & 19 & 14 & 11 & 15 & 14 & 15 & 13 & 4 & 77 & & \\
\hline Semecarpus forstenii & 10 & 28 & 15 & 14 & 52 & 25 & 17 & 22 & 35 & 5 & 43 & 21 & 32 \\
\hline Siphonodon celastrineus & 10 & 35 & 10 & 18 & 31 & 22 & 26 & 24 & 25 & 4 & 23 & 47 & 53 \\
\hline Terminalia sp. & 3 & 25 & 9 & 23 & 11 & 17 & 26 & 17 & 46 & 2 & 4 & & \\
\hline \multicolumn{14}{|l|}{ Secondary forest } \\
\hline Acalypha caturus & 10 & 43 & 13 & 9 & 20 & 15 & 28 & 19 & 30 & 3 & 60 & 8 & 20 \\
\hline Dendrocnide sp. 2 & 4 & 21 & 5 & 11 & 15 & 39 & 5 & 3 & 27 & 3 & 50 & & \\
\hline Glochidion rubrum & 3 & 13 & 10 & 24 & 12 & 13 & 21 & 25 & 9 & 2 & 49 & & \\
\hline Grewia glabra & 10 & 32 & 10 & 10 & 23 & 25 & 11 & 12 & 28 & 4 & 46 & 10 & 32 \\
\hline Homalanthus populneus & 10 & 52 & 13 & 7 & 60 & 25 & 19 & 19 & 22 & 3 & 84 & 10 & 36 \\
\hline Macaranga hispida & 10 & 41 & 19 & 17 & 28 & 30 & 16 & 21 & 22 & 5 & 137 & 20 & 29 \\
\hline Macaranga tanarius & 4 & 73 & 9 & 13 & 20 & 7 & 18 & 24 & 24 & 5 & 90 & 18 & 39 \\
\hline Mallotus mollissimus & 10 & 33 & 10 & 16 & 15 & 24 & 21 & 17 & 29 & 4 & 31 & 17 & 16 \\
\hline Pipturus argentus & 10 & 37 & 5 & 16 & 10 & 24 & 24 & 33 & 34 & 2 & 53 & 9 & 25 \\
\hline Tabernamontana macrocarpa & 4 & 19 & 22 & 11 & 23 & 22 & 7 & 11 & 20 & 6 & 25 & & \\
\hline Trema orientalis & 10 & 39 & 11 & 17 & 32 & 24 & 28 & 38 & 36 & 4 & 60 & 9 & 28 \\
\hline \multicolumn{14}{|l|}{ Agroforestry system } \\
\hline Coffea arabica & 10 & 23 & 17 & 14 & 28 & 13 & 13 & 12 & 17 & 3 & 31 & & \\
\hline Erythrina sp. & 10 & 30 & 10 & 10 & 16 & 24 & 7 & 9 & 20 & 4 & 55 & 26 & 23 \\
\hline Gliricida sepium & 10 & 32 & 10 & 10 & 29 & 24 & 7 & 7 & 26 & 2 & 68 & 11 & 26 \\
\hline Theobroma cacao & 10 & 18 & 16 & 15 & 58 & 18 & 14 & 18 & 26 & 3 & 60 & 31 & 35 \\
\hline
\end{tabular}

Aglaia argentea, Bischofia javanica, Litsea sp.3 and Meliosma sumatrana were natural forest species with particularly high intraspecific variance for most leaf traits. The two species Litsea sp.1 and Siphonodon celastrineus showed the highest variance in the gas exchange parameters among the natural forest species. Generally, natural forest species 
showed a higher intraspecific variance in $\mathrm{P}$ and $\mathrm{Ca}$ and gas exchange parameters than the secondary forest species.

Among the secondary forest species, Trema orientalis had the highest intraspecific variance for most leaf traits, followed by Macaranga hispida, Homalanthus populneus and Acalypha caturus. Macaranga hispida was the secondary forest species with highest intraspecific variance in leaf gas exchange parameters.

Looking at the four agroforestry species revealed that Theobroma cacao was overall most variable among the four and that Gliricidia sepium and Erythrina sp. had strikingly similar coefficients of variance throughout the parameters and particularly low intraspecific variance in $\mathrm{N}$.
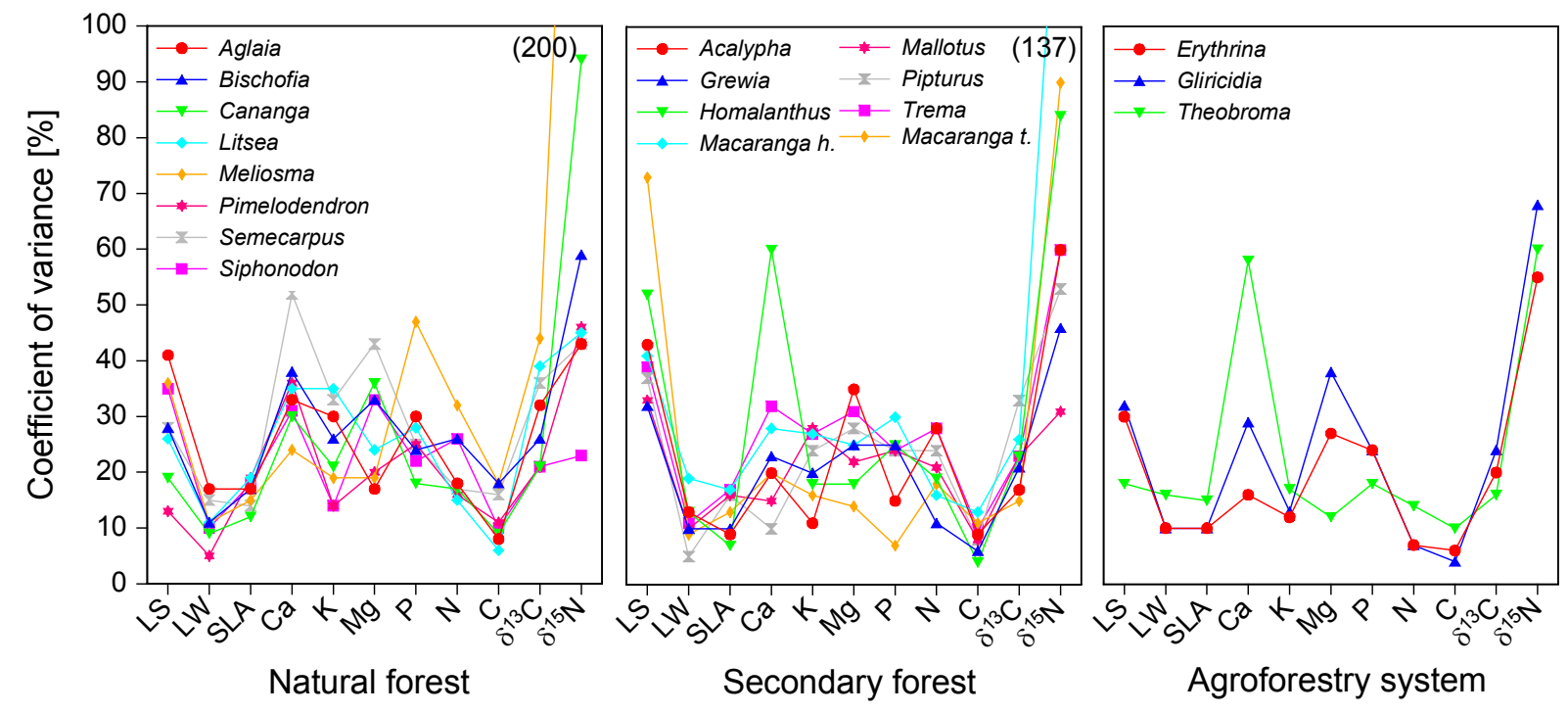

Figure 4.35 Intraspecific coefficient of variance (sd / mean (\%)) in 11 morphological and chemical leaf traits for eight natural forest species, eight secondary forest species and three agroforestry system species. (LS - Leaf size, LW - Length-width ratio, SLA - Specific leaf area)

\subsubsection{Variation of leaf attributes within land use types}

Studying the interspecific variance in normalized 18-species samples of the four land use types (four species in AF), the most important finding was that $\mathrm{P}$ was more variable than $\mathrm{N}$ among species in all land use types, except secondary forest. The variance of $\mathrm{N}$ among natural forest species was remarkably low, while the variance in $\mathrm{P}$ was much higher than among secondary forest species. Leaf size was the most variable parameter within all four land use types, followed by $\mathrm{Ca}$ and $\delta^{15} \mathrm{~N}$ (Table 4.16). 
Similar to the intraspecific variance, the interspecific variance of stomatal conductance was higher than that of $A_{\max }$, and secondary forest was the least variable land use type concerning leaf gas exchange of its species.

As can be seen in Table 4.16, natural forest was the land use type with overall highest interspecific variance for leaf traits. Five of the 12 listed leaf traits showed their maximum value of the coefficient of variance for the natural forest, whereas the other three land use types had the highest interspecific variance of the four for one or two parameters. Secondary forest had the highest coefficient of variance among the four land use types only for $\delta^{15} \mathrm{~N}$. $\mathrm{A}_{\max }$ and SLA varied most among the agroforestry species.

Table 4.16 Coefficient of variance (sd / mean (\%)) for morphological and chemical leaf traits in the normalized 18-species average samples of natural forest (NF), secondary forest (SF) and forest garden (FG), and in the species average of the four agroforestry system (AF) species. The coefficients for $\mathrm{A}_{\max }$ and $\mathrm{g}_{\mathrm{smax}}$ are calculated from eight-species samples for NF and SF, and from three species for AF. The coefficients of variance among the four land use types studied are listed in the fifth column. (n.d. - no data)

\begin{tabular}{|c|c|c|c|c|c|}
\hline \multirow[b]{2}{*}{ No. species } & \multirow{2}{*}{$\begin{array}{r}\text { NF } \\
(\%) \\
18 \\
\end{array}$} & \multirow{2}{*}{$\begin{array}{r}\text { FG } \\
(\%) \\
18 \\
\end{array}$} & \multirow{2}{*}{$\begin{array}{r}\text { SF } \\
(\%) \\
18\end{array}$} & \multicolumn{2}{|c|}{ AF Variance between } \\
\hline & & & & 4 & \\
\hline Leaf size & 98 & 75 & 91 & 96 & 42 \\
\hline Length-width ratio & 100 & 17 & 29 & 26 & 24 \\
\hline SLA & 29 & 33 & 28 & 34 & 15 \\
\hline $\mathrm{Ca}$ & 62 & 45 & 61 & 40 & 20 \\
\hline $\mathbf{P}$ & 41 & 45 & 29 & 32 & 32 \\
\hline $\mathbf{N}$ & 3 & 38 & 38 & 30 & 26 \\
\hline $\mathbf{C} / \mathbf{N}$ & 31 & 37 & 32 & 36 & 23 \\
\hline $\mathbf{N} / \mathbf{P}$ & 35 & 25 & 20 & 28 & 22 \\
\hline$\delta^{13} \mathrm{C}$ & 4 & 4 & 2 & 4 & 4 \\
\hline$\delta^{15} \mathrm{~N}$ & 40 & 65 & 96 & 73 & 13 \\
\hline $\mathbf{A}_{\max }$ & 43 & n.d. & 22 & 47 & 44 \\
\hline $\mathbf{g}_{\text {smax }}$ & 68 & n.d. & 17 & 53 & 36 \\
\hline
\end{tabular}

\subsubsection{Variation of leaf attributes among land use types}

The coefficient of variance for 12 important morphological, chemical and physiological leaf traits among the four land use types studied is accounted in the very right column of Table 4.16. The largest difference between the land use types was found for $\mathrm{A}_{\max }$, followed by leaf size and thereafter $\mathrm{g}_{\text {smax }}$ and $\mathrm{P}$, while the highest similarity was obtained for SLA 
(and $\delta^{15} \mathrm{~N}$ and $\delta^{13} \mathrm{C}$ ). The variance among land use types was analysed using means of the random sample, which is defined in Table 3.2.

\subsection{Functional groups}

\subsubsection{A graphic analysis of plant functional types}

The concentrations of major leaf nutrients, their internal ratios and main morphological characteristics of trees in the four land use types and of certain families and species were illustrated as radial values in radial diagrams. The radial axis for each parameter corresponds to the span of observed values for that parameter in a sample. The centre of the circle represents the lowest value of each parameter in the topical sample (entering $0 \%$ of the
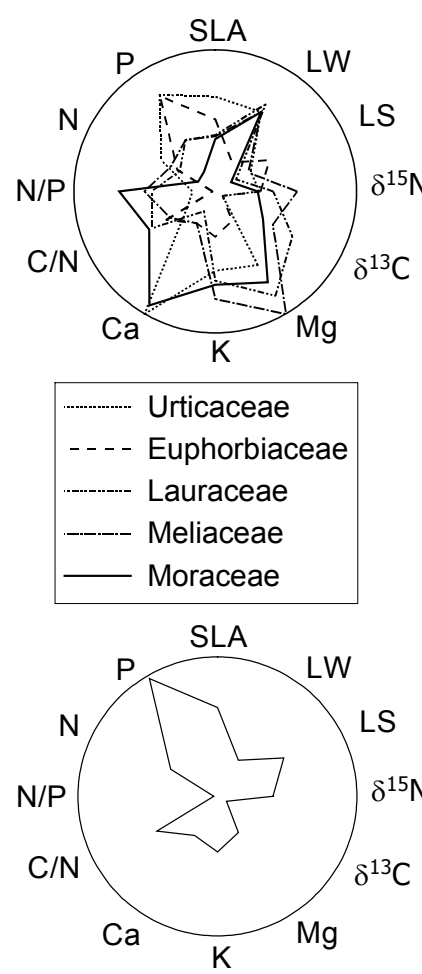

Euphorbiaceae

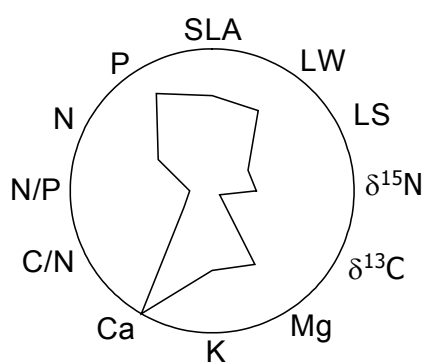

Urticaceae

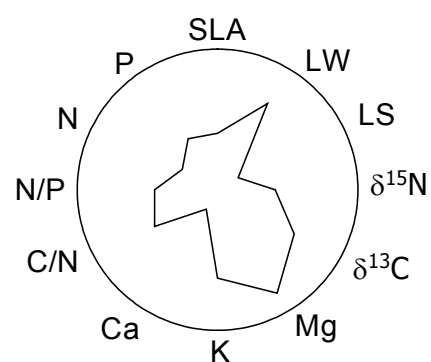

Lauraceae

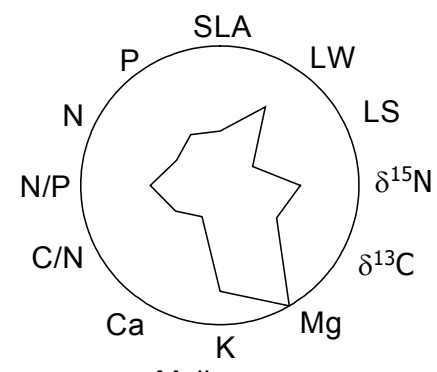

Meliaceae

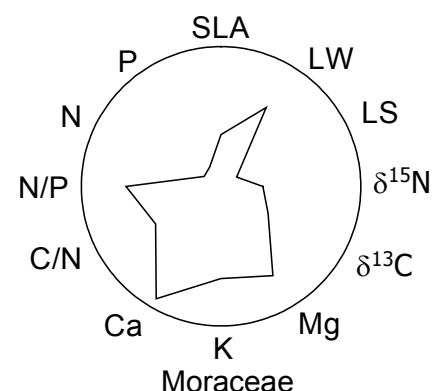

Moraceae

Figure 4.36 A graphic overview of the relative values of some important leaf traits in the five most frequent families of the random sample. Average values of the individuals included in the random sample for each family were used. The radial axis for each parameter corresponds to the span of observed values in the topical sample. Thus, the centre of the circle represents the lowest value of that parameter occurring in the sample (entering $0 \%$ of the range). The outer edge of the circle represents the highest value achieved in the sample, thus $100 \%$ of the range. The values for $\delta^{13} \mathrm{C}$ are denoted as absolute numbers, therefore $100 \%$ corresponds to the most negative value. (SLA Specific leaf area, LS - Leaf size, LW - Length-width ratio) 
range). The outer edge of the circle represents the highest values of the parameters found in the sample, thus $100 \%$ of the range. This form of illustration turned out to be useful for comparative overviews at a given level. It can immediately be recognized that the graphic pattern of different species are dissimilar also within a given land use type. On the other hand, other groups of similar species can be recognised across the land use types.

\subsubsection{Groups of species with similar trait profiles}

Vast differences between species can be observed in Figure 4.37. The profiles of the different species illustrated do not universally coincide within the land use types, and also not necessarily within a family. Certain groups with common patterns can however be discerned.

The three Euphorbiaceae species illustrated all showed different patterns that neither looked like the family means pattern, nor like the respective forest type, in which the species occurred. For example, Homalanthus populneus formed a pattern dissimilar to any other species illustrated. Its high P and SLA were common with the general secondary forest pattern, but the low mineral nutrient concentrations rather reminded on late stage, natural forest species. The overall strikingly low concentration of nutrients in the huge-leaved Macaranga hispida is interesting, and was not seen in any of the other illustrated species.

Trema orientalis, Grewia glabra and Gliricidia sepium showed a similar pattern, characterized by small leaf sizes, high $\delta^{13} \mathrm{C}$, low $\mathrm{C} / \mathrm{N}$ ratio, high $\mathrm{K}$ concentration and a rather high P-concentration and SLA. This pattern could also be recognized as the mean pattern for the agroforestry system. Pipturus argentus was also similar to this group, only diverging through a lower $\mathrm{K}$ concentration and higher $\mathrm{Ca}$ concentration than the others.

Another group of similar species was formed by the three natural forest species Lithocarpus sp., Semecarpus forstenii and Litsea sp.. The common traits in this group were low concentrations of both $\mathrm{N}$ and $\mathrm{P}$, but high $\mathrm{N} / \mathrm{P}$ ratio, very low concentrations of all three nutrients and, concerning morphology, very low SLA. These were all late stage natural forest species that mainly diverged from the natural forest means profile through their higher $\mathrm{C} / \mathrm{N}$ ratios and their strikingly low $\mathrm{Mg}$ and $\mathrm{K}$ concentrations.

Aglaia argentea and Bischofia javanica both had rather high $\mathrm{Mg}$ and $\mathrm{K}$ concentrations, which separated them from the other natural forest species illustrated, but cohered with the mean pattern for natural forest. These two still did not form a homogenous group, because of the remarkable differences in $\mathrm{C} / \mathrm{N}$ and length-with ratio. 


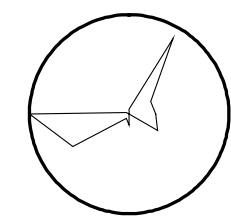

Semecarpus forstenii

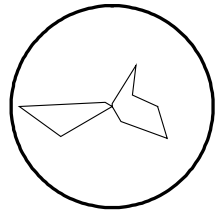

Lithocarpus sp

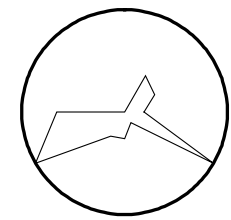

Litsea $s p$

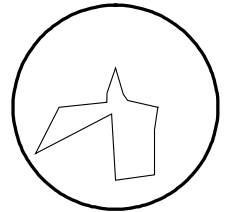

Bischofia javanica

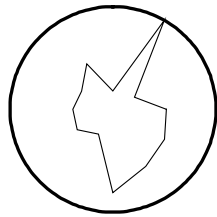

Aglaia argentea

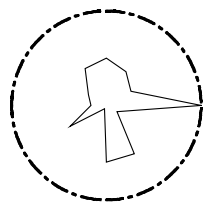

Theobroma cacao

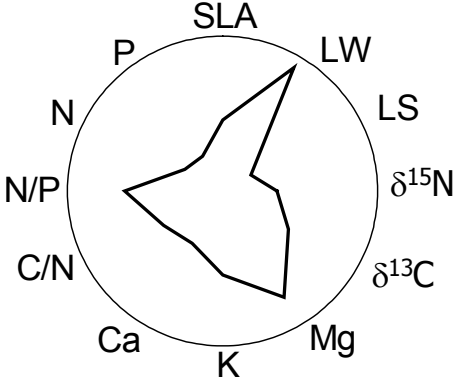

Natural

forest

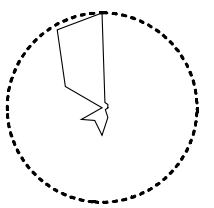

Homalanthus populneus

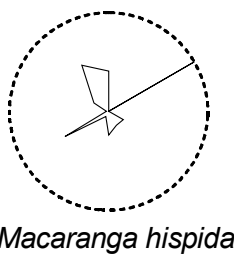

Forest garden

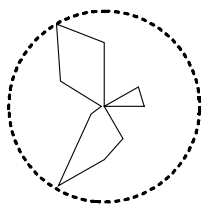

Pipturus argentus
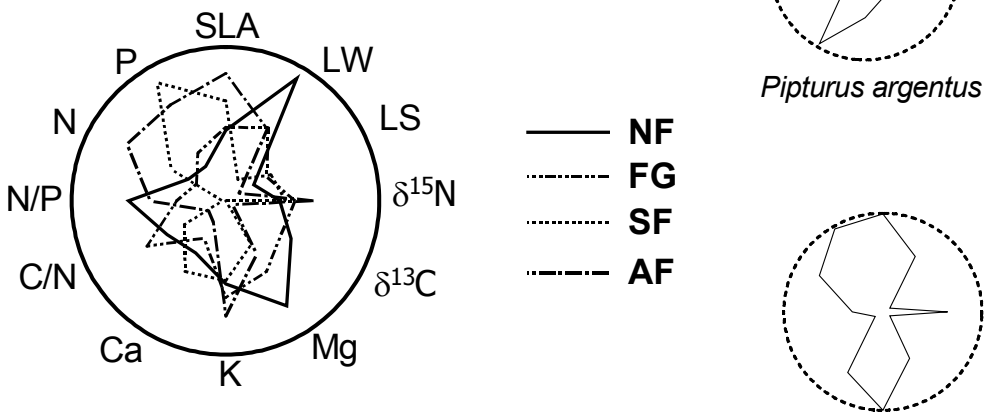

Grewia glabra

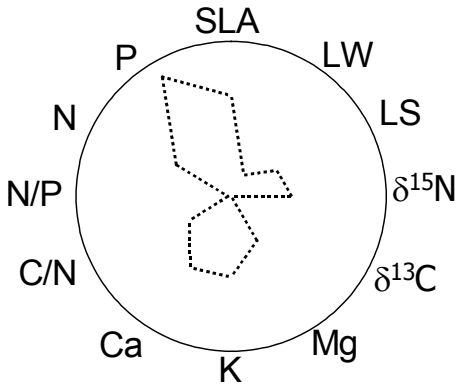

Secondary forest

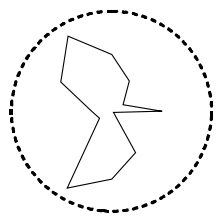

Trema orientalis

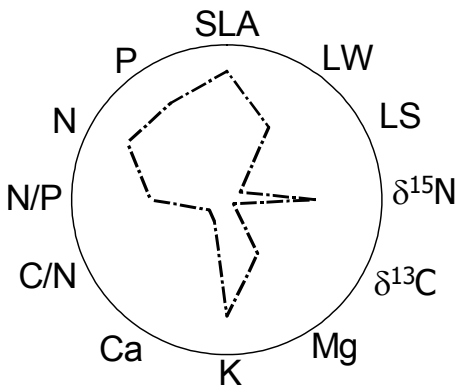

Agroforestry system

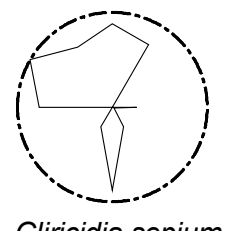

Gliricidia sepium

Figure 4.37 A graphic overview of the relative values of some important leaf traits in the four land use types studied and in 12 abundant species. The radial axis for each parameter corresponds to the span of observed values in the topical sample. Thus, the centre of the circle represents the lowest value of that parameter occurring in the sample (entering $0 \%$ of the range). The outer edge of the circle represents the highest value achieved in the sample, thus $100 \%$ of the range. The values for $\delta^{13} \mathrm{C}$ are denoted as absolute numbers, therefore $100 \%$ corresponds to the most negative value. (SLA - Specific leaf area, LS - Leaf size, LW - Length-width ratio) 


\subsubsection{Division of $\mathbf{1 0 7}$ tree species into functional groups}

The cluster analysis based on the five main predictors for leaf physiology resulted in a model where the 107 species in the study were divided into ten functional groups (clusters). The species belonging to each cluster are listed in Appendix 9. The cluster centroid values (or seeds) of each of the underlying leaf traits, the frequency of each functional group, as well as information on neighbouring groups are presented in Table 4.17.

Table 4.17 Ten functional groups identified through a disjoining cluster analysis. The model, comprising 107 tree species of four different land use types, has an expected $\mathrm{R}^{2}$ value of 0.97 . C - cluster (group) number, $\mathrm{F}-$ number of species in each cluster, SLA - specific leaf area $\left[\mathrm{cm}^{2} \mathrm{~g}^{-1}\right]$, Size - leaf size $\left[\mathrm{cm}^{2}\right], \delta^{13} \mathrm{C}-$ carbon isotope ratio [\%o], $\mathrm{N}$ - foliar nitrogen concentration $\left[\mathrm{g} \mathrm{kg}^{-1}\right.$ ], $\mathrm{P}$ - foliar phosphorus concentration $\left[\mathrm{g} \mathrm{kg}^{-1}\right.$ ], $\mathrm{Max}$ dist - maximum distance of an observation (species) from the cluster centroid, Next C - nearest other cluster, Dist - distance from centroid to nearest other cluster centroid, Typical species - examples of characteristic species of each cluster.

\begin{tabular}{|c|c|c|c|c|c|c|c|c|c|c|}
\hline $\mathbf{C}$ & $\mathbf{F}$ & SLA & Size & $\delta^{13} \mathrm{C}$ & $\mathbf{N}$ & $\mathbf{P}$ & $\begin{array}{r}\text { Max } \\
\text { dist }\end{array}$ & $\begin{array}{l}\text { Next } \\
\text { C }\end{array}$ & Dist & Typical species \\
\hline 1 & 4 & 236 & 38 & -29.7 & 41 & 2.6 & 51 & 7 & 85 & Erythrina sp., Homalanthus populneus \\
\hline 2 & & 150 & 141 & -31.1 & 22 & 1.6 & 41 & 6 & 50 & $\begin{array}{l}\text { Solanum sp., Trema orientalis, Cananga } \\
\text { odorata }\end{array}$ \\
\hline 3 & 3 & 177 & 322 & -27.8 & 40 & 4.1 & 40 & 5 & 64 & $\begin{array}{l}\text { Mallotus mollissimus, Tabernamontana } \\
\text { macrocarpa, Pipturus argentus }\end{array}$ \\
\hline 4 & 1 & 161 & 1251 & -26.9 & 27 & 2.9 & 0 & 10 & 646 & Macaranga tanarius \\
\hline 5 & 5 & 77 & 307 & -29.7 & 17 & 1.6 & 48 & 3 & 64 & Dysoxylum sp.1, Chisocheton sp.1 \\
\hline 6 & & 53 & 81 & -31.4 & 29 & 2.2 & 38 & 7 & 42 & Aralia sp., Siphonodon celastrineus \\
\hline 7 & & 135 & 25 & -31.9 & 19 & 1.3 & 60 & 6 & 42 & $\begin{array}{l}\text { Ficus spp., Terminalia sp., Meliosma } \\
\text { sumatrana }\end{array}$ \\
\hline 8 & 2 & 129 & 412 & -26.3 & 45 & 6.5 & 17 & 3 & 101 & Dendrocnide sp.2, Elmerillia tsiampacca \\
\hline 9 & 15 & 41 & 195 & -29.9 & 22 & 2.3 & 54 & 2 & 80 & $\begin{array}{l}\text { Semecarpus forstenii, Cryptocarya } \\
\text { crassinervia, Lithocarpus sp., Theobroma } \\
\text { cacao }\end{array}$ \\
\hline 10 & 4 & 109 & 647 & -28.6 & 18 & 2.5 & 39 & 8 & 211 & Dendrocnide stimulan, Macarnaga hispida \\
\hline
\end{tabular}

The first group was characterized by small leaves with high SLA and high N. The species closest to the cluster centroid was Erythrina sp.. The second group was dominated by secondary forest species like Trema orientalis and Solanum sp., but did also contain the species Cananga odorata, which occurred in the natural forest. The groups 3 and 4 consisted of species more or less exclusively occurring in the secondary forest. They were the only groups comprising species from just one land use type. These groups, which comprised only a few species, were characterized by large leaf sizes, relatively high SLA and high $\delta^{13} \mathrm{C}$ 
values. Species with relatively large, coriaceous leaves (low SLA), with corresponding low $\delta^{13} \mathrm{C}$ that are poor in $\mathrm{N}$ and $\mathrm{P}$ formed the fifth group. The sixth group was similar, but with smaller leaves with intermediate $\mathrm{N}$ and $\mathrm{P}$ concentrations. Both these types were typical for medium sized natural forest trees. The groups 7 and 9 contained species from all four land use types. The eighth functional group applied to two species in this sample only, which had remarkably high $\mathrm{P}$ and high $\delta^{13} \mathrm{C}$. The tenth type was characterised by large leaves with low N. 


\section{DisCussion}

\subsection{The steps from leaves to ecosystems}

Standing in the middle of a forest with the intention to investigate the function of the trees in that ecosystem by studying leaves, there are some deciding steps to take. First one has to know how to design an ecologically appropriate sampling strategy. Then, the parameters to be obtained have to be selected. Suitable, easy accessible leaf traits for reliable prediction of leaf physiology are desirable. The accurateness of, and interrelations between them should be investigated. When these data are achieved for a sample of individuals in the stand, the next step would be to scale up the results. The division of the studied trees or species into some groups of similar ecological characteristics can be very helpful in this situation, reducing the degree of complexity. Estimating the relative abundance of the different groups in the studied forest would then give an appropriate idea of the function of the ecosystem.

The results and constrains of these steps in a comparative study of four different land use types are the main features of the following discussion.

Further steps, towards calculations on ecosystem and global levels, are not trivial, but possible.

\subsection{The importance of sampling design in comparative leaf morphological studies}

\subsubsection{Contradictive results}

Comparing the means obtained by the different sampling designs showed some major differences (Table 4.4, Appendix 10). The observed contradiction between the inventory sample and the other two samples concerning leaf size might be associated with a certain bias due to the about $25 \%$ of the individuals in the forest inventory sample to which there was no morphological and chemical leaf trait data available. For example, individuals of the large-leaved Palmae genus Pigafetta were recorded in the inventory, but are not included in the mean value calculation. More fundamental though, is of course the fact that the inventory sample comprises all canopy strata, whereas the other two samples focus on upper canopy. This could also be the underlying reason for observed contradictions concerning leaf $\mathrm{N}$ concentration in the forest garden samples. 
Contradictions achieved between the species average sample and the other two, e.g. concerning SLA in the forest garden and magnesium in the secondary forest, can be explained by the presence of species with low SLA or high $\mathrm{Mg}$ respectively that are rare and thus have larger influence on the species average than on the random sample.

\subsubsection{The influence of sampling design on the results of parameter correlation analysis}

Correlation analyses within the random sample detected a higher number of significant correlations than the same analyses in the species average sample. (Correlation parameter data not shown) This is true for all four land use types, as well as the complete random sample. However, the difference between the two sampling designs was smaller in the forest garden sample than in the other three, because there were only a few, often just one, individual per species, which made the two samples very similar. Concordant, the greatest difference in number of found significances between the two sample designs was seen in the secondary forest, which was the land use type with the largest number of individuals per species sampled.

\subsubsection{Random sampling is the most suitable design for ecological studies of morphological and chemical leaf traits}

In theory, the most complete study of tree communities should of course comprise every tree present, and it is important to notice, that differences between land use types for the important leaf traits SLA and N were more pronounced in the inventory sample than in the random sample or species average. However, sampling every tree in a forest is in most cases not practically accomplishable. The two other sampling designs gave different results when used for correlation analyses of leaf traits within land use types, as well as for comparisons of leaf trait means among land use types. When comparing random sampling with species averages the potentially high influence of rare species in a species average becomes obvious. This kind of balance is discussed concerning SLA and Mg above. Therefore, the choice between random sampling design and species average design is important and depends on the aim of the study. If the objective of a study is to do a taxonomic characterisation of the species occurring on a plot, the species average will be the most suitable method, but if searching for the properties of an average tree in a certain stand, then the random sampling design should be applied. The random sampling method is more relevant for ecosystem 
studies and preferable for scaling up to landscape or global levels through calculations like those presented by Schulze et al. (1994).

\subsection{Possible sampling effect}

Most parameters showed few remarkable differences in standard deviations or mean values between the normalized 18-species average and the average of all species in the random sample of each land use type. Further, some standard deviations were larger in the normalized sample, while others were lower, compared to the all-species averages. These results indicate that there was no systematic sampling effect, despite the unbalanced number of species and tree individuals among the different samples in this study. Therefore, mean values and standard deviations of unequally sized samples will be considered comparable in the following discussion.

\subsection{Differences between important tree-based land use types in foliar morphology, chemistry, leaf physiology and canopy structure}

\subsubsection{Morphological leaf traits}

\subsubsection{Specific leaf area-SLA}

\section{SLA in the Sulawesi trees compared to other studies}

Castro-Díez et al. (2000) found a 6-fold variation in LMA (leaf mass area, the inverse of SLA) in a broad sample of seedlings of 52 native woody species in temperate and Mediterranean Europe, which is the same range as within the sample of one forest type (NF) in this study (including 69 species). The two studied Macaranga species in this study had SLA values in the lower part of the range found for nine Macaranga species seedlings in Borneo (160 $\mathrm{cm}^{2} \mathrm{~g}^{-1}$, compared to $159-278 \mathrm{~cm}^{2} \mathrm{~g}^{-1}$, Davies 1998). This might be explained by the fact that seedlings usually have higher SLA than mature trees (Thomas \& Winner 2002).

\section{Variation in SLA among land use types}

Low SLA is associated with nutrient retention, prevention from non-stomatal foliar transpiration and desiccation and gives generally longer leaf-life spans, through higher toughness (Reich 1997). These are typical characteristics of many species occurring in the 
natural forest, and thus explain the significantly lower mean SLA found in this land use type and the forest garden compared to the other two. The highest mean SLA was obtained in the agroforestry system and suggests a strategy where high growth rate is given higher priority than protection against herbivory and desiccation. The strategy of many secondary forest trees is similar, giving this land use type the second highest mean SLA.

\section{SLA related to leaf size and form}

SLA showed a negative correlation with length-width ratio in the complete random sample, natural forest and agroforestry system, as well as in the families Fabaceae and Euphorbiaceae. In contrast, the predominantly natural forest family Lauraceae and the pioneer dominated, but in different forest types present, Urticaceae showed positive correlations between SLA and length-width ratio. Among species of various ecological strategies a negative correlation would be expected, since low SLA and elongated leaf forms (high length-width ratio) are generally coinciding in late-successional species, whereas high SLA and rounder leaves are typical in pioneers. The found positive correlation within certain families might be explained as that additional length-growth was achieved by reducing dry mass density in a certain leaf, resulting in higher SLA in longer leaves.

A very weak negative relation of SLA to leaf size was found in the complete random sample $\left(\mathrm{r}^{2}=0.01(-), \mathrm{p}=0.04\right)$ and, more pronounced, in the agroforestry system, but not within any other land use type. The correlation detected within the agroforestry system can be explained as a result of combining Theobroma cacao, which had large leaves of low SLA, with the Fabaceae, which had small leaves of high SLA. Interestingly, in contrast to the species level or land use level, a clear positive correlation between SLA and leaf size could be detected if considering plot averages, taking all plots into account (data not shown). Similarly, Ackerly et al. (2002) found that leaf size and SLA were changing in parallel among shrub communities, giving a positive correlation in a sample of community averages, whereas they could not find any correlation between the two parameters at species level or within a community either. Ackerly et al. (2002) suggested that this could be an effect of the combination of communities characterized by different strategies. A strategy where reaching large leaf sizes is important does not allow high investments in leaf nutrients and structural tissue, which would give a low SLA. This relation would however not exist within or among species, explaining why no correlations were found in three land use types or in the complete random sample of individuals. 


\section{$S L A$ related to nitrogen concentration}

Leaf toughness, which can among others, be considered a herbivory defence strategy, has been shown to correlate with SLA (or LMA) in 16 Argentine and 23 British woody plants (Cornelissen et al. 1999). High leaf toughness combined with low $\mathrm{N}$ concentration makes late-successional species less attractive to herbivores. This could also be observed comparing the degree of herbivory damage in natural forest with the secondary forest and agroforestry system. There was a strong, positive correlation between SLA and leaf nitrogen, as well as phosphorus concentration in the complete random sample and within all four land use types. The tightest correlation between N and SLA was reached within the natural forest family Lauraceae and the Lauraceae species Litsea sp.1. Similar results have been reported from a natural forest stand in Brazil by Meir et al. (2001) and from a study comprising several successional stages in Venezuela by Reich et al. (1994).

Low SLA means a high cell density or a high dry-mass content of the cells. Higher cell biomass can be achieved through accumulation of any kind of metabolites, or increasing cell wall thickness (Castro-Díez et al. 2002). As cell walls are N-poor (Niemann et al. 1992) low SLA due to increased cell wall thickness would normally be coupled with low leaf $\mathrm{N}$ concentration. According to this, the lower SLA in the natural forest and forest garden compared to the secondary forest and agroforestry system in this study might primarily be due to higher cell wall thickness, since a close correlation between SLA and leaf N concentration existed.

\subsubsection{Leaf size}

\section{Leaf size distribution among natural forest species}

Bout \& Okitsu (1999) investigated leaf size variations of tree species occurring on elevations from 1200 to $2700 \mathrm{~m}$ asl in a tropical rainforest in the Philippines. They thereby used the leaf size classes defined by Raunkiaer (1934) and modified by Webb (1959). Aiba \& Kitayama (1999) did the same on 700 and $1700 \mathrm{~m}$ asl on Mount Kinabalu, Borneo, as did Schneider et al. (2003) in San Javier Valley in Venezuela on $2300 \mathrm{~m}$ asl. Compared to their data the species in this study were somewhat shifted towards the larger leaf-size classes, as depicted in Table 5.1. The difference compared to Mount Pulog, San Javier and the $1700 \mathrm{~m}$ Borneo sample is probably associated with the altitudinal differences. Bout \& Okitsu (1999) and Schneider et al. (2003) found a tendency of decreasing leaf sizes with increasing elevation, which is also obvious if comparing the two different plots in the Borneo study. Further support for this theory is given by the findings of Ackerly et al. (2002), concerning 
Table 5.1 Distribution of leaf sizes among natural forests tree species on Mount Pulog on the Philippine Luzon Island (Bout \& Okitsu 1999), Mt. Kinabalu, Borneo (Aiba \& Kitayama 1999), San Javier, Venezuela (Schneider et al. 2003) and Lore Lindu, Sulawesi. Species means classified according to Raunkiaer (1934) and Webb (1959) and presented as percentage of total number of species. The Mount Pulog sample consisted of $8 \%$ coniferous and fern species, which are not included in this table. The Borneo $700 \mathrm{~m}$-sample had 1\% missing data. (No. spec Total number of species)

\begin{tabular}{lccccccccc}
\hline $\begin{array}{l}\text { Study } \\
\text { region }\end{array}$ & $\begin{array}{l}\text { Altitude } \\
\text { [m asl] }\end{array}$ & $\begin{array}{l}\text { No. } \\
\text { spec }\end{array}$ & $\begin{array}{l}\text { Lepto } \\
\text { phyll }\end{array}$ & $\begin{array}{l}\text { Nano } \\
\text { phyll }\end{array}$ & $\begin{array}{l}\text { Micro } \\
\text { phyll }\end{array}$ & $\begin{array}{l}\text { Noto } \\
\text { phyll }\end{array}$ & $\begin{array}{l}\text { Meso } \\
\text { phyll }\end{array}$ & $\begin{array}{l}\text { Macro } \\
\text { phyll }\end{array}$ & Reference \\
\hline Mt. Pulog & $1200-700$ & 36 & 0 & 11 & 56 & 19 & 6 & 0 & Bout \& Okitsu 1999 \\
San Javier & 2300 & 38 & 0 & 0 & 22 & 24 & 46 & 8 & Schneider et al. 2003 \\
Borneo & 1700 & 121 & 2 & 2 & 36 & 36 & 23 & 1 & Aiba \& Kitayama 1999 \\
Borneo & 700 & 163 & 1 & 0 & 15 & 34 & 45 & 4 & Aiba \& Kitayama 1999 \\
Lore Lindu & $900-1100$ & 69 & 0 & 0 & 2 & 15 & 61 & 22 & This study \\
\hline
\end{tabular}

the relation between leaf size and nutrient availability and the general state of diminishing soil nutrient levels at higher altitudes. Leaf size belongs to those parameters that are subject to high phenotypic plasticity, depending on local environmental conditions like moisture and nutrient availability. Leaf size has also been proved to decrease with decreasing temperature, which is common on higher altitudes (Ackerly et al. 2002).

The difference between the Lore Lindu sample on 900 - $1100 \mathrm{~m}$ and the $700 \mathrm{~m}$ Borneo sample might have floristic reasons. Many large leaved genera that were not reported by Aiba \& Kitayama (1999) were present in the Lore Lindu sample. Considering the high altitude $(2300 \mathrm{~m})$, the species in San Javier also show relatively large leaf sizes.

\section{Leaf size differences between forest types}

Although still significantly different, it might be surprising that the difference in mean leaf size between the secondary forest and natural forest random samples was not larger (SF: $222 \pm 243 \mathrm{~cm}^{2}$ and NF: $140 \pm 161 \mathrm{~cm}^{2}$ ). The relatively small difference is explained by high numbers of the small leaved Homalanthus populneus, but also other species with minor leaf size, occurring in the secondary forests. The high standard deviation reminds on the remarkably high variability within SF. The presence of a few large leaved species among others from the genus Dendrocnide (Urticaceae) has contributed considerably to the elevation of the mean leaf size value for NF.

\subsubsection{Length-width ratio}

The significantly highest mean length-width ratio among the four land use types was found for the natural forest. The value $\left(2.87 \mathrm{~cm} \mathrm{~cm}^{-1}\right)$ is certainly influenced by the presence 
of three very long leaved genera, Arenga, Dracaena and Pandanus, with species means of 22, 21 and $15 \mathrm{~cm} \mathrm{~cm}^{-1}$ respectively, but as is visualized in the Figure 4.5 and Figure 4.6, the general leaf form of typical natural forest species is indeed rather elongated, whereas the typical pioneer leaf shape is rounded.

The round leaf shape of predominant secondary forest species was reflected by the significantly lowest mean length-width ratio (LW) obtained in this land use system $(1.57 \mathrm{~cm}$ $\left.\mathrm{cm}^{-1}\right)$. It is noteworthy that the rounded leaf shape within the secondary forest is consistent throughout the extended scale of leaf sizes existing: Homalanthus populneus has a similar leaf shape (LW $1.4 \mathrm{~cm} \mathrm{~cm}^{-1}$ ) to the 25 times larger leaves of Macaranga tanarius (LW 1.1 $\left.\mathrm{cm} \mathrm{cm}^{-1}\right)$.

Mc Donald et al. (2003) tested the manner of leaf size changes with soil-P reduction for adult sun leaves of 690 evergreen perennial plants in southeast Australia. They thereby found that leaf narrowing with little shortening, or shortening with little narrowing was as common as isometric leaf size reduction (length and width being shortened equally). Thus, local soil nutrient conditions could be one explanation to the large intraspecific variation in length-width ratio, as was found in several species in this study. Herbivory rate, leaf chemistry, leaf position on the branch and leaf angle are additional factors possibly affecting intraspecific variation of leaf form in a given environment (personal observations).

Similarly, differences in nutrient supply and light regimes are also possible explanations for the achieved differences in leaf form and size between natural and secondary forests.

\subsubsection{Compound leaves}

Aiba \& Kitayama (1999) reported 18\% compound leaved species from their plot in a submontane moist forest on $700 \mathrm{~m}$ on Mount Kinabalu. This is similar to the $14 \%$ of the species investigated in this study. On their $1700 \mathrm{~m}$ plot however, they found only $6.7 \%$ compound leaved species and no on $2700 \mathrm{~m}$ or $3100 \mathrm{~m}$. This suggests an altitudinal trend of decreasing occurrence of compound leaved tree species, which was confirmed by Schneider et al. (2003).

Compound leaves have also been reported more frequent in arid to semi arid areas, in lowland rainforests and in gap phases (Aiba \& Kitayama 1999; Schneider et al. 2003). The evolutionary reasons for these distribution patterns of compound leaves are less known though.

Interestingly, Schneider et al. (2003) found the same relations as this study assessed, concerning natural forest hosting a higher percentage of individuals, but lower percentage of species with compound leaves, than the secondary forest. Aiba \& Kitayama (1999) 
coherently found a lower proportion of compound leaved species in the natural forest than in the secondary forest. The three times higher frequency of compound leaved individuals found in the natural forest samples compared to the secondary forest might be explained by some competitive advantages of a couple of species (in this study e. g. Aglaia argentea, Meliosma sumatrana and Chisocheton spp.) that are independent of their compound leaf status. However, the coherence with Schneider's et al. (2003) and Aiba \& Kitayama's (1999) results suggests that there could also be an ecological explanation.

\subsubsection{Chemical leaf traits}

\subsubsection{Nitrogen and phosphorus dynamics and land use change}

Tropical rainforests have a high nitrogen turnover rate. Nitrogen incorporated in leaf tissue is returned to soil in approximately one year, where it is decomposed to plantavailable forms by micro-organisms (Swamy \& Proctor 1994), which are also important for $\mathrm{N}$ input through $\mathrm{N}_{2}$-assimilation. Yet, slash-and-burn management of forest areas have high impact on soil nitrogen and phosphorus dynamics through elimination of the soil microorganisms by heat (Giardina et al. 2000). Giardina et al. (2000) found that the main input of plant-available $\mathrm{N}$ and $\mathrm{P}$ by slash-and-burn is due to lysis of microbial biomass in the heated soil, rather than to ash of burned vegetation. Furthermore, they concluded that the soil-N improvement by this method is highly temporary because if volatilisation of $\mathrm{NH}_{3}$. This could be one reason why no significant differences in topsoil $\mathrm{N}$ could be determined between NF, SF and AF in this study, although the SF- and AF-stands were former slashand-burn sites. A reason why the forest garden showed a significantly lower topsoil $\mathrm{N}$ concentration than the natural and secondary forest stands might be the low tree density, according to Ayanaba \& Sanders (1981). They proposed that ammonium is rapidly converted to nitrate, if there are no tree roots competing with the nitrifying bacteria for the ammonium uptake. Nitrate is thereafter lost through leaching or denitrification. Crop species planted in cleared areas often only manage to take up very small amounts of the available nitrate and ammonia compared to trees, according to Ayanaba \& Sanders (1981).

Lawrence (2004) found more than twice as high P stocks in the $0-30 \mathrm{~cm}$ soil cover of secondary forests on slash-and-burn sites, than in natural forests in West Kalimantan, Indonesia. In contrast to Giardiana et al. (2000), this author proposes above-ground biomass of the former natural forest to be the main source for soil phosphorus after slash-and-burn. Since enhanced levels of plant accessible $\mathrm{P}$ have been shown to persist over longer periods than the highly temporary nitrogen increases (Giardina et al. 2000), these results could be 
associated with the achieved large influence of leaf $\mathrm{N}$ concentration on $\mathrm{A}_{\max }$ in the secondary forest stands.

\subsubsection{Foliar nitrogen concentration}

The achieved means of leaf nitrogen concentration in the four land use types studied were very similar between the random sample and the species average, with the largest difference obtained for secondary forest (species average $22.5 \mathrm{~g} \mathrm{~kg}^{-1}$ compared to 25.0 in the random sample). Similarly, the interspecific variability for $\mathrm{N}$ was low. Compared to the optimum values around $30 \mathrm{~g} \mathrm{~kg}^{-1}$ reported for some abundant mid- or late-successional deciduous tree species in the temperate zone by van den Burg (1990), the obtained mean nitrogen concentrations in this and other tropical studies were relatively low (species average means in this study in $\mathrm{g} \mathrm{kg}^{-1}: 21.7$ (NF), 22.5 (SF), 20.6 (FG), 33.4 (AF)).

Reich et al. (1994) studied leaf traits in Amazonian rainforest communities and reported foliar $\mathrm{N}$ values even somewhat lower than the results of this study. This was true especially for natural forest species ( $13-16$ compared to $\left.11-41 \mathrm{~g} \mathrm{~kg}^{-1}\right)$, whereas the difference between the two early-successional species samples was smaller (15 - 30 compared to 12 $\left.45 \mathrm{~g} \mathrm{~kg}^{-1}\right)$. The higher values in the Sulawesi natural forest species might be stand related, since the soils in the study region are very fertile (Dechert 2003). The wider span is likely due to the higher species number in the present study compared to Reich et al.. For further comparison, $\mathrm{N}$ values around $25 \mathrm{~g} \mathrm{~kg}^{-1}$ were reported for the early-successional Cecropia ficifolia and between 10 and $20 \mathrm{~g} \mathrm{~kg}^{-1}$ in four late-successional species in a nutrient poor Amazonian area (Ellsworth \& Reich 1996), which is comparable with the results of this study if keeping the different soil status in mind.

\subsubsection{Nitrogen isotope signature - $\delta^{15} N$}

\section{Soil - plant relation and microbial symbiosis for $N$ acquisition}

There is a complex relation between $\delta^{15} \mathrm{~N}$ values in plant material and the nitrogen concentration of the soil, depending on factors like discrimination against ${ }^{15} \mathrm{~N}$ by nitrification, denitrification, volatilisation of ammonia etc. (Kitayama \& Iwamoto 2001; Högberg \& Alexander 1995). Nevertheless, most authors do not consider soil nitrogen properties in association with studies on possible plant $\mathrm{N}_{2}$-fixation (Spriggs et al. 2003; Roggy et al. 1999). In this study the relations between $\delta^{15} \mathrm{~N}$ and total $\mathrm{N}$ in leaves and soil were only investigated at the level of land use means. An investigation at species level associated to the search for $\mathrm{N}_{2}$-fixing species was not possible. 
A significant positive correlation between foliar $\mathrm{N}$ and $\delta^{15} \mathrm{~N}$ was found within three land use types (NF: $r^{2}=0.08$; FG: $r^{2}=0.29$; SF: $\left.r^{2}=0.20, p<0.05\right)$. AF was excluded from this particular investigation because it is a very artificial system with low species number. The same relation was found by Kitayama \& Iwamoto (2001), who studied the $\delta^{15} \mathrm{~N}$ and $\mathrm{N}$ abundance in a tree leaf-litter-soil continuum on Mount Kinabalu, Borneo, Malaysia. It further agrees with results of experiments with different $\mathrm{N}$ availability (Högberg 1990; Högberg \& Johannisson 1993) and along natural N gradients (Garten 1993; Garten \& Miegroet 1994; Hobbie et al. 2000). Kitayama \& Iwamoto (2001) suggest that such a correlation might be explained by the increased proportion of leaf-N acquired by mycorrhiza at N-poor sites, as isotopic discrimination during the mycorrhizal transfer of $\mathrm{N}$ to the plant roots causes low leaf $\delta^{15} \mathrm{~N}$ values, assuming a positive correlation between soil and plant $\mathrm{N}$. A second possible interpretation presented by Kitayama \& Iwamoto (2001) is that the soil $\delta^{15} \mathrm{~N}$ gets adjusted towards a higher proportion of ${ }^{15} \mathrm{~N}$ on particularly nitrogen rich sites, because of the high nitrification rate that is common in N-rich soils. The nitrification produces ${ }^{15} \mathrm{~N}$-depleted $\mathrm{NO}_{3}$ that will disappear through denitrification or leakage. Thus the remaining $\mathrm{N}$ pool available for the tree roots would have an elevated ${ }^{15} \mathrm{~N}$ concentration in $\mathrm{N}$ rich soils. Kitayama \& Iwamoto (2001) proved their theory with found positive correlations between foliar $\delta^{15} \mathrm{~N}$ and $\mathrm{NO}_{3}$ concentrations in soil. In the present study though, $\mathrm{NO}_{3}$ concentration was not investigated.

Salas et al. (2001) proved that pruning influences the nodule formation ability and $\mathrm{N}_{2}$ fixation in the leguminous genera Erythrina. Thus, the extension and frequency of pruning is most likely of great importance for soil quality in the studied agroforestry systems, through the influence on $\mathrm{N}_{2}$-fixation, as well as the contribution of $\mathrm{N}$ from the decomposing plant material (3.1.2 Soil). The agroforestry system stands showed the highest soil $\delta^{15} \mathrm{~N}$ values among the four land use types studied. This is probably associated with the high mean foliar $\delta^{15} \mathrm{~N}$ found for this system, as soil $\delta^{15} \mathrm{~N}$ is influenced by the nitrogen input from leaf litter. Kitayama and Iwamoto (2001) stated that the $\delta^{15} \mathrm{~N}$ in litter is always higher than in the original foliage, which further contributes to an elevated soil mean $\delta^{15} \mathrm{~N}$. The low ratios of foliar $\delta^{15} \mathrm{~N}$ to soil $\delta^{15} \mathrm{~N}$ in the natural forest and agroforestry stands could be interpreted as additional support for the result that these two land use types had higher proportions of possible $\mathrm{N}_{2}$-fixing species than secondary forest and forest garden, which is further discussed below. 
Putative $\mathrm{N}_{2}$-fixing species

Spriggs et al. (2003) recognized the obvious problem of finding relevant reference values for investigating occurrence of $\mathrm{N}_{2}$-fixing species. They compared each of their studied species in pairs with spatially close members of known non- $\mathrm{N}_{2}$-fixing tree and shrub species (reference) in the fynbos in South Africa. The comparison only considered $\delta^{15} \mathrm{~N}$, and not total nitrogen concentration of leaves or soil. Every species with significantly lower $\delta^{15} \mathrm{~N}$ values than its reference species was considered to be depending on mycorrhiza for their $\mathrm{N}$ acquisition. Roggy et al. (1999) however, stressed the importance of including total leaf N concentration and developed a somewhat more sophisticated method for the same purpose.

It is indeed hard to generalize about any absolute values of total $\mathrm{N}, \delta^{15} \mathrm{~N}$ and possibly also soil nitrogen content that could be used as threshold between $\mathrm{N}_{2}$-fixers and non- $\mathrm{N}_{2-}$ fixers, but since the data of Roggy et al. cohere very well with the data in this study concerning total $\mathrm{N}, \delta^{15} \mathrm{~N}$, as well as the environmental factors of the study areas, their classification was applied to the sample of species investigated in this study. By these means an overview of the presence of putative $\mathrm{N}_{2}$-fixing species in the sample was enabled.

The results of the present study can be compared with those reported on pioneer species from a rainforest in French Guiana by Roggy et al. (1999) in Table 5.2. They found a somewhat higher proportion of possible $\mathrm{N}_{2}$-fixers in their sample of pioneers than what was recorded in the secondary forest in Sulawesi.

Table 5.2 Results of the investigation of putative $\mathrm{N}_{2}$-fixation by pioneer species in a rain forest in French Guiana conducted by Roggy et al. (1999) compared to the results in this study. All species present in each land use system was classified into three different groups according to their $\mathrm{N}_{2}$-fixing status. The amount of species is presented as percent of total.

\begin{tabular}{lccccc}
\hline & \multicolumn{5}{c}{$\begin{array}{c}\text { Proportion of species } \\
{[\%]}\end{array}$} \\
\cline { 2 - 6 } & $\begin{array}{c}\text { Pioneer species } \\
\text { sample of Roggy et al. } \\
(\mathbf{1 9 9 9 )}\end{array}$ & $\begin{array}{c}\text { Natural } \\
\text { forest }\end{array}$ & $\begin{array}{c}\text { Forest } \\
\text { garden }\end{array}$ & $\begin{array}{c}\text { Secondary } \\
\text { forest }\end{array}$ & $\begin{array}{c}\text { Agroforestry } \\
\text { system }\end{array}$ \\
\hline Putative $\mathrm{N}_{2}$-fixing & 35 & 30 & 16 & 23 & 50 \\
Putative non- $\mathrm{N}_{2}$-fixing & 22 & 26 & 32 & 26 & 50 \\
Uncertain other species & 43 & 41 & 47 & 51 & 0 \\
\hline Total species number & 23 & 69 & 19 & 35 & 4 \\
\hline
\end{tabular}

As can be seen in Table 5.2, as much as $40 \%$ to $50 \%$ of the species in three of the land use types could not be definitely identified as $\mathrm{N}_{2}$-fixing or not, because of low $\delta^{15} \mathrm{~N}$ combined with relatively low total $\mathrm{N}$ values, and were thus classified as "uncertain other species". It is unclear whether this rather frequent trait combination should be interpreted as existence of 
$\mathrm{N}_{2}$-fixation, but at nitrogen poor sites, generating only low total $\mathrm{N}$ values, or if there are other possible pathways discriminating against ${ }^{15} \mathrm{~N}$ besides those of the $\mathrm{N}_{2}$-fixing symbionts. The latter reason is however unlikely, according to literature (Högberg \& Johannisson 1993; Kitayama \& Iwamoto 2001).

The fact that the lowest proportion of non- $\mathrm{N}_{2}$-fixing species was found in the forest garden, suggests that $\mathrm{N}_{2}$-fixation ability had not been taken into account in the selection of natural forest trees to form the shading canopy.

Conclusions concerning the dependence on $N_{2}$-fixing symbionts among the studied tree species

Conclusively, the relations between soil and foliage nitrogen concentrations and ${ }^{15} \mathrm{~N}$ discriminating processes in the rhizosphere are very complex and available literature gives partly divergent explanations. Despite this, an appropriate way of investigating the dependence on $\mathrm{N}_{2}$-fixing free-living bacteria or symbionts for nitrogen acquisition in the 107 studied tree species of this work was found by means of applying a classification pattern according to Roggy et al. (1999). There are probably no universal classification method, but the Roggy model was assumed to be accurate for this specific sample because the four species with known $\mathrm{N}_{2}$-fixing status in the study fitted in the model and the results for SF are similar to those of Roggy et al.. The classification revealed a 30\% proportion of putative $\mathrm{N}_{2}$-fixing species in the natural forest, $23 \%$ in the secondary forest, $16 \%$ in the forest garden and $50 \%$ in the agroforestry system.

\subsubsection{Leaf gas exchange}

\subsubsection{Photosynthetic rate}

\section{Interspecific variations in $A_{\max }$}

Given the large variations in morphological leaf traits also among secondary forest species, the 1.4-fold difference between highest and lowest area-based species mean of $\mathrm{A}_{\max }$ appears astonishingly small in this land use system compared to the 3.7-fold differences achieved among the natural forest species. Thus, the eight secondary forest species form a relatively homogenous group concerning maximum photosynthetic net rates, compared to the eight natural forest species studied. If looking at stomatal conductance, this statement is further confirmed, since the difference in variation in this trait is even larger (1.9-fold in SF and 8.6-fold in NF). 
The $\mathrm{A}_{\max }$ rates of $14 \mu \mathrm{mol} \mathrm{m} \mathrm{m}^{-2} \mathrm{~s}^{-1}$ obtained for the two Macaranga species in this study were higher than the rates achieved by Davies (1998) in seedlings of nine Macaranga species, ranging from 7 to $13 \mu \mathrm{mol} \mathrm{m} \mathrm{m}^{-2}$. This can probably be assigned to the difference between seedlings and established trees under natural conditions (Thomas \& Winner 2002). Ishida et al. (1999) studied mature trees of Macaranga conifera and found $\mathrm{A}_{\max }$ rates similar to the results of this study $\left(12 \mu \mathrm{mol} \mathrm{m} \mathrm{m}^{-2} \mathrm{~s}^{-1}\right)$.

Marenco et al. (2001) investigated gas exchange in young trees of one late-successional (Dipteryx odorata) and one mid-successional (Swietenia macrophylla) species in the central Amazon. They thereby found $\mathrm{A}_{\max }$-rates similar to those found in this study (latesuccessional: $8.7 \mu \mathrm{mol} \mathrm{m} \mathrm{m}^{-2}$, mid-successional: $12.9 \mu \mathrm{mol} \mathrm{m}^{-2} \mathrm{~s}^{-1}$ ).

One of few other photosynthesis studies on mature trees was conducted on a small leaved, large stature pioneer in moist forests of Panama by Zotz \& Winter (1994). They reported an $\mathrm{A}_{\max }$-value of $18 \mu \mathrm{mol} \mathrm{m} \mathrm{s}^{-1}$, which is on the level of the likewise small leaved Homalanthus populneus $\left(18.3 \mu \mathrm{mol} \mathrm{m}^{-2} \mathrm{~s}^{-1}\right)$ and the mean value of the secondary forest achieved in this study $\left(17.5 \mu \mathrm{mol} \mathrm{m} \mathrm{m}^{-2} \mathrm{~s}^{-1}\right)$.

$A_{\max }$ related to leaf size

One of the most important differences between the correlation parameters found for $A_{\max }$-mass and those for $A_{\max }$-area was the strong dependence of $A_{\max }$-area on leaf size among the pioneer species. The larger the leaves, the lower their photosynthetic net rate per area unit $\left(\mathrm{p}=0.03, \mathrm{r}^{2}=0.56\right)$. This might be explained by boundary layer effects. According to this long, narrow leaf forms (high length-width ratio) probably have the same effect on gas exchange as small leaves, by reducing the boundary layer resistance and avoiding overheating through convection, which in turn allows high photosynthetic rate to be maintained at high insolation and air temperature. This theory was forwarded by Parkhurst \& Loucks and Givinish \& Vermeij and cited by Ackerly et al. (2002). However, the influence of this effect on the obtained $\mathrm{A}_{\max }$ is unclear, because it was measured in a closed cuvette close to the leaf edges. A second reason why large leaved species normally reach lower photosynthetic net rates than small, or lanceolate ones is a possible hydraulic limitation of water transport through the petiole.

The influence of leaf angle on $A_{\max }$

As have been shown, secondary forest had the highest $\mathrm{A}_{\max }$-values in the study and also the steepest leaf angles. Leaf angle had a considerable negative influence on $\mathrm{A}_{\max }$ among the 
studied secondary forest species. The two natural forest species with steepest leaf angles in this study, Meliosma sumatrana and Litsea sp., concordantly showed the lowest $\mathrm{A}_{\max }$-values within the natural forest, although no correlation between the two parameters existed in that land use type. The average observed leaf angle in the agroforestry system was the most horizontal among the three land use types. The shade tree species Gliricidia sepium had horizontal leaf angles and was extremely exposed to sunlight and heat throughout the day, but still showed high $\mathrm{A}_{\max }$ and high water use efficiency. On the contrary, the other important species in the agroforestry system, Theobroma cacao trees, was light sensitive. Especially the not yet fully developed leaves hang straight downwards $\left(180^{\circ}\right)$. This species consequently had lower $\mathrm{A}_{\max }$ than Gliricidia sepium.

Steep leaf angles could increase light capture in the mornings and afternoons, and mean less exposure to the high irradiation intensity at noon. Several authors claim that through the avoidance of the midday heat shock, plants with steep leaf angles can keep a relatively high water use efficiency and reduce the risk of damage by heat (King 1997; Ishida et al. 1999). It is discussed whether this is negative or positive for the overall daily carbon gain. Falster \& Westoby (2003) conducted tree architectural modelling and found evidence that the main effect of steeper leaf angles is reduction of exposure to excess light levels during midday, rather than maximising carbon gain. They assumed that the access to the more horizontal light is limited through shading effects of neighbouring trees.

Evaluating the light response curves of photosynthetic net rate for each species would possibly help understanding the relation between leaf angle and $A_{\max }$, since low $A_{\max }$ in a species with steep leaf angles might be a consequence of the fact that they have evolved with lower light intensities than horizontal leaves, and thus might reach their $\mathrm{A}_{\max }$ earlier, at lower light intensities. A reason why this correlation was found in the secondary forest, but not in the natural forest, might be the steeper average leaf angle in this land use type and the higher influence of shading by neighbouring trees in a typical SF stand structure, compared to NF. Further, a typical natural forest species leaf has lower SLA and might be better protected against damage by high light intensities and heat even in a more horizontal angle, yet with reduced transpiration and photosynthetic rates.

\subsubsection{Stomatal conductance for water vapour}

The mean $\mathrm{g}_{\mathrm{smax}}$ of secondary forest species $\left(609 \pm 205 \mathrm{mmol} \mathrm{m}^{-2} \mathrm{~s}^{-1}\right)$ was higher than that of natural forest species $\left(368 \pm 232 \mathrm{mmol} \mathrm{m}^{-2} \mathrm{~s}^{-1}\right)$ in this study. However, the two species Bischofia javanica and Cananga odorata, studied in the natural forest had $\mathrm{g}_{\text {smax }}$ 
values entering the range of the secondary forest species, which confirms the observed "cross-over" life history of these two species.

Comparable $g_{s}$ values were reported from the late-successional species Swietenia macrophylla (266 mmol m $\left.\mathrm{m}^{-2} \mathrm{~s}^{-1}\right)$ in the central Amazon by Marenco et al. (2001), whereas the mean $\mathrm{g}_{\mathrm{s}}$-values obtained by Huc et al. (1994) in French Guiana were lower (pioneers: $282 \mathrm{mmol} \mathrm{m}^{-2} \mathrm{~s}^{-1}$, late-successional: $191 \mathrm{mmol} \mathrm{m}^{-2} \mathrm{~s}^{-1}$ ). Given the difference between $\mathrm{g}_{\mathrm{s}}$ and $\mathrm{g}_{\text {smax }}$, the lower values measured by Huc et al. are probably primarily caused by the fact that they studied young treelets in a plantation, in contrast to the mature or premature trees studied in this work, as mature trees generally have higher gas exchange rates than young ones (Thomas \& Winner 2002).

\section{Stomatal conductance as depending on VPD}

Most plants exhibit a decline in $g_{s}$ with increasing water vapour pressure deficit (VPD) and considerable variation in the sensitivity of the response among different plant species have already been reported (Meinzer et al. 1993; Oren et al. 1999). Commonly, high sensibility (b) of stomatal conductance to VPD in a species is associated with a higher $\mathrm{g}_{\mathrm{s}}$ at a given VPD (Yong et al. 1997; Oren et al. 1999), which was also shown in the present study, as $g_{\text {smax }}$ was closely correlating with $b$ in a sample of 13 species.

However, the more detailed analysis revealed that stomatal conductance in the secondary forest species studied was much more sensible to VPD than in the natural forest species. Only two of the eight studied natural forest species showed a significant correlation between $g_{s}$ and VPD, whereas all secondary forest species and the three agroforestry species studied showed a significant correlation. No similar division between secondary and natural forest species in this respect have been found in literature, but Oren et al. (1999) reported that stomata regulation in drought tolerant, desert species was less sensitive to changes in VPD than drought sensitive species. Similarly, there might be a microclimatological explanation to the found difference between SF and NF. Typical secondary forest species with high SLA could be more drought sensitive than large stature, late-successional species, with more coriaceous leaves. Granier et al. (2000) investigated $\mathrm{g}_{\mathrm{c}}$ (canopy conductance, based on sapflux and above-canopy-climate data), as a function of VPD in forests dominated by various species. They found a slightly lower sensitivity to VPD in shade tolerant species than in the light demanding. Even if the found division between SF and NF species can not fully be explained by difference in drought or shade tolerance, it is certainly associated with the higher variability in microclimate in secondary vegetation compared to natural forest canopies (Culf 
et al. 1996), which demands a faster and more flexible response in stomatal conductance regulation to VPD.

\section{Stomatal conductance as depending on $\mathrm{Ca}$}

Furthermore, leaf calcium concentration had a large influence on $g_{\text {smax }}$ among the secondary forest species $\left(\mathrm{r}^{2}=0.67, \mathrm{p}=0.01\right)$, but played no role for $\mathrm{g}_{\mathrm{smax}}$ in the natural forest $\left(r^{2}=0.001, p=0.94\right)$. This great difference might have similar reasons as the dependence of VPD in the secondary forest, since leaf Ca concentrations influence the transpiration rate through the passive Ca-transport that regulates stomata opening (Ward \& Schroeder 1994).

\section{Stomatal conductance related to other leaf traits}

In the natural forest sample $g_{\text {smax }}$ was primarily depending on SLA according to the multiple regression analysis, but the correlation analysis showed no significant correlation between $g_{s m a x}$ and any leaf trait in this sample. Among the secondary forest species, $g_{s m a x}$ was linked to $\mathrm{Ca}, \mathrm{P}$ and leaf angle. The role of leaf angle concerning $\mathrm{g}_{\mathrm{smax}}$ is probably similar to its influence on $\mathrm{A}_{\max }$, as have been discussed above. Neither NF, nor SF showed any influence of $\mathrm{N}$ on $\mathrm{g}_{\mathrm{smax}}$, but in the 19-species sample, comprising NF, SF and AF, there was a significant correlation to leaf $\mathrm{N}$, which however was weaker than the relation to $\mathrm{P}(\mathrm{N}$ mass: $r^{2}=0.42, p<0.01$, P-mass: $r^{2}=0.64, p<0.01$, which might partly be explained by the high soil $\mathrm{N}$ concentration in the area.

\subsubsection{Carbon isotope signature}

\section{The Sulawesi data as compared to other tropical forests}

Several factors are known to contribute to heterogeneity in $\delta^{13} \mathrm{C}$ value among species and among plant communities or forests. Some predominant factors are light regimes or canopy openness (Martinelli et al. 1998), $\mathrm{CO}_{2}$-concentration and $\delta^{13} \mathrm{C}$ of the source air (Buchmann et al. 1997), differences in VPD and mineral nutrient availability (Leffler \& Enquist 2002). Several studies have confirmed that carbon isotope discrimination under given environmental conditions is a heritable trait (Martin \& Thorstenson 1988; Hubick et al. 1988). Since all leaves collected for this study grew under similar light regimes (all sun leaves from mature trees) and the soil and VPD conditions were comparable, the substantial variations in $\delta^{13} \mathrm{C}$ obtained in a given land use type can certainly be considered as due to species differences in $\delta^{13} \mathrm{C}$ discrimination. 
$\delta^{13} \mathrm{C}$ values as low as $-32.1 \%$ have been reported from tropical moist forests in Brazil (Martinelli et al. 1998). Typical values reported from dry tropical forests are somewhat higher: -29.0\% in Venezuela (Sobrado \& Ehleringer 1997) and -26.8\%o in northern Australia (Schulze et al. 1998). Körner et al. (1991) referred to an observed 5\%o-units decrease in $\delta^{13} \mathrm{C}$ in air $\mathrm{CO}_{2}$ when moving from arctic tundra to tropical forests. This latitudinal change might be one of several reasons why more negative $\delta^{13} \mathrm{C}$ were found in the present equatorial study than in sub-tropical or temperate zones.

Bonal et al. (2000) studied a sample of trees in tropical Guiana, which was comparable to this study, since it comprised only mature sun leaves from mature trees and covered a similar amount of species (102). In that sample they found a $\delta^{13} \mathrm{C}$ range of $7.3 \%$ (from 34.8 to $-27.5 \%$ ). This is very similar to the $7.8 \%$ range in the 107 species sample from Sulawesi (-33.8 to $-26.0 \%$ ). However, the Sulawesi range was about 1\%o-unit higher than the Guiana. A 7\%o range is much larger than most others reported so far. Shorter ranges have been reported even from studies comprising canopy and understorey species, probably because most studies include much lower species numbers than Bonal et al. (2000) and the present work.

\section{$\delta^{13} C$ in early-and late-successional species}

In the present study lower (more negative) $\delta^{13} \mathrm{C}$ means were found for natural forest ($30.2 \%)$ and forest garden $(-29.8 \%)$ than secondary forest $(-27.8 \%$ ) and the agroforestry system $(-27.9 \%)$. This is opposite to the simple paradigm that pioneer species generally have lower $\delta^{13} \mathrm{C}$, and thus, according to theory, a lower water use efficiency, than late-stage ones (Pate et al. 1998). This statement is based on studies conducted in plantations, on seedlings or under environmental conditions irrelevant for tropical ecosystems. In recent time several authors have therefore questioned that paradigm (Leffler \& Enquist 2002; Guehl et al. 1998; Bonal et al. 2000).

Guehl et al. (1998) studied 18 tree species in a rainforest in French Guiana and found that some very abundant late-stage canopy species presented lower $\delta^{13} \mathrm{C}$ values than pioneer species. Bonal et al. (2000), also studying tropical rainforest stands in French Guiana, observed less negative $\delta^{13} \mathrm{C}$ values in heliophilic tree species than in shade-tolerant ones. As it can be assumed that most of the species studied in the secondary forest stands are less shade-tolerant than the natural forest species, both Bonal's and Guehl's findings would in parallel confirm the results of this work. Neither Guehl et al. (1998) nor Bonal et al. (2000) could provide a straightforward ecophysiological interpretation of their results, but Bonal et 
al. hypothesise about the low $\delta^{13} \mathrm{C}$-values found as possibly associated with low $\mathrm{A}_{\max }$, however without further explanation. This theory that was not investigated by Bonal, was supported by the results of this study. In a sample of 19 species occurring in different land use types in Sulawesi highly significant positive correlations were found between $\delta^{13} \mathrm{C}$ and $\mathrm{A}_{\text {max }}$-area $\left(\mathrm{r}^{2}=0.36, \mathrm{p}<0.01\right)$, as well as $\mathrm{g}_{\text {smax }}\left(\mathrm{r}^{2}=0.41, \mathrm{p}<0.01\right)$, whereas no correlation to WUE existed. Analysing the relations within each land use type though, did not uncover any correlations between $\delta^{13} \mathrm{C}$ and $\mathrm{A}_{\max }$ or $\mathrm{g}_{\text {smax }}$.

\section{Variations in $\delta^{13}$ C among different leaf morphological types}

Leffler \& Enquist (2002) found significant differences in $\delta^{13} \mathrm{C}$ between soft and coriaceous leaves, where soft leaves had more negative $\delta^{13} \mathrm{C}$ values. This is opposite to the results of the present study, where one of the most negative species means of $\delta^{13} \mathrm{C}$ was found in the coriaceous-leaved Litsea sp.1. (-32.6\%), followed by other late-successional natural forest species with $\delta^{13} \mathrm{C}$ below $-31 \%$, for example within the families Lauraceae and Moraceae. The highest species means of $\delta^{13} \mathrm{C}$ (around -27\%) were achieved in rather softleaved species from secondary forest stands like Macaranga tanarius and Mallotus mollissimus and in Cananga odorata, which have softer leaves than many other natural forest species. Furthermore, the correlation analysis in the complete random sample of trees from four land use types detected a weak, but significant correlation of $\delta^{13} \mathrm{C}$ with SLA $\left(\mathrm{r}^{2}=\right.$ $0.08, \mathrm{p}<0.01$ ), which has also been reported by Vitousek et al. (1990). In the same sample $\delta^{13} \mathrm{C}$ showed to be negatively depending on total leaf C content, which Turner et al. (2000) also obtained in two tropical forests. As far as low SLA reflects how coriaceous leaves are, this and the found negative correlation between $\delta^{13} \mathrm{C}$ and total carbon content, are further evidence for an opposite relation to that reported by Leffler \& Enquist (2002).

Significant correlations were found between $\delta^{13} \mathrm{C}$ and length-width ratio (negative), as well as leaf size (positive) in the complete random sample and, with higher $r^{2}$, within the secondary forest sample. This might be explained by the positive influence of internal $\mathrm{CO}_{2}$ concentrations on the discrimination rate against ${ }^{13} \mathrm{C}$ by Rubisco, as that small and elongated leaves have a more efficient $\mathrm{CO}_{2}$-supply, because of less boundary layer resistance, and hence a higher discrimination rate, which is shown by the more negative $\delta^{13} \mathrm{C}$-values. Assuming a positive relation between $\delta^{13} \mathrm{C}$ and water use efficiency, a second possible explanation for these results might be the high evaporative demand in the canopy of the secondary forest stands. The larger and rounder the leaves, the better possibilities to build up a boundary layer of more humid air along the leaves, enabling a high water use efficiency 
even under extremely hot and dry conditions. Most natural forest species were very similar in leaf size and form, probably leading to small differences in boundary layer, which could explain why no correlation between leaf size or length-width ratio and $\delta^{13} \mathrm{C}$ could be detected within this forest type. Moreover, the microclimatological conditions in the natural forest canopy are generally less extreme than in secondary forest stands.

\subsubsection{Water use efficiency}

Huc et al. (1994) found a mean water use efficiency (WUE) of $43 \mu \mathrm{mol} \mathrm{mol}^{-1}$ in pioneers (ranging from 37 to 47), whereas the late stage species studied showed the higher mean value of $69 \mathrm{mmol} \mathrm{mol}^{-1}$ (64 and 74). Those results are similar to what was found in this study, where the secondary forest species showed an average of $45 \mu \mathrm{mol} \mathrm{mol}^{-1}$ (range: 28 64), and the natural forest species $51 \mu \mathrm{mol} \mathrm{mol}^{-1}$ (range: 34 - 84). Thus, both studies found higher WUE-values among natural forest species than within the secondary forest. However, it is important to notice that the difference between the land use types was not significant. The ranges were larger in the present study because of the higher number of species included. The higher values in NF could be a consequence of the smaller mean leaf size in this land use type, resulting in a thinner boundary layer, which enables a more efficient $\mathrm{CO}_{2-}$ supply as related to the water loss than in the average SF-leaf.

Contrary to $\mathrm{A}_{\max }$ and $\mathrm{g}_{\mathrm{smax}}$, the three agroforestry species formed a rather homogenous group concerning water use efficiency, with a higher mean than the two other land use types $\left(56 \mu \mathrm{mol} \mathrm{mol}{ }^{-1}\right)$.

It is interesting that despite, or maybe just because of, large interspecific differences within the land use types, no significant difference for WUE could be detected between the three land use types. Maybe some species specific leaf properties that are relatively independent on the species successional status, like leaf hairiness etc., have larger influence on water use efficiency than leaf traits more tightly related to land use type. This is a contrast to the vast differences in $A_{\max }$ and $g_{\text {smax }}$ means between the three land use types and is likely a reason why no correlation between WUE and $\delta^{13} \mathrm{C}$ could be detected. This supports the statement by Leffler \& Enquist (2002) that the relation between $\delta^{13} \mathrm{C}$ and WUE in tropical trees appears more complex than previously thought.

\subsubsection{LAI and related parameters}

The three-dimensional structure of the forest is of great importance as it determines radiation regimes, spatial competition etc.. There are several methods of describing and 
quantifying the three-dimensional structure and canopy cover: from above, over large areas with remote sensing, or from underneath the canopy with hemispherical photo techniques, which was the method used in this study.

\subsubsection{LAI in the studied stands as compared to other tropical forests}

Cournac et al. (2002) obtained LAI-values around 4 (ranging from 1.0 to 5.8, obtained with an optical device constructed by the authors) in a tropical lowland forest in French Guiana, which is comparable to the results of the present study. The mean LAI observed in the tropical submontane natural forest in this study was $3.6 \mathrm{~m}^{2} \mathrm{~m}^{-2}$ (range: $2.5-6.8$ ), which is also very similar to the $4.0 \mathrm{~m}^{2} \mathrm{~m}^{-2}$ reported from an undisturbed natural forest in Brazil by Meir et al. (2001). Trichon et al. measured PAI (plant area index, which includes branch and trunk areas, and thus reaches slightly higher values than LAI) and obtained values between 3.1 and $9.2 \mathrm{~m}^{2} \mathrm{~m}^{-2}$. These results should be particularly well comparable with the present study, since both were obtained in malesian natural forests with the same method. With the difference between PAI and LAI in mind, these data are also similar to the results of the present study. Some other literature data show higher LAI-values. Granier et al. (2000), working in the same area as Cournac, reported a mean LAI of $8.6 \mathrm{~m}^{2} \mathrm{~m}^{-2}$. These data however were collected with another method, using LiCor LAI 2000-equipment. It is hazardous to compare LAI values achieved with different technical methods and with different estimations and calculative approximations. Thus, it should be assured that the same equipment and the same calculation methods are used for comparing different forest types or different regions (Cournac et al. 2002).

\subsubsection{The relation between LAI and leaf traits}

LAI was negatively correlated with SLA and leaf N concentration if plot averages of several forest types were considered, representing a broad spectrum of growth strategies. The same correlation has been reported by Pierce et al. (1994) in a comparison of different forest types in Northern America and could be explained by the enhancing effects of an open canopy structure (low LAI) on plant growth rate, favouring trees with large, N-rich leaves. This kind of leaves typically also has high SLA values. In this study, of course the division between AF-plots with N-rich leaves and low stand level LAI on one hand, and NF-plots with high LAI and lower $\mathrm{N}$ on the other hand have influenced the found correlation.

If analysed within a forest type however, the relations between LAI, N and SLA depend on the heterogeneity of the forest stand studied. Natural forest sun canopies, mainly consisting of late-successional trees in their mature phase, have little variance in $\mathrm{N}$ 
concentration and SLA, whereas LAI in this forest type varies with the presence of gaps, but shows only low deviation as well. Therefore, the small variances in $\mathrm{N}$ concentration, SLA and LAI in natural forest stand are not likely to cohere. Pierce et al. (1994) also realized this, and concluded that using LAI to estimate canopy average SLA might provide inappropriate estimates of SLA in canopies that have recently been disturbed.

Pierce et al. (1994) further found the closest correlations between leaf $\mathrm{N}$ concentration and LAI at their coniferous sites in spring and explained this with the mobilization of $\mathrm{N}$ for new needle construction. The positive tendency found within the Sulawesi secondary forest stands, which are assumed to have a high growth rate, could have a similar explanation.

The agroforestry systems studied had great variances in LAI, also within plots, reflecting the heterogeneous structure of these systems. There was $5-10 \mathrm{~m}$ distance between the single cocoa trees, sparsely covered by shade trees. The small cocoa trees themselves had a very dense canopy (up to LAI $=9 \mathrm{~m}^{2} \mathrm{~m}^{-2}$ found on one of the plots studied). The mean leaf $\mathrm{N}$ concentration and SLA though, were very homogenous among the plots of this land use type, because of the low species number. Thus, no correlation between SLA or N and LAI existed within the agroforestry systems.

\subsubsection{The visible-sky parameter for forest dynamic assessment}

Trichon et al. (1998) used the hemispherical photo technique to qualitatively characterize the degree of disturbance and spatial changes in rainforest areas of Sumatra, Indonesia. Their method based on combining quantitative results with the qualitative observation of each picture, giving a valuable link between numeric values and actual disturbance or dynamic in a forest. They classified the pictures into three groups: gap, building and mature forest sites, which applied to terminology used in forest dynamic studies by Watt (1947) and Whitmore (1989). Trichon et al. (1998) state that the plant area index and leaf area index are not suitable for this quantification method, since similar LAI values were obtained at gaps and mature forest. Instead, the visible sky parameter should be used. A high percentage of visible sky suggests a potentially high dynamic. According to Whitmore at al. (1993) canopy openness calculated from hemispherical photos is also highly related to microclimate in gaps, and is thus important for forest regeneration issues.

Trichon's visible sky values ranged between 7.6 and $28.8 \%$ in the gap phases and from 1.4 to $5.1 \%$ on pictures classified as building and mature natural forest sites. Compared to this data the natural forest studied in this work would be classified as mature phase, having values ranging from 3.0 to $7.9 \%$, however with some gaps present. 


\subsubsection{MLA and visually observed leaf angles}

Even after adjusting recalculation, it is not possible to compare the visually observed leaf angle with the mean leaf angle calculated by the HemiView program (MLA) as equals. As obtained by different methods, the two parameters are differently defined in the threedimensional space. The visually observed single leaves were classified according to the angle and direction of the midrib, whereas the MLA and the adjusted values of the observed leaf angles do not indicate whether the leaf tips are directed upwards or downwards. Thus, a canopy consisting of $50 \%$ upwards $\left(45^{\circ}\right)$ and $50 \%$ downwards $\left(135^{\circ}\right)$ orientated leaves would generate a less informative MLA-value of $45^{\circ}$. However, in a light interception context this is of less significance. Further, MLA is an estimate of all leaves in the canopy, independent of age, position etc., whereas the observations of single leaves only considered fully sunlit mature leaves, which usually have a wider leaf angle than newly developed leaves.

Means of the visually observed leaf angles are conclusively more reliable and true for mature sun leaves of the observed species, whereas MLA might be more representative for the whole canopy, including all strata and all age classes. These differences should be kept in mind, when comparing the achieved leaf angle data. Because of the divergences mentioned above, only the observed leaf angles will be subject to discussion, also in relation with photosynthetic rates etc..

\subsubsection{Differences in mean leaf angle between land use types}

The secondary forest had the steepest mean leaf angle of the three land use types. Among the secondary forest species studied, there were several large-leaved species with characteristically steep hanging leaves. Typical examples are two Macaranga species and Mallotus mollissimus from the most frequent family in the secondary forest, Euphorbiaceae.

The mean leaf angle of the agroforestry systems was horizontal, as a result of pooling the often slightly upwards directed leaves of Gliricidia sepium with the large, heavier Theobroma cacao leaves that have wider leaf angles.

The natural forest showed a smaller mean leaf angle (more horizontal) than the secondary forest, but steeper than the agroforestry system. This was revealed by the observation of eight species, but nonetheless coheres with the overall impression if looking at a NF canopy. A natural forest sun canopy consists in general of many small-leaved trees with quite horizontal leaf angles, with some species with more steep leaves, like Litsea sp. and Meliosma sumatrana. 


\subsection{Potential predictor parameters for leaf physiology}

Each species allocation between protection and production reflects the balance between different selective forces that have acted on the plant and influenced its life strategy through evolution. Therefore, the search for leaf traits connected to leaf performance is crucial to the understanding of the functional ecology of plant species (Castro-Díez et al. 2000). The use of leaf parameters, especially such relating to acquisition and use of resources, has been proposed to be suitable for predicting function (Westoby 1998; Garnier et al. 2001). Often proposed predictors for photosynthetic capacity are foliar N and SLA. This study delivers further evidence for the relevance of SLA, discusses the appropriateness of $\delta^{13} \mathrm{C}$ and demonstrates the superiority of $\mathrm{P}$ compared to $\mathrm{N}$ as predictor for leaf physiology among many of the studied tree species.

\subsection{1 $\delta^{13} \mathrm{C}$ as predictor parameter}

Huc et al. (1994) studied foliar gas exchange and $\delta^{13} \mathrm{C}$ in a sample of 3 pioneer and 2 late-stage species growing under common conditions in a plantation in the lowlands of French Guiana. They showed that these two groups had different ecophysiological characters even when growing under the same conditions. Foliar $\delta^{13} \mathrm{C}$ was proved to be a valuable parameter for distinguishing the two functional types. As have been discussed above, the present study showed positive correlations between $\delta^{13} \mathrm{C}$ and $\mathrm{A}_{\max }$ and $\mathrm{g}_{\text {smax }}$, in the 19-species sample $\left(\mathrm{A}_{\max }-\mathrm{area}: \mathrm{r}^{2}=0.36, \mathrm{p}<0.01 ; \mathrm{A}_{\max }\right.$-mass: $\mathrm{r}^{2}=0.45, \mathrm{p}<0.01$; $\mathrm{g}_{\text {smax }}$ : $\left.r^{2}=0.41, p<0.01\right)$. Because of this close relation it can be recommended to use $\delta^{13} \mathrm{C}$ as a predictor for foliar gas exchange rates in mixed samples of species from different forest types, despite the fact that no correlation to WUE was found in this study.

\subsection{2 $P$ is closer correlated than $\mathbf{N}$ to leaf gas exchange in some forest types}

An important result of this study is that leaf $\mathrm{P}$ concentration showed a higher correlation to $\mathrm{A}_{\max }$-mass, $\mathrm{A}_{\max }$-area and $\mathrm{g}_{\mathrm{smax}}$, than did $\mathrm{N}$ in the 19 species sample. This is opposite to the suggestions of some authors who propose $\mathrm{N}$ as the leaf trait over all closest related to photosynthetic capacity (Pierce et al. 1994). The relevance of $P$ for leaf physiology has however also been stressed (Meir et al. 2001; Reich et al. 1993; Ellesworth \& Reich 1996). Reich et al. (1993) investigated in which forest types or species, and under which environmental conditions $A_{\max }$ is primarily dependent on $\mathrm{N}$. They found the highest correlations between $\mathrm{A}_{\max }$-mass and $\mathrm{N}$ in fast growing species, with high SLA in resourcerich environments. This is confirmed by the results of this study, where secondary forests 
show the closest $A_{\max }-N$ relation, whereas the mixed 19-species sample showed higher $\mathrm{P}$ dependence. Concordant, a correlation between $\mathrm{P}$ and $\mathrm{A}_{\max }$ was reported by Ellesworth \& Reich (1996) from a mid-successional species in the Amazon, but was not found for the early-successional species in the same study. The overall N-rich soil in the Lore Lindu study region mentioned earlier, probably contributed to a higher dependence on $\mathrm{P}$ in plants of the area. Only the most $\mathrm{N}$ demanding species, occurring in the secondary forest stand, would still show a considerable influence of $\mathrm{N}$ on $\mathrm{A}_{\max }$.

\subsubsection{SLA is an important predictor for leaf physiology}

SLA is implicated in many functional aspects of plants, such as gas exchange (Reich et al. 1997; Ellsworth \& Reich 1996), leaf toughness, decomposition rate (Cornelissen 1999) and relative growth rate (Cornelissen 1999; Lambers \& Poorter 1992; Castro-Díez 2000). Further, Reich et al. (1997) found that SLA was negatively correlated with leaf life span.

Looking at the results of the multiple regression analysis, it can be concluded that SLA stands for the highest degree of explanation for $\mathrm{A}_{\max }$ and $\mathrm{g}_{\text {smax }}$, especially in the natural forest. Similarly, other authors have also found SLA to be closer related than the often proposed predictor $\mathrm{N}$ to $\mathrm{A}_{\max }$ in mid- and late-successional species (Reich et al. 1997; Ellsworth \& Reich 1996). The secondary forest models though, were more influenced by N and $\mathrm{Ca}$ than SLA in this study.

Several authors have found a linear positive correlation between relative growth rate and SLA in different plants (Walker \& Langridge 2002; Hunt \& Cornelissen 1997; Reich 1997). Davies (1998) found correlations between LMA and $A_{\max }$ and a successional ranking of nine Macaranga species. The correlation between SLA for a species and its growth rate, which is in turn related to photosynthetic net rate, has been explained as that leaves growing fast need their cells to be big, with a high liquid content and less sclerophyllous tissue, to permit efficient transportation of the photosynthesis components. Moreover, investment in cell walls and structural tissue allows less biomass to be allocated to the photosynthetic apparatus (Castro-Díez 2000). Edwards et al. (2000) investigated leaf sclerophylly, in terms of toughness and strength, and found a positive correlation with SLA, which further confirms these arguments. Thus, trees investing in dense cell walls, low SLA, to achieve high leaf longevity and low herbivory loss thus pay their price in reduced photosynthetic capacity.

Conclusively, there is evidence for SLA to be a highly relevant predictor for leaf physiology. Furthermore, SLA as predictor parameter has the advantage that it is generally 
not seasonally fluctuating, and showed remarkably low inter-, as well as intraspecific variation compared to several other leaf traits.

\subsubsection{Different parameters suitable for predicting different forest types}

As already mentioned, the multiple regression analysis, as well as the results of the correlations between leaf physiological data and morphological and chemical leaf traits, indicate that different predictors should be used for different forest types. Further, for highest possible precision maybe a combination of parameters should be used. Reich et al. (1997) also proposed that combining some parameters (N and SLA) would give the best prediction of $\mathrm{A}_{\max }$ in a wide range of species in different climatic zones.

As a conclusion of the discussion on the single parameters above, a suitable set of predictors could be as suggested in Table 5.3.

Table 5.3 Different parameters are recommended for different forest types after analysis of correlation and multiple regressions for predicting foliar gas exchange. The parameters are listed in order of decreasing relevance.

\begin{tabular}{lll}
\hline & $\mathbf{A}_{\max }$ & $\mathbf{g}_{\text {smax }}$ \\
& & \\
\hline Natural forest & SLA Leaf size & SLA \\
Secondary forest & $\mathrm{N}$ Leaf angle SLA Ca & $\mathrm{Ca}$ P N Leaf angle \\
Mixed 19-species sample & $\mathrm{P}$ SLA N $\delta^{13} \mathrm{Ca}$ & $\mathrm{P}$ SLA N $\delta^{13} \mathrm{C}$ \\
\hline
\end{tabular}

\subsection{Plant functional types}

It has long been clear to ecologists that variation in plant function seldom correlates with taxonomic structures. Important functional and life history traits of taxonomically closely related species can differ greatly. Therefore, many plant ecologists are challenged by the task of organizing these variations in more or less generally applicable patterns.

One of the first steps was to recognize obvious differences like growth rate, potential maximum height, reproduction strategies and habitat characteristics. According to these basic observations one of the first rough dichotomies was suggested: the pioneer - climax division. Additional factors considered were those influencing the establishment of seedlings and shade tolerance (Swain \& Whitmore 1988; Turner 2001). Lately, however, this view of two clearly separated groups has been questioned (Huc et al. 1994). The pioneer - climax (or early - late-successional) dichotomy is for many purposes not sophisticated enough. Swain and Whitmore (1988) recognised that difference in nutrient demands, photosynthetic 
rate among other traits should also be considered for classifying species, but stated that their knowledge at the time was inadequate. Turner (2001) suggests that the pioneer-late successional division should rather be considered an axis, a continuum, along which he has not found any evidence of discrete species clusters.

Non-pioneer species have been successfully used for reforestation of open sites in the French Guiana lowland (Huc et al. 1994), although shade tolerant non-pioneer species are thought to have little possibilities to establish and grow under the conditions in open sites (Bazzaz 1979). This is one part of extensive evidence for the hypothesis that several different groups of tree species could be identified within and across land use systems and forest types. However, there is no universal classification method (Köhler et al. 2000). Körner (1994) points out that functional groups can be formed at any organizational level, and for any kind of function and Turner (2001) says that there are no discrete clusters, but a continuum, as discussed above. Thus, the number of possible groups is in theory infinite (Körner 1994).

Groupings based on potential maximal height or shade tolerance are two examples of occurring methods (Swaine \& Whitmore 1988). Some authors propose the use of single leaf traits like SLA or $\delta^{13} \mathrm{C}$ (Huc et al. 1994) for distinguishing functional types, whereas others use a battery of life history characteristics (Turner 2001). The selection of criteria for grouping is completely depending on the intended purpose of the grouping. For forming functional groups with the aim of scaling up ecological key functions from species to ecosystem level, a combination of morphological and physiological related traits has been recommended by Körner (1994). He also stresses that broadly defined groups, at as high organizational level as possible, are superior to highly specific, but hardly applicable groups, caused by fear of complexity.

In the following three sub-chapters, three possible methods for identifying plant functional types will be discussed. They are based on partly different parameters, and the analyses differ, but they are all applied on the tree species occurring in different land use types in Sulawesi.

\subsubsection{A graphic analysis of species groups}

The first method tested for classifying species was a graphic method, which might be suitable for analysis of a lower number of species. The advantage of this method is the obvious visual impression. On the other hand, a certain degree of subjectivity when comparing the forms is as inevitable as undesired. 
Looking at the circular illustrations of leaf chemical and morphological traits in Figure 4.36 and Figure 4.37 one visually recognizes the vast differences between the patterns of the studied species, families and land use types. Groups of similar diagrams can be formed. As described below, this way of grouping suggested to a certain extent other groups than what was indicated in the physiology study. However, the functional grouping has a broader approach than only depicting $\mathrm{A}_{\max }$ and $\mathrm{g}_{\text {smax }}$ values. Thus, there is no direct contradiction in this result.

Most striking was the clear separation revealed by this method between Aglaia argentea and the three other late-stage natural forest species depicted. In the investigations on maximal photosynthetic rate in natural forest species, Aglaia argentea was found among those with the highest net rates, at the same level as Semecarpus forstenii, which is a completely different type, according to this graphic overview. Semecarpus forstenii and Litsea sp.1 however, showed very different rates in photosynthesis, but have a similar graphic pattern. In contrast, the found homogenous group of Gliricidia sepium, Trema orientalis, Grewia glabra and Pipturus argentus also form a uniform group in terms of physiology, showing nearly identical rates in photosynthesis and maximal stomatal conductance. Homalanthus populneus though, which could not be significantly separated from the latter group concerning photosynthetic net rate, has a completely different graphic pattern. Homalanthus populneus forms a pattern not similar to any other species illustrated, having the highest SLA and a remarkably high $\mathrm{P}$ concentration, but low levels of all other nutrients. Its high P and SLA are common with the general secondary forest pattern, but the very low mineral nutrient concentrations rather reminds on late-stage, natural forest species.

The striking overall low concentrations of nutrients in the huge leaved Macaranga hispida are interesting. It might be associated with the highly coriaceous leaf structure of this species, leaving a low nutrient-to-carbon ratio.

\subsubsection{Cluster analysis of 107 Sulawesi tree species}

The second way of detecting functional types tested within this work was a computer based hierarchic cluster analysis. With respect to the found suitable predictors of leaf physiology for the mixed 19-species sample in this study, the cluster analysis was based on the five most influent leaf traits (SLA, leaf size, N, P and $\delta^{13} \mathrm{C}$ ).

Next to the question concerning which parameters shall be used for the classification, the number of groups had to be defined. Most works comprise either a low number of classes (about 5) or a high (20 - 50) (Köhler et al. 2000). A high number enables more 
detailed definitions of each functional type, but leads on the other hand to a more complex and problematic interpretation. Köhler et al. (2000) therefore suggest a number of classes between 10 and 20 for optimising accuracy and interpretation in a sample of tropical tree species. For the cluster analysis comprising the 107 species in this study the number of clusters was set to 10, in order to avoid forcing formation of unnatural groups and further increase the difficulty of the following interpretation.

Looking at the functional groups suggested in the analysis, it is remarkable, how mixed some of the given clusters are, regarding species from different land use types. Furthermore, it is noteworthy, that however comprising only half as many species as the natural forest, the secondary forest is the only land use type represented in every cluster of the model. This might be associated with the relatively large influence of SLA and leaf size in the model, which are parameters with higher variance among secondary forest species than within the other land use types. As was shown in the in-depth study of the eight secondary forest species though, the variance of gas exchange rates did not correspond to the high morphological diversity within that land use type. But, as argued above concerning the graphic method, the grouping concept has a broader purpose than only depicting $\mathrm{A}_{\max }$ and $\mathrm{g}_{\text {smax }}$. The forest garden only contributed 19 species to this study, but covered six of the proposed ten functional groups, whereas the 69 natural forest species were divided into seven groups. The four agroforestry system species belonged to three different functional types in this model.

The interpretation of the species composition of certain groups is facilitated by considering the life history of the species. For example, if taking the high $\mathrm{A}_{\max }$ and the "cross-over" life history traits (See 2.5.3) of the species Cananga odorata, which occurs in the natural forest, into account it is not surprising that it was classified to the second group. This group is dominated by secondary forest species like Trema orientalis and Solanum sp.. In other cases the measurable predictor parameters used in the analysis have to be combined with qualitative morphological data for finding relevant explanations. This is the case in group ten, which is characterised by large leaves that are seldom affected by herbivores. This is likely a consequence of their low $\mathrm{N}$ concentration and relatively high sclerophylly. At least two of the four species in this group have irritating hairs, which might be a further successful defence mean against herbivory damage. 


\subsubsection{Four ecological classes according to Turner}

Whereas the first two methods presented consider quantitative morphological and chemical leaf traits, Turner (2001) suggests a scheme of four compartments for classifying tree species exclusively after life history traits (Figure 5.1). Life history traits can in some cases also be measured, like life duration or tree height, but are mainly qualitative, like gap requirement for seedling establishment etc.. It could be argued that this model is less innovative since it still includes pioneer - climax as one of its criteria, but the combination with other life history characteristics forms a potentially useful classification instrument. Yet, a great disadvantage of Turner's model is the limited possibility of combining traits freely, through the fixed square form. For instance, a species does not fit into this model if it is large in size but has a short expected life span. Furthermore, the total number of four possible functional types among tree species of all forest types allows only a very rough division. All members of the main category "large, canopy emerging natural forest species" are forced to the same group in this model ("Canopy").

To test this classification model it was applied to the 16 species occurring in two different forest types that were included in the physiological in-depth study. The three tree species in the agroforestry systems can not be classified with this model because the life history traits required are not known for these exclusively cultivated species.

Starting with the secondary forest, fitting the eight species into any of the four categories was relatively easy. Acalypha caturus, Macaranga tanarius, Macaranga hispida, Mallotus mollissimus and Pipturus argentus were classified as small pioneers. Trema orientalis and Grewia glabra were classified as large pioneers, because of their relatively large potential tree stature and small-leaved, richly branched canopy. The only difficulty was faced concerning Homalanthus populneus. This species has a considerably higher potential longevity than the six species in the small-pioneer category, but has not as high potential tree height as Trema orientalis.

The limited frames of this model further showed their inconvenience, when applied to the species found in the natural forest. According to this model Bischofia javanica would be a large pioneer, although it is unclear whether it requires gaps for its regeneration. Cananga odorata with its potentially high growth rate, but larger stature than most pioneers, also fall 


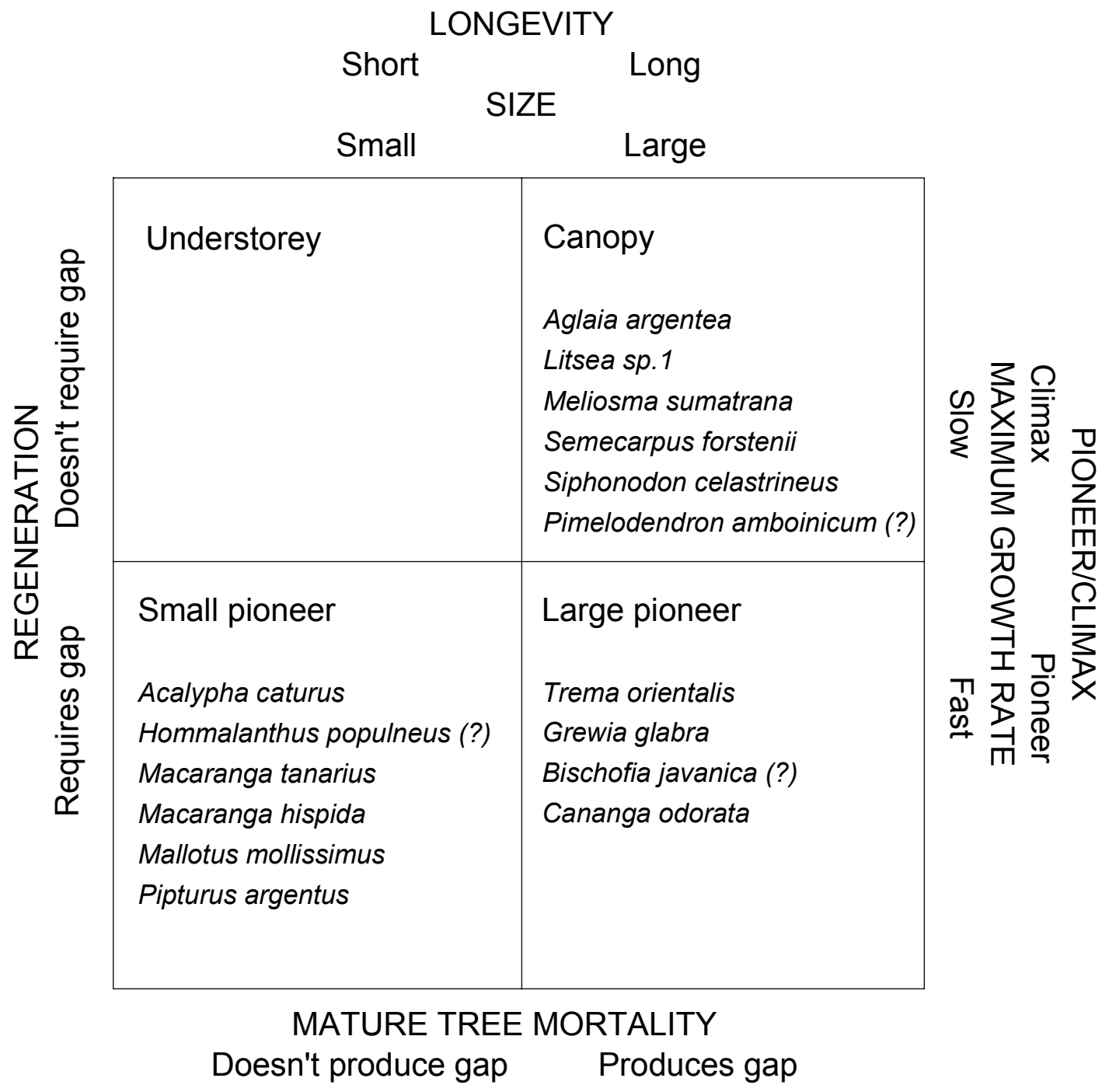

Figure 5.1 Two-way classification of tree species from the tropical rainforest based on size at maturity and the pioneer-climax axis, constructed by Turner (2001) based on several other authors: The bottom and left headings to the central box are based on Shugart's system; the top and right inner headings are based on the system of Lieberman et al.; Favoricon recognised the axis potential size and maximum growth rate (References: see Turner 2001). The model was applied on the 16 natural or secondary forest species included in the physiology study. (?) indicates that the classification of a species was not unambiguous.

into the large-pioneer group. Aglaia argentea, Litsea sp.1, Meliosma sumatrana, Semecarpus forstenii and Siphonodon celastrineus were rather easily categorized as canopy species, whereas the knowledge of Pimelodendron amboinicum as being able to produce flowers and fruits already at relatively small tree sizes gave doubts on its classification. 


\subsubsection{Conclusions concerning methods for classification of functional groups}

Conclusively, the three models for classifying tree species as functional types tested here, yielded many similar results, but did also show some dissimilarities, partly as a consequence of different underlying criteria. For example, the cluster analysis and the graphic method both put Litsea sp.1 and Semecarpus forstenii close together and both led to the conclusion that Macaranga hispida constitutes a very distinctive functional type with few similar species.

The three models could all be considered useful instruments, depending on the available resources for a study. By minimum equipment and funding, the use of Turner's model gives useful, but limited information, only requiring some easy achievable data that for some well documented species not even demand a visit to the forest. If there is a possibility to visit the forest and some simple leaf traits can be obtained, the graphic analysis of constitutional types will reveal more knowledge on the species studied than in the first case, and has the fortune of not preset any rigid frames like Turner's model. In the third case, when additionally to the possibilities in the second case, there is also a possibility to do calculations in large data sets, the third classification method offers extraordinary possibilities to first find a relevant amount of potential functional types in the data set investigated, second, search for the optimal parameter combination for a certain purpose, and third, with high statistic precision arrange the studied species into the defined classes.

\subsection{Functional and morphological diversity}

\subsubsection{Intra- and interspecific diversity}

The diversity, or variance, within and among species and within and among land use types was analysed by calculating the coefficient of variance (sd / mean (\%)) and the quota of the highest and lowest values obtained in a sample.

In most studies interspecific variation of leaf traits have been found higher than the intraspecific. This is also true for the present work. Ackerly et al. (2002) showed a 2-fold intraspecific and 5-fold interspecific variation in SLA in a 22-woody species sample. The highest intraspecific range in SLA found in the present study was, equally with Ackerly's results, 2-fold, in a small-leaved, low-SLA species $\left(40-80 \mathrm{~cm}^{2} \mathrm{~g}^{-1}\right.$, Pimelodendron amboinicum), compared to a 6-fold variation among the natural forest species studied, as well as in the whole sample comprising four land use types. Comparing the coefficients of 
variance in Table 4.15 and Table 4.16 gives further evidence that interspecific variance within land use types was generally higher than the intraspecific variance also in this study.

\subsubsection{Different degree of variance for different parameters}

Garnier et al. (2001) studied a large sample of woody species and herbs in southern France and found the interspecific variation of SLA higher than of $\mathrm{N}$ concentration ( 5 and 3.5-fold, respectively). Foliar N concentration however, showed a higher intraspecific variation than SLA, which Garnier et al. explained with a more plastic response to soil properties of this parameter than SLA. Garnier's results on intraspecific variance were confirmed by this study, where $\mathrm{N}$ was also slightly more variable than SLA in most species. Concerning the interspecific variance of $\mathrm{N}$ and SLA though, dissimilarity between land use types was revealed in this study. Coherent with the results of Garnier et al., the interspecific variance of SLA was higher than that of $\mathrm{N}$ in the natural forest and the agroforestry system, whereas secondary forest and forest garden showed a higher variance of $\mathrm{N}$ than of SLA. Again, this division could be explained with a higher plasticity of typical secondary forest species than natural forest species in the response to environmental variations.

Looking at the gas-exchange parameters revealed that the intraspecific variance in $g_{\text {smax }}$ was generally higher than in $\mathrm{A}_{\max }$, indicating that stomatal conductance responds to more environmental variables than photosynthetic rate. Further, it is interesting that among the four leaf traits closest related to leaf function, $\mathrm{N}$ and SLA showed consequently lower variability than $\mathrm{Ca}$ and $\mathrm{P}$.

\subsubsection{General differences in diversity between land use types}

Natural forest was physiologically much more divers than the secondary forest, and showed a higher diversity also for most chemical and morphological parameters. Only the intraspecific variance of leaf size and the interspecific variance of leaf $\mathrm{N}$ content were considerably higher in SF than in NF. The three tree species in the agroforestry system showed a high variance in $\mathrm{A}_{\max }$, ranged over three of Raunkiaer's leaf size classes, and showed generally an interspecific diversity similar to the other land use types, despite its low species number. Forest garden showed less morphological diversity than the other land use types, but was similar in chemical leaf traits variance.

The remarkably low interspecific variance in $\mathrm{N}$ in the natural forest, is probably associated with the overall high soil-N content in the study area, a lower plasticity as mentioned above and the higher dependence on $\mathrm{P}$ of gas exchange in that forest type, which 
might result in a similar $\mathrm{N}$ level among species. Concordant, the secondary forest, as the only land use type with a significantly $\mathrm{N}$-depending $\mathrm{A}_{\max }$, showed a much higher variability in $\mathrm{N}$.

The high diversity of leaf size found within, as well as among, secondary forest species might reflect the generally higher variability in the physical environment in secondary vegetation compared to natural forests (Culf et al. 1996). The studied secondary forest stands were smaller patches, situated between large natural forest areas and open land, which is likely to cause a high microclimatic variability. A further reason could be the fast change in stand structure and successional stage of secondary forest stands, compared to the relatively long-term stable natural forests. This demands a high phenotypic plasticity in the response to heterogeneous environmental conditions like light regime and $\mathrm{N}$-supply, which particularly affects leaf morphology.

\subsubsection{The relation between adaptive flexibility and the variance in chemical and morphological leaf traits}

Combining the coefficients of variance with physiology and life history data of the species showed that high intraspecific variance for chemical and morphological leaf traits is often related to high $\mathrm{A}_{\max }$, as for example in Trema orientalis and Bischofia javanica, which both had high variance in most leaf traits. This might be interpreted as a higher flexibility in these species that enable them to quickly adapt to, and make use of, local or temporal resources for maximizing their photosynthetic net rate. Further, an overall higher variance was found in the so called cross-over species like Meliosma sumatrana and Bischofia javanica, supporting the theory that these species are particularly adaptive to different environments.

\subsubsection{Ecosystem stability as a function of functional and taxonomic diversity}

Tilman et al. (2001) showed that aboveground biomass, as well as total biomass increased with the number of species and functional groups in a 7-year experiment in grasslands. It is not unlikely that the same relation could exist in tree communities. At a certain number of functional groups the degree of functional stability (or reliability, according to terminology of Naem \& Li 1997) of the ecosystem was increased with the number of species within each group in Tilman's experiment. The effects were explained by niche complementarity and the possibility of similar species to replace weak or disappeared ones within a functional group. Other authors have ascribed the total number of functional 
groups a higher degree of explanation for ecosystem stability than the number of species within each group (Naeem \& Li 1997). Although it is likely that some species, or combination of species, are essential for certain ecosystem functions, while others are less critical as such, the interactions are complex and the relation between species diversity and functional diversity is certainly not linear (Lawton \& Brown 1994).

\subsubsection{Conclusion}

As a consequence of its exceptionally high species number, it is likely that the natural forest will show the highest number of species within each hypothetic functional group among the land use types studied. The number of hypothetic functional groups in this forest type is also considerable, and the intra- and interspecific variance for important leaf traits was on average the highest. Thus, according to Tilman et al. (2001) and Naem \& Li (1997), it is likely that the natural forest will possess a higher reliability in a long time perspective, where reliability is defined as the probability that a system will provide a consistent level of performance over a given unit of time (terminology of Naem \& Li 1997). Concerning resilience though, the secondary forest, with its high photosynthetic net rate and highly plastic response to variable environmental conditions confirmed in this study, probably has a higher ability to quickly regenerate in case of disturbance.

Conclusively, although this work revealed a surprisingly high number of functional groups among the studied secondary forest species, the proved higher intra- and interspecific variation in leaf traits and the higher taxonomic diversity of the natural forest, combined with decisive differences in life history lead to the statement that conversion of rainforests into secondary forests, or agroforestry systems, means not only loss of taxonomic diversity, but a great reduction of functional diversity and reliability of tree based ecosystems. 


\section{SUMMARY}

This work was conducted in Central Sulawesi, Indonesia, as a part of the GermanIndonesian research project SFB 552, studying trees in the prevailing tree-based land use types natural and secondary forest (NF, SF), forest garden (FG) and agroforestry system $(\mathrm{AF})$.

Main objectives were to investigate typical values of maximum light-saturated net photosynthesis $\left(A_{\max }\right)$, stomatal conductance $\left(g_{s}\right)$ and morphological and chemical leaf traits of the four land use types and its tree species. The interrelations between these parameters were analysed, as well as the degree of functional and morphological diversity among land use types and at intra- and interspecific level. Furthermore, suitable morphological or chemical leaf traits were searched that could serve as predictors for leaf physiology and for functional groups among the studied tree species. Additionally, different sampling designs for comparative leaf morphological and chemical studies were evaluated and various ways of forming functional groups of the studied species were tested and discussed.

Mature sun leaves were collected on mature or premature trees for investigation of morphological and chemical leaf traits according to a randomised plot sampling design, as well as targeted on common species for in-depth studies. $\mathrm{A}_{\max }$ and $\mathrm{g}_{\mathrm{s}}$ were measured with portable porometer systems. The random sampling included 354 tree individuals of 107 species and the in-depth physiology study comprised 60 trees of 19 species. The canopy structure on the plots was characterized by means of hemispherical photos.

Evaluating different sampling designs revealed that random sampling is the overall most suitable method for assessing ecosystem functions through leaf trait studies.

The eight NF species in the in-depth study showed the lowest $A_{\max }, 7.5 \pm 3.7 \mu \mathrm{mol} \mathrm{m}^{-2}$ $\mathrm{s}^{-1}$, compared to $17.5 \pm 3.3 \mu \mathrm{mol} \mathrm{m} \mathrm{m}^{-2} \mathrm{~s}^{-1}$ among eight SF species. The AF had a mean $\mathrm{A}_{\max }$ of $13.2 \pm 5.9 \mu \mathrm{mol} \mathrm{m}^{-2} \mathrm{~s}^{-1}$. The NF species also had the lowest mean $\mathrm{g}_{\text {smax }}$ among the three land use systems (NF: $368 \pm 232$, SF: $609 \pm 205, \mathrm{AF}: 521 \pm 267 \mathrm{mmol} \mathrm{m}^{-2} \mathrm{~s}^{-1}$ ), whereas no significant difference in mean water use efficiency could be detected. Looking at land use level means of morphological parameters, SF had the largest, roundest leaves, while AF showed the smallest leaves with highest specific leaf area (SLA). NF had relatively small, elongated leaves, with low SLA. The analysis of foliar chemical concentrations showed that NF and FG had the lowest $\mathrm{P}$ concentration, AF intermediate and SF the highest. Foliar N concentration was lowest in NF and FG, intermediate in SF and highest in AF, while the N/P ratio was similar between NF and AF, intermediate in FG and lowest in SF. Combining the 
foliar $\delta^{15} \mathrm{~N}$ with total $\mathrm{N}$ values suggested that up to $30 \%$ of the species studied in the natural forest might possess $\mathrm{N}_{2}$-fixing symbionts, as did $23 \%$ of the secondary forest species and $16 \%$ of the forest garden species. Of the four species studied in the agroforestry system, two are known $\mathrm{N}_{2}$-fixing and the other two non- $\mathrm{N}_{2}$-fixing.

Concerning easy achievable predictors for leaf gas exchange, it was found that for a more precise prediction different parameters should be used for $\mathrm{g}_{\text {smax }}$ and $\mathrm{A}_{\max }$ and for different land use types. In the 19-species sample, covering three land use types, a combination of P and SLA gave the best prediction of leaf physiology. SLA is recommended for estimating $\mathrm{A}_{\max }$ and $\mathrm{g}_{\text {smax }}$ among natural forest species. $\mathrm{N}$ and leaf angle were found to be important for secondary forest $\mathrm{A}_{\max }$, whereas Ca should also be taken into account when assessing $\mathrm{g}_{\text {smax }}$ in the same land use type. Conclusively, $\mathrm{N}$ had much less influence on leaf physiology in the studied species than generally proposed, instead $\mathrm{P}$ was the more important factor for leaf physiology in the studied sample.

The main result of the analysis of the coefficient of variance for the studied leaf traits was that interspecific diversity was highest within NF for a majority of the included parameters. P showed higher variance than $\mathrm{N}$ within all land use types, except SF. Species with generalist life histories often had a higher variance in the studied leaf traits than other species.

The cluster analysis for division of the 107 studied species into ten functional groups gave that the natural forest covered seven groups, whereas the secondary forest was represented in all ten. Most of the groups comprised species from two or more land use types, suggesting that the functional diversity of tree species is considerable within both natural and secondary forest.

Yet, if taking the coefficient of variance and life histories into account, it can be concluded that conversion of natural forest into agroforestry land or secondary forests leads not only to a reduction of taxonomic diversity, but also to a great loss of functional diversity and ecosystem reliability. 


\section{REFERENCES}

ACHARD, F., EVA, H.D., STIBIG, H.J., MAYAUX, P., GALLEGO, J., RICHARDS, T. \& MALINGREAU, J.P. 2002. Determination of Deforestation Rates of the World's Humid Tropical Forests. Science 297: 999-1002.

ACKERLY, D.D., KNIGHT, C.A., WEISS, S.B., BARTON, K. \& STARMER, K.P. 2002. Leaf size, specific leaf area and microhabitat distribution of chaparral woody plants: contrasting patterns in species level and community level analyses. Oecologia 130: 449-457.

AIBA, S. \& KITAYAMA, K. 1999. Structure, composition and species diversity in an altitude-substrate matrix of rain forest tree communities on Mount Kinabalu, Borneo. Plant Ecology 140: 139-157.

AYANABA, A. \& SANDERS, F.E. 1981. Microbiological factors. In Characterization of soils in relation to their classification and management for crop production: examples from some areas of the humid tropics. Clarendon Press, Oxford.

BARTHLOTT, W. 2003. Biodiversity - a challenge for research and policy. $16^{\text {th }}$ Annual Meeting, Society for Tropical Ecology, Rostock.

BAZZAZ, F.A. 1979. The physiological ecology of plant succession. Annual Review of Ecology and Systematics 10: 351-371.

BONAL, D., SABATIER, D., MONTPIED, P., TREMEAUX, D. \& GUEHL, J.M. 2000. Interspecific variability of $\delta^{13} \mathrm{C}$ among trees in rainforests of French Guiana: functional groups and canopy integration. Oecologia 3: 454-468.

BORCHERT, R. 1998. Responses of Tropical Trees to Rainfall Seasonality and its LongTerm Changes. Climatic Change 39: 381-393.

BOUT, I.E. \& OKITSU, S. 1999. Leaf size zonation pattern of woody species along an altitudinal gradient on Mt. Pulog, Philippines. Plant Ecology 145: 197-208.

BUCHMANN, N., GUEHL, J.M., BARIGAH, T.S. \& EHLERINGER, J.R. 1997. Interseasonal comparison of $\mathrm{CO}_{2}$ concentrations, isotopic composition, and carbon dynamics in an Amazonian rainforest (French Guiana). Oecologia 110: 120-131.

CASTRO-DÍEZ, P., PUYRAVAUD, J.P. \& CORNELISSEN, J.H.C. 2000. Leaf structure and anatomy as related to leaf mass per area variation in seedlings of a wide range of woody plant species and types. Oecologia 124: 476-486.

CORNELISSEN, J.H.C., PEREZ-HARGUINDEGUY, N., DIAZ, S., GRIME, J.P., MARZANO, B., CABIDO, M., VENDRAMINI, F. \& CERABOLINI, B. 1999. Leaf structure and defence control litter decomposition rate across species and life forms in regional floras on two continents. New Phytologist 143: 191-200.

CORNELISSEN, J.H.C., CARNELLI, A.L. \& CALLAGHAN, T.V. 1999. Generalities in the growth, allocation and leaf quality responses to elevated $\mathrm{CO}_{2}$ in eight woody species. New Phytologist 141: 401-409. 
CORNELISSEN, J.H.C., CERABOLINI, B., CASTRO-DÍEZ, P., VILLAR-SALVADOR, P., MONTSERRAT-MARTÍ, G., PUYRAVAUD, J.P., MAESTRO, M., WERGER, M.J.A. \& AERTS, R. 2003. Functional traits of woody plants: correspondence of species rankings between field adults and laboratory-grown seedlings? Journal of Vegetation Science 14: 311-322.

COURNAC, L., DUBOIS, M.-A., CHAVE, J. \& RIERA, B. 2002. Fast determination of light availability and leaf area index in tropical forests. Journal of Tropical Ecology 18: 295-302.

CULF, A.D., ESTEVES, J.L., MARQUES, A. \& ROCHA, H.R. 1996. Radiation, temperature and humidity over forest and pasture in Amazonia. In Amazonian Deforestation and Climate. (Ed. Gash, J.H.C., Nobre, C.A., Roberts, J.M. \& Victoria, R.L.). John Wiley, Chichester.

DAVIES, S.J. 1998. Photosynthesis of nine pioneer Macaranga species from Borneo in relation to life history. Ecology 79: 2292-2308.

DECHERT, G. 2003. Nutrient dynamics and their control in land use systems of forest margins in Central Sulawesi, Indonesia. PhD Thesis.

EBERSBERGER, S. 2002. "The National Park is where the slope becomes too steep for agriculture" Forest tenure in a rainforest margin in Central Sulawesi, Indonesia. Pacific News 19: 4-7.

EDWARDS, C., READ, J. \& SANSON, G. 2000. Characterising schlerophylly: some mechanical properties of leaves from heath and forest. Oecologia 123: 158-167.

ELLENBERG, H. 1996. Vegetation Mitteleuropas mit den Alpen : in ökologischer, dynamischer und historischer Sicht. Ulmer Verlag, Stuttgart.

ELLSWORTH, D.S. \& REICH, P.B. 1996. Photosynthesis and leaf nitrogen in five Amazonian tree species during early secondary succession. Ecology 77: 581-594.

FALSTER, D.S. \& WESTOBY, M. 2003. Leaf size and angle vary widely across species: what consequences for light interception? New Phytologist 158: 509-525.

FARQUHAR, G.D. \& RICHARDS, R.A. 1984. Isotopic composition of plant carbon correlates with water-use efficiency of wheat genotype. Australian Journal of Plant Physiology 11: 539-552.

FOOD AND AGRICULTURE ORGANISATION OF THE UNITED NATIONS (FAO) 2001. Global forest resources assessment 2000. Main report. FAO, Rome.

GARNIER, E., LAURENT, G., BELLMANN, A., DEBAIN, S., BERTHELIER, P., DUCOUT, B., ROUMET, C. \& NAVAS, M.-L. 2001. Consistency of species ranking based on functional leaf traits. New Phytologist 152: 69-83.

GARTEN, C.T. \& TAYLOR, G.E. 1992. Foliar $\delta^{13}$ C within a temperate deciduous forest: spatial, temporal and species sources of variation. Oecologia 90: 1-7. 
GARTEN, C.T. 1993. Variation in foliar $15 \mathrm{~N}$ abundance and the availability of soil nitrogen on Walker branch watershed. Ecology 74: 2098-2113.

GARTEN, C.T. \& VAN MIEGROET, H. 1994. Relationships between soil nitrogen dynamics and natural 15N abundance in plant foliage from Great Smoky Mountains National Park. Canadian Journal of Forestry 24: 1636-1645.

GIARDINA, C.P., SANFORD, R.L. \& DØCKERSMITH, I.C. 2000. Changes in soil phosphorus and nitrogen during slash-and-burn clearing of a dry tropical forest. Soil Science Society of America Journal 64: 399-405.

GRANIER, A., LOUSTAU, D. \& BRÉDA, N. 2000. A generic model of forest canopy conductance dependent on climate, soil water availability and leaf area index. Annals of Forest Science 57: 755-765.

GUEHL, J.M., DOMENACH, A.M., BEREAU, M., BARIGAH, T.S., CASABIANCA, H., FERHI, A. \& GARBAYE, J. 1998. Functional diversity in an Amazonian rainforest of French Guiana. A dual isotope approach $\left(\delta^{15} \mathrm{~N}\right.$ and $\left.\delta^{13} \mathrm{C}\right)$. Oecologia 116: 316-330.

HAGEMEIER, M. 2002. Funktionale Kronenarchitektur mitteleuropäischer Baumarten am Beispiel von Hängebirke, Waldkiefer, Traubeneiche, Hainbuche, Winterlinde und Rotbuche. PhD Thesis.

HANDLEY, L.L., LOZANO, J.M.R. \& SCRIMGEOUR, C.M. 1999. Plant $\delta^{15} \mathrm{~N}$ associated with arbuscular mycorrhiza, drought and nitrogen deficiency. Rapid Communication in Mass Spectrometry 13: 1320-1324.

HOBBIE, E.A., MACKO, S.A. \& SHUGART, H.H. 1999. Interpretation of nitrogen isotope signatures using the NIFTE model. Oecologia 120: 405-415.

HOBBIE, E.A., MACKO, S.A. \& WILLIAMS, M. 2000. Correlations between foliar $\delta^{15} \mathrm{~N}$ and nitrogen concentrations may indicate plant-mycorrhizal interactions. Oecologia 122: $273-283$.

HOOPER, D.U. \& VITOUSEK, P.M. 1997. The Effects of Plant Composition and Diversity on Ecosystem Processes. Science 277: 1302-1305.

HUBICK, K.T., SHORTER, R. \& FARQUHAR, G.D. 1988. Heritability and genotype x environment interactions of carbon isotope discrimination and transpiration efficiency in peanut (Arachis hypogea L.). Australian Journal of Plant Physiology 15: 799-813.

HUC, R., FERHI, A. \& GUEHL, J.M. 1994. Pioneer and late stage tropical rainforest tree species (French Guiana) growing under common conditions differ in leaf gas exchange regulation, carbon isotope discrimination and leaf water potential. Oecologia 99: 297-305.

HUNT, R. \& CORNELISSEN, J.H.C. 1997. Components of relative growth rate and their interrelations in 59 temperate plant species. New Phytologist. 135: 395-417.

HÖGBERG, P. 1990. Forests losing large quantities of nitrogen have elevated ${ }^{15} \mathrm{~N}:{ }^{14} \mathrm{~N}$ ratios. Oecologia 84: 229-231. 
HÖGBERG, P. \& JOHANNISSON, C. $1993 .{ }^{15} \mathrm{~N}$ abundance in forests is correlated with losses of nitrogen. Plant and Soil 157: 147-150.

HÖGBERG, P. \& ALEXANDER, I.J. 1995. Roles of root symbiosis in African woodland and forests: Evidence from ${ }^{15} \mathrm{~N}$ abundance and foliar analysis. Journal of Ecology 83: 217224.

ISHIDA, A., TOMA, T. \& MARJENAH. 1999. Leaf gas exchange and chlorophyll flourescence in relation to leaf angle, azimuth, and canopy position in the tropical pioneer tree, Macaranga conifera. Tree Physiology 19: 117-124.

JENKINS, M. 2003. Prospects for Biodiversity. Science 302: 1175-1177.

JORDAN, C.F. 1985. Nutrient Cycling in Tropical Forest Ecosystems. John Wiley \& Sons Ltd., Chichester, New York, Brisbane, Toronto, Singapore.

KESSLER, M., KEßLER, P.J.A., GRADSTEIN, S.R., BACH, K., SCHMULL, M. \& PITOPANG, R. 2004. Tree diversity in primary forest and different land use systems in Central Sulawesi, Indonesia. Biodiversity and Conservation (in press).

KEßLER, P.J.A., BOS, M.M., SIERRA DAZA, S.E.C., KOP, A., WILLEMSE, L.P.M., PITOPANG, R. \& GRADSTEIN, S.R. 2002. Checklist of woody plants of Sulawesi, Indonesia. BLUMEA / Nationaal Herbarium Nederland, Leiden.

KING, D.A. 1997. The Functional Significance of Leaf Angle in Eucalyptus. Australian Journal of Botany 45: 619-639.

KITAYAMA, K. \& IWAMOTO, K. 2001. Patterns of natural ${ }^{15} \mathrm{~N}$ abundance in the leaf-tosoil continuum of tropical rain forests differing in N availability on Mount Kinabalu, Borneo. Plant and Soil 229: 203-212.

KÖHLER, P., DITZER, T. \& HUTH, A. 2000. Concepts for the aggregation of tropical tree species into functional types and the application to Sabah's low land rain forests. Journal of Tropical Ecology 16: 591-602.

KÖRNER, Ch., FARQUHAR, G.D. \& WONG, S.C. 1991. Carbon isotope discrimination by plants follows latitudinal and altitudinal trends. Oecologia 88: 30-40.

KÖRNER, CH. 1994. Scaling from species to vegetation: The usefulness of functional groups. In Biodiversity and ecosystem function. (Ed. Schulze, E.D. \& Mooney, H.A.). Springer Verlag, Berlin Heidelberg.

LAWRENCE, D. 2004. Land-Use Change, Biodiversity and Ecosystem Functioning in West Kalimantan. In Land Use, Nature Conservation and the Stability of Rainforest Margins in Southeast Asia. Springer Verlag, Berlin Heidelberg.

LAWTON, J.H. \& BROWN, V.K. 1994. Redundancy in ecosystems. In Biodiversity and ecosystem function . (Ed. Schulze, E.D. \& Mooney, H.A.). Springer Verlag, Berlin Heidelberg.

LEFFLER, A.J. \& ENQUIST, B.J. 2002. Carbon isotope composition of tree leaves from Guanacaste, Costa Rica: comparison across tropical forests and tree life history. Journal of Tropical Ecology 18: 151-159. 
MAERTENS, M., ZELLER, M. \& BIRNER, R. 2004. Does Technical Progress in Agriculture Have a Forest Saving or a Forest Clearing Effect? In Land Use, Nature Conservation and the Stability of Rainforest Margins in Southeast Asia. Springer Verlag, Berlin Heidelberg.

MARENCO, R.A., DE GONÇALVES, J.F. \& VIEIRA, G. 2001. Leaf gas exchange and carbohydrates in tropical trees differing in successional status in two light environments in central Amazonia. Tree Physiology 21: 1311-1318.

MARTIN, B. \& THORSTENSON, Y.R. 1988. Stable carbon isotope composition $\left(\delta^{13} \mathrm{C}\right)$, water-use efficiency and biomass productivity of Lycopersicon esculentum, Lycopersicon penelli and the F1 hybrid. Journal of Plant Physiology 88: 213-217.

MARTINELLI, L.A., ALMEIDA, S., BROWN, I.F., MOREIRA, M.Z., VICTORIA, R.L., STERNBERG, L.S.L., FERREIRA, C.A.C. \& THOMAS, W.W. 1998. Stable carbon isotope ratio of tree leaves, boles and fine litter in a tropical forest in Rondônia, Brazil. Oecologia 114: 170-179.

MCDONALD, P.G.M., FONSECA, C.R., OVERTON, J.M. \& WESTOBY, M. 2003. Leafsize divergence along rainfall and soil-nutrient gradients: is the method of size reduction common among clades? Functional Ecology 17: 50-57.

MEINZER, F.C., GOLDSTEIN, G., HOLBROOK, N.M., JACKSON, P. \& CAVELIER, J. 1993. Stomatal and environmental control of transpiration in a lowland tropical forest tree. Plant Cell and Environment 16: 429-436.

MEIR, P., GRACE, J. \& MIRANDA, A.C. 2001. Leaf respiration in two tropical rainforests: constraints on physiology by phosphorous, nitrogen and temperature. Functional Ecology 15: 378-387.

MORECROFT, M.D. \& ROBERTS, J.M. 1999. Photosynthesis and stomatal conductance of mature canopy Oak (Quercus robur) and Sycamore (Acer pseudoplatanus) trees throughout the growing season. Functional Ecology 13: 332-342.

NAEEM, S. \& LI, S. 1997. Biodiversity enhances ecosystem reliability. Nature 390: 507-509.

NIEMANN, G.J., PUREVEEN, J.B.M., EIJKEL, G.B., POORTER, H. \& BOON, J.J. 1992. Differences in relative growth-rate in 11 grasses correlate with differences in chemical composition as determined by pyrolysis mass-spectrometry. Oecologia 89: 567-573.

OREN, R., SPERRY, J.S., KATUL, G.G., PATAKI, D.E., EWERS, B.E., PHILIPS, N. \& SCHÄFER, K.V.R. 1999. Survey and synthesis of intra- and interspecific variation in stomatal sensitivity to vapour pressure deficit. Plant Cell and Environment 22: 15151526.

PANGAU-ADAM, M.Z. 2003. Avian nest predation in forest margin areas in Lore Lindu National Park, Central Sulawesi, Indonesia. PhD Thesis.

PATE, J.S., UNCOVIC, M.J., ERSKINE, P.D. \& STEWART, G.R. 1998. Australian mulga ecosystems $-{ }^{13} \mathrm{C}$ and ${ }^{15} \mathrm{~N}$ natural abundances of biota components and their ecophysiological significance. Plant Cell and Environment 21: 1231-1242. 
PIERCE, L.L., RUNNING, S.W. \& WALKER, J. 1994. Regional-scale relationship of leaf area index to specific leaf area and leaf nitrogen content. Ecological Applications 4: 313-321.

PITOPANG, R., KEßLER, P.J.A., GRADSTEIN, S.R., GUHARDJA, E., TJITROSUDIRDJO, S. \& WIRIADINATA, H. 2004. Tree composition in secondary forest of Lore Lindu National Park, Central Sulawesi, Indonesia. In Land Use, Nature Conservation and the Stability of Rainforest Margins in Southeast Asia. Springer Verlag, Berlin Heidelberg.

RAUNKIAER, C. 1934. The life forms of plants and statistical plant geography. Clarendon Press, Oxford.

RAVEN, H.P., EVERT, R.F. \& CURTIS, H. 1985. Biologie der Pflanzen. de Gruyter, Berlin, New York.

REES, M., CONDIT, R., CRAWLEY, M., PACALA, S. \& TILMAN, D. 2001. Long-Term Studies of Vegetation Dynamics. Science 293: 650-655.

REICH, P.B., WALTERS, M.B., ELLSWORTH, D.S. \& UHL, C. 1994. Photosynthesisnitrogen relations in Amazonian tree species I. Patterns among species and communities. Oecologia 97: 62-72.

REICH, P.B. \& WALTERS, M.B. 1994. Photosynthesis-nitrogen relations in Amazonian tree species II. Variation in nitrogen vis-a-vis specific leaf area influences. Oecologia 97: 73-81.

REICH, P.B., WALTERS, M.B. \& ELLSWORTH, D.S. 1997. From tropics to tundra: Global convergence in plant functioning. Proceedings of the National Academy of Sciences, USA 94: 13730-13734.

REINERS, W.A., BOUWMAN, A.F., PARSONS, W.F.J. \& KELLER, M. 1994. Tropical rain forest conversion to pasture: changes in vegetation and soil properties. Ecological Applications 4: 363-377.

ROGGY, J.C., PRÉVOST, M.F., GOURBIERE, F., CASABIANCA, H., GARBAYE, J. \& DOMENACH, A.M. 1997. Leaf natural $15 \mathrm{~N}$ abundance and total $\mathrm{N}$ concentration as potential indicators of plant $\mathrm{N}$ nutrition in legumes and pioneer species in a rain forest of French Guiana. Oecologia 120: 171-182.

SALAS, E., NYGREN, P., DOMENACH, A.M., BERNINGER, F. \& RAMÍREZ, C. 2001. Estimating biological $\mathrm{N}_{2}$ fixation by a tropical legume tree using the non-nodulating phenophase as the reference in the ${ }^{15} \mathrm{~N}$ natural abundance method. Soil Biology and Biochemistry 33: 1859-1868.

SCHNEIDER, J.V., ZIPP, D., GAVIRIA, J. \& ZIZKA, G. 2003. Successional and mature stands in an upper Andean rain forest transect of Venezuela: do leaf characteristics of woody species differ? Journal of Tropical Ecology 19: 251-259.

SCHULZE, E.D., KELLIHER, F.M., KÖRNER, Ch., LLOYD, J. \& LEUNING, R. 1994. Relationships among maximum stomatal conductance, ecosystem surface conductance, carbon assimilation rate, and plant nitrogen nutrition: A Global Ecology Scaling Exercise. Annual Review of Ecology and Systematics 25: 629-660. 
SCHULZE, E.D., WILLIAMS, R.J., FARQUHAR, G.D., SCHULZE, W., LANGRIDGE, J.L., MILLER, J.M. \& WALKER, B.H. 1998. Carbon and nitrogen isotope discrimination and nitrogen nutrition along a rainfall gradient in northern Australia. Australian Journal of Plant Physiology 25: 413-425.

SCHULZE, E.D., WIRTH, C. \& HEIMANN, M. 2000. Climate Change: Managing Forests After Kyoto. Science 289: 2058-2059.

SIEBERT, S.F. 2002. From shade- to sun-grown perennial crops in Sulawesi, Indonesia: Implications for biodiversity conservation and soil fertility. Biodiversity and Conservation 11: 1889-1902.

SPRIGGS, A., STOCK, W.D. \& DAKORA, F.D. 2003. Influence of mycorrhizal associations on foliar $\delta^{15} \mathrm{~N}$ value of legume and non-legume shrubs and trees in the fynbos of South Africa: Implications for estimating $\mathrm{N}_{2}$-fixation using the ${ }^{15} \mathrm{~N}$ natural abundance method. Plant and Soil 255: 495-502.

SWAINE, M.D. \& WHITMORE, T.C. 1988. On the definition of ecological species groups in tropical rain forests. Vegetatio 75: 81-86.

SWAMY, H.J. \& PROCTOR, J. 1994. Litter-fall and nutrient cycling in 4 rainforests in the Sringeri area of the Indian western Ghats. Global Ecology and Biogeography Letters 5: $155-165$.

THOMAS, S.C. \& WINNER, W.E. 2002. Photosynthetic differences between saplings and adult trees: an integration of field results by meta-analysis. Tree Physiology 22: 117127.

TILMAN, D., REICH, P.B., KNOPS, J., WEDIN, D., MIELKE, T. \& LEHMAN, C. 2001. Diversity and Productivity in a Long-Term Grassland Experiment. Science 294: 843845.

TRICHON, V., WALTER, J.N. \& LAUMONIER, Y. 1998. Identifying spatial patterns in the tropical rain forest structure using hemispherical photographs. Plant Ecology 137: 227-244.

TURNER, I.M., LUCAS, P.W., BECKER, P., WONG, S.C., YONG, J.W.H., CHOONG, M.F. \& TYREE, M.T. 2000. Tree leaf form in Brunei: a heath forest and a mixed dipterocarp forest compared. Biotropica 32: 53-61.

TURNER, I.M. 2001. The Ecology of Trees in the Tropical Rain Forest. Cambridge University Press, Cambridge.

VAN DEN BURG, J. 1990. Foliar analysis for determination of tree nutrient status. A compilation of literature data. 2. Literature 1985-1989. Institute for Forestry and Urban Ecology, Wageningen.

VAN RHEENEN, T., ELBEL, C., SCHWARZE, S., NURYARTONO, N., ZELLER, M. \& SANIM, B. 2004. Encroachments on Primary Forests: Are They Really Driven by Despair? In Land Use, Nature Conservation and the Stability of Rainforest Margins in Southeast Asia. Springer Verlag, Berlin Heidelberg. 
VITOUSEK, P.M., FIELD, C.B. \& MATSON, P.A. 1990. Variation in foliar $\delta^{13}$ C in Hawaiian Metrosideros polymorpha: A case of internal resistance? Oecologia 84: 362370.

WALKER, B.H. \& LANGRIDGE, J.L. 2002. Measuring Functional Diversity in Plant Communities with Mixed Life Forms: A Problem of Hard and Soft Attributes. Ecosystems 5: 529-538.

WARD, J.M. \& SCHROEDER, J. 1994. Calcium-activated K+ channels and calcium-induced calcium release by slow vacuolar ion channels in guard cell vacuoles implicated in the control of stomatal closure. The Plant Cell 6: 669-683.

WATT, A.S. 1947. Pattern and process in plant community. Journal of Ecology 35: 1-22.

WEBB, L.J. 1959. A Physiognomic Classification of Australian Rain Forests. Journal of Ecology 47: 551-570.

WESTOBY, M. 1998. A leaf-height-seed (LHS) plant ecology strategy scheme. Plant and Soil 199: 213-227.

WHITMORE, T.C. 1989. Canopy gaps and the two major groups of forest trees. Ecology 70: 536-538.

WHITMORE, T.C., BROWN, N.D., SWAINE, M.D., KENNEDY, D., GOODWINBAILEY, G.I. \& GONG, W.K. 1993. Use of hemispherical photographs in forest ecology: measurement of gap size and radiation totals in a Bornean tropical rainforest. Journal of Tropical Ecology 9: 131-151.

WHITMORE, T.C. 1993. Tropische Regenwälder. Spectrum Akademischer Verlag, Heidelberg Berlin New York.

YIN, X., LATINGA, E.A., SCHAPENDONK, H.C.M. \& ZHONG, X. 2003. Some quantitative relationships between leaf area index and canopy nitrogen content and distribution. Annals of Botany 91: 893-903.

YONG, J.W.H., WONG, S.C. \& FARQUHAR, G.D. 1997. Stomatal responses to changes in vapour pressure difference between leaf and air. Plant, Cell and Environment 20: 1213-1216.

ZOTZ, G. \& WINTER, K. 1994. Photosynthesis of a tropical canopy tree, Ceiba pentandra, in a lowland forest in Panama. Tree Physiology 14: 1291-1301. 


\section{ACKNOWLEDGEMENTS}

I wish to thank the following persons for their direct, or indirect contributions to this thesis:

My two supervisors Prof. Dr. C. Leuschner and Prof.Dr. D. Hölscher

Prof. Dr. S.R. Gradstein, Department of Systematic Botany, University of Göttingen, for being the second examiner of this thesis and for good cooperation within the sub-project $\mathrm{C} 2$

Ato and Udin with friends from the Herbarium Celebense, who became completely indispensable, competent and reliable companions in the forest and were excellent tree climbers Jana Juhrband and Marc Hagemeier, for cooperation in the field and sharing gas-exchange data

Paul Keßler, National Herbarium of the Netherlands, Leiden, and the Department of Systematic Botany, University of Göttingen for species identification, as well as for introducing me to practical work in a tropical forest and setting a good example of how to be a field work leader

The STORMA laboratory in Palu, who managed to conduct lots of reliable analyses, despite the, from time to time immense, technical problems

The STORMA coordination office and drivers for managing all kinds of ground service

The skilful tower constructors, without whom we'd never reached the canopies

Uli Falk for helping with the hemispheric pictures

The village head of Wuasa, for letting us conduct our research in his district

The extended Kabi family in Wuasa, for warm hospitality

Three colleagues, who's presence during different periods was of decisive importance for the proceeding of the process...

Alex, for sharing her experience of Indonesia with me during our first months in Napu

Gesa, for a lot of laughter and endless chats at the terrace in Palu

Sandra, for always being reachable across the corridor at the institute in Göttingen

All those Palu, Napu and Gimpu people who became friends of mine, making my stay in Indonesia so pleasant

Annette \& Christof for lots of support and nice and relaxing spare time in Göttingen

My house mates in J1 Nuri 24: Gesa, Miet \& Robert

Last but not least (rather most): My whole family, for supporting and encouraging me and for managing a lot of things at home during my absence 
APPENDICES 
Appendix 1. Correlation parameters $r^{2}$ (italics, above) and p (below) for Pearson's correlation analysis of leaf size versus a number of morphological and chemical leaf traits a number of important families in natural and secondary forest and agroforestry systems of the study area. One species from each of these families and Theobroma cacao, as

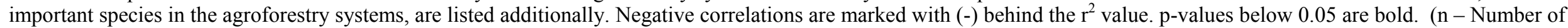
tree individuals, LW - Length-width ratio, SLA - Specific leaf area)

\begin{tabular}{|c|c|c|c|c|c|c|c|c|c|c|c|c|}
\hline Family & $\begin{array}{l}\text { Euphorb- } \\
\text { iaceae }\end{array}$ & Lauraceae & Fabaceae & Meliaceae & Moraceae & Urticaceae & $\begin{array}{l}\text { Aglaia } \\
\text { argentea }\end{array}$ & 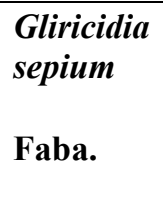 & $\begin{array}{l}\text { Homa- } \\
\text { lanthus } \\
\text { populneus } \\
\text { Euph. }\end{array}$ & Litsea sp. & $\begin{array}{l}\text { Pipturus } \\
\text { argentus } \\
\text { Urtic. }\end{array}$ & $\begin{array}{l}\text { Theobroma } \\
\text { cacao }\end{array}$ \\
\hline $\mathbf{n}$ & 85 & 23 & 31 & 20 & 13 & 57 & 10 & 10 & 10 & 10 & 10 & 10 \\
\hline \multirow[t]{2}{*}{ LW } & $0.06(-)$ & $0.28(-)$ & $0.65(-)$ & $0.05(-)$ & $0.50(-)$ & $0.17(-)$ & $0.12(-)$ & $0.15(-)$ & $0.45(-)$ & $<0.001$ & $0.41(-)$ & $0.07(-)$ \\
\hline & 0.02 & 0.01 & $<0.01$ & 0.36 & 0.01 & $<0.01$ & 0.32 & 0.26 & 0.03 & 0.96 & 0.04 & 0.43 \\
\hline \multirow[t]{2}{*}{ SLA } & 0.007 (-) & $0.45(-)$ & 0.31 & 0.11 & $0.08(-)$ & $0.08(-)$ & 0.33 & 0.05 & $0.001(-)$ & 0.01 & $0.16(-)$ & 0.25 \\
\hline & 0.43 & $<0.01$ & $<0.01$ & 0.16 & 0.39 & 0.04 & 0.08 & 0.53 & 0.92 & 0.78 & 0.25 & 0.14 \\
\hline \multirow[t]{2}{*}{$\mathrm{Ca}$} & $<0.001$ (-) & $0.01(-)$ & $0.13(-)$ & $0.10(-)$ & $0.16(-)$ & 0.08 & $0.03(-)$ & $0.48(-)$ & $0.04(-)$ & 0.02 & 0.10 & $0.44(-)$ \\
\hline & 0.84 & 0.60 & 0.03 & 0.20 & 0.22 & 0.03 & 0.61 & 0.02 & 0.58 & 0.70 & 0.37 & 0.03 \\
\hline \multirow[t]{2}{*}{ K } & $<0.001$ & $0.02(-)$ & $0.09(-)$ & 0.13 & $0.002(-)$ & 0.07 & $0.003(-)$ & $0.04(-)$ & $0.36(-)$ & 0.01 & 0.06 & 0.15 \\
\hline & 0.81 & 0.57 & 0.09 & 0.14 & 0.87 & 0.04 & 0.87 & 0.59 & 0.06 & 0.73 & 0.47 & 0.25 \\
\hline \multirow[t]{2}{*}{ Mg } & 0.006 & $0.03(-)$ & $0.03(-)$ & 0.02 & $0.04(-)$ & $<0.001(-)$ & $0.04(-)$ & $0.45(-)$ & 0.02 & 0.24 & 0.04 & $<0.001$ (-) \\
\hline & 0.48 & 0.44 & 0.36 & 0.60 & 0.54 & 0.94 & 0.60 & 0.03 & 0.70 & 0.14 & 0.58 & 0.93 \\
\hline \multirow[t]{2}{*}{$\mathbf{P}$} & $0.002(-)$ & $0.05(-)$ & 0.02 & 0.23 & 0.28 & 0.04 & $0.001(-)$ & $0.02(-)$ & $0.01(-)$ & 0.002 & 0.18 & 0.07 \\
\hline & 0.63 & 0.32 & 0.48 & 0.05 & 0.08 & 0.14 & 0.91 & 0.67 & 0.76 & 0.90 & 0.21 & 0.45 \\
\hline \multirow[t]{2}{*}{$\mathbf{N}$} & 0.02 & $0.39(-)$ & 0.007 & $<0.001$ & $0.003(-)$ & 0.009 & $0.02(-)$ & $0.004(-)$ & $<0.001$ (-) & $0.03(-)$ & $0.01(-)$ & $0.04(-)$ \\
\hline & 0.19 & $<0.01$ & 0.65 & 0.98 & 0.86 & 0.48 & 0.73 & 0.85 & 0.98 & 0.65 & 0.77 & 0.57 \\
\hline \multirow[t]{2}{*}{$\mathrm{C}$} & $0.02(-)$ & 0.02 & $0.10(-)$ & $0.004(-)$ & 0.009 & $0.06(-)$ & $0.36(-)$ & 0.22 & 0.60 & 0.008 & $<0.001$ & 0.52 \\
\hline & 0.17 & 0.52 & 0.07 & 0.79 & 0.78 & 0.07 & 0.06 & 0.16 & $<0.01$ & 0.79 & 0.98 & 0.01 \\
\hline \multirow[t]{2}{*}{$\mathbf{C} / \mathbf{N}$} & $0.04(-)$ & 0.55 & $0.07(-)$ & $0.02(-)$ & 0.02 & $0.02(-)$ & $0.04(-)$ & 0.19 & 0.01 & 0.01 & 0.002 & 0.36 \\
\hline & 0.07 & $<0.01$ & 0.15 & 0.60 & 0.70 & 0.33 & 0.59 & 0.20 & 0.75 & 0.76 & 0.89 & 0.06 \\
\hline \multirow[t]{2}{*}{$\delta^{13} \mathrm{C}$} & 0.06 & $0.08(-)$ & $0.06(-)$ & $<0.001$ & $<0.001$ & 0.01 & $0.22(-)$ & $0.05(-)$ & $0.07(-)$ & $0.07(-)$ & 0.34 & $0.22(-)$ \\
\hline & 0.02 & 0.20 & 0.18 & 0.95 & 0.96 & 0.45 & 0.16 & 0.52 & 0.45 & 0.44 & 0.07 & 0.17 \\
\hline \multirow[t]{2}{*}{$\mathbf{N} / \mathbf{P}$} & 0.02 & $0.04(-)$ & $0.03(-)$ & $0.19(-)$ & $0.23(-)$ & $0.02(-)$ & $<0.001$ (-) & 0.01 & 0.009 & $0.003(-)$ & $0.25(-)$ & $0.13(-)$ \\
\hline & 0.23 & 0.41 & 0.33 & 0.07 & 0.13 & 0.37 & 0.94 & 0.76 & 0.78 & 0.87 & 0.14 & 0.30 \\
\hline \multirow[t]{2}{*}{$\mathbf{C} / \mathbf{P}$} & $0.006(-)$ & 0.13 & $0.06(-)$ & $0.28(-)$ & $0.23(-)$ & $0.02(-)$ & $0.001(-)$ & 0.07 & 0.10 & 0.008 & $0.25(-)$ & $<0.001(-)$ \\
\hline & 0.47 & 0.11 & 0.17 & 0.02 & 0.13 & 0.25 & 0.90 & 0.44 & 0.37 & 0.80 & 0.13 & 0.93 \\
\hline \multirow[t]{2}{*}{$\delta^{15} \mathrm{~N}$} & $<0.001$ & $0.07(-)$ & $0.01(-)$ & $0.005(-)$ & $0.03(-)$ & 0.01 & $<0.001$ & $0.07(-)$ & 0.22 & 0.11 & 0.40 & $0.32(-)$ \\
\hline & 0.93 & 0.24 & 0.55 & 0.78 & 0.65 & 0.42 & 0.93 & 0.46 & 0.17 & 0.34 & 0.04 & 0.08 \\
\hline
\end{tabular}


Appendix 2. Correlation parameters $\mathrm{r}^{2}$ (italics, above) and p (below) for Pearson's correlation analysis of specific leaf area versus a number of morphological and chemical leaf

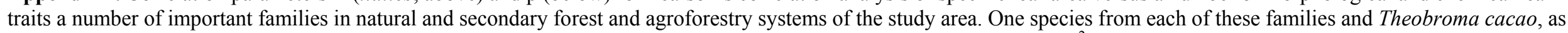
important species in the agroforestry system, are listed additionally. Negative correlations are marked with (-) behind the $r^{2}$ value. $p$-values $<0.05$ are bold. (n - Number of individuals, LW - Length-width ratio)

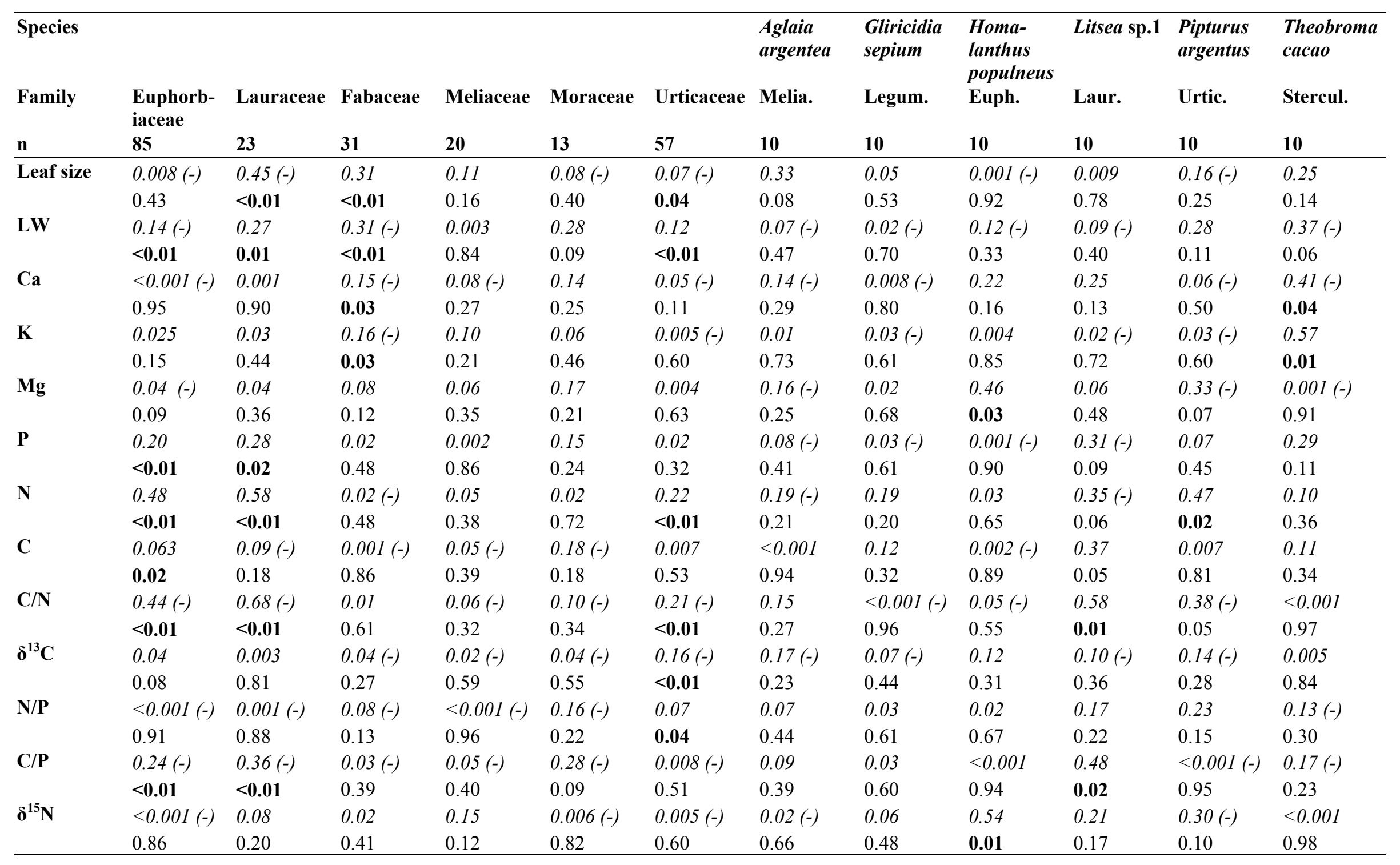


Appendix 3. Correlation parameters $\mathrm{r}^{2}$ (italics, above) and $\mathrm{p}$ (below) for Pearson's correlation analysis of $\delta^{13} \mathrm{C}$ versus a number of morphological and chemical leaf traits a number of important families in natural and secondary forest and agroforestry systems of the study area. One species from each of these families and the important species of the agroforestry systems, Theobroma cacao, are listed. Negative correlations are marked with (-) behind the $\mathrm{r}^{2}$ value. $\mathrm{p}$-values $<0.05$ are bold. ( $\mathrm{n}-\mathrm{Number}$ of individuals, LW - Length-width ratio, SLA - specific leaf area)

\begin{tabular}{|c|c|c|c|c|c|c|c|c|c|c|c|c|}
\hline \multicolumn{7}{|l|}{ Species } & \multirow{2}{*}{$\begin{array}{l}\text { Aglaia } \\
\text { argentea } \\
\text { Melia. }\end{array}$} & \multirow{2}{*}{$\begin{array}{l}\text { Gliricidia } \\
\text { sepium }\end{array}$} & \multirow{2}{*}{$\begin{array}{l}\text { Homa- } \\
\text { lanthus } \\
\text { populneus } \\
\text { Euph. }\end{array}$} & \multirow{2}{*}{$\begin{array}{l}\text { Litsea sp.1 } \\
\text { Laur. }\end{array}$} & \multirow{2}{*}{$\begin{array}{l}\text { Pipturus } \\
\text { argentus } \\
\text { Urtic. }\end{array}$} & \multirow{2}{*}{$\begin{array}{l}\text { Theobroma } \\
\text { cacao } \\
\text { Stercul. }\end{array}$} \\
\hline Family & $\begin{array}{l}\text { Euphorb- } \\
\text { iaceae }\end{array}$ & Lauraceae & Fabaceae & Meliaceae & Moraceae & Urticaceae & & & & & & \\
\hline $\mathbf{n}$ & 85 & 23 & 31 & 20 & 13 & 57 & 10 & 10 & 10 & 10 & 10 & 10 \\
\hline \multirow[t]{2}{*}{ Leaf size } & 0.06 & $0.08(-)$ & $0.06(-)$ & $<0.001$ & $<0.001$ & 0.01 & $0.24(-)$ & $0.05(-)$ & $0.07(-)$ & $0.07(-)$ & 0.34 & $0.22(-)$ \\
\hline & 0.02 & 0.20 & 0.18 & 0.95 & 0.96 & 0.45 & 0.14 & 0.52 & 0.45 & 0.44 & 0.07 & 0.17 \\
\hline \multirow[t]{2}{*}{ LW } & $0.38(-)$ & $<0.001(-)$ & $0.008(-)$ & $0.21(-)$ & $0.25(-)$ & $0.28(-)$ & $<0.001$ & 0.15 & $0.02(-)$ & $0.004(-)$ & $0.61(-)$ & 0.10 \\
\hline & $<0.01$ & 0.92 & 0.63 & 0.06 & 0.13 & $<0.01$ & 0.97 & 0.26 & 0.67 & 0.87 & $<0.01$ & 0.36 \\
\hline \multirow[t]{2}{*}{ SLA } & 0.04 & 0.003 & $0.04(-)$ & $0.02(-)$ & $0.04(-)$ & $0.16(-)$ & $0.20(-)$ & $0.07(-)$ & 0.12 & $0.10(-)$ & $0.14(-)$ & 0.005 \\
\hline & 0.08 & 0.81 & 0.27 & 0.58 & 0.55 & $<0.01$ & 0.18 & 0.44 & 0.31 & 0.36 & 0.28 & 0.84 \\
\hline \multirow[t]{2}{*}{ Ca } & 0.06 & 0.14 & $0.10(-)$ & $0.002(-)$ & 0.15 & $0.001(-)$ & $0.05(-)$ & 0.04 & 0.31 & 0.004 & 0.03 & $<0.001(-)$ \\
\hline & 0.02 & 0.07 & 0.08 & 0.86 & 0.20 & 0.77 & 0.52 & 0.56 & 0.09 & 0.86 & 0.60 & 0.96 \\
\hline \multirow[t]{2}{*}{$\mathbf{K}$} & 0.12 & 0.49 & 0.07 & 0.003 & 0.006 & 0.05 & 0.005 & 0.02 & 0.17 & $0.02(-)$ & 0.38 & 0.09 \\
\hline & $<0.01$ & $<0.01$ & 0.15 & 0.80 & 0.80 & 0.12 & 0.84 & 0.66 & 0.22 & 0.72 & 0.05 & 0.40 \\
\hline \multirow[t]{2}{*}{ Mg } & $0.002(-)$ & 0.29 & 0.002 & 0.33 & $0.0001(-)$ & $0.08(-)$ & $0.01(-)$ & $0.09(-)$ & 0.14 & $0.09(-)$ & 0.04 & $0.08(-)$ \\
\hline & 0.65 & $<0.01$ & 0.77 & 0.01 & 0.97 & 0.03 & 0.73 & 0.39 & 0.27 & 0.38 & 0.56 & 0.42 \\
\hline \multirow[t]{2}{*}{$\mathbf{P}$} & 0.23 & 0.007 & 0.11 & 0.004 (-) & 0.02 & 0.23 & $0.06(-)$ & $0.03(-)$ & 0.23 & 0.49 & 0.09 & 0.006 \\
\hline & $<0.01$ & 0.70 & 0.07 & 0.79 & 0.67 & $<0.01$ & 0.49 & 0.65 & 0.15 & 0.02 & 0.39 & 0.82 \\
\hline \multirow[t]{2}{*}{$\mathbf{N}$} & 0.26 & $0.001(-)$ & 0.35 & $0.001(-)$ & 0.29 & 0.06 & $<0.001$ (-) & 0.27 & $0.30(-)$ & 0.04 & 0.02 & $0.006(-)$ \\
\hline & $<0.01$ & 0.88 & $<0.01$ & 0.88 & 0.07 & 0.07 & 0.98 & 0.12 & 0.10 & 0.60 & 0.66 & 0.83 \\
\hline \multirow[t]{2}{*}{ C } & 0.02 & $0.07(-)$ & $0.006(-)$ & $0.002(-)$ & $0.20(-)$ & 0.03 & 0.29 & 0.04 & $0.25(-)$ & $0.51(-)$ & $<0.001$ & $0.03(-)$ \\
\hline & 0.20 & 0.21 & 0.67 & 0.83 & 0.13 & 0.23 & 0.10 & 0.56 & 0.13 & 0.02 & 0.96 & 0.64 \\
\hline \multirow[t]{2}{*}{$\mathbf{C} / \mathbf{N}$} & $0.28(-)$ & $0.004(-)$ & $0.25(-)$ & 0.001 & $0.44(-)$ & $0.04(-)$ & 0.08 & $0.09(-)$ & 0.24 & $0.19(-)$ & $0.05(-)$ & $0.001(-)$ \\
\hline & $<0.01$ & 0.78 & $<0.01$ & 0.89 & 0.01 & 0.16 & 0.42 & 0.39 & 0.15 & 0.19 & 0.53 & 0.93 \\
\hline \multirow[t]{2}{*}{$\mathbf{N} / \mathbf{P}$} & $0.05(-)$ & $0.03(-)$ & $0.01(-)$ & 0.005 & 0.09 & $0.18(-)$ & 0.10 & 0.09 & $0.44(-)$ & $0.47(-)$ & $0.05(-)$ & $<0.001$ \\
\hline & 0.04 & 0.46 & 0.53 & 0.75 & 0.34 & $<0.01$ & 0.36 & 0.40 & 0.03 & 0.02 & 0.52 & 0.95 \\
\hline \multirow[t]{2}{*}{$\mathbf{C} / \mathbf{P}$} & $0.31(-)$ & $0.07(-)$ & $0.10(-)$ & 0.02 & 0.004 & $0.22(-)$ & 0.12 & 0.04 & $0.38(-)$ & $0.51(-)$ & $0.18(-)$ & 0.003 (-) \\
\hline & $<0.01$ & 0.23 & 0.07 & 0.56 & 0.84 & $<0.01$ & 0.32 & 0.59 & 0.05 & 0.02 & 0.21 & 0.87 \\
\hline \multirow[t]{2}{*}{$\delta^{15} \mathbf{N}$} & 0.05 & 0.22 & 0.10 & $0.01(-)$ & $0.03(-)$ & 0.09 & $0.23(-)$ & 0.12 & 0.12 & $0.16(-)$ & 0.84 & 0.12 \\
\hline & 0.03 & 0.02 & 0.08 & 0.64 & 0.61 & 0.02 & 0.15 & 0.32 & 0.31 & 0.23 & $<0.01$ & 0.32 \\
\hline
\end{tabular}


Appendix 4. Means and standard deviation of leaf size, length-width ratio and specific leaf area (SLA) of all species investigated in the study, occurring in natural forest, secondary forest, forest garden and/or agroforestry systems in and around Lore Lindu National Park, Central Sulawesi, Indonesia. Calculated from 10 leaves per species.

\begin{tabular}{|c|c|c|c|c|c|c|c|}
\hline \multirow[t]{2}{*}{ Family } & \multirow[t]{2}{*}{ Species } & \multicolumn{2}{|c|}{$\begin{array}{c}\text { Leaf size } \\
{\left[\mathrm{cm}^{2}\right]}\end{array}$} & \multicolumn{2}{|c|}{$\begin{array}{c}\text { Length- } \\
\text { width ratio }\end{array}$} & \multicolumn{2}{|c|}{$\underset{\left[\mathrm{cm}^{2} \mathbf{g}^{-1}\right]}{\text { SLA }}$} \\
\hline & & mean & sd & mean & sd & mean & sd \\
\hline Actinidiaceae & Saurauia sp. & 84.8 & 13.1 & 2.6 & 0.1 & 109.2 & 4.7 \\
\hline \multirow[t]{2}{*}{ Anacardiaceae } & Dracontomelon dao & 194.2 & 71.4 & 1.8 & 0.2 & 120.4 & 4.8 \\
\hline & Semecarpus forstenii & 168.2 & 66.1 & 2.8 & 0.8 & 67.8 & 13.2 \\
\hline Annonaceae & Cananga odorata & 150.6 & 52.6 & 2.1 & 0.6 & 162.6 & 18.3 \\
\hline \multirow[t]{2}{*}{ Apocynaceae } & Rauvolfia sumatrana & 97.4 & 21.6 & 1.8 & 0.1 & 145.1 & 17.7 \\
\hline & Tabernamontana macrocarpa & 321.6 & 61.8 & 1.8 & 0.4 & 176.7 & 19.1 \\
\hline \multirow[t]{2}{*}{ Araliaceae } & Aralia sp. & 81.0 & 15.6 & 2.2 & 0.2 & 53.0 & 10.2 \\
\hline & Artrophyllum sp. & 104.7 & 19.3 & 3.1 & 0.4 & 77.5 & 8.2 \\
\hline \multirow[t]{2}{*}{ Burseraceae } & Burseraceae sp.1 & 198.0 & 26.1 & 1.6 & 0.6 & 75.3 & 4.3 \\
\hline & Burseraceae sp.2 & 142.4 & 25.4 & 2.6 & 0.9 & 117.1 & 8.1 \\
\hline Capparaceae & Capparis pubiflora & 62.3 & 19.3 & 3.1 & 0.2 & 106.0 & 10.0 \\
\hline Celastraceae & Siphonodon celastrineus & 62.5 & 23.8 & 2.2 & 0.2 & 94.7 & 13.1 \\
\hline Combretaceae & Terminalia sp. & 54.0 & 13.3 & 2.3 & 0.2 & 116.3 & 27.1 \\
\hline Dilleniaceae & Dillenia sp. & 68.1 & 18.1 & 2.6 & 0.1 & 89.0 & 11.4 \\
\hline Elaeocarpaceae & Elaeocarpus sp. & 111.0 & 39.4 & 2.7 & 0.5 & 115.1 & 8.1 \\
\hline \multirow[t]{10}{*}{ Euphorbiaceae } & Acalypha caturus & 127.0 & 68.7 & 1.3 & 0.3 & 113.6 & 13.3 \\
\hline & Antidesma stipulare & 54.0 & 11.0 & 2.5 & 0.6 & 99.04 & 18.4 \\
\hline & Baccaurea sp. & 201.2 & 34.6 & 2.8 & 0.2 & 79.2 & 9.7 \\
\hline & Bischofia javanica & 77.3 & 23.5 & 1.5 & 0.6 & 98.4 & 18.7 \\
\hline & Glochidion rubrum & 97.9 & 12.9 & 2.0 & 0.2 & 99.4 & 23.7 \\
\hline & Homalanthus populneus & 51.3 & 21.1 & 1.4 & 0.3 & 178.6 & 27.9 \\
\hline & Macaranga hispida & 646.7 & 269.4 & 1.3 & 0.2 & 109.3 & 16.0 \\
\hline & Macaranga tanarius & 1250.7 & 778.8 & 1.1 & 0.1 & 160.8 & 27.7 \\
\hline & Mallotus mollissimus & 320.4 & 138.1 & 1.2 & 0.1 & 161.3 & 24.2 \\
\hline & Pimelodendron amboinicum & 29.4 & 10.1 & 2.5 & 0.3 & 94.8 & 18.9 \\
\hline \multirow[t]{2}{*}{ Fabaceae } & Erythrina sp. & 54.0 & 19.1 & 1.4 & 0.2 & 217.6 & 34.0 \\
\hline & Gliricidia sepium & 8.9 & 3.2 & 2.6 & 0.3 & 164.9 & 19.5 \\
\hline Fagaceae & Lithocarpus sp. & 155.8 & 25.4 & 2.1 & 0.3 & 66.0 & 2.8 \\
\hline Flacourtiaceae & Osmelia philipinia & 62.1 & 7.3 & 2.3 & 0.3 & 121.4 & 15.8 \\
\hline Guttiferae & Garcinia sp. & 55.0 & 13.7 & 2.2 & 0.2 & 102.8 & 10.7 \\
\hline \multirow{9}{*}{ Lauraceae } & Actinodaphne sp. & 112.7 & 47.2 & 2.0 & 0.3 & 92.9 & 8.4 \\
\hline & Beilschmiedia sp. & 74.7 & 14.8 & 2.8 & 0.4 & 146.5 & 24.0 \\
\hline & Cryptocarya crassinerviopsis & 234.8 & 56.3 & 1.7 & 0.2 & 87.1 & 16.9 \\
\hline & Lauraceae sp.1 & 72.8 & 18.3 & 4.0 & 0.3 & 130.8 & 6.5 \\
\hline & Lauraceae sp.2 & 151.6 & 19.7 & 2.3 & 0.1 & 87.1 & 4.3 \\
\hline & Litsea sp.1 & 223.9 & 53.4 & 2.0 & 0.4 & 62.1 & 10.4 \\
\hline & Litsea $\mathrm{sp} .2$ & 45.7 & 8.9 & 2.4 & 0.3 & 114.9 & 12.1 \\
\hline & Litsea sp.3 & 86.9 & 21.7 & 3.0 & 0.8 & 120.3 & 12.6 \\
\hline & Nothaphoebe umbellata & 44.1 & 9.9 & 2.3 & 0.7 & 151.9 & 60.9 \\
\hline Liliaceae & Dracaena sp. & 195.2 & 15.0 & 21.4 & 5.7 & 40.5 & 6.6 \\
\hline Magnoliaceae & Elmerillia tsiampacca & 381.4 & 103.5 & 2.5 & 0.5 & 114.6 & 16.8 \\
\hline \multirow[t]{7}{*}{ Meliaceae } & Aglaia sp. & 94.5 & 20.9 & 2.0 & 0.3 & 110.3 & 15.6 \\
\hline & Aglaia argentea & 160.6 & 92.8 & 3.0 & 0.7 & 82.9 & 10.2 \\
\hline & Chisocheton sp.1 & 237.0 & 40.5 & 2.0 & 0.5 & 117.3 & 8.9 \\
\hline & Chisocheton sp.2 & 83.5 & 28.7 & 2.7 & 0.4 & 95.3 & 11.3 \\
\hline & Dysoxylum sp.2 & 320.3 & 94.8 & 2.0 & 0.6 & 114.7 & 18.7 \\
\hline & Dysoxylum sp.4 & 189.7 & 32.7 & 2.5 & 0.9 & 129.1 & 12.6 \\
\hline & Dysoxylum sp. 5 & 120.7 & 24.4 & 2.7 & 0.1 & 101.9 & 10.1 \\
\hline
\end{tabular}


Continued

\begin{tabular}{|c|c|c|c|c|c|c|c|}
\hline \multirow[t]{2}{*}{ Family } & \multirow[t]{2}{*}{ Species } & \multicolumn{2}{|c|}{$\begin{array}{c}\text { Leaf size } \\
{\left[\mathrm{cm}^{2}\right]}\end{array}$} & \multicolumn{2}{|c|}{$\begin{array}{l}\text { Length-width } \\
\text { ratio }\end{array}$} & \multicolumn{2}{|c|}{$\begin{array}{c}\text { SLA } \\
{\left[\mathrm{cm}^{2} \mathrm{~g}^{-1}\right]}\end{array}$} \\
\hline & & mean & sd & mean & sd & mean & sd \\
\hline \multirow[t]{11}{*}{ Moraceae } & Artocarpus intiger & 73.7 & 9.9 & 2.7 & 0.1 & 108.5 & 9.7 \\
\hline & Ficus sp.1 & 82.6 & 18.3 & 2.5 & 0.3 & 128.5 & 10.1 \\
\hline & Ficus sp.4 & 260.1 & 55.9 & 1.3 & 0.2 & 82.0 & 19.9 \\
\hline & Ficus sp.5 & 50.1 & 6.9 & 2.5 & 0.1 & 87.0 & 13.4 \\
\hline & Ficus sp.6 & 56.4 & 13.8 & 2.1 & 0.4 & 107.6 & 15.4 \\
\hline & Ficus sp.7 & 168.4 & 35.1 & 2.3 & 0.4 & 85.5 & 10.7 \\
\hline & Ficus sp. 8 & 91.3 & 13.6 & 2.1 & 0.1 & 119.3 & 4.9 \\
\hline & Ficus sp.9 & 60.7 & 9.5 & 3.1 & 0.1 & 123.8 & 12.8 \\
\hline & Ficus sp.10 & 12.8 & 2.9 & 2.3 & 0.1 & 77.1 & 10.7 \\
\hline & Ficus sp.11 & 73.2 & 23.5 & 3.0 & 0.1 & 128.5 & 18.5 \\
\hline & Ficus sp.12 & 101.1 & 17.4 & 2.1 & 0.9 & 117.2 & 10.9 \\
\hline \multirow[t]{2}{*}{ Myristicaceae } & Horsfieldia costulata & 153.5 & 18.5 & 1.9 & 0.6 & 132.5 & 11.4 \\
\hline & Horsfieldia sp. & 88.8 & 27.8 & 2.1 & 0.2 & 99.0 & 5.6 \\
\hline Myrtaceae & Syzygium sp. & 73.3 & 17.3 & 1.8 & 0.1 & 110.6 & 10.2 \\
\hline Oleaceae & Chionanthus sp. & 42.3 & 9.1 & 2.2 & 0.4 & 116.7 & 29.6 \\
\hline Palmae & Arenga pinnata & 589.4 & 31.22 & 22.4 & 7.7 & & \\
\hline Pandanaceae & Pandanus sp. & 307.1 & 61.8 & 14.77 & 1.2 & 77.0 & 4.3 \\
\hline Polygalaceae & Xanthophyllum sp. & 29.7 & 8.5 & 2.5 & 0.3 & 116.8 & 8.9 \\
\hline \multirow[t]{2}{*}{ Rubiaceae } & Coffea arabica & 51.4 & 11.9 & 2.4 & 0.4 & 106.5 & 14.9 \\
\hline & Myrmeconauclea & 155.0 & 18.7 & 2.3 & 0.1 & 113.3 & 13.5 \\
\hline Rutaceae & Melicope glabra & 148.2 & 17.5 & 2.8 & 0.42 & 110.4 & 14.9 \\
\hline Sabiaceae & Meliosma sumatrana & 32.0 & 12.9 & 2.5 & 0.44 & 99.9 & 28.4 \\
\hline \multirow[t]{2}{*}{ Sapindaceae } & Nephelium sp. & 126.6 & 25.4 & 2.4 & 0.23 & 144.5 & 19.3 \\
\hline & Rhysotechia sp. & 58.5 & 17.2 & 2.4 & 0.21 & 139.5 & 16.4 \\
\hline Sapotaceae & Palaquium quercifolium & 100.2 & 20.8 & 2.1 & 0.42 & 149.4 & 6.5 \\
\hline Sarcospermaceae & Sarcosperma paniculata & 131.9 & 26.7 & 2.1 & 0.78 & 123.6 & 5.6 \\
\hline Solanaceae & Solanum $\mathrm{sp}$. & 122.0 & 25.0 & 1.6 & 0.33 & 130.2 & 13.4 \\
\hline Staphylaceae & Turpinia sphaerocarpa & 58.5 & 17.4 & 1.8 & 0.62 & 90.7 & 2.1 \\
\hline \multirow[t]{2}{*}{ Sterculiaceae } & Pterospermum javanicum & 102.6 & 23.7 & 2.1 & 0.28 & 106.6 & 16.3 \\
\hline & Theobroma cacao & 199.3 & 53.7 & 2.0 & 0.71 & 120.9 & 24.7 \\
\hline Tiliaceae & Grewia glabra & 60.8 & 16.4 & 2.4 & 0.34 & 177.2 & 36.8 \\
\hline Ulmaceae & Trema orientalis & 93.0 & 38.1 & 1.9 & 0.29 & 128.2 & 26.5 \\
\hline \multirow[t]{10}{*}{ Urticaceae } & Dendrocnide sp.1 & 591.4 & 473.7 & 1.5 & 0.37 & 131.5 & 44.9 \\
\hline & Dendrocnide sp.2 & 285.3 & 59.9 & 1.2 & 0.06 & 104.8 & 11.9 \\
\hline & Dendrocnide sp. 3 & 411.9 & 103.6 & 1.1 & 0.04 & 128.7 & 18.6 \\
\hline & Dendrocnide stimulan & 107.9 & 51.4 & 2.6 & 0.58 & 157.2 & 10.9 \\
\hline & Oreocnide rubescens & 88.6 & 38.7 & 3.5 & 0.45 & 128.8 & 12.5 \\
\hline & Pipterus argentus & 267.9 & 127.1 & 1.3 & 0.08 & 139.9 & 23.7 \\
\hline & Pouzolzia sp. & 73.0 & 24.3 & 2.8 & 0.54 & 134.1 & 18.7 \\
\hline & Urticaceae sp.1 & 148.6 & 13.1 & 1.4 & 0.09 & 123.8 & 22.0 \\
\hline & Urticaceae sp.2 & 38.4 & 10.6 & 3.9 & 0.51 & 236.0 & 29.1 \\
\hline & Urticaceae sp.3 & 40.8 & 16.7 & 3.0 & 0.07 & 97.6 & 12.4 \\
\hline Verbenaceae & Geunsia sp. & 109.1 & 26.2 & 2.3 & 0.31 & 130.8 & 16.6 \\
\hline \multirow[t]{10}{*}{ Unidentified } & 5 & 28.9 & 6.3 & 1.9 & 0.33 & 107.5 & 6.7 \\
\hline & 6 & 25.3 & 6.6 & 2.2 & 0.41 & 135.1 & 22.8 \\
\hline & 8 & 42.9 & 8.1 & 2.2 & 0.23 & 120.4 & 22.7 \\
\hline & 9 & 108.9 & 23.6 & 2.4 & 0.13 & 64.9 & 4.0 \\
\hline & 10 & 208.3 & 60.3 & 2.1 & 0.62 & 91.6 & 31.1 \\
\hline & 14 & 600.8 & 76.8 & 1.7 & 0.10 & 84.4 & 17.5 \\
\hline & 18 & 104.2 & 29.8 & 2.2 & 0.26 & 136.5 & 15.8 \\
\hline & 19 & 135.4 & 29.8 & 2.5 & 0.41 & 144.1 & 14.3 \\
\hline & 324 & 83.8 & 23.7 & 1.5 & 0.06 & 95.4 & 3.0 \\
\hline & 345 & 124.2 & 29.4 & 1.6 & 0.34 & 121.3 & 26.7 \\
\hline
\end{tabular}


Appendix 5. Leaf size, length-width ratio and specific leaf area (SLA) of all families investigated in the study, occurring in natural forest, secondary forest, forest garden and/or agroforestry systems in and around Lore Lindu National Park, Central Sulawesi, Indonesia. Means and standard deviation calculated from 10 leaves per species.

\begin{tabular}{|c|c|c|c|c|c|c|c|}
\hline \multirow[b]{2}{*}{ Family } & \multirow{2}{*}{$\begin{array}{c}\text { No. } \\
\text { species per } \\
\text { family }\end{array}$} & \multicolumn{2}{|c|}{$\begin{array}{c}\text { Leaf size } \\
{\left[\mathrm{cm}^{2}\right]}\end{array}$} & \multicolumn{2}{|c|}{$\begin{array}{l}\text { Length-width } \\
\text { ratio }\end{array}$} & \multicolumn{2}{|c|}{$\begin{array}{c}\text { SLA } \\
{\left[\mathrm{cm}^{2} \mathrm{~g}^{-1}\right]}\end{array}$} \\
\hline & & mean & sd & mean & sd & mean & sd \\
\hline Actinidiaceae & 1 & 84.8 & 13.1 & 2.6 & 0.1 & 109.2 & 4.7 \\
\hline Anacardiaceae & 2 & 175.6 & 65.9 & 2.5 & 0.8 & 82.8 & 27.1 \\
\hline Annonaceae & 1 & 150.6 & 52.6 & 2.1 & 0.6 & 162.6 & 18.3 \\
\hline Apocynaceae & 2 & 237.6 & 122.5 & 1.8 & 0.3 & 164.8 & 23.9 \\
\hline Araliaceae & 2 & 95.8 & 21.1 & 2.8 & 0.5 & 69.3 & 14.7 \\
\hline Burseraceae & 2 & 170.2 & 38.0 & 2.1 & 0.9 & 96.2 & 22.3 \\
\hline Caparaceae & 1 & 62.3 & 19.4 & 3.0 & 0.2 & 106.0 & 10.0 \\
\hline Celastraceae & 1 & 62.5 & 23.8 & 2.2 & 0.2 & 94.7 & 13.1 \\
\hline Combretaceae & 1 & 54.0 & 13.3 & 2.3 & 0.2 & 116.3 & 27.1 \\
\hline Dilleniaceae & 1 & 68.1 & 18.1 & 2.6 & 0.1 & 89.0 & 11.4 \\
\hline Elaeocarpaceae & 1 & 111.0 & 39.4 & 2.7 & 0.5 & 115.1 & 8.1 \\
\hline Euphorbiaceae & 10 & 291.0 & 461.1 & 1.7 & 0.6 & 122.0 & 37.8 \\
\hline Fabaceae & 2 & 31.4 & 26.7 & 2.0 & 0.6 & 191.2 & 38.2 \\
\hline Fagaceae & 1 & 155.8 & 25.4 & 2.1 & 0.3 & 66.0 & 2.8 \\
\hline Flacourtiaceae & 1 & 62.1 & 7.3 & 2.3 & 0.3 & 121.4 & 15.8 \\
\hline Guttiferae & 1 & 55.0 & 13.7 & 2.2 & 0.2 & 102.8 & 10.7 \\
\hline Lauraceae & 9 & 118.8 & 75.3 & 2.5 & 0.8 & 109.0 & 34.5 \\
\hline Liliaceae & 1 & 195.2 & 15.0 & 21.4 & 5.7 & 40.5 & 6.6 \\
\hline Magnoliaceae & 1 & 381.4 & 103.5 & 2.5 & 0.5 & 114.6 & 16.8 \\
\hline Meliaceae & 7 & 179.0 & 97.1 & 2.4 & 0.7 & 107.8 & 18.9 \\
\hline Moraceae & 10 & 90.5 & 71.4 & 2.4 & 0.6 & 105.5 & 23.0 \\
\hline Myristicaceae & 2 & 107.1 & 39.3 & 2.0 & 0.3 & 108.5 & 17.2 \\
\hline Myrtaceae & 1 & 73.3 & 17.3 & 1.8 & 0.1 & 110.6 & 10.2 \\
\hline Oleaceae & 1 & 42.3 & 9.1 & 2.2 & 0.4 & 116.7 & 29.6 \\
\hline Palmae & 1 & 589.4 & 312.2 & 22.4 & 7.7 & & \\
\hline Pandanaceae & 1 & 307.1 & 61.8 & 14.7 & 1.2 & 77.0 & 4.38 \\
\hline Polygalaceae & 1 & 29.7 & 8.5 & 2.5 & 0.3 & 116.8 & 8.9 \\
\hline Rubiaceae & 2 & 85.9 & 52.4 & 2.4 & 0.3 & 108.7 & 13.8 \\
\hline Rutaceae & 1 & 148.2 & 17.5 & 2.8 & 0.4 & 110.4 & 14.9 \\
\hline Sabiaceae & 1 & 45.8 & 35.6 & 2.6 & 0.4 & 97.6 & 26.3 \\
\hline Sapindaceae & 2 & 92.5 & 41.1 & 2.4 & 0.2 & 142.0 & 17.3 \\
\hline Sapotaceae & 1 & 100.2 & 20.8 & 2.1 & 0.4 & 149.4 & 6.5 \\
\hline Sarcospermaceae & 1 & 131.9 & 26.7 & 2.1 & 0.7 & 123.6 & 5.6 \\
\hline Solanaceae & 1 & 122.0 & 25.0 & 1.6 & 0.3 & 130.2 & 13.4 \\
\hline Staphylaceae & 1 & 58.5 & 17.4 & 1.8 & 0.6 & 90.7 & 2.1 \\
\hline Sterculiaceae & 2 & 150.9 & 63.9 & 2.1 & 0.5 & 113.8 & 21.6 \\
\hline Tiliaceae & 1 & 60.8 & 16.4 & 2.4 & 0.3 & 177.2 & 36.8 \\
\hline Ulmaceae & 1 & 93.0 & 38.1 & 1.9 & 0.2 & 128.5 & 26.5 \\
\hline Urticaceae & 10 & 195.2 & 239.7 & 2.4 & 1.0 & 139.9 & 44.3 \\
\hline Verbenaceae & 1 & 109.1 & 26.9 & 2.3 & 0.3 & 130.8 & 16.6 \\
\hline Unidentified 10 & 1 & 208.3 & 60.3 & 2.1 & 0.6 & 91.6 & 31.1 \\
\hline Unidentified 14 & 1 & 600.8 & 76.8 & 1.7 & 0.1 & 84.4 & 17.5 \\
\hline Unidentified 18 & 1 & 104.2 & 29.8 & 2.2 & 0.2 & 136.5 & 15.8 \\
\hline Unidentified 19 & 1 & 135.4 & 29.8 & 2.5 & 0.4 & 144.1 & 14.3 \\
\hline Unidentified 5 & 1 & 28.9 & 6.3 & 1.9 & 0.3 & 107.5 & 6.7 \\
\hline Unidentified 6 & 1 & 25.3 & 6.6 & 2.2 & 0.4 & 135.1 & 22.8 \\
\hline Unidentified 8 & 1 & 42.9 & 8.1 & 2.2 & 0.2 & 120.4 & 22.7 \\
\hline Unidentified 9 & 1 & 108.9 & 23.6 & 2.4 & 0.1 & 64.9 & 4.0 \\
\hline Unidentified 324 & 1 & 83.8 & 23.7 & 1.5 & 0.06 & 95.4 & 3.0 \\
\hline Unidentified 345 & 1 & 124.2 & 29.4 & 1.6 & 0.3 & 121.3 & 26.7 \\
\hline
\end{tabular}




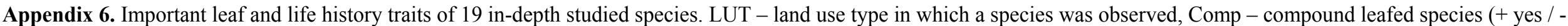

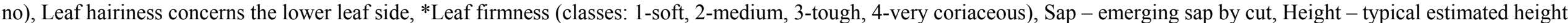
of mature trees in their primary habitats (in parenthesis: max height recorded in any LUT, if much deviant), Flowers or fruits: the studied trees were observed concerning their reproductive state during one year, Leaf angle classes represent the angle of the midrib to a vertical line: $0^{\circ}$ equals vertically upwards. Herb rate - Estimated leaf loss through herbivory according to observations of many individuals in the area, during one year $\quad * *$ classes: 0-nothing, 1-little, 2-intermediate, 3-much $\quad * * *$ These species were never observed wild.

\begin{tabular}{|c|c|c|c|c|c|c|c|c|c|c|}
\hline Species & Family & LUT & $\begin{array}{c}\text { Comp } \\
(+/-)\end{array}$ & $\begin{array}{c}\text { Leaf } \\
\text { hairiness }\end{array}$ & $\begin{array}{c}\text { Leaf } \\
\text { toughness } \\
*\end{array}$ & $\begin{array}{c}\text { Height } \\
(\mathbf{m})\end{array}$ & $\begin{array}{c}\text { Flowers } \\
\text { or } \\
\text { fruits } \\
\end{array}$ & $\begin{array}{c}\text { Leaf } \\
\text { angle } \\
\left({ }^{\circ}\right) \\
\end{array}$ & $\begin{array}{c}\text { Herb } \\
\text { Rate } \\
* * \\
\end{array}$ & Sap \\
\hline \multicolumn{11}{|l|}{ Natural forest } \\
\hline Aglaia argentea & Meliaceae & NF & + & glabrous & 3 & 35 & yes & $91-120$ & 1 & white \\
\hline Pimelodendron amboinicum & Euphorbiaceae & $\mathrm{NF}$ & - & glabrous & 3 & $15(20)$ & yes & $61-90$ & 0 & no \\
\hline Bischofia javanica & Euphorbiaceae & NF SF & + & glabrous & 3 & $25(35)$ & no & $91-120$ & 1 & reddish \\
\hline Cananga odorata & Annonaceae & NF SF & - & glabrous & 2 & $20(25)$ & no & $91-120$ & 2 & no \\
\hline Litsea sp.1 & Lauraceae & NF & - & pubescent & 4 & 30 & yes & $121-150$ & 2 & no \\
\hline Meliosma sumatrana & Sabiaceae & NF SF & + & glabrous & 2 & $20(30)$ & yes & $151-180$ & 1 & no \\
\hline Semecarpus forstenii & Anacardiaceae & NF & - & glabrous & 4 & 35 & yes & $121-150$ & 0 & clear (black by air exposure), skin irritating \\
\hline Siphonodon celastrineus & Celastraceae & $\mathrm{NF}$ & - & glabrous & 3 & $25(35)$ & yes & $91-120$ & 1 & yellow \\
\hline \multicolumn{11}{|l|}{$\underline{\text { Secondary forest }}$} \\
\hline Acalypha caturus & Euphorbiaceae & $\mathrm{SF}$ & - & pubescent & 2 & 5 & yes & $121-150$ & 2 & no \\
\hline Grewia glabra & Tiliaceae & SF NF & - & glabrous & 1 & $7(30)$ & yes & $121-150$ & 1 & no \\
\hline Homalanthus populneus & Euphorbiaceae & $\mathrm{SF}$ & - & glabrous & 1 & $5(10)$ & yes & $121-150$ & 1 & white, sticky \\
\hline Macaranga hispida & Euphorbiaceae & SF NF & - & hairy & 3 & $6(15)$ & yes & $151-180$ & 2 & no \\
\hline Macaranga tanarius & Euphorbiaceae & SF NF & - & glabrous & 2 & 6 & yes & $151-180$ & 3 & clear, rubbery \\
\hline Mallotus mollissimus & Euphorbiaceae & $\mathrm{SF}$ & - & pubescent & 1 & $7(15)$ & yes & $121-150$ & 2 & black \\
\hline Pipturus argentus & Urticaceae & SF NF & - & hairy & 2 & 6 & yes & $91-120$ & 2 & no \\
\hline Trema orientalis & Ulmaceae & SF NF & - & pubescent & 2 & $7(30)$ & no & $91-120$ & 3 & no \\
\hline \multicolumn{11}{|l|}{ Agroforestry system } \\
\hline Erythrina sp. & Fabaceae & AF SF & + & glabrous & 1 & $7(12)$ & no & $91-120$ & 3 & no \\
\hline Gliricidia sepium & Fabaceae & $\mathrm{AF}$ & + & glabrous & 2 & $7 * * *$ & yes & $61-90$ & 0 & no \\
\hline Theobroma cacao & Sterculiaceae & AF FG & - & glabrous & 3 & $1.5^{* * *}$ & yes & $91-120$ & 1 & no \\
\hline
\end{tabular}




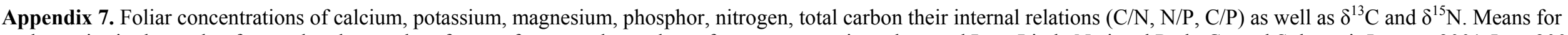

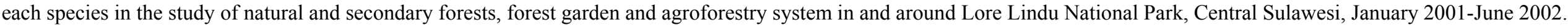
Standard deviation only available if more than one individual per species occurred in the sample.

\begin{tabular}{|c|c|c|c|c|c|c|c|c|c|c|c|c|c|c|c|c|c|c|c|c|c|c|c|}
\hline \multirow[b]{2}{*}{ Family } & \multirow[b]{2}{*}{ Species } & \multicolumn{2}{|c|}{$\underset{\left[\mathrm{g} \mathrm{kg}^{-1}\right]}{\mathbf{C a}}$} & \multicolumn{2}{|c|}{$\underset{\left[\mathrm{g} \mathrm{kg}^{-1}\right]}{\mathrm{K}}$} & \multicolumn{2}{|c|}{$\underset{\left[\mathrm{g} \mathrm{kg}^{-1}\right]}{\mathbf{M g}}$} & \multicolumn{2}{|c|}{$\begin{array}{c}\mathbf{P} \\
{\left[\mathrm{g} \mathrm{kg}^{-1}\right]}\end{array}$} & \multicolumn{2}{|c|}{$\begin{array}{c}\mathbf{N} \\
{[\%]}\end{array}$} & \multicolumn{2}{|c|}{$\begin{array}{c}\mathrm{C} \\
{[\%]}\end{array}$} & \multicolumn{2}{|c|}{$\mathbf{C} / \mathbf{N}$} & \multicolumn{2}{|c|}{$\begin{array}{l}\delta^{13} \mathrm{C} \\
{[\% 0]}\end{array}$} & \multicolumn{2}{|c|}{$\mathbf{N} / \mathbf{P}$} & \multicolumn{2}{|c|}{$\mathbf{C} / \mathbf{P}$} & \multicolumn{2}{|c|}{$\begin{array}{l}\delta^{15} \mathrm{~N} \\
{[\% 0]}\end{array}$} \\
\hline & & mean & sd & mean & sd & mean & sd & mean & sd & mean & sd & mean & sd & mean & sd & mean & sd & mean & sd & mean & sd & mean & sd \\
\hline Actinidiaceae & Saurauia sp. & & & & & & & & 1.94 & & 45.1 & & & 23.3 & & -28.0 & & & & & & 0.77 & \\
\hline \multirow[t]{2}{*}{ Anacardiaceae } & Dracontomelon dao & 27.98 & & 11.70 & & 6.64 & & 2.41 & & 1.97 & & 43.9 & & 22.3 & & -27.9 & & 8.16 & & 181 & & 4.47 & \\
\hline & Semecarpus forstenii & 12.38 & 5.58 & 6.72 & 0.74 & 1.90 & 0.75 & 1.01 & 0.56 & 1.42 & 0.24 & 38.4 & 3.0 & 27.3 & 5.9 & -29.4 & 0.8 & 16.33 & 7.15 & 449 & 190 & 2.28 & 0.47 \\
\hline Annonaceae & Cananga odorata & 19.21 & 1.48 & 7.01 & 0.10 & 2.90 & 0.41 & 1.72 & 0.24 & 1.99 & 0.28 & 46.7 & 0.9 & 23.8 & 3.8 & -27.5 & 1.4 & 11.61 & 0.59 & 275 & 38 & 0.26 & 1.26 \\
\hline \multirow[t]{2}{*}{ Apocynaceae } & Rauvolfia sumatrana & 17.62 & & 16.98 & & 9.68 & & 2.10 & & 3.67 & & 45.6 & & 12.4 & & -29.3 & & 17.48 & & 217 & & 2.22 & \\
\hline & Tabernamontana macrocarpa & 14.98 & 3.48 & 26.36 & 2.74 & 5.91 & 0.70 & 4.12 & 0.92 & 4.02 & 0.27 & 48.8 & 2.6 & 12.2 & 1.3 & -27.8 & 1.6 & 10.10 & 1.99 & 124 & 36 & 5.09 & 1.25 \\
\hline \multirow[t]{2}{*}{ Araliaceae } & Aralia sp. & 22.64 & & 15.07 & & 5.79 & & 2.22 & & 2.88 & & 44.1 & & 15.3 & & -31.4 & & 12.94 & & 198 & & 2.55 & \\
\hline & Artrophyllum & 15.39 & & 20.66 & & 3.18 & & 2.21 & & 1.52 & & 49.0 & & 32.3 & & -30.5 & & 6.88 & & 222 & & 1.67 & \\
\hline \multirow{2}{*}{ Burseraceae } & Burseraceae sp.1 & 14.98 & & 6.65 & & 1.81 & & 1.57 & & 1.21 & & 45.7 & & 37.9 & & -28.5 & & 7.68 & & 290 & & -0.69 & \\
\hline & Burseraceae sp.2 & 14.85 & & 21.18 & & 5.02 & & 2.37 & & 1.63 & & 46.1 & & 28.3 & & -28.9 & & 6.88 & & 194 & & -0.71 & \\
\hline Caparaceae & Capparis pubiflora & 44.66 & & 35.13 & & 11.61 & & 0.86 & & 2.49 & & 40.1 & & 16.1 & & -31.1 & & 28.88 & & 464 & & 5.07 & \\
\hline Celastraceae & Siphonodon celastrineus & 21.49 & 1.58 & 19.46 & 0.23 & 8.34 & 1.63 & 1.77 & 0.76 & 2.32 & 0.57 & 45.7 & 2.0 & 20.2 & 4.1 & -29.8 & 1.6 & 13.64 & 2.61 & 280 & 108 & 5.19 & 3.39 \\
\hline Combretaceae & Terminalia sp. & 36.30 & 4.08 & 8.22 & 0.57 & 3.15 & 1.27 & 1.97 & 0.34 & 1.89 & 0.50 & 39.7 & 3.7 & 21.6 & 3.6 & -29.1 & 0.6 & 10.17 & 4.65 & 208 & 57 & 4.47 & 0.19 \\
\hline Dilleniaceae & Dillenia sp. & 8.02 & & 9.77 & & 3.00 & & 1.25 & & 1.21 & & 45.3 & & 37.6 & & -28.8 & & 9.64 & & 362 & & 2.85 & \\
\hline Elaeocarpaceae & Elaeocarpus sp. & 4.63 & & 7.83 & & 2.00 & & 1.55 & & 2.31 & & 37.1 & & 16.1 & & -27.3 & & 14.87 & & 238 & & 1.43 & \\
\hline \multirow[t]{11}{*}{ Euphorbiaceae } & Acalypa catturus & 22.81 & 4.58 & 10.90 & 1.75 & 3.11 & 1.13 & 3.74 & 0.53 & 1.91 & 0.50 & 42.2 & 3.5 & 23.0 & 4.1 & -28.0 & 0.7 & 5.18 & 1.44 & 114 & 18 & 2.87 & 2.00 \\
\hline & Antidesma stipularis & 17.06 & & 9.43 & & 6.03 & & 1.15 & & 1.51 & & 44.8 & & 29.6 & & -31.7 & & 13.14 & & 389 & & 2.88 & \\
\hline & Antidesma sp. 2 & 11.22 & 0.70 & 8.82 & 2.25 & 3.66 & 0.89 & 1.50 & 0.55 & 1.20 & 0.02 & 48.5 & 0.8 & 40.5 & 1.2 & -30.3 & 2.7 & 8.62 & 3.30 & 347 & 123 & 2.14 & 0.20 \\
\hline & Baccaurea sp. & 32.30 & & 6.96 & & 4.96 & & 0.75 & & 0.92 & & 38.2 & & 41.4 & & -29.5 & & 12.39 & & 512 & & 0.33 & \\
\hline & Bischofia javanica & 12.77 & 5.35 & 13.45 & 3.83 & 4.70 & 3.76 & 1.37 & 0.38 & 1.57 & 0.77 & 41.0 & 6.5 & 29.1 & 9.6 & -29.5 & 1.5 & 11.33 & 3.24 & 308 & 54 & 2.50 & 1.56 \\
\hline & Glochidion rubrum & 9.56 & 1.16 & 7.25 & 1.31 & 2.74 & 0.62 & 1.59 & 0.21 & 1.64 & 0.35 & 44.1 & 5.7 & 27.8 & 7.0 & -28.8 & 0.6 & 10.21 & 0.89 & 281 & 57 & 7.98 & 3.92 \\
\hline & Homalanthus populneus & 15.01 & 7.29 & 9.39 & 1.96 & 2.46 & 0.44 & 3.63 & 0.81 & 2.61 & 0.56 & 44.5 & 2.6 & 17.7 & 3.7 & -28.0 & 0.8 & 7.45 & 1.78 & 128 & 29 & 1.47 & 1.70 \\
\hline & Macaranga hispida & 12.68 & 3.58 & 8.55 & 2.27 & 2.62 & 0.64 & 2.51 & 0.76 & 1.82 & 0.30 & 42.4 & 5.3 & 23.9 & 5.0 & -28.6 & 1.5 & 7.62 & 1.68 & 179 & 45 & 1.24 & 1.58 \\
\hline & Macaranga tanarius & 13.33 & 2.67 & 10.04 & 1.61 & 3.32 & 0.48 & 2.90 & 0.20 & 2.70 & 0.48 & 42.9 & 4.5 & 16.3 & 4.0 & -26.9 & 1.4 & 9.41 & 2.24 & 148 & 22 & 2.70 & 2.42 \\
\hline & Mallothus mollissimus & 24.78 & 3.85 & 10.46 & 3.24 & 3.19 & 0.73 & 3.68 & 1.06 & 2.59 & 0.64 & 42.7 & 3.5 & 17.4 & 4.1 & -27.1 & 1.1 & 7.46 & 2.31 & 125 & 35 & 3.64 & 1.27 \\
\hline & Pimelodendron amboinicum & 21.47 & 8.96 & 6.77 & 2.64 & 3.02 & 0.93 & 1.29 & 0.41 & 1.26 & 0.18 & 38.0 & 3.7 & 30.8 & 5.3 & -28.0 & 6.1 & 11.08 & 5.28 & 343 & 177 & 1.74 & 0.89 \\
\hline Fagaceae & Lithocarpus sp. & 11.25 & 3.19 & 5.01 & 0.83 & 2.67 & 0.06 & 1.01 & 0.05 & 1.58 & 0.10 & 41.3 & 2.5 & 26.0 & 0.0 & -30.8 & 0.1 & 15.63 & 0.19 & 408 & 4 & 2.96 & 0.62 \\
\hline Flacourtiaceae & Osmelia philipinia & 13.15 & & 21.84 & & 6.85 & & 1.71 & & 2.22 & & 48.4 & & 21.8 & & -29.5 & & 12.95 & & 282 & & 3.39 & \\
\hline Guttiferale & Garcinia sp. & 25.56 & & 5.94 & & 2.92 & & 0.75 & & 1.40 & & 44.6 & & 31.8 & & -28.9 & & 18.62 & & 592 & & 1.52 & \\
\hline
\end{tabular}




\section{Continued}

\begin{tabular}{|c|c|c|c|c|c|c|c|c|c|c|c|c|c|c|c|c|c|c|c|c|c|c|c|}
\hline \multirow[b]{2}{*}{ Family } & \multirow[b]{2}{*}{ Species } & \multicolumn{2}{|c|}{$\underset{\left[\mathrm{g} \mathrm{kg}^{-1}\right]}{\mathbf{C a}}$} & \multicolumn{2}{|c|}{$\underset{\left[\mathrm{g} \mathrm{kg}^{-1}\right]}{\mathrm{K}}$} & \multicolumn{2}{|c|}{$\underset{\left[\mathrm{g} \mathrm{kg}^{-1}\right]}{\mathbf{M g}}$} & \multicolumn{2}{|c|}{$\underset{\left[\mathbf{g ~ k g}^{-1}\right]}{\mathbf{P}}$} & \multicolumn{2}{|c|}{$\begin{array}{c}\mathbf{N} \\
{[\%]}\end{array}$} & \multicolumn{2}{|c|}{$\begin{array}{c}\mathrm{C} \\
{[\%]}\end{array}$} & \multicolumn{2}{|c|}{$\mathrm{C} / \mathrm{N}$} & \multicolumn{2}{|c|}{$\begin{array}{l}\delta^{13} \mathrm{C} \\
{[\%]}\end{array}$} & \multicolumn{2}{|c|}{$\mathbf{N} / \mathbf{P}$} & \multicolumn{2}{|c|}{$\mathbf{C} / \mathbf{P}$} & \multicolumn{2}{|c|}{$\begin{array}{l}\delta^{15} \mathrm{~N} \\
{[\%]}\end{array}$} \\
\hline & & mean & sd & mean & sd & mean & sd & mean & sd & mean & sd & mean & sd & mean & sd & mean & sd & mean & sd & mean & sd & mean & sd \\
\hline \multirow[t]{9}{*}{ Lauraceae } & Actinodaphne sp. & 9.63 & 2.13 & 9.09 & 2.46 & 3.73 & 1.16 & 1.52 & 0.47 & 1.96 & 0.13 & 50.3 & 0.5 & 25.8 & 1.5 & -31.5 & 0.9 & 13.82 & 4.15 & 351 & 88 & 1.68 & 1.70 \\
\hline & Beilschmiedia sp. & 14.80 & & 31.26 & & 15.33 & & 2.67 & & 2.60 & & 45.3 & & 17.4 & & -29.8 & & 9.72 & & 169 & & 4.15 & \\
\hline & Cryptocarya crassinervia & 15.27 & 5.02 & 17.67 & 6.05 & 8.00 & 2.23 & 2.07 & 0.85 & 1.57 & 0.04 & 46.4 & 0.7 & 29.6 & 0.6 & -29.9 & 1.9 & 8.37 & 2.41 & 246 & 69 & 2.46 & 1.08 \\
\hline & Lauraceae sp.1 & 16.12 & & 9.93 & & 3.33 & & 6.68 & & 3.00 & & 47.1 & & 15.7 & & -30.9 & & 4.49 & & 70 & & 3.23 & \\
\hline & Lauraceae sp.2 & 7.73 & & 12.75 & & 2.64 & & & & 1.54 & & 44.1 & & 28.6 & & -29.4 & & & & & & 3.83 & \\
\hline & Litsea $\mathrm{sp} .1$ & 17.75 & 4.08 & 8.86 & 0.62 & 2.46 & 0.49 & 1.02 & 0.07 & 1.35 & 0.02 & 48.6 & 0.4 & 35.9 & 0.8 & -32.6 & 0.7 & 13.32 & 0.77 & 479 & 37 & 1.96 & 0.19 \\
\hline & Litsea $\mathrm{sp} .2$ & 13.02 & 13.56 & 11.10 & 5.03 & 3.88 & 1.47 & 1.71 & 0.05 & 1.98 & 0.06 & 45.2 & 0.1 & 22.9 & 0.6 & -30.9 & 0.7 & 11.54 & 0.01 & 263 & 6 & 2.84 & 0.33 \\
\hline & Litsea sp.3 & 17.38 & 8.82 & 11.96 & 3.38 & 5.17 & 1.56 & 2.54 & 1.14 & 3.05 & 0.81 & 46.5 & 2.0 & 16.6 & 6.4 & -31.6 & 1.1 & 13.19 & 5.20 & 211 & 86 & 2.85 & 0.75 \\
\hline & Nothaphoebe umbellata & 37.66 & & 43.68 & & 15.65 & & 2.41 & & 2.90 & & 45.4 & & 15.6 & & -26.6 & & 12.06 & & 188 & & 8.75 & \\
\hline \multirow[t]{2}{*}{ Fabaceae } & Erythrina sp. & 11.64 & 2.32 & 16.18 & 2.31 & 3.23 & 1.11 & 3.64 & 0.86 & 4.26 & 0.40 & 45.3 & 2.5 & 10.6 & 1.4 & -27.4 & 1.2 & 12.16 & 2.13 & 131 & 34 & 2.02 & 1.10 \\
\hline & Gliricidia sepium & 17.04 & 4.34 & 18.21 & 2.26 & 2.99 & 1.00 & 3.02 & 0.68 & 4.13 & 0.28 & 47.7 & 3.0 & 11.6 & 1.0 & -27.9 & 0.4 & 14.29 & 2.83 & 165 & 37 & 2.18 & 1.62 \\
\hline \multirow{2}{*}{$\begin{array}{l}\text { Liliaceae } \\
\text { Magnoliaceae }\end{array}$} & Liliaceae sp.1 & 14.71 & & 9.19 & & 9.40 & & 2.29 & & 2.23 & & 45.3 & & 20.3 & & -29.9 & & 9.76 & & 198 & & 4.05 & \\
\hline & Elmerillia tsiampacca & 12.77 & 6.23 & 16.68 & 0.66 & 2.73 & 0.57 & 1.76 & 0.37 & 1.81 & 0.50 & 45.7 & 0.7 & 26.3 & 7.6 & -28.9 & 1.5 & 10.18 & 0.72 & 264 & 58 & 3.60 & 1.26 \\
\hline \multirow[t]{8}{*}{ Meliaceae } & Aglaia sp.2 & 20.28 & & 23.55 & & 5.00 & & 1.86 & & 2.72 & & 45.6 & & 16.7 & & -29.6 & & 14.64 & & 245 & & 5.01 & \\
\hline & Aglaia argentea & 17.90 & 6.37 & 17.03 & 7.01 & 4.87 & 1.33 & 2.42 & 1.07 & 2.33 & 0.41 & 47.8 & 2.7 & 21.3 & 4.9 & -30.6 & 1.3 & 10.88 & 4.00 & 229. & 91 & 3.21 & 1.21 \\
\hline & Chisocheton sp.1 & 15.34 & & 12.39 & & 3.39 & & 2.39 & & 2.50 & & 51.4 & & 21.0 & & -30.2 & & 10.44 & & 214.87 & & 4.18 & \\
\hline & Chisocheton sp.2 & 35.89 & & 12.36 & & 10.95 & & 1.33 & & 2.22 & & 44.4 & & 20.0 & & -29.4 & & 16.67 & & 333.46 & & 2.36 & \\
\hline & Dysoxylum sp.1 & 17.26 & & 18.73 & & 12.40 & & 1.99 & & 1.98 & 0.64 & 47.3 & 1.8 & 25.3 & 9.1 & -29.9 & 1.1 & 12.23 & & 231.13 & & 1.68 & 1.77 \\
\hline & Dysoxylum sp.2 & 13.56 & 2.73 & 16.39 & 3.79 & 9.43 & 3.42 & 2.07 & 0.33 & 2.49 & 0.24 & 46.9 & 0.8 & 19.0 & 1.9 & -28.9 & 0.7 & 12.33 & 2.79 & 230.25 & 34 & 3.37 & 0.35 \\
\hline & Dysoxylum sp.4 & 16.73 & & 9.78 & & 2.18 & & 2.28 & & 2.75 & & 46.1 & & 17.0 & & -32.2 & & 12.04 & & 201.84 & & 6.20 & \\
\hline & Dysoxylum sp.5 & 14.70 & & 15.83 & & 3.70 & & 1.77 & & 2.13 & & 38.0 & & 18.0 & & -30.2 & & 12.01 & & 214.44 & & 5.32 & \\
\hline \multirow{11}{*}{ Moraceae } & Artocarpus intiger & 16.62 & & 11.95 & & 2.07 & & 1.31 & & 2.43 & & 45.0 & & 18.5 & & -29.5 & & 18.60 & & 344.20 & & 3.00 & \\
\hline & Ficus sp.1 & 48.31 & & 12.70 & & 8.25 & & 1.35 & & 1.70 & & 35.5 & & 20.8 & & -30.7 & & 12.66 & & 263.69 & & 3.73 & \\
\hline & Ficus sp.2 & 35.56 & & 15.19 & & 6.95 & & 1.24 & & 1.48 & & 41.8 & & 28.3 & & -31.5 & & 11.96 & & 338.00 & & 2.68 & \\
\hline & Ficus sp.3 & 44.72 & & 14.01 & & 9.93 & & 1.10 & & 1.68 & & 35.6 & & 21.1 & & -29.9 & & 15.28 & & 322.85 & & 3.07 & \\
\hline & Ficus sp.4 & 14.13 & & 11.78 & & 3.32 & & 1.88 & & 2.00 & & 41.1 & & 20.5 & & -28.4 & & 10.63 & & 218.23 & & 0.98 & \\
\hline & Ficus sp.5 & 25.55 & & 15.03 & & 6.45 & & 1.37 & & 1.49 & & 42.9 & & 28.8 & & & & 10.87 & & 312.56 & & & \\
\hline & Ficus sp.6 & 31.72 & & 10.11 & & 3.79 & & 1.12 & & 1.57 & & 41.9 & & 26.6 & & -30.5 & & 13.99 & & 372.65 & & 0.98 & \\
\hline & Ficus sp.7 & 16.62 & & 19.20 & & 3.95 & & 1.74 & & 1.23 & & 48.6 & & 39.4 & & -31.3 & & 7.11 & & 280.17 & & 4.43 & \\
\hline & Ficus sp. 8 & 71.96 & & 22.49 & & 5.38 & & 1.93 & & 1.77 & & 33.4 & & 18.9 & & -26.0 & & 9.17 & & 172.95 & & 3.28 & \\
\hline & Ficus sp.9 & 33.79 & & 18.50 & & 3.29 & & 1.49 & & 1.41 & & 44.5 & & 32.0 & & -33.1 & & 9.49 & & 299.46 & & 2.01 & \\
\hline & Ficus sp.10 & 42.59 & & 12.27 & & 3.67 & & 0.56 & & 1.93 & & 42.1 & & 22.0 & & -27.5 & & 34.28 & & 748.13 & & 2.63 & \\
\hline
\end{tabular}


Continued

\begin{tabular}{|c|c|c|c|c|c|c|c|c|c|c|c|c|c|c|c|c|c|c|c|c|c|c|c|}
\hline \multirow[b]{2}{*}{ Family } & \multirow[b]{2}{*}{ Species } & \multicolumn{2}{|c|}{$\underset{\left[\mathrm{g} \mathrm{kg}^{-1}\right]}{\mathbf{C a}}$} & \multicolumn{2}{|c|}{$\underset{\left[\mathrm{g} \mathrm{kg}^{-1}\right]}{\mathbf{K}}$} & \multicolumn{2}{|c|}{$\underset{\left[\mathrm{g} \mathrm{kg}^{-1}\right]}{\mathbf{M g}}$} & \multicolumn{2}{|c|}{$\underset{\left[\mathrm{g} \mathrm{kg}^{-1}\right]}{\mathbf{P}}$} & \multicolumn{2}{|c|}{$\begin{array}{c}\mathbf{N} \\
{[\%]}\end{array}$} & \multicolumn{2}{|c|}{$\begin{array}{c}\mathrm{C} \\
{[\%]}\end{array}$} & \multicolumn{2}{|c|}{$\mathbf{C} / \mathbf{N}$} & \multicolumn{2}{|c|}{$\begin{array}{l}\delta^{13} \mathbf{C} \\
{[\% 0]}\end{array}$} & \multicolumn{2}{|c|}{$\mathbf{N} / \mathbf{P}$} & \multicolumn{2}{|c|}{$\mathbf{C} / \mathbf{P}$} & \multicolumn{2}{|c|}{$\begin{array}{l}\delta^{15} \mathbf{N} \\
{[\% 0]}\end{array}$} \\
\hline & & mean & sd & mean & sd & mean & sd & mean & sd & mean & sd & mean & sd & mean & sd & mean & sd & mean & sd & mean & sd & mean & sd \\
\hline \multirow{4}{*}{ Myristicaceae } & Ficus sp.11 & 22.28 & & 14.36 & & 5.65 & & 1.98 & & 2.07 & & 41.7 & & 20.0 & & -29.8 & & 10.45 & & 210.60 & & 1.36 & \\
\hline & Ficus sp.12 & 34.60 & & 16.19 & & 6.55 & & 1.80 & & 1.86 & & 41.9 & & 22.5 & & -27.8 & & 10.36 & & 232.99 & & 0.42 & \\
\hline & Horsfieldia costulata & 16.76 & & 17.33 & & 5.22 & & 1.62 & & 1.99 & & 50.0 & & 25.2 & & -32.3 & & 12.30 & & 309.41 & & 4.17 & \\
\hline & Horsfieldia sp. & 14.39 & & 7.08 & & 4.69 & & 0.89 & & 1.39 & & 50.5 & & 36.5 & & -29.5 & & 15.62 & & 569.43 & & 0.23 & \\
\hline Myrtaceae & Syzygium sp. & 18.38 & & 10.96 & & 5.09 & & 1.43 & & 3.15 & & 45.5 & & 14.4 & & -29.9 & & 22.08 & & 318.25 & & 2.41 & \\
\hline Oleaceae & Chionanthus sp. & 7.87 & 3.31 & 12.88 & 4.64 & 1.72 & 0.55 & 1.54 & 0.14 & 1.12 & 0.15 & 46.3 & 0.5 & 41.8 & 4.7 & -31.5 & 1.4 & 7.28 & 0.61 & 302.98 & 24 & 2.19 & 0.47 \\
\hline Palmae & Arenga pinnata & 15.97 & & 32.91 & & 16.32 & & 2.76 & & 1.64 & & 45.5 & & 27.7 & & -29.6 & & 5.94 & & 164.65 & & 3.16 & \\
\hline Pandanaceae & Pandanus sp. & 6.36 & & 12.75 & & 3.98 & & 1.57 & & 1.65 & & 44.2 & & 26.9 & & -29.7 & & 10.46 & & 281.31 & & 4.01 & \\
\hline Polygalaceae & Xanthophyllum sp. & 6.95 & & 7.20 & & 3.73 & & 1.09 & & 1.97 & & 51.3 & & 26.1 & & -30.7 & & 18.08 & & 471.74 & & 3.90 & \\
\hline Rubiaceae & Coffea arabica & 15.90 & 4.44 & 14.00 & 3.66 & 4.88 & 2.53 & 1.99 & 0.25 & 3.02 & 0.39 & 47.0 & 1.4 & 15.8 & 1.9 & -28.8 & 1.0 & 15.34 & 2.55 & 239.43 & 28 & 5.06 & 1.59 \\
\hline \multirow{5}{*}{$\begin{array}{l}\text { Rutaceae } \\
\text { Sabiaceae } \\
\text { Sapindaceae }\end{array}$} & Myrmeconauclea sp. & 17.09 & & 9.24 & & 7.80 & & 1.99 & & 3.33 & & 47.3 & & 14.2 & & -29.3 & & 16.75 & & 237.57 & & 3.09 & \\
\hline & Melicope glabra & & & & & & & & & & & & & & & -29.38 & . & & 0.07 & 0.05 & & & \\
\hline & Meliosma sumatrana & 10.82 & 2.79 & 13.55 & 2.64 & 3.35 & 0.64 & 1.23 & 0.52 & 1.44 & 0.45 & 40.8 & 7.4 & 29.3 & 5.1 & -29.2 & 0.9 & 13.55 & 6.75 & 383.51 & 166 & 1.64 & 2.42 \\
\hline & Nephelium sp. & 26.67 & & 17.09 & & 5.69 & & 1.30 & & 1.65 & & 46.4 & & 28.1 & & -30.7 & & 12.68 & & 355.90 & & 2.28 & \\
\hline & Rhysotechia sp. & 15.16 & & 12.97 & & 5.48 & & 2.05 & & 2.77 & & 47.4 & & 17.1 & & -29.2 & & 13.52 & & 231.24 & & 3.26 & \\
\hline \multirow{2}{*}{$\begin{array}{l}\text { Sapotaceae } \\
\text { Sarcospermaceae }\end{array}$} & Palaquium quercifolium & 17.54 & & 14.22 & & 4.47 & & 1.52 & & 2.13 & & 43.6 & & 20.4 & & -28.3 & & 14.02 & & 286.45 & & & \\
\hline & Sarcosperma paniculata & 14.51 & & 20.80 & & 4.29 & & 1.89 & & 2.07 & & 48.5 & & 23.5 & & -28.5 & & 10.93 & & 256.53 & & 2.91 & \\
\hline Solanaceae & Solanum sp. & 40.26 & & 12.30 & & 2.91 & & 4.27 & & 3.76 & & 47.3 & & 12.6 & & -27.9 & & 8.82 & & 110.90 & & 3.90 & \\
\hline Staphylaceae & Turpinia sphaerocarpa & 23.93 & & 6.56 & & 4.15 & & 0.94 & & 1.56 & & 44.3 & & 28.4 & & -27.6 & & 16.61 & & 471.88 & & -0.30 & \\
\hline \multirow[t]{2}{*}{ Sterculiaceae } & Pterospermum javanicum & 16.69 & 1.86 & 7.51 & 0.30 & 2.13 & 0.60 & 1.75 & 0.15 & 1.86 & 0.03 & 47.6 & 0.8 & 25.6 & 0.0 & -30.9 & 0.3 & 10.63 & 1.09 & 272.43 & 28 & 1.99 & 0.04 \\
\hline & Theobroma cacao & 12.30 & 6.11 & 13.93 & 2.49 & 4.64 & 0.51 & 2.26 & 0.34 & 1.96 & 0.21 & 43.3 & 3.5 & 22.3 & 3.0 & -28.4 & 0.9 & 8.87 & 1.76 & 195.37 & 31 & 5.05 & 2.44 \\
\hline Tiliaceae & Grewia glabra & 28.45 & 6.44 & 19.94 & 4.59 & 4.37 & 0.96 & 3.70 & 1.07 & 3.42 & 0.41 & 46.1 & 2.9 & 13.7 & 1.8 & -28.2 & 1.3 & 10.24 & 4.09 & 138.16 & 56 & 3.73 & 1.72 \\
\hline Ulmaceae & Trema orientalis & 32.75 & 9.88 & 15.22 & 4.12 & 4.10 & 1.23 & 3.41 & 0.80 & 3.00 & 0.80 & 41.5 & 4.0 & 15.0 & 5.7 & -27.9 & 1.3 & 9.22 & 3.19 & 127.19 & 27 & 3.14 & 1.77 \\
\hline \multirow[t]{7}{*}{ Urticaceae } & Dendrocnide sp.1 & 48.15 & 17.37 & 13.83 & 1.31 & 7.25 & 1.21 & 1.72 & 0.48 & 2.28 & 0.93 & 39.6 & 4.4 & 18.7 & 5.2 & -29.7 & 0.1 & 13.05 & 2.00 & 237.06 & 36 & 0.59 & 0.38 \\
\hline & Dendrocnide sp.2 & 31.46 & 4.71 & 17.80 & 5.63 & 4.37 & 1.73 & 2.66 & 1.04 & 1.83 & 0.10 & 41.8 & 0.8 & 22.9 & 0.8 & -28.1 & 0.9 & 7.46 & 2.04 & 172.07 & 51 & 1.65 & 0.83 \\
\hline & Dendrocnide sp.3 & 28.65 & & 25.41 & & 10.36 & & 6.54 & & 4.45 & & 42.8 & & 9.6 & & -26.3 & & 6.80 & & 65.44 & & 5.94 & \\
\hline & Dendrocnide stimulan & 19.39 & & 12.35 & & 3.49 & & 2.05 & & 1.88 & & 36.9 & & 20.0 & & -32.1 & & 9.17 & & 179.95 & & 3.25 & \\
\hline & Oreocnide pubescens & 33.71 & 18.47 & 10.21 & 1.39 & 5.26 & 1.23 & 1.65 & 0.19 & 1.98 & 0.01 & 42.1 & 0.4 & 21.6 & 0.6 & -28.8 & 1.9 & 12.06 & 1.40 & 256.71 & 26 & 1.95 & 2.33 \\
\hline & Pipterus argentus & 34.48 & 7.06 & 13.34 & 3.09 & 3.69 & 1.00 & 3.77 & 0.70 & 2.82 & 0.56 & 42.0 & 2.8 & 15.5 & 4.8 & -27.8 & 1.1 & 7.68 & 2.12 & 115.27 & 24 & 2.85 & 1.95 \\
\hline & Pouzolzia sp. & 34.49 & 3.66 & 13.01 & 1.68 & 7.98 & 1.96 & 1.70 & 0.26 & 2.18 & 0.31 & 40.7 & 1.8 & 19.0 & 2.9 & -29.4 & 1.2 & 12.91 & 1.68 & 243.40 & 34 & 2.12 & 1.63 \\
\hline
\end{tabular}


Continued

\begin{tabular}{|c|c|c|c|c|c|c|c|c|c|c|c|c|c|c|c|c|c|c|c|c|c|c|c|}
\hline \multirow[b]{2}{*}{ Family } & \multirow[b]{2}{*}{ Species } & \multicolumn{2}{|c|}{$\underset{\left[\mathrm{g} \mathrm{kg}^{-1}\right]}{\mathbf{C a}}$} & \multicolumn{2}{|c|}{$\underset{\left[\mathrm{g} \mathrm{kg}^{-1}\right]}{\mathrm{K}}$} & \multicolumn{2}{|c|}{$\underset{\left[\mathrm{g} \mathrm{kg}^{-1}\right]}{\mathrm{Mg}}$} & \multicolumn{2}{|c|}{$\begin{array}{c}\mathbf{P} \\
{\left[\mathrm{g} \mathrm{kg}^{-1}\right]}\end{array}$} & \multicolumn{2}{|c|}{$\begin{array}{c}\mathbf{N} \\
{[\%]}\end{array}$} & \multicolumn{2}{|c|}{$\begin{array}{c}\mathrm{C} \\
{[\%]}\end{array}$} & \multicolumn{2}{|c|}{$\mathrm{C} / \mathrm{N}$} & \multicolumn{2}{|c|}{$\begin{array}{l}\delta^{13} \mathrm{C} \\
{[\% 0]}\end{array}$} & \multicolumn{2}{|c|}{$\mathbf{N} / \mathbf{P}$} & \multicolumn{2}{|c|}{$\mathbf{C} / \mathbf{P}$} & \multicolumn{2}{|c|}{$\begin{array}{l}\delta^{15} \mathbf{N} \\
{[\% \%]}\end{array}$} \\
\hline & & mean & sd & mean & sd & mean & sd & mean & sd & mean & sd & mean & sd & mean & sd & mean & sd & mean & sd & mean & sd & mean & sd \\
\hline \multirow{16}{*}{$\begin{array}{l}\text { Verbenaceae } \\
\text { Unidentified }\end{array}$} & Urticaceae sp.1 & 62.15 & & 9.85 & & 3.96 & & 3.97 & & 1.39 & & 34.9 & & 25.2 & & -29.0 & & 3.49 & & 87.94 & & -0.25 & \\
\hline & Urticaceae sp.2 & 37.52 & & 8.40 & & 6.95 & & 2.59 & & 4.09 & & 45.2 & & 11.0 & & -29.7 & & 15.78 & & 174.27 & & -0.39 & \\
\hline & Urticaceae sp. 3 & 61.26 & & 6.57 & & 9.34 & & 1.64 & & 1.35 & & 37.2 & & 27.6 & & -27.0 & & 8.23 & & 226.84 & & -0.66 & \\
\hline & Geunsia sp. & 11.04 & & 12.22 & & 1.63 & & 2.27 & & 2.08 & & 49.7 & & 23.9 & & -27.9 & 0.8 & 9.19 & & 219.29 & & 6.61 & 5.86 \\
\hline & Unidentified 5 & 21.51 & & 14.42 & & 8.09 & & 1.18 & & 1.30 & & 44.9 & & 34.5 & & -31.6 & & 11.06 & & 380.92 & & 2.82 & \\
\hline & Unidentified 6 & 24.22 & 6.23 & 12.75 & 4.14 & 5.77 & 1.35 & 1.33 & 0.14 & 1.88 & 0.19 & 46.1 & 0.9 & 24.6 & 2.1 & -31.9 & 0.1 & 14.21 & 0.03 & 349.80 & 30 & 2.47 & 0.70 \\
\hline & Unidentified 8 & 13.87 & & 6.51 & & 4.30 & & 1.21 & & 1.42 & & 44.5 & & 31.3 & & -33.8 & & 11.75 & & 367.66 & & 1.87 & \\
\hline & Unidentified 9 & 20.59 & & 6.60 & & 6.57 & & 0.82 & & 1.37 & & 50.6 & & 36.8 & & -29.9 & & 16.78 & & 618.05 & & 1.82 & \\
\hline & Unidentified 10 & 23.71 & 14.40 & 7.36 & 3.97 & 3.75 & 1.79 & 1.05 & 0.35 & 1.74 & 0.54 & 45.4 & 4.6 & 27.8 & 11.2 & -31.2 & 0.2 & 16.94 & & 605.38 & & 3.86 & \\
\hline & Unidentified 12 & 22.68 & & 8.16 & & 5.72 & & 1.59 & & 2.17 & & 48.3 & & 22.3 & & -31.1 & & 13.64 & & 304.07 & & 3.47 & \\
\hline & Unidentified 13 & 12.63 & & 33.51 & & 7.99 & & 3.37 & & 4.03 & & 46.6 & & 11.6 & & -29.2 & & 11.96 & & 138.30 & & 6.41 & \\
\hline & Unidentified 14 & 14.58 & & 9.16 & & 2.81 & & 1.22 & & 1.47 & & 45.1 & & 30.6 & & -29.9 & & 12.03 & & 368.63 & & 1.13 & \\
\hline & Unidentified 18 & 20.33 & & 6.20 & & 4.98 & & 1.24 & & 1.69 & & 40.5 & & 24.0 & & -30.2 & & 13.67 & & 327.99 & & 0.15 & \\
\hline & Unidentified 19 & 7.54 & & 15.85 & & 3.74 & & 1.75 & & 2.43 & & 49.4 & & 20.3 & & -30.1 & & 13.93 & & 282.81 & & 3.21 & \\
\hline & Unidentified 324 & 12.00 & & 9.16 & & 0.94 & & 2.31 & & 1.89 & & 51.2 & & 27.0 & & -29.5 & & 8.18 & & 221.18 & & 0.52 & \\
\hline & Unidentified 345 & 10.82 & & 15.71 & & 3.76 & & 2.28 & & 1.54 & & 44.6 & & 28.9 & & -29.2 & & 6.75 & & 195.34 & & 1.72 & \\
\hline
\end{tabular}




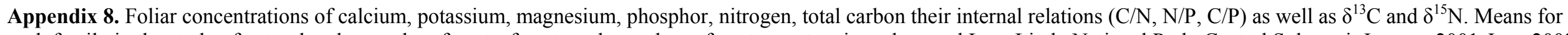

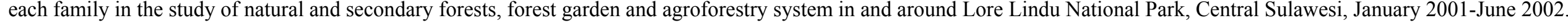
Standard deviation only available when $n>1$ tree per family in the sample.

\begin{tabular}{|c|c|c|c|c|c|c|c|c|c|c|c|c|c|c|c|c|c|c|c|c|c|c|c|}
\hline \multirow[b]{2}{*}{ Family } & \multirow{2}{*}{$\begin{array}{l}\text { No. } \\
\text { spec/ } \\
\text { fam }\end{array}$} & \multicolumn{2}{|c|}{$\begin{array}{c}\mathrm{Ca} \\
{\left[\mathrm{g} \mathrm{kg}^{-1}\right]}\end{array}$} & \multicolumn{2}{|c|}{$\frac{K}{\left[\mathrm{~K} \mathrm{~kg}^{-1}\right]}$} & \multicolumn{2}{|c|}{$\underset{\left[\mathrm{g} \mathrm{kg}^{-1}\right]}{\mathrm{Mg}}$} & \multicolumn{2}{|c|}{$\begin{array}{c}P \\
{\left[g^{-1} g^{-1}\right]}\end{array}$} & \multicolumn{2}{|c|}{$\begin{array}{c}\mathbf{N} \\
{[\%]}\end{array}$} & \multicolumn{2}{|c|}{$\begin{array}{c}\mathrm{C} \\
{[\%]}\end{array}$} & \multicolumn{2}{|c|}{$\mathbf{C} / \mathbf{N}$} & \multicolumn{2}{|c|}{$\mathbf{N} / \mathbf{P}$} & \multicolumn{2}{|c|}{$\mathbf{C} / \mathbf{P}$} & \multicolumn{2}{|c|}{$\begin{array}{l}\delta^{13} \mathbf{C} \\
{[\% \text { ] }}\end{array}$} & \multicolumn{2}{|c|}{$\begin{array}{l}\delta^{15} \mathbf{N} \\
{[\%,]}\end{array}$} \\
\hline & & mean & sd & mean & sd & mean & sd & mean & sd & mean & sd & mean & sd & mean & sd & mean & sd & mean & sd & mean & sd & mean & sd \\
\hline Actinidiaceae & 1 & & & & & & & & & 1.94 & & 45.1 & & 23.2 & & & & & & -28.0 & & 0.8 & \\
\hline Anacardiaceae & 2 & 16.3 & & 8.0 & & 3.09 & & 1.36 & & 1.55 & & 39.7 & & 25.6 & & 14.3 & & 382 & & -29.0 & & 2.8 & \\
\hline Annonaceae & 1 & 19.2 & 1.5 & 7.0 & 1.0 & 2.90 & 0.41 & 1.72 & 0.24 & 1.99 & 0.28 & 46.6 & 0.9 & 23.4 & 3.6 & 11.6 & 0.6 & 275 & 38 & -27.5 & 1.4 & 0.3 & 1.3 \\
\hline Apocynaceae & 2 & 15.5 & 3.2 & 24.5 & 4.8 & 6.66 & 1.79 & 3.71 & 1.21 & 3.94 & 0.28 & 48.1 & 2.7 & 12.2 & 1.3 & 11.6 & 3.7 & 143 & 52 & -28.1 & 1.5 & 4.5 & 1.7 \\
\hline Araliaceae & 2 & 19.0 & 5.1 & 17.9 & 4.0 & 4.49 & 1.85 & 2.21 & 0.01 & 2.20 & 0.96 & 46.6 & 3.5 & 21.2 & 12.0 & 9.9 & 4.3 & 210 & 17 & -30.9 & 0.6 & 2.1 & 0.6 \\
\hline Burseraceae & 2 & 14.9 & 0.1 & 13.9 & 10.3 & 3.42 & 2.27 & 1.97 & 0.56 & 1.42 & 0.29 & 45.9 & 0.3 & 32.3 & 7.1 & 7.3 & 0.6 & 243 & 68 & -28.7 & 0.3 & -0.7 & 0.0 \\
\hline Caparaceae & 1 & 44.7 & & 35.1 & & 11.61 & & 0.86 & & 2.49 & & 40.1 & & 16.1 & & 28.9 & & 464 & & -31.1 & & 5.1 & \\
\hline Celastraceae & 1 & 21.5 & 1.6 & 19.5 & 0.2 & 8.34 & 1.63 & 1.77 & 0.76 & 2.32 & 0.56 & 45.7 & 2.0 & 19.7 & 4.2 & 13.6 & 2.6 & 281 & 108 & -29.8 & 1.6 & 5.2 & 3.4 \\
\hline Combretaceae & 1 & 36.3 & 4.1 & 8.2 & 0.6 & 3.15 & 1.27 & 1.97 & 0.34 & 1.89 & 0.50 & 39.7 & 3.7 & 21.0 & 3.5 & 10.2 & 4.7 & 209 & 58 & -29.1 & 0.6 & 4.5 & 0.2 \\
\hline Dilleniaceae & 1 & 8.0 & & 9.8 & & 3.00 & & 1.25 & & 1.21 & & 45.3 & & 37.4 & & 9.6 & & 362 & & -28.8 & & 2.9 & \\
\hline Elaeocarpaceae & 1 & 4.6 & & 7.8 & & 2.00 & & 1.55 & & 2.31 & & 37.1 & & 16.1 & & 14.9 & & 239 & & -27.4 & & 1.4 & \\
\hline Euphorbiaceae & 10 & 17.5 & 7.1 & 9.8 & 2.6 & 3.00 & 1.16 & 3.15 & 1.11 & 2.21 & 0.67 & 43.3 & 3.9 & 19.6 & 7.0 & 7.6 & 2.4 & 163 & 86 & -28.1 & 1.3 & 2.5 & 2.2 \\
\hline Fabaceae & 2 & 14.4 & 4.6 & 17.0 & 2.4 & 3.10 & 1.09 & 3.31 & 0.84 & 4.22 & 0.36 & 46.4 & 3.1 & 11.0 & 1.4 & 13.5 & 3.0 & 149 & 40 & -27.9 & 0.8 & 1.9 & 1.3 \\
\hline Fagaceae & 1 & 11.2 & 3.2 & 5.0 & 0.8 & 2.67 & 0.06 & 1.01 & 0.05 & 1.58 & 0.10 & 41.3 & 2.5 & 26.1 & & 15.6 & 0.2 & 409 & 4 & -30.9 & 0.1 & 3.0 & 0.6 \\
\hline Flacourtiaceae & 1 & 13.1 & & 21.8 & & 6.85 & & 1.71 & & 2.22 & & 48.4 & & 21.8 & & 13.0 & & 283 & & -29.5 & & 3.4 & \\
\hline Guttiferae & 1 & 25.6 & & 5.9 & & 2.92 & & 0.75 & & 1.40 & & 44.6 & & 31.8 & & 18.6 & & 592 & & -28.9 & & 1.5 & \\
\hline Lauraceae & 9 & 15.2 & 8.0 & 14.4 & 8.8 & 5.83 & 3.81 & 2.18 & 1.30 & 2.15 & 0.73 & 47.1 & 2.2 & 21.9 & 7.0 & 11.5 & 4.1 & 271 & 115 & -30.8 & 1.7 & 2.8 & 1.7 \\
\hline Liliaceae & 1 & 14.7 & & 9.2 & & 9.40 & & 2.29 & & 2.23 & & 45.3 & & 20.3 & & 9.8 & & 198 & & -29.9 & & 4.1 & \\
\hline Magnoliaceae & 1 & 12.8 & 6.2 & 16.7 & 0.7 & 2.73 & 0.57 & 1.76 & 0.37 & 1.80 & 0.50 & 45.7 & 0.6 & 25.4 & 7.8 & 10.2 & 0.7 & 265 & 59 & -28.9 & 1.5 & 3.6 & 1.3 \\
\hline Meliaceae & 7 & 17.4 & 6.5 & 16.4 & 5.5 & 6.51 & 3.47 & 2.18 & 0.75 & 2.36 & 0.36 & 46.9 & 3.0 & 19.9 & 4.4 & 11.9 & 3.2 & 233 & 65 & -30.1 & 1.2 & 3.4 & 1.4 \\
\hline
\end{tabular}

Continued on next page 
Continued

\begin{tabular}{|c|c|c|c|c|c|c|c|c|c|c|c|c|c|c|c|c|c|c|c|c|c|c|c|}
\hline \multirow[b]{2}{*}{ Family } & \multirow{2}{*}{$\begin{array}{l}\text { No. } \\
\text { spec/ } \\
\text { fam }\end{array}$} & \multicolumn{2}{|c|}{$\begin{array}{c}\mathrm{Ca} \\
{\left[\mathrm{g} \mathrm{kg}^{-1}\right]}\end{array}$} & \multicolumn{2}{|c|}{$\underset{\left[\mathrm{g} \mathrm{kg}^{-1}\right]}{\mathrm{K}}$} & \multicolumn{2}{|c|}{$\underset{\left[\mathrm{g} \mathrm{kg}^{-1}\right]}{\mathbf{M g}}$} & \multicolumn{2}{|c|}{$\begin{array}{c}\mathbf{P} \\
{\left[\mathrm{g} \mathrm{kg}^{-1}\right]}\end{array}$} & \multicolumn{2}{|c|}{$\begin{array}{c}\mathbf{N} \\
{[\%]}\end{array}$} & \multicolumn{2}{|c|}{$\begin{array}{c}\mathrm{C} \\
{[\%]}\end{array}$} & \multicolumn{2}{|c|}{$\mathrm{C} / \mathbf{N}$} & \multicolumn{2}{|c|}{$\mathbf{N} / \mathbf{P}$} & \multicolumn{2}{|c|}{$\mathbf{C} / \mathbf{P}$} & \multicolumn{2}{|c|}{$\begin{array}{l}\delta^{13} \mathrm{C} \\
{[\% \text { ] }}\end{array}$} & \multicolumn{2}{|c|}{$\begin{array}{l}\delta^{15} \mathbf{N} \\
{[\% \circ]}\end{array}$} \\
\hline & & mean & sd & mean & sd & mean & sd & mean & sd & mean & sd & mean & sd & mean & sd & mean & sd & mean & sd & mean & sd & mean & sd \\
\hline Moraceae & 10 & 33.7 & 15.9 & 14.9 & 3.5 & 5.33 & 2.25 & 1.45 & 0.41 & 1.74 & 0.32 & 41.2 & 4.2 & 23.7 & 6.0 & 13.5 & 6.9 & 317 & 142 & -29.7 & 2.0 & 2.4 & 1.2 \\
\hline Myristicaceae & 2 & 15.6 & 1.7 & 12.2 & 7.2 & 4.99 & 0.38 & 1.25 & 0.51 & 1.69 & 0.42 & 50.3 & 0.4 & 29.7 & 7.8 & 14.0 & 2.3 & 439 & 184 & -30.9 & 2.0 & 2.2 & 2.8 \\
\hline Myrtaceae & 1 & 18.4 & & 11.0 & & 5.09 & & 1.43 & & 3.15 & & 45.5 & & 14.4 & & 22.1 & & 318 & & -29.9 & & 2.41 & \\
\hline Oleaceae & 1 & 7.9 & 3.3 & 12.9 & 4.6 & 1.72 & 0.55 & 1.54 & 0.14 & 1.11 & 0.14 & 46.3 & 0.5 & 41.7 & 5.1 & 7.3 & 0.6 & 303 & 24 & -31.5 & 1.4 & 2.18 & 0.5 \\
\hline Palmae & 1 & 16.0 & & 32.9 & & 16.32 & & 2.76 & & 1.64 & & 45.5 & & 27.7 & & 5.9 & & 165 & & -29.6 & & 3.16 & \\
\hline Pandanaceae & 1 & 6.4 & & 12.8 & & 3.98 & & 1.57 & & 1.65 & & 44.2 & & 26.8 & & 10.5 & & 281 & & -29.7 & & 4.01 & \\
\hline Polygalaceae & 1 & 6.9 & & 7.2 & & 3.73 & & 1.09 & & 1.97 & & 51.3 & & 26.0 & & 18.1 & & 472 & & -30.7 & & 3.9 & \\
\hline Rubiaceae & 2 & 16.4 & 4.6 & 12.9 & 3.9 & 5.55 & 2.72 & 1.98 & 0.26 & 3.00 & 0.35 & 46.7 & 1.3 & 15.6 & 1.9 & 15.4 & 2.2 & 240 & 29 & -29.0 & 1.0 & 4.87 & 1.6 \\
\hline Rutaceae & 1 & & & & & & & & & & & & & & & & & & & -29.4 & & 5.29 & \\
\hline Sabiaceae & 1 & 9.7 & 3.7 & 12.3 & 2.4 & 3.45 & 0.88 & 1.52 & 0.63 & 1.34 & 0.24 & 40.7 & 6.4 & 30.4 & 6.4 & 9.7 & 2.8 & 297 & 110 & -29.7 & 1.3 & -0.63 & 0.8 \\
\hline Sapindaceae & 2 & 20.9 & 8.1 & 15.0 & 2.9 & 5.59 & 0.15 & 1.68 & 0.53 & 2.21 & 0.79 & 46.9 & 0.7 & 21.2 & 7.8 & 13.1 & 0.6 & 294 & 88 & -30.0 & 1.0 & 2.77 & 0.7 \\
\hline Sapotaceae & 1 & 17.5 & & 14.2 & & 4.47 & & 1.52 & & 2.13 & & 43.6 & & 20.5 & & 14.0 & & 286 & & -28.3 & & & \\
\hline Sarcospermaceae & 1 & 14.5 & & 20.8 & & 4.29 & & 1.89 & & 2.07 & & 48.5 & & 23.4 & & & & & & & & & \\
\hline Solanaceae & 1 & 40.3 & & 12.3 & & 2.91 & & 4.27 & & 3.76 & & 47.3 & & 12.6 & & 8.8 & & 111 & & -27.9 & & 3.9 & \\
\hline Staphylaceae & 1 & 23.9 & & 6.6 & & 4.15 & & 0.94 & & 1.56 & & 44.3 & & 28.4 & & 16.6 & & 472 & & -27.6 & & -0.3 & \\
\hline Sterculiaceae & 2 & 14.1 & 6.9 & 12.2 & 4.1 & 4.40 & 0.93 & 2.14 & 0.38 & 1.92 & 0.20 & 43.5 & 3.7 & 22.7 & 3.2 & 9.3 & 2.0 & 208 & 38 & -28.9 & 1.1 & 4.0 & 2.5 \\
\hline Tiliaceae & 1 & 28.4 & 7.2 & 20.3 & 5.4 & 4.27 & 1.14 & 3.85 & 0.99 & 3.49 & 0.34 & 45.6 & 2.9 & 13.1 & 1.5 & 9.7 & 2.7 & 125 & 31 & -28.3 & 1.3 & 4.0 & 1.7 \\
\hline Ulmaceae & 1 & 32.8 & 9.9 & 15.2 & 4.1 & 4.10 & 1.23 & 3.41 & 0.80 & 3.00 & 0.80 & 41.5 & 4.0 & 13.8 & 5.7 & 9.2 & 3.2 & 127 & 28 & -27.9 & 1.3 & 3.1 & 1.8 \\
\hline Urticaceae & 10 & 35.4 & 9.9 & 13.4 & 3.9 & 4.68 & 2.22 & 3.20 & 1.18 & 2.57 & 0.70 & 41.6 & 3.1 & 16.2 & 4.9 & 8.9 & 3.0 & 151 & 62 & -28.1 & 1.4 & 2.4 & 1.8 \\
\hline Verbenaceae & 1 & 11.0 & & 12.2 & & 1.63 & & 2.27 & & 2.08 & & 49.7 & & 23.9 & & 9.2 & & 219 & & -27.9 & 0.8 & 6.6 & 5.9 \\
\hline Unidentified 5 & 1 & 21.5 & & 14.4 & & 8.09 & & 1.18 & & 1.30 & & 44.9 & & 34.5 & & 11.1 & & 381 & & -31.6 & & 2.8 & \\
\hline Unidentified 6 & 1 & 24.2 & 6.2 & 12.7 & 4.1 & 5.77 & 1.35 & 1.33 & 0.14 & 1.88 & 0.19 & 46.1 & 0.8 & 24.5 & 2.1 & 14.2 & 0.04 & 350 & 30 & -31.9 & 0.1 & 2.5 & 0.7 \\
\hline Unidentified 8 & 1 & 13.9 & & 6.5 & & 4.30 & & 1.21 & & 1.42 & & 44.5 & & 31.3 & & 11.8 & & 368 & & -33.8 & & 1.9 & \\
\hline Unidentified 9 & 1 & 20.6 & & 6.6 & & 6.57 & & 0.82 & & 1.37 & & 50.6 & & 36.9 & & 16.8 & & 618 & & -29.9 & & 1.8 & \\
\hline Unidentified 10 & 1 & 23.7 & 14.4 & 7.4 & 4.0 & 3.75 & 1.79 & 1.05 & 0.35 & 1.74 & 0.53 & 45.5 & 4.6 & 26.1 & 11.3 & 16.9 & & 605 & & -31.2 & 0.2 & 3.9 & \\
\hline Unidentified 12 & 1 & 22.7 & & 8.2 & & 5.72 & & 1.59 & & 2.17 & & 48.3 & & 22.3 & & 13.6 & & 304 & & -31.1 & & 3.5 & \\
\hline Unidentified 13 & 1 & 12.6 & & 33.5 & & 7.99 & & 3.37 & & 4.03 & & 46.6 & & 11.6 & & 12.0 & & 138 & & -29.2 & & 6.4 & \\
\hline
\end{tabular}

Continued on next page 


\begin{tabular}{|c|c|c|c|c|c|c|c|c|c|c|c|c|c|c|c|c|c|c|c|c|c|c|c|}
\hline \multirow[b]{2}{*}{ Family } & \multirow{2}{*}{$\begin{array}{c}\text { No. } \\
\text { spec/ } \\
\text { fam }\end{array}$} & \multicolumn{2}{|c|}{$\begin{array}{c}\mathrm{Ca} \\
{\left[\mathrm{g} \mathrm{kg}^{-1}\right]}\end{array}$} & \multicolumn{2}{|c|}{$\begin{array}{c}\mathrm{K} \\
{\left[\mathrm{g} \mathrm{kg}^{-1}\right]}\end{array}$} & \multicolumn{2}{|c|}{$\begin{array}{c}\mathrm{Mg} \\
{\left[\mathrm{g} \mathrm{kg}^{-1}\right]}\end{array}$} & \multicolumn{2}{|c|}{$\begin{array}{c}\mathbf{P} \\
{\left[\mathrm{g} \mathrm{kg}^{-1}\right]}\end{array}$} & \multicolumn{2}{|c|}{$\begin{array}{c}\mathbf{N} \\
{[\%]}\end{array}$} & \multicolumn{2}{|c|}{$\begin{array}{c}\mathrm{C} \\
{[\%]}\end{array}$} & \multicolumn{2}{|c|}{$\mathrm{C} / \mathrm{N}$} & \multicolumn{2}{|c|}{$\mathbf{N} / \mathbf{P}$} & \multicolumn{2}{|c|}{$\mathbf{C} / \mathbf{P}$} & \multicolumn{2}{|c|}{$\begin{array}{l}\delta^{13} \mathrm{C} \\
{[\% \circ]}\end{array}$} & \multicolumn{2}{|c|}{$\begin{array}{l}\delta^{15} \mathbf{N} \\
{[\% \%]}\end{array}$} \\
\hline & & mean & sd & mean & sd & mean & sd & mean & sd & mean & sd & mean & sd & mean & sd & mean & sd & mean & sd & mean & sd & mean & sd \\
\hline Unidentified 14 & 1 & 14.6 & & 9.2 & & 2.81 & & 1.22 & & 1.47 & & 45.1 & & 30.7 & & 12.0 & & 369 & & -29.9 & & 1.1 & \\
\hline Unidentified 18 & 1 & 20.3 & & 6.2 & & 4.98 & & 1.24 & & 1.69 & & 40.5 & & 24.0 & & 13.7 & & 328 & & -30.2 & & 0.2 & \\
\hline Unidentified 19 & 1 & 7.5 & & 15.8 & & 3.74 & & 1.75 & & 2.43 & & 49.4 & & 20.3 & & 13.9 & & 283 & & -30.1 & & 3.2 & \\
\hline Unidentified 324 & 1 & 12.0 & & 9.2 & & 0.94 & & 2.31 & & 1.89 & & 51.2 & & 27.1 & & 8.2 & & 221 & & -29.5 & & 0.5 & \\
\hline Unidentified 345 & 1 & 10.8 & & 15.7 & & 3.76 & & 2.28 & & 1.54 & & 44.6 & & 29.0 & & 6.8 & & 195 & & -29.2 & & 1.7 & \\
\hline
\end{tabular}


Appendix 9. Ten functional groups identified among 107 tree species studied by means of a disjoining cluster analysis, based on the leaf traits specific leaf area, leaf size, $\mathrm{N}, \mathrm{P}$ and $\delta^{13} \mathrm{C}$. The distance value indicates the distance from a species to the respective cluster centre. The species are listed according to increasing distance, within each functional group (cluster).

\begin{tabular}{|c|c|c|c|}
\hline Cluster & Species & Family & Distance \\
\hline 1 & Erythrina sp. & Fabaceae & 12 \\
\hline 1 & Urticaceae sp. 2 & Urticaceae & 12 \\
\hline 1 & Homalanthus populneus & Euphorbiaceae & 49 \\
\hline 1 & Grewia glabra & Tiliaceae & 52 \\
\hline 2 & Solanum sp. & Solanaceae & 6 \\
\hline 2 & Sarcosperma paniculata & Sarcospermaceae & 7 \\
\hline 2 & Unidentified 345 & Unidentified & 8 \\
\hline 2 & Acalypha caturus & Euphorbiaceae & 15 \\
\hline 2 & Nephelium sp. & Sapindaceae & 16 \\
\hline 2 & Unidentified 19 & Unidentified & 18 \\
\hline 2 & Geunsia sp. & Verbenaceae & 18 \\
\hline 2 & Burseraceae sp.2 & Burseraceae & 19 \\
\hline 2 & Elaeocarpus sp. & Elaeocarpaceae & 21 \\
\hline 2 & Unidentified 13 & Unidentified & 22 \\
\hline 2 & Urticaceae sp.1 & Urticaceae & 22 \\
\hline 2 & Unidentified 18 & Unidentified & 24 \\
\hline 2 & Unidentified 12 & Unidentified & 26 \\
\hline 2 & Horsfieldia costulata & Myristicaceae & 27 \\
\hline 2 & Dysoxylum sp.4 & Meliaceae & 27 \\
\hline 2 & Ficus sp.12 & Moraceae & 28 \\
\hline 2 & Myrmeconauclea sp. & Rubiaceae & 32 \\
\hline 2 & Rauvolfia sumatrana & Apocynaceae & 34 \\
\hline 2 & Trema orientalis & Ulmaceae & 34 \\
\hline 2 & Palaquium quercifolium & Sapotaceae & 34 \\
\hline 2 & Dendrocnide sp.1 & Urticaceae & 35 \\
\hline 2 & Melicope glabra & Rutaceae & 36 \\
\hline 2 & Cananga odorata & Annonaceae & 42 \\
\hline 3 & Mallotus mollissimus & Euphorbiaceae & 17 \\
\hline 3 & Tabernamontana macrocarpa & Apocynaceae & 25 \\
\hline 3 & Pipturus argentus & Urticaceae & 40 \\
\hline 4 & Macaranga tanarius & Euphorbiaceae & 0 \\
\hline 5 & Dendrocnide sp.3 & Urticaceae & 7 \\
\hline 5 & Ficus sp.4 & Moraceae & 28 \\
\hline 5 & Pandanus sp. & Pandanaceae & 34 \\
\hline 5 & Dysoxylum sp.1 & Meliaceae & 41 \\
\hline 5 & Chisocheton sp.1 & Meliaceae & 48 \\
\hline
\end{tabular}




\begin{tabular}{|c|c|c|c|}
\hline Cluster & Species & Family & Distance \\
\hline 6 & Chisocheton sp.2 & Meliaceae & 4 \\
\hline 6 & Unidentified 324 & Unidentified & 4 \\
\hline 6 & Horsfieldia sp.2 & Myristicaceae & 9 \\
\hline 6 & Bischofia javanica & Euphorbiaceae & 10 \\
\hline 6 & Glochidion rubrum & Euphorbiaceae & 16 \\
\hline 6 & Dillenia sp. & Dilleniaceae & 16 \\
\hline 6 & Artocarpus intiger & Moraceae & 20 \\
\hline 6 & Aglaia sp.2 & Meliaceae & 21 \\
\hline 6 & Ficus sp.3 & Moraceae & 22 \\
\hline 6 & Siphonodon celastrineus & Celastraceae & 22 \\
\hline 6 & Syzygium sp. & Myrtaceae & 22 \\
\hline 6 & Saurauia sp. & Actinidiaceae & 23 \\
\hline 6 & Pterospermum javanicum & Sterculiaceae & 24 \\
\hline 6 & Artrophyllum sp. & Araliaceae & 25 \\
\hline 6 & Turpinia sphaerocarpa & Staphylaceae & 26 \\
\hline 6 & Dysoxylum sp.5 & Meliaceae & 27 \\
\hline 6 & Actinodaphne sp. & Lauraceae & 29 \\
\hline 6 & Ficus sp.8 & Moraceae & 29 \\
\hline 6 & Litsea $\mathrm{sp} .3$ & Lauraceae & 29 \\
\hline 6 & Unidentified 9 & Unidentified & 36 \\
\hline 6 & Oreocnide pubescens & Urticaceae & 37 \\
\hline 6 & Aralia sp. & Araliaceae & 39 \\
\hline 7 & Terminalia $\mathrm{sp.}$ & Combretaceae & 6 \\
\hline 7 & Litsea $\mathrm{sp} .2$ & Lauraceae & 8 \\
\hline 7 & Unidentified 8 & Unidentified & 9 \\
\hline 7 & Chionanthus sp. & Oleaceae & 10 \\
\hline 7 & Ficus sp.9 & Moraceae & 11 \\
\hline 7 & Osmelia phillipinia & Flacourtiaceae & 11 \\
\hline 7 & Ficus sp.6 & Moraceae & 15 \\
\hline 7 & Coffea arabica & Rubiaceae & 15 \\
\hline 7 & Garcinia sp. & Guttiferae & 19 \\
\hline 7 & Capparis pubiflora & Caparaceae & 19 \\
\hline 7 & Rhysotechia sp. & Sapindaceae & 20 \\
\hline 7 & Xanthophyllum sp. & Polygalaceae & 22 \\
\hline 7 & Antidesma stipularis & Euphorbiaceae & 23 \\
\hline 7 & Ficus sp.2 & Moraceae & 23 \\
\hline 7 & Ficus sp.11 & Moraceae & 23 \\
\hline 7 & Lauraceae sp.1 & Lauraceae & 24 \\
\hline 7 & Pouzolzia sp. & Urticaceae & 25 \\
\hline 7 & Urticaceae sp.3 & Urticaceae & 26 \\
\hline 7 & Unidentified 5 & Unidentified & 26 \\
\hline 7 & Meliosma sumatrana & Sabiaceae & 29 \\
\hline 7 & Unidentified 6 & Unidentified & 29 \\
\hline 7 & Nothaphoebe umbellata & Lauraceae & 31 \\
\hline 7 & Ficus sp.1 & Moraceae & 32 \\
\hline 7 & Pimelodendron amboinicum & Euphorbiaceae & 34 \\
\hline 7 & Beilschmiedia sp. & Lauraceae & 35 \\
\hline 7 & Ficus sp.5 & Moraceae & 38 \\
\hline 7 & Ficus sp.10 & Moraceae & 59 \\
\hline 7 & Gliricidia sepium & Fabaceae & 61 \\
\hline
\end{tabular}




\begin{tabular}{cllc}
\multicolumn{2}{l}{ Continued } & & \\
\hline Cluster & Species & Family & Distance \\
\hline 8 & Dendrocnide sp. 2 & Urticaceae & 17 \\
8 & Elmerillia tsiampacca & Magnoliaceae & 17 \\
\hline 9 & Antidesma sp. 2 & Euphorbiaceae & 0 \\
9 & Burseraceae sp. 1 & Burseraceae & 10 \\
9 & Baccaurea sp. & Euphorbiaceae & 14 \\
9 & Semecarpus forstenii & Anacardiaceae & 21 \\
9 & Ficus sp. 7 & Moraceae & 22 \\
9 & Unidentified 10 & Unidentified & 26 \\
9 & Aglaia argentea & Meliaceae & 28 \\
9 & Lithocarpus sp. & Fagaceae & 33 \\
9 & Dracaena sp. & Liliaceae & 35 \\
9 & Litsea sp.1 & Lauraceae & 38 \\
9 & Lauraceae sp. 2 & Lauraceae & 43 \\
9 & Dracontomelon dao & Anacardiaceae & 46 \\
9 & Theobroma cacao & Sterculiaceae & 47 \\
9 & Cryptocarya crassinervia & Lauraceae & 49 \\
9 & Dysoxylum sp. 2 & Meliaceae & 54 \\
\hline 10 & Arenga pinnata & Palmae & 20 \\
10 & Unidentified 14 & Unidentified & 25 \\
10 & Dendrocnide stimulan & Urticaceae & 28 \\
10 & Macaranga hispida & Euphorbiaceae & 40 \\
\hline
\end{tabular}


Appendix 10A. Means and standard deviations calculated for morphological and chemical leaf traits of trees and species occurring on the natural forest plots NF1 and NF2. Calculations according to the three different sampling designs and as a normalized species average, where the species number is normalized to 18 . (Inventory - Total inventory sample, Random - Random sample, Sp. average - Species average, Norm. sp. average - Normalized species average)

\section{Natural forest}

\begin{tabular}{|c|c|c|c|c|c|c|c|c|}
\hline \multirow{6}{*}{$\begin{array}{l}\text { Sampling method } \\
\text { No. individuals } \\
\text { sampled } \\
\text { No. species sampled } \\
\text { Stratum sampled } \\
\text { dbh }\end{array}$} & \multicolumn{2}{|c|}{ Inventory } & \multicolumn{2}{|c|}{ Random } & \multicolumn{2}{|c|}{ Sp. average } & \multicolumn{2}{|c|}{ Norm. sp. average } \\
\hline & \multicolumn{2}{|c|}{198} & \multicolumn{2}{|c|}{43} & & \\
\hline & \multicolumn{2}{|c|}{53} & \multicolumn{2}{|c|}{28} & \multicolumn{2}{|c|}{28} & \multicolumn{2}{|c|}{18} \\
\hline & \multicolumn{2}{|c|}{ All } & \multicolumn{2}{|c|}{ Upper canopy } & \multicolumn{2}{|c|}{ Upper canopy } & \multirow{2}{*}{\multicolumn{2}{|c|}{$\begin{array}{c}\text { Upper canopy } \\
\text { All }\end{array}$}} \\
\hline & $>10$ & $\mathrm{~cm}$ & $\mathbf{A}$ & & & & & \\
\hline & mean & sd & mean & sd & mean & sd & mean & sd \\
\hline Leaf size $\left[\mathrm{cm}^{2}\right]$ & 167.6 & 166.9 & 159.7 & 215.2 & 156.1 & 155.0 & 142.7 & 139.6 \\
\hline Length-width ratio & 2.4 & 2.0 & 2.4 & 0.6 & 2.3 & 0.6 & 3.0 & 3.0 \\
\hline SLA $\left[\mathbf{c m}^{2} \mathbf{g}^{-1}\right]$ & 103.2 & 22.6 & 116.2 & 36.5 & 122.8 & 36.7 & 105.6 & 30.4 \\
\hline $\mathrm{Ca}\left[\mathrm{g} \mathrm{kg}^{-1}\right]$ & 19.5 & 10.7 & 22.6 & 13.9 & 22.7 & 11.1 & 23.1 & 14.4 \\
\hline $\mathrm{K}\left[\mathrm{g} \mathrm{kg}^{-1}\right]$ & 12.4 & 4.7 & 10.8 & 4.7 & 11.9 & 4.9 & 13.4 & 7.0 \\
\hline $\mathrm{Mg}\left[\mathrm{g} \mathrm{kg}^{-1}\right]$ & 4.5 & 2.5 & 3.7 & 1.7 & 3.9 & 1.3 & 5.6 & 3.1 \\
\hline$P\left[g_{k g}^{-1}\right]$ & 1.8 & 0.8 & 1.7 & 0.7 & 2.0 & 0.9 & 1.6 & 0.6 \\
\hline$N\left[\mathrm{~g} \mathrm{~kg}^{-1}\right]$ & 19.0 & 0.5 & 20.9 & 0.7 & 21.9 & 0.7 & 19.3 & 0.6 \\
\hline $\mathrm{C}\left[\mathrm{g} \mathrm{kg}^{-1}\right]$ & 426 & 36 & 415 & 51 & 426 & 37 & 429 & 39 \\
\hline $\mathbf{C} / \mathbf{N}$ & 23.6 & 5.6 & 21.8 & 6.4 & 21.6 & 5.9 & 24.1 & 7.4 \\
\hline$N / P$ & 12.0 & 3.1 & 12.7 & 4.6 & 12.7 & 5.1 & 13.5 & 4.7 \\
\hline $\mathrm{C} / \mathrm{P}$ & 281 & 110 & 280 & 140 & 278 & 148 & 311 & 96 \\
\hline$\delta^{13} \mathrm{C}[\%]$, & -29.3 & 1.2 & -29.7 & 1.4 & -29.3 & 1.5 & -29.9 & 1.3 \\
\hline$\delta^{15} \mathrm{~N}[\% 0]$ & 2.4 & 1.2 & 1.9 & 1.9 & 2.5 & 1.6 & 3.0 & 1.2 \\
\hline $\begin{array}{l}\text { Fraction of } \\
\text { compound leaves [\%] }\end{array}$ & 26 & & 23 & & 14 & & 6 & \\
\hline
\end{tabular}


Appendix 10B. Means and standard deviations calculated for morphological and chemical leaf traits in the secondary forest, according to the three different sampling designs and as a normalized species average, where the species number is normalized to 18 for every land use type. (Inventory - Total inventory sample, Random Random sample, Sp. average - Species average, Norm. sp. average - Normalized species average)

\section{Secondary forest}

\begin{tabular}{|c|c|c|c|c|c|c|c|c|}
\hline \multirow{5}{*}{$\begin{array}{l}\text { Sampling method } \\
\text { No. individuals } \\
\text { sampled } \\
\text { No. species sampled } \\
\text { Stratum sampled } \\
\text { dbh }\end{array}$} & \multicolumn{2}{|c|}{ Inventory } & \multicolumn{2}{|c|}{ Random } & \multicolumn{2}{|c|}{ Sp. average } & \multicolumn{2}{|c|}{ Norm. sp. average } \\
\hline & \multicolumn{2}{|c|}{78} & \multicolumn{2}{|c|}{160} & & & & \\
\hline & \multicolumn{2}{|c|}{23} & \multicolumn{2}{|c|}{35} & \multirow{2}{*}{\multicolumn{2}{|c|}{$\begin{array}{c}35 \\
\text { Upper canopy } \\
\text { All }\end{array}$}} & \multirow{2}{*}{\multicolumn{2}{|c|}{$\begin{array}{c}18 \\
\text { Upper canopy } \\
\text { All }\end{array}$}} \\
\hline & \multicolumn{2}{|c|}{$\begin{array}{c}\text { All } \\
>10 \mathrm{~cm}\end{array}$} & \multicolumn{2}{|c|}{$\begin{array}{c}\text { Upper canopy } \\
\text { All }\end{array}$} & & & & \\
\hline & mean & sd & mean & sd & mean & sd & mean & sd \\
\hline Leaf size $\left[\mathrm{cm}^{2}\right]$ & 113.5 & 117.2 & 222.7 & 243.5 & 188.9 & 222.9 & 161.6 & 146.5 \\
\hline Length-width ratio & 2.0 & 2.4 & 1.5 & 0.5 & 1.9 & 0.6 & 1.7 & 0.5 \\
\hline SLA $\left[\mathrm{cm}^{2} \mathrm{~g}^{-1}\right]$ & 145.6 & 38.2 & 137.6 & 33.0 & 122.0 & 33.4 & 128.1 & 35.5 \\
\hline $\mathrm{Ca}\left[\mathrm{g} \mathrm{kg}^{-1}\right]$ & 18.5 & 7.8 & 24.1 & 11.8 & 23.5 & 15.8 & 22.8 & 13.9 \\
\hline$K\left[\mathrm{~g} \mathrm{~kg}^{-1}\right]$ & 11.1 & 4.4 & 12.8 & 4.9 & 14.1 & 5.3 & 12.5 & 4.5 \\
\hline $\mathrm{Mg}\left[\mathrm{g} \mathrm{kg}^{-1}\right]$ & 3.5 & 2.0 & 3.4 & 1.3 & 4.3 & 2.2 & 3.4 & 1.8 \\
\hline$P\left[g_{k g}^{-1}\right]$ & 2.8 & 1.0 & 3.4 & 1.0 & 2.8 & 1.3 & 2.8 & 0.8 \\
\hline$N\left[\mathrm{~g} \mathrm{~kg}^{-1}\right]$ & 23.7 & 7.4 & 25.0 & 7.8 & 22.5 & 8.6 & 22.9 & 8.6 \\
\hline $\mathrm{C}\left[\mathrm{g} \mathrm{kg}^{-1}\right]$ & 442 & 26 & 436 & 36 & 438 & 38 & 444 & 32 \\
\hline $\mathrm{C} / \mathrm{N}$ & 21.0 & 6.1 & 19.2 & 6.3 & 21.5 & 6.7 & 22.0 & 7.1 \\
\hline N/P & 9.1 & 2.7 & 7.6 & 2.2 & 8.9 & 2.4 & 8.2 & 1.6 \\
\hline $\mathrm{C} / \mathrm{P}$ & 192 & 107 & 140 & 54 & 190 & 75 & 174 & 57 \\
\hline$\delta^{13} \mathrm{C}[\%$ & -28.4 & 1.2 & -27.8 & 1.0 & -28.4 & 1.1 & -28.1 & 0.6 \\
\hline$\delta^{15} \mathbf{N}[\% \circ]$ & 2.6 & 2.1 & 2.7 & 2.2 & 2.5 & 2.0 & 2.4 & 2.3 \\
\hline $\begin{array}{l}\text { Fraction of } \\
\text { compound leaves [\%] }\end{array}$ & 8 & & 5 & & 20 & & 17 & \\
\hline
\end{tabular}


Appendix 10C. Means and standard deviations calculated for morphological and chemical leaf traits in forest garden, according to the three different sampling designs and as a normalized species average, where the species number is normalized to 18 . (Inventory - Total inventory sample, Random - Random sample, Sp. average Species average, Norm. sp. average - Normalized species average)

\section{Forest garden}

\begin{tabular}{|c|c|c|c|c|c|c|c|c|}
\hline \multirow{5}{*}{$\begin{array}{l}\text { Sampling method } \\
\text { No. individuals } \\
\text { sampled } \\
\text { No. species sampled } \\
\text { Stratum sampled } \\
\text { dbh }\end{array}$} & \multicolumn{2}{|c|}{ Inventory } & \multicolumn{2}{|c|}{ Random } & \multicolumn{2}{|c|}{ Sp. average } & \multicolumn{2}{|c|}{ Norm. sp. average } \\
\hline & \multicolumn{2}{|c|}{86} & \multicolumn{2}{|c|}{26} & \multirow{2}{*}{\multicolumn{2}{|c|}{18}} & \\
\hline & \multicolumn{2}{|c|}{33} & \multicolumn{2}{|c|}{18} & & & 18 & \\
\hline & $\begin{array}{r}A \\
>10\end{array}$ & & Upper & canopy & \multicolumn{2}{|c|}{ Upper canopy } & \multicolumn{2}{|c|}{ Upper canopy } \\
\hline & mean & sd & mean & sd & mean & sd & mean & sd \\
\hline Leaf size $\left[\mathrm{cm}^{2}\right]$ & 149.3 & 185.5 & 205.1 & 139.1 & 188.5 & 142.3 & 188.5 & 142.3 \\
\hline Length-width ratio & 2.5 & 2.2 & 2.2 & 0.3 & 2.1 & 0.3 & 2.1 & 0.4 \\
\hline SLA $\left[\mathrm{cm}^{2} \mathrm{~g}^{-1}\right]$ & 116.0 & 22.0 & 118.2 & 33.0 & 115.8 & 38.2 & 115.8 & 38.2 \\
\hline $\mathrm{Ca}\left[\mathrm{g} \mathrm{kg}^{-1}\right]$ & 19.1 & 10.9 & 18.0 & 8.8 & 20.1 & 9.1 & 20.1 & 9.1 \\
\hline $\mathrm{K}\left[\mathrm{g} \mathrm{kg}^{-1}\right]$ & 14.0 & 5.1 & 14.4 & 8.4 & 15.3 & 9.4 & 15.3 & 9.4 \\
\hline $\operatorname{Mg}\left[\mathrm{g} \mathrm{kg}^{-1}\right]$ & 4.8 & 2.5 & 4.3 & 2.6 & 4.6 & 2.9 & 4.6 & 2.9 \\
\hline$P\left[g_{k g}^{-1}\right]$ & 1.9 & 0.6 & 2.0 & 0.8 & 2.0 & 0.9 & 2.0 & 0.9 \\
\hline $\mathbf{N}\left[\mathrm{g} \mathrm{kg}^{-1}\right]$ & 22.1 & 6.0 & 19.7 & 7.0 & 20.6 & 7.9 & 20.6 & 7.9 \\
\hline $\mathrm{C}\left[\mathrm{g} \mathrm{kg}^{-1}\right]$ & 453 & 36 & 458 & 29 & 457 & 34 & 457 & 34 \\
\hline $\mathrm{C} / \mathbf{N}$ & 22.0 & 6.4 & 26.0 & 8.5 & 25.4 & 9.5 & 25.4 & 9.5 \\
\hline $\mathbf{N} / \mathbf{P}$ & 12.4 & 3.0 & 10.2 & 2.3 & 10.5 & 2.6 & 10.5 & 2.6 \\
\hline $\mathrm{C} / \mathrm{P}$ & 256 & 75 & 268 & 114 & 267 & 125 & 267 & 125 \\
\hline$\delta^{13} \mathrm{C}[\% o]$ & -29.4 & 1.3 & -29.8 & 1.2 & -29.6 & 1.3 & -29.6 & 1.3 \\
\hline$\delta^{15} N[\% o]$ & 3.6 & 1.6 & 2.9 & 1.7 & 3.1 & 2.0 & 3.1 & 2.0 \\
\hline $\begin{array}{l}\text { Fraction of } \\
\text { compound leaves [\%] }\end{array}$ & 8 & & 4 & & 5 & & 6 & \\
\hline
\end{tabular}


Appendix 11A. Means and standard deviation of leaf size, length-width ratio and specific leaf area (SLA) calculated in the random sample of each land use type. Different letters mark significantly different means $(\mathrm{p}<$ 0.05). (Ind - Number of individuals sampled, NF - natural forest, SF - Secondary forest, FG - Forest garden, AF - Agroforestry system)

\begin{tabular}{lrrrrrrr}
\hline $\begin{array}{l}\text { Land } \\
\text { use } \\
\text { type }\end{array}$ & Ind & mean & Leaf size & \multicolumn{2}{c}{ Length-width ratio } & \multicolumn{2}{c}{$\begin{array}{c}\text { SLA } \\
{\left[\mathbf{c m}^{\mathbf{2}} \mathbf{g}^{-1}\right]}\end{array}$} \\
\hline NF & 119 & $140.2^{\mathrm{b}}$ & 161.3 & mean & sd & mean & sd \\
SF & 160 & $222.7^{\mathrm{d}}$ & 243.5 & $2.87^{\mathrm{c}}$ & 2.97 & $115.7^{\mathrm{a}}$ & 35.5 \\
FG & 26 & $205.1^{\mathrm{c}}$ & 139.1 & $1.57^{\mathrm{a}}$ & 0.50 & $137.6^{\mathrm{b}}$ & 33.0 \\
$\mathrm{AF}$ & 49 & $79.3^{\mathrm{a}}$ & 76.3 & $2.24^{\mathrm{abc}}$ & 0.36 & $118.2^{\mathrm{a}}$ & 33.0 \\
\hline
\end{tabular}

Appendix 11B. Means with standard deviation of leaf concentrations of cations, $P, N$ and $C$ in random samples of each land use type. Significant different means are marked with letters $(p<0.05)$. NF - natural forest, SF secondary forest, FG - forest garden, AF - agroforestry system, Ind - number of individual trees sampled

\begin{tabular}{|c|c|c|c|c|c|c|c|c|c|c|c|c|c|}
\hline \multirow{2}{*}{$\begin{array}{l}\text { Land } \\
\text { use } \\
\text { type }\end{array}$} & \multirow[b]{2}{*}{ Ind } & \multicolumn{2}{|c|}{$\begin{array}{c}\mathrm{Ca} \\
{\left[\mathrm{g} \mathrm{kg}^{-1}\right]}\end{array}$} & \multicolumn{2}{|c|}{$\begin{array}{c}\mathrm{K} \\
{\left[\mathrm{g} \mathrm{kg}^{-1}\right]}\end{array}$} & \multicolumn{2}{|c|}{$\begin{array}{c}\mathrm{Mg} \\
{\left[\mathrm{g} \mathrm{kg}^{-1}\right]}\end{array}$} & \multicolumn{2}{|c|}{$\begin{array}{c}P \\
{\left[\mathrm{~g} \mathrm{~kg}^{-1}\right]}\end{array}$} & \multicolumn{2}{|c|}{$\begin{array}{c}\mathbf{N} \\
{[\%]}\end{array}$} & \multicolumn{2}{|c|}{$\begin{array}{c}\mathrm{C} \\
{[\%]}\end{array}$} \\
\hline & & mean & sd & mean & sd & mean & sd & mean & sd & mean & sd & mean & sd \\
\hline NF & 119 & $20.8^{b}$ & 11.7 & $13.0^{\mathrm{ab}}$ & 6.1 & $5.5^{\mathrm{b}}$ & 3.0 & $1.7^{\mathrm{a}}$ & 0.6 & $2.13^{\mathrm{a}}$ & 0.70 & $44.0^{\mathrm{a}}$ & 4.3 \\
\hline SF & 160 & $24.1^{\mathrm{b}}$ & 11.8 & $12.8^{\mathrm{a}}$ & 4.9 & $3.4^{\mathrm{a}}$ & 1.3 & $3.4^{\mathrm{c}}$ & 1.0 & $2.50^{\mathrm{b}}$ & 0.78 & $43.6^{\mathrm{a}}$ & 3.6 \\
\hline $\mathrm{FG}$ & 26 & $18.1^{\mathrm{a}}$ & 8.8 & $14.4^{\mathrm{ab}}$ & 8.3 & $4.3^{\mathrm{ab}}$ & 2.6 & $2.0^{\mathrm{a}}$ & 0.8 & $1.97^{\mathrm{a}}$ & 0.70 & $45.8^{\mathrm{a}}$ & 2.9 \\
\hline $\mathrm{AF}$ & 49 & $14.6^{\mathrm{a}}$ & 5.8 & $15.5^{\mathrm{b}}$ & 3.7 & $3.7^{\mathrm{a}}$ & 1.5 & $2.8^{\mathrm{b}}$ & 0.9 & $3.48^{\mathrm{c}}$ & 1.06 & $45.3^{\mathrm{a}}$ & 3.7 \\
\hline
\end{tabular}

Appendix 11C. Means with standard deviation of $\mathrm{C} / \mathrm{N}, \mathrm{C} / \mathrm{P}, \mathrm{N} / \mathrm{P}$ ratios, $\delta^{13} \mathrm{C}$ and $\delta^{15} \mathrm{~N}$ in random samples of for each land use system. Significant different means are marked with letters $(\mathrm{p}<0.05)$. NF - natural forest, SF secondary forest, FG - forest garden, AF - agroforestry system, Ind - number of individual trees sampled

\begin{tabular}{|c|c|c|c|c|c|c|c|c|c|c|c|}
\hline \multirow{2}{*}{$\begin{array}{l}\text { Land } \\
\text { use } \\
\text { type }\end{array}$} & \multirow[b]{2}{*}{ Ind } & \multicolumn{2}{|c|}{$\mathrm{C} / \mathbf{N}$} & \multicolumn{2}{|c|}{$\mathbf{C} / \mathbf{P}$} & \multicolumn{2}{|c|}{$\mathbf{N} / \mathbf{P}$} & \multicolumn{2}{|c|}{$\begin{array}{l}\delta^{13} \mathbf{C} \\
{[\% \text { ] }}\end{array}$} & \multicolumn{2}{|c|}{$\begin{array}{l}\delta^{15} \mathbf{N} \\
{[\% o]}\end{array}$} \\
\hline & & mean & sd & mean & sd & mean & sd & mean & sd & mean & sd \\
\hline $\mathrm{NF}$ & 119 & $22.1^{\mathrm{c}}$ & 7.5 & $290^{\mathrm{b}}$ & 114 & $13.0^{c}$ & 4.1 & $-30.1^{a}$ & 1.4 & $2.56^{\mathrm{a}}$ & 1.53 \\
\hline SF & 160 & $19.2^{\mathrm{b}}$ & 6.3 & $140^{\mathrm{a}}$ & 54 & $7.6^{\mathrm{a}}$ & 2.2 & $-27.8^{\mathrm{b}}$ & 1.1 & $2.72^{\mathrm{a}}$ & 2.22 \\
\hline $\mathrm{FG}$ & 26 & $26.0^{c}$ & 8.5 & $268^{\mathrm{b}}$ & 114 & $10.2^{b}$ & 2.3 & $-29.8^{a}$ & 1.3 & $2.97^{\mathrm{a}}$ & 1.79 \\
\hline $\mathrm{AF}$ & 49 & $14.4^{\mathrm{a}}$ & 5.2 & $171^{\mathrm{a}}$ & 48 & $12.4^{\mathrm{c}}$ & 3.5 & $-27.8^{\mathrm{c}}$ & 1.0 & $3.23^{\mathrm{a}}$ & 2.35 \\
\hline
\end{tabular}


Appendix 12A. Means of leaf size, length-width ratio and specific leaf area (SLA) in the five most frequent families in the random samples. Total number of species representing each family on the study sites and total number of individuals sampled (Ind) are given. Different letters mark significantly different means $(p<0.05)$.

\begin{tabular}{|c|c|c|c|c|c|c|c|c|}
\hline \multirow[b]{2}{*}{ Family } & \multirow[b]{2}{*}{ Ind } & \multirow[b]{2}{*}{ Species } & \multicolumn{2}{|c|}{$\begin{array}{c}\text { Leaf size } \\
{\left[\mathrm{cm}^{2}\right]}\end{array}$} & \multicolumn{2}{|c|}{ Length-width ratio } & \multicolumn{2}{|c|}{$\begin{array}{c}\text { SLA } \\
{\left[\mathrm{cm}^{2} / \mathrm{g}\right]}\end{array}$} \\
\hline & & & mean & sd & mean & sd & mean & sd \\
\hline Euphorbiaceae & 85 & 10 & $243^{\mathrm{ab}}$ & 317 & $1.44^{b}$ & 0.37 & $144^{\mathrm{a}}$ & 36 \\
\hline Lauraceae & 23 & 9 & $135^{\mathrm{b}}$ & 78 & $2.44^{\mathrm{a}}$ & 0.76 & $103^{\mathrm{c}}$ & 21 \\
\hline Meliaceae & 20 & 7 & $212^{\mathrm{a}}$ & 99 & $2.38^{\mathrm{a}}$ & 0.61 & $103^{\mathrm{c}}$ & 19 \\
\hline Moraceae & 13 & 10 & $99^{\mathrm{b}}$ & 66 & $2.43^{\mathrm{a}}$ & 0.52 & $106^{\mathrm{c}}$ & 20 \\
\hline Urticaceae & 57 & 10 & $254^{\mathrm{a}}$ & 195 & $1.71^{\mathrm{b}}$ & 0.75 & $129^{\mathrm{b}}$ & 26 \\
\hline
\end{tabular}

Appendix 12B. Means with standard deviation of cat ions, $\mathrm{P}, \mathrm{N}$ and $\mathrm{C}$ for the most frequent families in the random samples covering four land use systems. Significantly different means are marked with different letters $(\mathrm{p}<0.05)$. Number of species representing each family in any of the investigated land use types (Spec) and total numbers of individuals sampled from each family (Ind) are presented.

\begin{tabular}{|c|c|c|c|c|c|c|c|c|c|c|c|c|c|c|}
\hline \multirow[b]{2}{*}{ Family } & \multirow[b]{2}{*}{ Ind } & \multirow[b]{2}{*}{ Spec } & \multicolumn{2}{|c|}{$\begin{array}{c}\mathrm{Ca} \\
{\left[\mathrm{g} \mathrm{kg}^{-1}\right]}\end{array}$} & \multicolumn{2}{|c|}{$\begin{array}{c}\mathbf{K} \\
{\left[\mathrm{g} \mathrm{kg}^{-1}\right]}\end{array}$} & \multicolumn{2}{|c|}{$\underset{\left[\mathrm{g} \mathrm{kg}^{-1}\right]}{\mathbf{M g}}$} & \multicolumn{2}{|c|}{$\begin{array}{c}\mathbf{P} \\
{\left[\mathrm{g} \mathrm{kg}^{-1}\right]}\end{array}$} & \multicolumn{2}{|c|}{$\begin{array}{c}\mathbf{N} \\
{[\%]}\end{array}$} & \multicolumn{2}{|c|}{$\begin{array}{c}\mathrm{C} \\
{[\%]}\end{array}$} \\
\hline & & & mean & sd & mean & sd & mean & sd & mean & sd & mean & sd & mean & sd \\
\hline Euphorbiaceae & 85 & 10 & $17.5^{\mathrm{b}}$ & 7.1 & $9.8^{\mathrm{c}}$ & 2.6 & $3.0^{\mathrm{c}}$ & 1.2 & $3.2^{\mathrm{a}}$ & 1.1 & $2.2^{\mathrm{b}}$ & 0.7 & $43.3^{b}$ & 3.9 \\
\hline Lauraceae & 23 & 9 & $15.2^{\mathrm{b}}$ & 8.0 & $14.4^{\mathrm{ab}}$ & 8.8 & $5.8^{\mathrm{ab}}$ & 3.8 & $2.2^{\mathrm{bc}}$ & 1.3 & $2.2^{\mathrm{bc}}$ & 0.7 & $47.2^{\mathrm{a}}$ & 2.2 \\
\hline Meliaceae & 20 & 7 & $17.4^{\mathrm{b}}$ & 6.5 & $16.4^{\mathrm{a}}$ & 5.5 & $6.5^{\mathrm{a}}$ & 3.5 & $2.2^{\mathrm{b}}$ & 0.7 & $2.4^{\mathrm{b}}$ & 0.4 & $46.9^{\mathrm{a}}$ & 3.0 \\
\hline Moraceae & 13 & 10 & $33.7^{\mathrm{a}}$ & 15.9 & $14.9^{\mathrm{ab}}$ & 3.5 & $5.3^{\mathrm{ab}}$ & 2.3 & $1.5^{\mathrm{c}}$ & 0.4 & $1.7^{\mathrm{c}}$ & 0.3 & $41.2^{\mathrm{b}}$ & 4.2 \\
\hline Urticaceae & 57 & 10 & $35.4^{\mathrm{a}}$ & 9.9 & $13.4^{\mathrm{b}}$ & 3.9 & $4.7^{b}$ & 2.2 & $3.2^{\mathrm{a}}$ & 1.2 & $2.6^{\mathrm{a}}$ & 0.7 & $41.6^{\mathrm{b}}$ & 3.1 \\
\hline
\end{tabular}

Appendix 12C. Means with standard deviation of $\mathrm{C} / \mathrm{N}, \mathrm{C} / \mathrm{P}, \mathrm{N} / \mathrm{P}$ ratios, $\delta^{13} \mathrm{C}$ and $\delta^{15} \mathrm{~N}$ for the five most frequent families in the random samples. Significant different means are marked with letters $(p<0.05)$. Number of species representing each family in any of the investigated land use types (Spec / Fam) and total number of individuals sampled from each family (Ind) are presented.

\begin{tabular}{|c|c|c|c|c|c|c|c|c|c|c|c|c|}
\hline \multirow[b]{2}{*}{ Family } & \multirow[b]{2}{*}{ Ind } & \multirow[b]{2}{*}{ Spec } & \multicolumn{2}{|c|}{$\mathbf{C} / \mathbf{N}$} & \multicolumn{2}{|c|}{$\mathbf{N} / \mathbf{P}$} & \multicolumn{2}{|c|}{$\mathbf{C} / \mathbf{P}$} & \multicolumn{2}{|c|}{$\begin{array}{l}\delta^{13} \mathbf{C} \\
{[\% \%]}\end{array}$} & \multicolumn{2}{|c|}{$\begin{array}{l}\delta^{15} \mathbf{N} \\
{[\% o]}\end{array}$} \\
\hline & & & mean & sd & mean & sd & mean & sd & mean & sd & mean & sd \\
\hline Euphorbiaceae & 85 & 10 & $21.4^{\mathrm{b}}$ & 7.0 & $7.6^{\mathrm{a}}$ & 2.4 & $16.3^{\mathrm{c}}$ & 8.6 & $-28.1^{\mathrm{a}}$ & 1.3 & $2.47^{\mathrm{a}}$ & 2.18 \\
\hline Lauraceae & 23 & 9 & $24.1^{\mathrm{ab}}$ & 7.0 & $11.5^{\mathrm{c}}$ & 4.1 & $27.1^{\mathrm{ab}}$ & 11.5 & $-30.8^{\mathrm{b}}$ & 1.7 & $2.81^{\mathrm{a}}$ & 1.72 \\
\hline Meliaceae & 20 & 7 & $20.6^{\mathrm{b}}$ & 4.4 & $11.9^{\mathrm{cd}}$ & 3.2 & $23.3^{\mathrm{b}}$ & 6.5 & $-30.1^{\mathrm{b}}$ & 1.2 & $3.45^{\mathrm{a}}$ & 1.37 \\
\hline Moraceae & 13 & 10 & $24.6^{\mathrm{a}}$ & 6.0 & $13.5^{\mathrm{d}}$ & 6.9 & $31.7^{\mathrm{a}}$ & 14.2 & $-29.7^{b}$ & 2.0 & $2.38^{\mathrm{a}}$ & 1.24 \\
\hline Urticaceae & 57 & 10 & $17.3^{\mathrm{c}}$ & 4.9 & $8.9^{\mathrm{b}}$ & 3.0 & $15.1^{\mathrm{c}}$ & 6.2 & $-28.1^{\mathrm{a}}$ & 1.4 & $2.43^{\mathrm{a}}$ & 1.85 \\
\hline
\end{tabular}

